\title{
HISTORIA LOCAL DE NARANJA AMARGA (CITRUS $\times$ AURANTIUM L., RUTACEAE) DEL VIEJO MUNDO ASILVESTRADA EN EL CORREDOR DE LAS ANTIGUAS MISIONES JESUÍTICAS DE LA PROVINCIA DE MISIONES
}

(ARGENTINA). CARACTERIZACIÓN DESDE UNA PERSPECTIVA INTERDISCIPLINARIA.

Lic. Pablo César Stampella

\section{Directoras}

Dra. María Lelia Pochettino

Dra. Norma Inés Hilgert

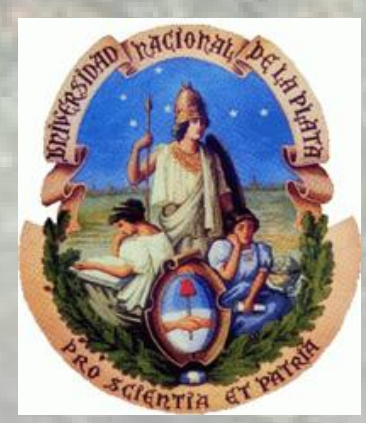

Tesis para optar por el grado de Doctor en Ciencias Naturales

Facultad de Ciencias Naturales y Museo Universidad Nacional de La Plata 


\title{
HISTORIA LOCAL DE NARANJA AMARGA $(C I T R U S \times A U R A N T I U M$ L., RUTACEAE) DEL VIEJO MUNDO ASILVESTRADA EN EL CORREDOR DE LAS ANTIGUAS MISIONES JESUÍTICAS DE LA PROVINCIA DE MISIONES (ARGENTINA). CARACTERIZACIÓN DESDE UNA PERSPECTIVA INTERDISCIPLINARIA.
}

Lic. Pablo César Stampella

\author{
Directoras
}

Dra. María Lelia Pochettino

Dra. Norma Inés Hilgert

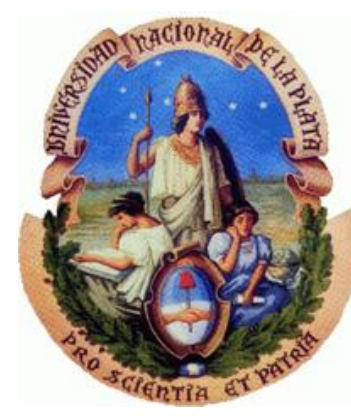

Tesis para optar por el grado de Doctor en Ciencias Naturales

Facultad de Ciencias Naturales y Museo

Universidad Nacional de La Plata 
Quiero dedicar esta tesis a Emilia y Juana, mis amores, la trastienda de esta tesis

A mi mamá Marta y mis hermanos, Mauricio y Mariano. A mi papá y abuelos que ya forman parte del tiempo

A todas las familias, amigos en Misiones, de ellos lo que cuento 


\section{AGRADECIMIENTOS}

Quiero agradecer a Emilia y Juana por sostener el sentido de esta tesis, el día a día que no está escrito en este documento, las intensidades, tantas cosas.

A Tany y Norma por invitarme a conocer este mundo que es la etnobotánica, acompañarme con libertad, enseñarme a escuchar, a preguntar.

A los pobladores locales de los distintos enclaves con quienes hemos trabajado agradezco la amistad, los mates, tereré, comidas, frutos y caminatas. A los niños y niñas que siempre me han acompañado en las caminatas por los trillos del monte en la búsqueda de frutas, ellos son los conocedores de lo que anhelé conocer durante mi trabajo de campo. A Liliana Maruñk, directora de la Escuela No 590 de Cerro Mártires por toda su hospitalidad, a Ruli, a Raúl Barrufaldi y Simone, "Nene" Ibarra. A todo el personal de las Ruinas de Santa María la Mayor donde me he alojado y disfrutado de la belleza de una de las ruinas más hermosas, aunque un poco olvidadas.

A mis compañeros y compañeras del LEBA: Patricia (Pato) Arenas, Patricia (Colo) Riat, Laura Pérez, Belén Doumecq, Natalia Petrucci, Jeremías Puentes, Verónica Lema, Aylén Capparelli, Agustín Martínez y Matilde Vojkovic. A los colegas del Instituto de Biología Subtropical (Iguazú), Fernando Zamudio, Mónica Kujawska y Violeta Furlán. A Dorita Vignale y a Alejandra Lambaré.

A mis compañeros y compañeras de la cátedra de Introducción a la Botánica, a Adriana Mengascini, Mónica Rodríguez, Pablo Simon, Andrea Mallo, Nancy Neschuk, Guillermo Doffo, a todos y todas.

A Gustavo (Vitu) Delucchi, Julio Hurrell, Pablo Cabanillas, Elián Guerrero, Héctor Keller, Nancy y Rafa, Cacho Sáenz, Guillermo Gil, Claudia López Lastra, Cátedra de Fruticultura de la FCAyF (UNLP). A Ana M. Gorosito Kramer y Bartomeu Melià, y a Estéban Hernández Bermejo por compartir conmigo "puntas" en el ovillo que es la bibliografía jesuítica y el enfoque histórico. A Teresa Iglesias y M. Estela Ferrarini. A la "Vasca" Arambarri, que fue mi consejera en las materias optativas de grado. A María Ester Urrutia, profesora de Botánica en la UNLu, que me impulsó (y me dio techo, como si fuera poco...) en mi decisión de venir a estudiar a La Plata. 
A Marcos Núñez, Rodrigo Dutra y Marcelo Kostlin por su colaboración en las distintas campañas.

A las bibliotecarias y bibliotecarios de las bibliotecas de las FCNyM, FCAyF, FaHCE y Central (UNLP); Biblioteca Central "Prof. A. R. Cortázar", de Historia Argentina y Americana "Dr. E. Ravignani” y Teoría e Historia del Arte "J. E. Payró” (UBA). Al personal de los herbarios: Museo de La Plata, Arboretum Spegazzini, Instituto de Botánica del Nordeste e Instituto de Botánica Darwinion.

A los evaluadores de esta tesis Dres. Ana Ladio, Gustavo Giberti y Gabriela Schiavoni por sus sugerencias que contribuyeron al mejoramiento de este trabajo.

A mis amigos y amigas de la vida: Cur y Delia, Pome, Eric y Leti, Nahu y Solana, Migue (¡cómo te extrañamos negro...!), Jero y Romi, Pey y Emi, Nico, Tonga, Raulo y Emi, Alejandra y Noé. A todos los sobrinos de la vida: Naia, Simón, Sarita, Siro, Uma, Ulises y Lila. A mis suegros, Teresa y Oscar, también por el aguante. A Juan, Cecilia, Martín y Manuel, Alberto y Domingo Pagnotta, Quico González y Oscar, amigos del barrio. 
ÍNDICE

1. RESUMEN/ABSTRACT 10

2. INTRODUCCIÓN GENERAL 16

$\begin{array}{lll}\text { 2.1. Introducción } & 17\end{array}$

2.2. Hipótesis y predicciones 20

2.3. Objetivo general y específicos 21

$\begin{array}{lll}\text { 2.4. } & \text { Antecedentes } & 22\end{array}$

2.5. Marco teórico 26

3. METODOLOGÍA GENERAL 33

3.1. Consentimiento informado 34

3.2. Selección de sitios de estudio e informantes 34

3.3. Trabajo de campo 36

3.4. Colecta de material de referencia y determinación 37

3.5. Etnobotánica histórica 38

3.6. Análisis de los datos 39

4. ÁREA DE ESTUDIO 40

4.1. Fitogeografía 42 
4.2. Los pobladores

4.3. Historia local 48

5. RESULTADOS 56

5.1. LOS CÍTRICOS INTRODUCIDOS EN EL SUBTRÓPICO ARGENTINO: HISTORIA E IMPORTANCIA LOCAL

5.1.1. Introducción

5.1.2. Materiales y métodos

5.1.3. Resultados

5.1.3.1.Historia de ingreso y de uso de Citrus en el NEA durante el período 62 colonial

5.1.3.2.Inmigraciones, inicios de la citricultura argentina y situación actual de los cítricos

5.1.4. Discusión

5.2. VARIABILIDAD LOCALMENTE RECONOCIDA DE CÍTRICOS (CITRUS L., RUTACEAE) EN EL SUR DE MISIONES (ARGENTINA): 74 TAXONOMÍA LOCAL Y USOS

5.2.1. Introducción y objetivos

5.2.2. Materiales y métodos 76

5.2.3. Resultados

5.2.3.1.Características socioculturales e historia local de los enclaves estudiados 
5.2.3.3.Los cítricos y las discontinuidades de la variabilidad localmente reconocida

5.2.3.4.Descriptores, la percepción de la variabilidad

5.3. VARIABILIDAD LOCALMENTE RECONOCIDA DE CÍTRICOS (CITRUS L., RUTACEAE) EN EL SUR DE MISIONES (ARGENTINA): MICROAMBIENTES Y PRÁCTICAS DE MANEJO

5.3.1. Introducción

5.3.2. Materiales y métodos

5.3.3. Resultados

5.3.3.3.Las prácticas de manejo en la dinámica entre el monte y el campo

5.3.3.5.Las prácticas de manejo y los cambios morfológicos-organolépticos: el caso de las mandarinas comunes 
LA PROVINCIA DE MISIONES (ARGENTINA)

5.4.1. Introducción

5.4.2. Área de estudio y población

5.4.3. Materiales y métodos

5.4.4. Resultados

5.4.4.1.La filiación de los informantes en los dos departamentos estudiados

5.4.4.2.La importancia de los citricos en la medicina herbolaria local

5.4.5. Discusión

6. DISCUSIÓN GENERAL

7. CONCLUSIONES

8. ANEXOS

8.1. Consentimiento previamente informado

8.2. Listados de publicaciones derivadas de esta tesis

8.3. Imágenes de los amigos y amigas en Misiones

9. BIBLIOGRAFÍA 
1. RESUMEN/ABSTRACT 
Los cítricos son frutales exóticos en América, introducidos a lo largo de cinco siglos a partir del contacto entre ambos hemisferios, que han sido apropiados y resignificados por comunidades locales y pueblos originarios. Los mismos se han constituido en cultivos de gran importancia, reconociéndose asimismo poblaciones espontáneas en varios enclaves de Argentina, generalmente asociados a ambientes boscosos o selváticos. El objetivo general de esta tesis es diseñar los procesos locales de selección cultural en poblaciones de cítricos introducidas en el área de las Misiones Jesuíticas y aportar al concepto de domesticación. Para ello se parte de las siguientes premisas: Ase considera la domesticación en un sentido amplio, no sólo como modificaciones morfofisiológicas que adaptan la planta a un determinado ambiente sino también como proceso, una extensión de la unidad doméstica hacia el paisaje, resultando en la domesticación del mismo; B- la noción de paisaje como ambiente interpretado, sobre el cual se llevan a cabo prácticas inherentes a diferentes aspectos culturales de quienes lo habitan; prácticas cuyo efecto no necesariamente es negativo o destructivo.

Este caso de estudio es abordado mediante distintas metodologías articuladas entre sí, característica del enfoque interdisciplinario. La metodología etnobotánica histórica y la etnohistórica fueron empleadas para el análisis de los documentos históricos relativos a las variedades de cítricos ingresadas, procedencias y rutas de ingreso, como también para el relevamiento de los distintos espacios productivos de la época de las misiones jesuíticas (Siglos XVII-XVIII). Mediante las metodologías etnobotánica y etnoecológica se relevó la diversidad actual, la percepción de la variabilidad, los usos locales, los microambientes donde se encuentran y las prácticas de manejo sobre las plantas y los microambientes. También se relevaron los usos medicinales de los cítricos asociados a enclaves cercanos a Paraguay y Brasil (cuencas del Paraná y Uruguay, respectivamente) y las variaciones de acuerdo a la situación en el gradiente de urbanización/ruralidad. La metodología botánica fue empleada para la identificación de las plantas involucradas y análisis morfológico-organoléptico de la variabilidad de acuerdo a las prácticas de manejo sobre el entorno.

Se relevaron las variedades históricas ingresadas tempranamente a partir del siglo XVI, las posibles procedencias, rutas de ingreso y otros aspectos referidos a su "naturalización” y cultivo en las Misiones jesuíticas. Las menciones generales de estas variedades fueron acompañadas con las obras de Tratados de Cítricos (o Hespérides) de los siglos XVI a XIX, abundantes en detalles que ejemplificaron la diversidad pasada. 
Mediante el trabajo de campo en el sur de Misiones (Argentina) se ha relevado una alta diversidad de etnovariedades (30) cultivadas y espontáneas, estructuradas en 9 etnoespecies, algunas de ellas de introducción histórica y otras más recientes, con variados usos asignados.

Asimismo, se relevaron 7 microambientes definidos por la presencia de las etnoespecies con diferentes intensidades en las prácticas de manejo. Las prácticas relevadas fueron dirigidas principalmente a los microambientes antes que a los cítricos en sí. La variabilidad de usos medicinales y la importancia de las etnoespecies, analizadas de acuerdo a su distribución en la cuenca del Paraná y del Uruguay, y a la situación en el gradiente de urbanización/ruralidad, mostró diferencias de importancia en algunas etnoespecies y propiedades medicinales. También, la percepción de la variabilidad del género, que resulta en esquemas de clasificaciones locales complejos, indican una fuerte relación con las comunidades locales estudiadas.

Se discuten los procesos de generación de variabilidad sobre este género y sobre el paisaje, de acuerdo a los mecanismos de variabilidad genética intrínsecos del género, la historia de introducción y las prácticas sobre las plantas y los microambientes que resultan en la domesticación del paisaje. Este enfoque ecológico-histórico aporta asimismo en la discusión de la terminología de uso corriente como "naturalización” o "asilvestramiento" proponiéndose, en cambio, el término antropización de las plantas que acompañan el avance de la unidad doméstica sobre el ambiente. Todo esto lleva a percibir los paisajes como selvas antropogénicas, antes que ambientes prístinos, y por ello, susceptibles de estrategias de conservación in situ o biocultural que engloben a las comunidades locales, la diversidad de paisajes, las etnoespecies y las prácticas asociadas a las mismas.

El enfoque interdisciplinario empleado permitió caracterizar la diversidad actual y las introducciones históricas, como también identificar prácticas de manejo sustentables y generadoras de variabilidad a distintos niveles. Estos frutales exóticos constituyen elementos identitarios que contribuyen a la definición de las comunidades y escenarios cotidianos. La decisión de incorporar elementos exóticos debe entenderse en el marco de las cosmovisiones de estos grupos nativos. Por lo tanto, estas plantas de introducción relativamente reciente, y con registro escrito, permiten al investigador comprender y 
diseñar la domesticación del paisaje como proceso multidimensional del entorno físico social y simbólico. 
Citric are exotic fruit in America, which have been introduced through a span of five centuries from the contact between both hemispheres and appropriated and resignificated by local communities and native people. They have become crops of great importance, and spontaneous populations of citric can be, as well, been recognized in several points of the Argentina, generally associated to forest environments. The main objective of this thesis is to design those local processes of cultural selection in population of citric that have been introduced in the area of Jesuit Missions and to contribute to the concept of domestication. To reach this aim, the research takes the following premises as a starting point: A. Domestication is considered in a broad sense, not only as those morphological and physiological modifications that adapt a plant to a determined environment, but as a process and an extension of the domestic unit to the landscape, resulting in its domestication. B- the idea of landscape as an interpreted environment, over which several practices -inherent to different cultural aspects of its inhabitants- are transferred, practices that are not necessarily negative nor destructive.

This case study is performed by means of diverse methodologies articulated between them. This articulation is a characteristic of interdisciplinary research. The methodology of historic ethnobotany and ethnohistory have been employed for the analysis of historic documents relative to the citric varieties introduced, their precedence and ways of access, as well as for recording the different productive spaces in the time of Jesuit Missions $\left(17^{\text {th }}-18^{\text {th }}\right.$ centuries). By means of ethnobotanical and ethnoecological methodologies, present diversity has been recorded, along with management practices of plants and microenvironments. Medicinal uses of citric have also been registered in those settlements near to Paraguay and Brazil (in the basin of Paraná and Uruguay River, respectively), as well as their variations according to their situation in a gradient of urbanization/rurality. Botanical methodology was employed to the identification of the collected plants and the morphological and organoleptic analysis of the variability according to the practices for environment management.

Those historic varieties, early introduced since 16th century have been identified, in order to analyze their possible precedence, ways of access and other aspects referred to their "naturalization" and cultivation in Jesuit Missions. General mentions to these varieties have been accompanied with the opus of Tratados de Cítricos (Hesperides) from $16^{\text {th }}$ to $19^{\text {th }}$ century that abounds in details about past diversity. On the other hand, field work in Misiones allowed to record a high diversity of ethnovarieties (30), 
cultivated and spontaneous, structured in 9 ethnospecies, some of them of historic introduction and others more recent. All of them have several assigned uses.

As well, 7 microenvironments have been identified, defined by the presence of the mentioned ethnospecies with different intensity in their management practices. The recorded practices were addressed mainly to microenvironments more than to citric in themselves. The variability of medicinal uses and the importance of ethnospecies analyzed according to their distribution along Parana and Uruguay River basin, and to their situation in the gradient of urbanization/rurality, showed important differences in several ethnospecies and their medicinal properties. In addition, the perception of the genus variability, expressed in complex.

The processes of generation of variability in the genus and in the landscape are discussed, taking into consideration the mechanisms of genetic variability intrinsic of the genus, its history of introduction, and the practices on plants and microenvironments that result in landscape domestication. This historic-ecological approach contributes as well to the discussion of terms of current use as "naturalization" or "feral", by proposing instead, the term "anthropization" for those plants that accompany the advancement of domestic unit over the environment. These reflections conduct to the perception of landscapes as anthropogenic forests, more than as pristine environments, and consequently susceptible of strategies in situ or biocultural conservation that take into consideration local communities, landscape diversity, ethnospecies and their associated practices.

The interdisciplinary approach here employed allowed to characterize present and historic diversity and to identify those sustainable management practices that promote diversity in different levels. These exotic fruits constitute today identitary elements that contribute to the definition of the communities and their daily sceneries. The decision for incorporating foreign elements must be understood in the frame of the cosmovision of native groups. Therefore, these plants with a relative recent introduction, that are present in written record, allow the researcher to understand and to design landscape domestication as a multidimensional process of physical, social and symbolic environment. 
2. INTRODUCCIÓN GENERAL 


\subsection{INTRODUCCIÓN}

La interdisciplinariedad en el campo de las etnociencias requiere de una interrelación entre distintas disciplinas y enfoques que se complementan en torno a los sujetos de estudio quienes, asimismo, interactúan activamente en el proceso de investigación, redefiniéndola. De esta manera es frecuente $-\mathrm{y}$ hasta necesario- la elaboración de un proyecto que deberá ser modificado al comenzar los trabajos de campo. El título propuesto para esta tesis gira en torno a la "naranja amarga", conocida como "apepú", nombre en lengua guaraní, como indicativo de su apropiación local. A lo largo de la investigación se ha ampliado el estudio a los cítricos (Citrus L., Rutaceae, Aurantioideae) en general debido a varios factores: nuevos reportes de poblaciones adventicias, mayor abundancia de otras variedades ("mandarina común", "limón mandarina", "naranja común", entre otras), interés de los pobladores locales, que llevaron al aprecio de otros cítricos. Asimismo, los procesos de hibridación entre las diferentes variedades (descriptos en el capítulo 2.4) generan nuevas combinaciones que son propagadas por los pobladores locales.

El proceso de asentamiento y colonización europea en América implicó también la introducción de frutales que, habiendo ingresado por distintas vías y en diferentes pulsos, fueron incluidos en el repertorio de plantas utilizadas por poblaciones con modos de subsistencia diversos. Un caso muy interesante es el de los cítricos, los que, por tratarse de frutales perennes, se han constituido en cultivos permanentes (NOA y Litoral). Actualmente se reconocen como espontáneos, semiinvasivos e invasivos en áreas protegidas como el Parque Nacional (en adelante PN) Iguazú (Misiones, Argentina) y el PN do Iguaçu (Brasil), donde se encuentran a raíz de las plantas y pies de injerto remanentes de antiguos huertos (Herrera \& Malmierca 1995; Paszko \& Herrera 2006; Rodolfo et al., 2008). Sin embargo, las poblaciones de cítricos no constituyen una amenaza para la flora nativa, menos aún en ambientes sin manejo antrópico, como se tratará a lo largo de este trabajo.

Los frutales euroasiáticos, traídos por los españoles y portugueses a partir de 1493, se han constituido en cultivos perennes en toda América resultando una relación estrecha entre los pueblos y los frutales de más de 500 años de antigüedad y con distintas intensidades $\mathrm{y}$ direcciones de cambio en diferentes órganos, principalmente los utilizados. Actualmente, muchos de estos frutales son cultivados -e incluso son 
espontáneos- en nuestro país: "manzanas" (Malus sylvestris Mill. y M. domestica Borkh.) en el norte de Patagonia; “duraznos" [Prunus persica (L.) Batsch.], "peras” (Pyrus communis L.) y "membrillos" (Cydonia oblonga Mill.) en Prepuna, Cuyo, valles montañosos y serranos; y cítricos subtropicales en la selva paranaense, litoral y valles serranos del NOA, entre otros (Zuloaga et al., 2008; Delucchi et al., 2009; Hurrell et al., 2010; Stampella et al., 2013b). A diferencia de los demás frutales mencionados, la mayoría de los cítricos poseen una corta historia de relación con los europeos debido a su ingreso por parte de los musulmanes pocos siglos antes. A partir del siglo XVI, inmediatamente después de su introducción en América, los cítricos se escaparon de cultivo resultando en poblaciones espontáneas en los bosques y montañas de las Antillas (Acosta, 1590; Cobo, 1890-1892; Puente y Olea, 1900) y desde mediados del mismo siglo, en Paraguay subtropical (Gade, 1976). Los viajeros del siglo XIX y principios del XX señalan la presencia de naranjales silvestres en los alrededores de las ruinas jesuíticas o donde ha habido asentamientos jesuíticos (Azara, 1847; Hernández, 1888, Gambón 1904; Bertoni, 1918), incluso en época jesuítica (Sánchez Labrador, 1910). Esta "naturalización" posibilitó -y aún posibilita- el manejo in situ de dichas poblaciones sin llegar a ser cultivados en un sentido estricto, diversificando de esta manera las distintas unidades del paisaje local donde crecen estos frutales.

Los cítricos, al igual que otros frutales euroasiáticos espontáneos, constituyen un caso de resignificación de plantas exóticas por comunidades locales. En el NE de Argentina, como en el E de Paraguay y S de Brasil, esta apropiación, recreación y reelección constante de los cítricos y de los conocimientos asociados a los mismos por diferentes comunidades, está reflejada en la diversidad de etnoespecies y usos de las mismas (Martínez-Crovetto, 1981; Keller \& Romero, 2006; Gandolfo et al., 2010; Zamudio \& Hilgert, 2011; Kujawska et al., 2012), su importancia en la cultura popular litoraleña (Fiesta Nacional de la naranja, Bella Vista) y la asociación Ruinas Jesuíticas-naranjos descripta a lo largo del tiempo (Holmberg, 1887; Gambón, 1904; Ambrossetti, 2008a, b), entre otros tópicos. Esto es reforzado históricamente por la denominación guaraní de algunas de sus variedades: "apepú” [C. × aurantium (grupo naranja amarga)], que data de la interacción cultural entre jesuitas y guaraníes. Desde el punto de vista botánico, "apepú" es a veces una variedad de endocarpo dulce de la misma "naranja amarga" o "naranja agria" que ingresa al Nuevo Mundo con la conquista y colonización (Webber, 1943a; Swingle, 1943), otras una planta híbrida, morfológicamente intermedia, entre la 
“naranja dulce" y la "naranja amarga" (Lista, 1883; Gade, 1976) posiblemente originada en tierras sudamericanas $-\mathrm{y}$ por lo tanto criolla- algo similar a lo ocurrido con el "pomelo" [Citrus $\times$ aurantium L. (grupo pomelo)] en la Isla de Barbados, durante el siglo XVII (Bowman \& Smitter Jr., 1990). Esta apropiación en sentido utilitario, cognitivo y ecológico expresa una fuerte interrelación con las sociedades locales del Nuevo Mundo.

Con respecto a la diversidad de usos de estos frutales puede ahondarse en su empleo como fruta fresca, condimento, saborizante, en la elaboración de bebidas refrescantes, bebidas alcohólicas, conservas, confituras, y para la extracción de aceites esenciales (Gade, 1979; Burgstaller, 1985; Hilgert, 1997; Hurrell et al., 2010). Además, presentan una amplia diversidad de propiedades medicinales de acuerdo a las variedades consideradas y partes de la planta utilizadas. Tradicionalmente, las flores tienen propiedades sedantes, hipnóticas y antidepresivas; la cáscara de los frutos es usada como aperitiva, antiespasmódica y en resfríos; el jugo como refrescante, antiescorbútico, antihemorrágico, para dolores de cabeza y como repelente de insectos y piojicida, y el follaje como antipirético (Guerra y Sánchez T., 1984; Martínez-Crovetto, 1981; Ripoll, 1985; Burgstaller, 1985; Paul \& Cox, 1995). Científicamente, las propiedades etnomedicinales fueron corroboradas y ampliadas resaltando además otros aspectos medicinales como sus propiedades antioxidantes, debido a la presencia de flavonoides (Bocco et al., 1998; Benavente-García et al., 1997; Stampella et al., 2013c), así como en el tratamiento de enfermedades virales (Bisset, 1994; Alonso, 2004; Álvarez Ruíz et al., 1999).

El propósito de este trabajo es trazar las rutas de ingreso de los cítricos, identificar el origen de las diásporas de los cítricos, analizar las prácticas pasadas y su contexto histórico; y actualmente, documentar la abundancia, riqueza y distribución de los mismos en la zona de estudio, así como también el conocimiento local acerca de la nomenclatura, usos, percepción de la variabilidad y formas de manejo. Asimismo, se espera evidenciar el efecto que la selección cultural tiene sobre las poblaciones de cítricos manejadas in situ, contribuyendo a la consolidación de un modelo que permita entender los procesos de domesticación actuales y los que en el pasado condujeron al desarrollo de la agricultura. 
A largo plazo, el estudio comparativo de poblaciones de naranjas, y cítricos en general, constituirá una inmejorable oportunidad para caracterizar los procesos de construcción del Conocimiento Botánico Tradicional, ya que partiríamos de un material vegetal similar cultivado en España e introducido a América hace 5 siglos, y caracterizaríamos el estado actual de esas poblaciones y su vinculación con los seres humanos a partir de procesos locales. Asimismo analizaríamos los procesos convergentes y/o divergentes ocurridos.

\subsection{HIPÓTESIS (H) Y PREDICCIONES (P)}

H: Las poblaciones asilvestradas de cítricos en el NEA presentan diferencias morfológicas y organolépticas según el origen de la planta madre y la historia de uso (o de falta de uso) de la misma, lo que refleja los procesos diferenciales de selección cultural en distintos enclaves.

P: Esperamos encontrar diferencias en las poblaciones asilvestradas de naranja amarga expresadas morfológicamente y químicamente debidas a criterios diferenciales del Conocimiento Botánico Tradicional en diferentes enclaves.

H: Los cítricos en el NEA presentan diferencias en la diversidad de especies, uso y percepción, y en las características morfoanatómicas de los órganos objeto de selección intencional en función al grupo cultural con el cual están relacionados.

P: La diversidad de cítricos cambia según las características socioculturales de los habitantes. A nivel provincial, esperamos hallar dos macro regiones: la cuenca del río Uruguay (San Javier, Concepción y Apóstoles) y la cuenca del río Paraná (La Candelaria y San Ignacio), debido a que los pobladores de los respectivos países limítrofes asociados a esas cuencas (Brasil y Paraguay) tienen raíces culturales distintas y por lo tanto seleccionan y emplean estos recursos de modo diferencial. Dado que los sitios de estudio están muy próximos a las fronteras suponemos que el intercambio con los pueblos vecinos modeló la presencia y uso de estos recursos. 
$\mathrm{H}$ : La riqueza y diversidad de cítricos aumenta en cercanía a zonas con actividades productivas rurales, en particular la agrosilvícola, ya que conllevan modificaciones en el ambiente que favorecen su establecimiento y dispersión. Asimismo, habrá un gradiente de disminución de riqueza y diversidad entre dichas zonas rurales, el ámbito periurbano y urbano.

P: La diversidad de cítricos asilvestrados o reproducidos por semillas en la provincia de Misiones está asociada a diferentes actividades productivas (en particular aquellas que involucran producción ganadera extensiva), por lo tanto esperamos hallar menor diversidad de estos recursos en sitios poco modificados. En contextos urbanos, con poblaciones de raíces culturales comparables, habrá mayor diversidad y uso de cítricos asilvestrados en los barrios con espacios verdes mayores.

\subsection{OBJETIVO GENERAL Y ESPECÍFICOS}

OBJETIVO GENERAL: Diseñar los procesos locales de selección cultural en poblaciones de cítricos introducidas en el área de las Misiones Jesuíticas y aportar al concepto de domesticación.

\section{OBJETIVOS ESPECÍFICOS}

1. Realizar un relevamiento de la etnobotánica histórica de este recurso de modo de identificar rutas y épocas de ingreso de las semillas o plántulas, así como también las regiones de procedencia probable de las mismas.

2. Relevar poblaciones de cítricos destinados al consumo local en las cuencas del Paraná y Uruguay, discriminando asimismo sitios de muestreo en el gradiente urbanoperiurbano-rural, áreas protegidas y algunas de las ruinas mejores preservadas (Patrimonio UNESCO).

3. Relevar los saberes locales y las prácticas culturales asociadas a dichas plantas, y conocer los patrones actuales de manejo de las mismas. 
4. Caracterizar las poblaciones de cítricos desde el punto de vista etnoecológico y analizar la variabilidad morfológica y organoléptica de las mismas.

5. Analizar si existe relación entre la variabilidad morfológica de las distintas poblaciones de "mandarinas" (Citrus reticulata Blanco) y la presencia o ausencia de uso y manejo humano (presión selectiva) así como también en distintos enclaves socioculturales y en relación a espacios con actividad agrosilvícolas. Evaluar comparativamente la dinámica del conocimiento y de los usos locales presentes en los distintos enclaves a estudiar.

6. Como objetivo a largo plazo, comparar los resultados de este proyecto con los obtenidos por proyectos similares realizados en otras zonas de Argentina (Noroeste, Provincia de Buenos Aires) y Europa (España) para distintos frutales euroasiáticos (manzanos, perales, durazneros, membrillos, vides).

\subsection{ANTECEDENTES}

\subsubsection{BIOLOGÍA REPRODUCTIVA DE CITRUS Y TAXONOMÍA}

El género Citrus comprende algunas de las especies de árboles frutales de mayor

relevancia económica mundial. Es nativo de las zonas cálidas del sur y sudeste de Asia hasta las zonas templadas de China, Australia e islas del Pacífico sudoccidental (Gmitter $\& \mathrm{Hu}, 1990)$. Tiene una larga historia de domesticación y algunos taxa ampliamente difundidos en cultivo -especialmente los portainjertos- muchas veces son espontáneos en las zonas cálidas y templado-cálidas del mundo (Gade, 1976; Roose et al., 1995; Spiegel-Roy \& Goldschmidt, 1996; Mabberley, 1998, 2001; Janick, 2005; Zhang \& Mabberley, 2008; Randall, 2012; Stampella et al., 2013b).

La clasificación intragenérica de Citrus es compleja debido a la presencia frecuente de procesos de hibridación, agamospermia (poliembrionía nucelar), mutación de yemas y autotetraploidía. Es decir, además del embrión cigótico se forman uno o más embriones derivados del nucelo del óvulo, por lo tanto clones del pie receptor. Esta variabilidad reproductiva favorece la aparición de una multiplicidad de fenotipos que puede propagarse naturalmente por "semillas" o bien culturalmente mediante injertos. Dado que los híbridos agamospermos pueden estabilizarse en distintos cultivares, al mismo 
tiempo que son meióticamente normales y fértiles, el género presenta características muy variables, situación que se refleja en las controversias sobre el número de especies: entre 16 y 162, según los autores (Swingle, 1943; Webber, 1943b; Swingle \& Reece, 1967; Hodgson, 1965; Tanaka, 1954, 1966, 1969, 1977). De hecho, Grant (1989: 476) dice que en vez de observarse especies bien definidas se aprecia "una serie de variedades diferentes, muchas de ellas híbridas de una combinación u otra, que relacionan las especies nombradas formando una red, un inmenso singámeon", situando de esta manera a los complejos agámicos entre los patrones de variación más intrincados conocidos en las plantas (Figura 1).

Figura 1. Estructura de un complejo agámico o "singameon". Tomado de Babcock y Stebbins (1938) en Grant (1989). En horizontal se indican las hibridaciones y en vertical los cambios de ploidías. Las barras discontinuas indican posibilidad de hibridación, mientras que las continuas indican imposibilidad.

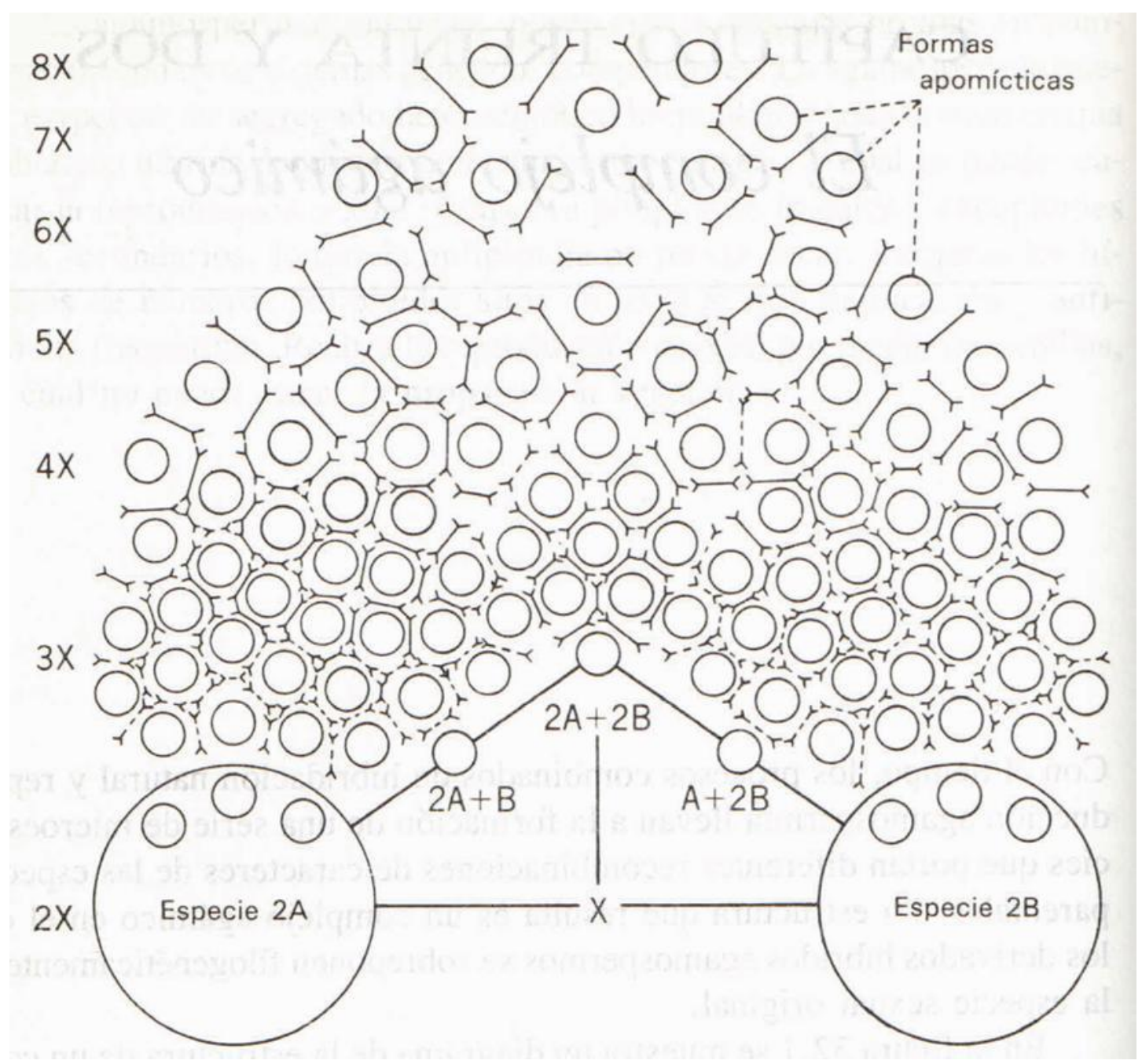


Distintos estudios morfológicos, genéticos, filogenéticos y biomoleculares (Luro et al., 1995; Nicolosi et al., 2000; Nicolosi, 2007; Bayer et al., 2009; Kyndt et al., 2010; Marlykynti et al., 2011; Uzun \& Yesiloglu, 2012; García-Lor et al., 2013; Kumar et al., 2013; Penjor et al., 2013, entre otros) aportaron a la comprensión del género, y en la actualidad se aceptan entre 20 y 25 especies (Mabberley, 1997, 1998, 2001, 2004, 2008), criterio adoptado en la presente contribución. Para el caso de los cítricos cultivados, Mabberley (1997) propone diferenciarlos en 3 taxa biológicos y 4 taxa híbridos: Citrus maxima (Burm.) Merr., C. $\times$ aurantium [C. maxima $\times$ C. reticulata], Citrus $\times$ aurantiifolia (Christm.) Swingle [C. maxima $\times$ ?]; Citrus medica L., Citrus $\times$ limon (L.) Osbeck [C. medica $\times$ ?], Citrus $\times$ jambhiri Lush [C. medica $\times$ C. reticulata $]$ (ahora Citrus $\times$ taitensis Risso) y C. reticulata. Estos taxa muchas veces pueden diferenciarse por el grado de homocigosis (especies biológicas, presentando semillas con un único embrión de origen cigótico) o heterocigosis (taxa híbridos, con semillas poliembriónicas).

Para la Argentina, se han citado 4 taxones adventicios:

1. C. $\times$ aurantium Grupo „Naranja amarga ${ }^{e e}[C$. maxima $\times$ C. reticulata $]$, en Jujuy, Salta, Tucumán, Formosa, Chaco, Misiones, Corrientes, Santa Fe, Córdoba y Buenos Aires (Miranda et al., 2000; Bacigalupo, 2005; Seo \& Xifreda, 2008; IBODA, 2014);

2. C. $\times$ aurantium Grupo „Pomelo"e $(=C . \times$ paradisi Macfad. $)[(C$. maxima $\times C$. reticulata) $\times$ C. maxima], en la provincia de Buenos Aires (Hurrell et al., 2010);

3. C. $\times$ taitensis $[$ C. reticulata $\times$ C. medica L., o bien C. reticulata $\times C . \times$ limon (L.) Osbeck], en Misiones (Stampella et al., 2013b);

4. Citrus trifoliata L. [= Poncirus trifoliata (L.) Raf.], en Entre Ríos y Buenos Aires (Bacigalupo, 2005; Seo \& Xifreda, 2008; IBODA, 2014). 


\subsubsection{DISPERSIÓN DE CITRUS ALREDEDOR DEL MUNDO}

Como se dijo en el apartado anterior, el género es nativo del sur y sudeste de Asia hasta las zonas templadas de China, Australia e islas del Pacífico sudoccidental. Al parecer las primeras menciones de los frutos comestibles (naranjas y pomelos) se remontan a poco más de 4000 años antes del presente, al Imperio de Ta Yu (China) (Webber, 1943a: 2). Para Europa Clásica (Imperios Griego y Romano) sólo se conocía el "cidro" (C. medica) nombrado en los escritos de Teofrasto ( $c a .2300$ años antes del presente) y mencionada su "naturalización" en Cilicia (hoy Turquía, al norte de Siria) por Dioscórides (Siglo I) (Webber, 1943a: 2). Sin embargo, nuevos hallazgos arqueobotánicos no sólo indican una antigüedad mayor para el "cidro" en Italia, sino la posible presencia de $C$. $\times$ limon y $C$. $\times$ aurantium de acuerdo al análisis de restos seminales (Pagnoux et al., 2013). Esto no ha podido ser determinado con certeza debido a la dificultad en la comparación entre variedades actuales e históricas.

La caída del imperio Romano y la expansión del imperio Árabe (siglos VI-X) marcan un nuevo hito en la dispersión de los cítricos. Durante el siglo X los árabes llegan a India desde donde llevan la "naranja amarga" [C. $\times$ aurantium (naranja amarga)], la "lima" $(C . \times$ aurantiifolia $)$ y el "limón" $(C . \times$ limon $)-$ con toda la variabilidad incluida en estas denominaciones- hacia el resto del imperio, ingresando posteriormente (siglo X) hacia el norte de África, Península Ibérica y costas mediterráneas (Gallesio, 1811) donde la "naranja" -y los "naranjales"- y el "limón" son mencionados en los escritos andaluces por primera vez en el siglo X (Ramón-Laca, 2003). Durante los siglos XI y XII también es mencionado C. maxima en Al-Andalus, reconocido como "pampelmusa" o "zamboa", presumiblemente originario de la península Indo-malaya. De hecho, Magallanes describe unas naranjas grandes con las que fueron obsequiados al pasar por las Islas Molucas (Indonesia) (López de Gómara, 1941) y, Puente y Olea (1900) se refiere a unas introducciones asentadas en los Archivos de la Casa de la Contratación de "ciertos naranjos de fruta grande, llevados desde Filipinas".

Otros cítricos aparecen en escena posteriormente. La "naranja dulce" $[C . \times$ aurantium (naranja dulce)] llega a Europa como consecuencia de los viajes de los portugueses (entre ellos, Vasco da Gama) hacia oriente, pasando por África y la India, y, de hecho, en los primeros tiempos fue conocida como "naranja Portugal" o, simplemente, "Portugal". La primera mención de la "mandarina" (C. reticulata) data del viaje de 
Osbeck (1771) a China donde describe una naranja "de calidad" con piel suelta. Finalmente, el "pomelo" $[C . \times$ aurantium (pomelo)] parece tener su origen en la Isla de Barbados (Centroamérica) durante el siglo XVII como consecuencia de hibridación espontánea entre C. maxima y $C$. $\times$ aurantium [naranja dulce] o por mutación somática del primero (Bowman \& Smitter Jr., 1990).

El relativo aislamiento de diferentes enclaves hasta fines del siglo XV resultó -quizá- en la generación de distintas variedades locales de cítricos caracterizadas por diferentes hibridaciones y selecciones por parte de las poblaciones humanas, de acuerdo a diferentes criterios de percepción y uso. Así, luego del arribo de los europeos al Nuevo Mundo son ingresados tempranamente y cultivados en huertos de las colonias de españoles y portugueses.

\subsection{MARCO TEÓRICO}

Este trabajo se inserta en el campo de la Etnoecología, definida como el estudio, holístico y multidisciplinario, de los sistemas de conocimientos, prácticas y creencias que los diferentes grupos tienen sobre su ambiente (Toledo, 1992, 2002). El abordaje etnoecológico focaliza en los actores sociales participando en una red de relaciones, localizada en tiempo y espacio (Nazarea, 1999). Esta definición pone en relieve la profunda interrelación entre las prácticas que modifican el ambiente (aprovisionamiento y construcción de un paisaje habitable) y su relación con las creencias y los conocimientos. De este modo, al resultar de la integración de lo natural y lo cultural, la construcción del paisaje puede abordarse desde la interacción de tres esferas: praxis: prácticas productivas; corpus: repertorio de saberes o sistema cognitivo; y kosmos: el sistema de creencias o cosmovisión (Toledo \& Barreras-Bassols, 2008).

Así, esta tríada de conocimientos, creencias y prácticas se hallan intrincadas conformando un complejo conocido como Conocimiento Ecológico Tradicional (CET), definido como un cuerpo acumulativo de conocimientos, prácticas y creencias sobre las relaciones entre los seres vivos y el ambiente (Berkes et al., 2000). La conformación de este corpus es adaptativa, combinando conocimientos ecológicos ancestrales y actuales derivados de aciertos, pero también de errores y crisis, y transmitiéndose de generación en generación mediante prácticas compartidas (Rindos, 1984; Davidson-Hunt \& Berkes, 
2003; Lozada et al., 2006; Eyssartier et al., 2008; Pochettino \& Lema, 2008). De acuerdo a Cotton (1998) se pueden diferenciar tres aspectos: utilitario, cognitivo y ecológico que, de alguna manera, reseñan la historia de las etnociencias como disciplina. A lo largo de esta tesis exploraremos diferentes aspectos de los tres enfoques de manera complementaria, focalizándonos fundamentalmente en el último.

El concepto de "tradicional" ha sido definido de distintas maneras, pero en líneas generales se asocia a un conocimiento de antigua data. Cabe aclarar que la palabra "tradicional" se emplea aquí en el sentido de "local” (Nazarea, 1999; Reyes García \& Martí Sanz, 2007), o sea, situado en tiempo y espacio. A diferencia de lo planteado por Berkes et al. (2000) no se remitirá únicamente a sociedades con prolongada continuidad histórica en el uso de los recursos, dado que se considera -en la génesis de el CET- una visión sintética que complementa la práctica y experimentación con conocimientos derivados de diversas fuentes, entre ellas el conocimiento científico (Pochettino \& Lema, 2008; Pochettino et al., 2008). Este corpus de conocimientos a su vez está influenciado por factores tales como edad, sexo, ocupación, amistades, disponibilidad del acceso a los recursos, pluriculturalidad, entre otros (Lozada et al., 2006; Poderoso et al., 2012) y su documentación y estudio son de crucial importancia para estrategias conjuntas (comunidades locales y Estado) de conservación in situ de variedades locales, especies raras y de desarrollo sustentable de comunidades situadas en las cercanías de áreas protegidas (Iskandar \& Ellen, 1999; Berkes et al., 2000; Davidson-Hunt \& Berkes, 2003; Calvet-Mir et al., 2010; Carvalho \& Frazão-Moreira, 2011), entre otros proyectos.

De esta manera el enfoque etnocientífico aborda el tema desde una perspectiva más amplia y actual e intenta, a partir de la interpretación científica de los hechos, realizar comparaciones de los conocimientos asociados a las prácticas y comportamientos que una sociedad particular posee sobre el entorno vegetal, a través del tiempo y en diferentes ambientes (Hilgert, 2007; Albuquerque \& Hurrell, 2010).

Con el fin de superar la visión determinista, donde los seres humanos se adaptan al ambiente y los aspectos socioculturales quedan sujetos a la disponibilidad de los recursos, se tendrá en cuenta la participación activa de los sujetos en la construcción del entorno a través del tiempo, fundamentalmente a través de la proyección hacia el mismo, mediante la praxis, de distintos aspectos relacionados a los conocimientos y las 
creencias en la conformación de los paisajes. Esta proyección de diferentes aspectos socioculturales hacia el ambiente permite identificar prácticas pasadas (y actuales) en el presente (Buxó, 2006; Capparelli et al., 2011) e inferir criterios de selección sobre las plantas y los paisajes.

En este sentido, la Ecología Histórica surge como alternativa al mencionado modelo determinista-ambiental enfatizando en la dimensión temporal como fuente para la interpretación y manejo de los ecosistemas del presente. Nutrida del Materialismo Histórico, de la Ecología Cultural, del Materialismo Cultural y de la Ecología Evolutiva, enfoca su universo de estudio en las interrelaciones (influencias mutuas) entre los humanos y la naturaleza (biosfera), entre la cultura y el ambiente, a través del tiempo como un fenómeno dialéctico antes que dicotómico (Balée, 1998; Rival, 1998). Entre sus postulados, plantea el fin de los ambientes "naturales" o "prístinos", no sólo en el sentido del crecimiento demográfico, globalización y avance de la agricultura industrial, sino también al considerar la coevolución entre sociedad y ambiente en su profundidad temporal. Para ello emplea diversas aproximaciones metodológicas como la ecología, etnoecología, etnohistoria y arqueología. Asimismo, enfatiza en la diversidad de prácticas sobre el entorno, discriminando aquellas sustentables, relacionadas con poblaciones locales caracterizadas por saberes adaptativos y cosmologías en relación a la naturaleza, de aquellas que impactan negativamente sobre la diversidad a diferentes niveles, comúnmente asociadas a la moderna economía de mercado (Pochettino et al., 2008; Toledo \& Barreras-Bassols, 2008). Además, focaliza en los efectos cualitativos diferenciales sobre la biósfera de las distintas economías políticas (procesos macroeconómicos) y de sus trayectos históricos, aspectos que no serán tratados en esta tesis.

Por lo tanto, muchos -si no todos- los ambientes considerados "prístinos" son producto de prácticas pasadas. Heckenberger et al. (2003) presentan evidencias arqueológicas de patrones de asentamiento complejos relacionados con áreas de selva muy modificadas en el Matto Grosso de Brasil, avivando así los debates acerca de la capacidad de carga de los ecosistemas amazónicos, tamaño poblacional y patrones de asentamiento, como también el impacto humano en el ambiente y el conocimiento local. Más cerca de la zona de estudio, Reis et al. (2014) cuestionan el origen "natural" de los bosques de Araucaria angustifolia (Bertol.) Kuntze y A. araucana (Molina) K. Koch del NE argentino y de Patagonia, respectivamente. Según estos autores el uso de las semillas 
como alimento, el conocimiento de las características ecológicas de las especies y el manejo in situ y ex situ de las poblaciones favoreció la expansión y abundancia en el pasado, por lo cual estas prácticas deberían tenerse en cuenta en las estrategias de conservación-desarrollo de dichos paisajes.

En ese contexto surge un concepto central en esta disciplina: el de paisaje, entendido como fenómeno biocultural, construido a través del tiempo por la interacción entre las sociedades locales y el entorno (Balée, 1998). Este concepto presenta distintas definiciones, pero enfatizaremos aquellos autores que lo conciben como una proyección de la cultura hacia la naturaleza a través del tiempo (Crumley \& Marquardt, 1990, en Balée, 1998). Así, el entorno es percibido de acuerdo a los significados simbólicos diferenciales en base a distintas valoraciones. Por ejemplo, un monte es percibido y valorado de diferentes maneras por los distintos actores locales: grandes productores y empresas multinacionales interesadas en monocultivos de pino o yerba mate, productores ganaderos, pequeños productores (familiares) diversificados que aprovechan este espacio para ciertas actividades de aprovisionamiento dentro de un marco de estrategia de uso múltiple del entorno, o bien para grupos M'bya que dependen cotidianamente de este espacio para recolección y caza, agricultura de roza y quema y prácticas agrosilvícolas (Pochettino et al., 2002; Bartolomé, 2009). De esta manera se erigen en ambientes simbólicos producto de actividades humanas al dar significado a la naturaleza desde diferentes puntos de vista y de acuerdo a distintas creencias y valoraciones (Greider \& Garkovich, 1994), los que, por otra parte, se ponen en juego en tensiones constantes y relativas a un contexto cultural y temporal determinado.

Desde este enfoque pueden problematizarse algunos conceptos que abordaremos a lo largo de esta tesis, muchas veces presentados como opuestos y contradictorios, como por ejemplo: ¿qué es un paisaje cultural? ¿qué es el paisaje natural? ¿existen ecosistemas terrestres naturales? ¿y selvas prístinas?. Asimismo, relacionado a los cuestionamientos anteriores ¿es correcto denominar naturalización o asilvestramiento al proceso por el cual una planta exótica o cultivada se vuelve espontánea? ¿se tienen en cuenta las prácticas sobre los ambientes considerados "naturales" que muchas veces favorecen la "naturalización? 
Estas problemáticas pueden abordarse a la luz de las interrelaciones entre los seres humanos y las plantas. La domesticación de plantas es un proceso coevolutivo basado en relaciones simbióticas entre plantas y humanos, resultante de la manipulación de los genotipos por selección cultural (Rindos, 1984; Harlan, 1992; Casas, 2001). Este proceso está caracterizado por diferentes grados de relación ser humano-planta a su vez con diferenciaciones morfológicas entre las formas silvestres y aquellas totalmente domesticadas, éstas últimas definidas por su completa dependencia respecto al ser humano para sobrevivir y reproducirse (Harlan, 1992; Casas, 2001). Estos caracteres morfológicos y fisiológicos que diferencian las plantas domesticadas de los antecesores silvestres se denominan en su conjunto "Síndrome de Domesticación” (Gepts, 2004) y son bien conocidos para las plantas anuales (Koinange et al., 1996; Poncet et al., 1998; Li et al., 2006) pero poco abordados para las especies perennes siendo los trabajos de Zohary \& Spiegel-Roy (1975), Zohary (2004), McKey et al. (2010) y Miller \& Gross (2011) una excepción al respecto.

Este continuo existente entre las plantas completamente domesticadas y sus antecesores silvestres está representado por un rango de diferenciaciones morfológicas y adaptaciones ecológicas (Harlan, 1992) denominadas en su conjunto "domesticación incipiente", mientras que a las plantas se las llama "semidomesticadas" o "cultivos transicionales" (Lema, 2010). Debido a sus características intrínsecas (alta tasa de hibridación, ciclos de vida largos, fases juveniles prolongadas), los frutales perennes se constituyen en ejemplos de esta interacción. Diversas prácticas de manejo de poblaciones y paisajes, descriptas como cultivo en sentido amplio (ver más adelante), producen cambios significativos en los órganos vegetales no necesariamente significando la domesticación de las especies. Estas prácticas son ampliamente descriptas por Harlan (1992), Casas (2001) y Lema (2010) y consideradas dentro del concepto amplio de cultivo (sensu lato) donde prima la conciencia de las prácticas de manejo, oponiéndose al concepto de erradicación. En la literatura científica se presentan varios casos (la mayoría mexicanos) involucrando especies útiles de Anacardiaceae (Spondias purpurea L.), Arecaceae (Astrocaryum tucuma Mart., Bactris gasipaes Kunth), Bignoniaceae (Crescentia cujete L.), Fabaceae [Leucaena esculenta (Moc. \& Sessé ex. DC.) Benth.], Cactaceae [Escontria chiotilla (F.A.C. Weber) Rose, Polaskia chende Gibson \& Horak, Stenocereus pruinosus (Otto ex Pfeiff.) Buxb., S. stellatus (Pfeiff.) Riccob.], Malpighiaceae [Byrsonima crassifolia (L.) Kunth.] y Sapotaceae 
[Chrysophyllum cainito L., Sideroxylon palmeri (Rose) T.D. Penn.] (Casas \& Caballero, 1996; Casas et al., 1997, 1999, 2006; Casas, 2001; Cruz \& Casas, 2002; Arellano \& Casas, 2003; González Soberanis \& Casas, 2004; Schroth et al., 2004; Miller \& Schaal, 2005; Blancas et al., 2010; Ekué et al., 2010; Parker et al., 2010; Parra et al., 2010; Raya-Pérez et al., 2010; Aguirre-Dugua et al., 2012).

Las plantas consideradas "silvestres" tampoco escapan de las prácticas de manejo y en consecuencia, el paisaje también puede ser domesticado sin que necesariamente ocurra domesticación de plantas en un sentido estricto. Se conoce como "Domicultura" a las modificaciones sobre el ambiente que crean un paisaje apropiado socialmente, una incorporación del ambiente al hogar (Chase-Sardi, 1989; Harlan, 1992; Politis, 1996). Mediante prácticas de manejo no intencionales (como pueden ser recolección, tolerancia e inducción) se modifican parámetros poblacionales de diferentes taxa, como la distribución y abundancia de los mismos (Rindos, 1984; Lema, 2010). Las plantas involucradas no necesariamente presentan cambios morfológicos ni fisiológicos detectables pero sí una fuerte asociación a los pobladores locales en lo relativo a aspectos simbólicos, afectivos, utilitarios (Yen, 1989; Harlan, 1992).

El proceso de selección cultural sobre el entorno, resulta en la domesticación tanto del paisaje como de las especies, entendiendo este proceso no como modificaciones genéticas y dependencia del cultivo, sino como una verdadera incorporación y extensión de la unidad doméstica (en adelante UD) hacia el entorno. Por ejemplo, el monte entendido como un ambiente selvático (variable fitogeográficamente de acuerdo al enclave considerado) opuesto al campo, con dominancia de herbáceas- es uno de estos microambientes apropiado y resignificado, siendo cultivado y domesticado. En comunidades M'bya es considerado parte de la UD, un espacio lleno de componentes simbólicos y pragmáticos (Pochettino et al., 2002; Crivos et al., 2007). Lejos de tratarse de ambientes "prístinos" estos bosques, principalmente los peridomiciliarios, se encuentran altamente modificados y no sólo en sentido de degradación de los mismos. Algo similar ocurre con las zonas de cultivos anuales (roza y quema) que, luego de abandonados evolucionan hacia diferentes sistemas productivos como plantaciones forestales, sistemas agrosilvícolas y silvopastoriles (Aumeeruddy, 1998; Abreu \& Watanabe, 2008). Otras veces, simplemente, son abandonados regenerándose el monte. Éstos se caracterizan muchas veces por la alta diversidad de plantas útiles en comparación con otros espacios menos intervenidos (Posey, 1985). 
Así, si el monte es percibido como un ambiente "prístino" o "natural" las especies vegetales exóticas que se reproducen por sus propios medios sin intervención humana directa, se denominan naturalizadas (Richardson et al., 2000) aunque también asilvestradas. Pues bien, en el caso en que se considere al monte como una extensión de la UD -por lo tanto domesticado-, como también la historia local -muchas veces desconocida- de las prácticas dirigidas al entorno en la construcción de los paisajes ¿Se puede hablar de naturalización de plantas exóticas en un ambiente antropogénico? ¿No sería más correcto hablar de plantas antropizadas o adaptadas a ambientes antropizados? 
3. METODOLOGÍA GENERAL 
A lo largo de la investigación se emplearon distintas aproximaciones metodológicas articuladas entre sí, características de las etnociencias y su actual enfoque interdisciplinario. De esta manera, varias aproximaciones pertenecientes a diferentes disciplinas relacionadas al tema de investigación se complementan y articulan en un estudio de caso. En este apartado se comentarán las generalidades metodológicas y su articulación, relegando a cada apartado de Resultados (5.1.3., 5.2.3., 5.3.3. y 5.4.4.) un desarrollo más extenso de los métodos y los materiales empleados en relación a la temática.

\subsection{CONSENTIMIENTO INFORMADO}

Al inicio del trabajo de campo se obtuvo el consentimiento previamente informado de un adulto de cada UD involucrado en la investigación. Para ello se explicó brevemente, en lenguaje apropiado y divulgativo, los objetivos, fundamentación, implicancias y alcances de la investigación (Alexiades \& Laird, 2002; Alexiades \& Peluso, 2002; Laird \& Posey, 2002; Laird \& Noejovich; 2002; Lewis, 2010) acordando con los participantes distintos ítems de consentimiento, como por ejemplo: toma de muestras vegetales, imágenes fotográficas, grabaciones, socialización de los conocimientos locales, identidad, entre otros (ver Anexo 9.1.).

\subsection{SELECCIÓN DE SITIOS DE ESTUDIO E INFORMANTES}

Durante el mes de junio de 2010 se realizó un viaje prospectivo por el sur de la provincia de Misiones, recorriendo las inmediaciones de las reducciones misioneras de San Javier, Santa María la Mayor, Santos Mártires del Japón, Concepción de la Sierra, Apóstoles Pedro y Pablo, San Carlos (Corrientes), San José (asociados a la cuenca del río Uruguay); y La Candelaria, Santa Ana, Nuestra Señora de Loreto y San Ignacio Miní (correspondientes a la cuenca del Paraná).

Luego de esta primera campaña exploratoria, se seleccionaron los departamentos de San Ignacio y Concepción de la Sierra, ubicados en diferentes cuencas y con influencias culturales de los países vecinos: cuenca del Paraná (relacionada a Paraguay) y cuenca del Uruguay (relacionada a Brasil). Dentro de los mismos, se seleccionaron poblaciones 
en un gradiente de urbanización/ruralidad (Tabla 1). Asimismo, para la selección se tuvo en cuenta la accesibilidad y la predisposición de los pobladores a participar en la investigación de acuerdo al consentimiento informado. Así, los 6 sitios muestreados son, en el ámbito rural: San Ignacio (SI) y Concepción de la Sierra (CS); periurbano: Puerto Viejo (PV) y La Corita (LC); y rural: Teyú Cuaré (TC) y Cerro Mártires (CM).

Tabla 1. Enclaves estudiados discriminados por cuenca, gradiente de urbanización/ruralidad, Distrito Fitogeográfico y coordenadas georeferenciales.

\begin{tabular}{|c|c|c|}
\hline & Cuenca del Paraná & Cuenca del Uruguay \\
\hline \multirow[t]{3}{*}{ Urbano } & San Ignacio (SI) & Concepción de la Sierra (CS) \\
\hline & D. de "los laureles" & D. de "los campos" \\
\hline & $27^{\circ} 15^{\prime} 31^{\prime \prime} \mathrm{S} 55^{\circ} 32^{\prime} 21^{\prime \prime} \mathrm{W}$ & $27^{\circ} 58^{\prime} 50^{\prime \prime} \mathrm{S} 55^{\circ} 31^{\prime} 18^{\prime \prime} \mathrm{W}$ \\
\hline \multirow[t]{3}{*}{ Periurbano } & Puerto Viejo (PV) & La Corita (LC) \\
\hline & D. fluvial paranaense & D. de los campos / del urunday \\
\hline & $27^{\circ} 14^{\prime} 53^{\prime \prime} \mathrm{S} 55^{\circ} 32^{\prime} 46^{\prime \prime} \mathrm{W}$ & $27^{\circ} 53^{\prime} 36^{\prime \prime} \mathrm{S} 55^{\circ} 21^{\prime} 15^{\prime \prime} \mathrm{W}$ \\
\hline \multirow[t]{4}{*}{ Rural } & Teyú Cuaré (TC) & Cerro Mártires (CM) \\
\hline & D. fluvial paranaense / del & D. del urunday / de los laureles \\
\hline & urunday & $27^{\circ} 49^{\prime} 11^{\prime \prime} \mathrm{S} 55^{\circ} 24^{\prime} 41^{\prime \prime} \mathrm{W}$ \\
\hline & $27^{\circ} 17^{\prime} 55^{\prime \prime} \mathrm{S} 55^{\circ} 34^{\prime} 27^{\prime \prime} \mathrm{W}$ & \\
\hline
\end{tabular}

Esta división de cuencas ya se puede apreciar en los documentos del período jesuítico y post-jesuítico de acuerdo a las diferentes ocupaciones durante el siglo XIX de Paraguay y Brasil (Barreyro, 1979; Carbonell, 1992). Actualmente, se pueden relevar diferencias relacionadas a la vegetación dominante y tipos de suelo, los sistemas productivos de apropiación, la influencia de las fronteras con los países vecinos de Paraguay y Brasil e historia local de ocupación del territorio, que serán desarrollados en el capítulo 4. La selección de los sitios de estudio de acuerdo a un gradiente de urbanización/ruralidad está relacionada a la hipótesis 3 sobre los cambios en diferentes aspectos del CET, y de la riqueza y abundancia de cítricos, como también de diferentes -y contrastanteshistorias de vida. 
Con el objeto de lograr una caracterización general de las etnovariedades de cítricos y de los saberes y prácticas asociadas a las mismas, se identificaron informantes calificados en dichos ejes temáticos. Para la selección de los mismos, inicialmente se realizó una aproximación al azar, seguida de la visita a personas recomendadas por los primeros contactados [técnica conocida como "bola de nieve" (Bernard, 2000)].

\subsection{TRABAJO DE CAMPO}

Durante los años 2010 y 2013 se realizaron 8 campañas en diferentes momentos del año en los distintos enclaves antes mencionados. Las mismas se llevaron a cabo en junio y septiembre de 2010; marzo y julio de 2011; abril-mayo y julio de 2012; y febrero y mayo-junio de 2013. De este modo, se trató de tomar muestras en los distintos momentos del ciclo anual de los cítricos.

Se entrevistó un total de 58 informantes pertenecientes a $43 \mathrm{UD}$, distribuidos en los enclaves estudiados según la tabla 2.

Tabla 2. Número de UD e informantes por enclave estudiados.

\begin{tabular}{|lcc|}
\hline Cuenca & PARANÁ & URUGUAY \\
Departamento & San Ignacio & Concepción de la Sierra \\
Urbano & San Ignacio & Concepción \\
UD & 7 & 8 \\
Informantes & 8 & 9 \\
Periurbano & Puerto Viejo & La Corita \\
UD & 5 & 6 \\
Informantes & 8 & 8 \\
Rural & Teyú Cuaré & Cerro Mártires \\
UD & 6 & 12 \\
Informantes & 6 & 19 \\
Total UD & 18 & 26 \\
Total & 22 & 36 \\
informantes & & \\
\hline
\end{tabular}


Se emplearon estrategias metodológicas propias de la etnobotánica y etnoecología para el abordaje de la interrelación ser humano-planta y ser humano-entorno, que consistieron en trabajo de campo en los enclaves antes mencionados. Se emplearon técnicas como observación participante, entrevistas semiestructuradas y estructuradas, caminatas con los informantes - muy útiles para el relevamiento de los recursos vegetales empleados en los distintos microambientes-, listados libres y ranking de preferencia (Cotton, 1998; Cunningham, 2001; Martin, 2001; Laird, 2002; Tuxill \& Nabhan, 2001; Albuquerque et al., 2014). También se usó la técnica etnográfica de historia de vida con el fin de indagar en la relación entre los pobladores locales, los cítricos y las distintas unidades ecogeográficas, de manera retrospectiva hacia décadas relativamente recientes (principios de siglo XX) (Nazarea, 1998; Trinidade Medeiros et al., 2014).

\subsection{COLECTA DE MATERIAL DE REFERENCIA Y DETERMINACIÓN}

La metodología botánica fue empleada para la colecta y procesamiento de material vegetal asociado a los conocimientos locales relevados durante el trabajo de campo (Cotton, 1998; Lima dos Santos et al., 2014). Para todos los casos se tomaron las coordenadas del sitio donde se colectó el material mediante GPS Garmin e-Trex.

El material de referencia se recolectó -en lo posible- por triplicado, y fue depositado primeramente en la Colección de Frutos y Semillas (CFS) del Laboratorio de Etnobotánica y Botánica Aplicada (LEBA), de la Facultad de Ciencias Naturales y Museo (UNLP) y, para los ejemplares espontáneos o nativos, se depositaron en el Herbario del Museo de La Plata (LP). El material de referencia constó de ejemplares fértiles y estériles de diferentes etnovariedades de cítricos como también de otras plantas o partes de plantas características de diferentes ambientes de la UD. También se confeccionó una carpoteca con los frutos de las distintas etnovariedades y bajo diferentes formas de cultivo, conservados en Etanol $70^{\circ}$ (EtOH) con agregado de ácido acético $(\mathrm{AcOH})$. El agregado de $\mathrm{AcOH}$ se realizó para evitar la disolución de los cristales de hesperidina según el protocolo de Higby (1943). El material de referencia fue identificado botánicamente mediante los textos de Dimitri $(1980,1987)$ y Burkart $(1974,1979)$ y la nomenclatura actualizada de acuerdo a IBODA (2014). Asimismo, para material fragmentado o estéril se emplearon en algunos casos particulares atlas de 
alimentos y medicamentos tales como Winton \& Winton $(1932,1935)$ o bien tratados de morfología vegetal como Metcalfe \& Chalk $(1979,1983)$.

Para la determinación de las etnovariedades de cítricos se emplearon los trabajos de Webber (1943b), Swingle (1943), Palacios (1978), Anderson (1996) y Rivera Núñez et al. (1998), mientras que para su nomenclatura se siguieron los trabajos de Mabberley (1997, 2004, 2008) y Zhang \& Mabberley (2008).

Asimismo, se consultaron los ejemplares de Citrus y taxa afines de los herbarios antes mencionados (CFS/LEBA, LP) y de la Facultad de Ciencias Agrarias y Forestales (UNLP) (LPAG), del Museo Argentino de Ciencias Naturales (BA), Instituto de Botánica Darwinion (SI) y del Instituto de Botánica del Nordeste (CTES).

\subsection{ETNOBOTÁNICA HISTÓRICA}

La información histórica, de crucial importancia en la caracterización temporal del contexto local, fechas, rutas y etnoespecies introducidas, así como las prácticas y los usos de las mismas, fue analizada mediante la metodología propia de la etnohistoria y de la etnobotánica histórica. Este enfoque consiste en el análisis antropológico diacrónico de fuentes históricas con el objetivo de indagar en la relación entre las comunidades locales y su entorno vegetal (Hernández Bermejo \& Lora González, 1996; Giovannetti, 2005; Touwaide, 2010; Trinidade Medeiros, 2010a, b; Capparelli et al., 2005; Rosso, 2013).

Se emplearon diferentes tipos de fuentes históricas como relatos de cronistas de Indias, Cartas Anuas y obras de los Jesuitas, Tratados de Cítricos (Hespérides) de los siglos XVI a XIX, relatos de naturalistas y viajeros a Misiones de los siglos XIX y XX, catálogos de las Estaciones Experimentales de fines de siglo XIX y principios del XX y varios tomos de la Revista IDIA, correspondientes a mediados de siglo pasado. Se consultaron además trabajos etnográficos y etnohistóricos actuales de la zona en estudio, así como también libros de citricultura contemporáneos, que serán detallados en el apartado 5.1.2. 


\subsection{ANÁLISIS DE DATOS}

La información relevada fue organizada en diferentes bases de datos empleando los programas Microsoft Office Excel 2007 y STATISTICA 7.0.

Con el fin de obtener datos significativos y expresivos de las relaciones entre ellos, se calcularon diferentes índices (ver apartado 5.4.4) de diversidad específica (etnoespecies y etnovariedades) e importancia relativa (IR) (Begossi, 1996; Albuquerque et al., 2014; Atanazio da Silva et al., 2014). Se realizaron análisis estadísticos descriptivos con el fin de caracterizar los distintos enclaves y el CET en relación a los cítricos. Se emplearon técnicas estadísticas no paramétricas con el fin de realizar comparaciones entre variables (Chi-cuadrado). Se empleó el Análisis de Componentes Principales (PCA, técnica de ordenamiento descriptiva), con el fin de analizar la variabilidad de los datos mediante una representación gráfica y las correlaciones entre los mismos (Höft et al, 1999). 
4. ÁREA DE ESTUDIO 
Los trabajos de campo se llevaron a cabo en la porción sur de la provincia de Misiones (Argentina), limitando al sur con la provincia de Corrientes (Argentina), al este con Rio Grande do Sul (Brasil) y al oeste con Itapúa (Paraguay). Tal como se expone en la Tabla 1, se trabajó en 3 sitios, respectivamente, de los departamentos de San Ignacio y Concepción de la Sierra, ubicados en diferentes cuencas y con influencias culturales de los países vecinos (Figura 2).

Figura 2. Área de estudio. Localización de la provincia de Misiones (sombreado en gris) y de los departamentos estudiados (en celeste). Referencias, SI: San Ignacio; PV: Puerto Viejo; TC: Teyú Cuaré; y CS: Concepción de la Sierra; LC: La Corita; CM: Cerro Mártires.

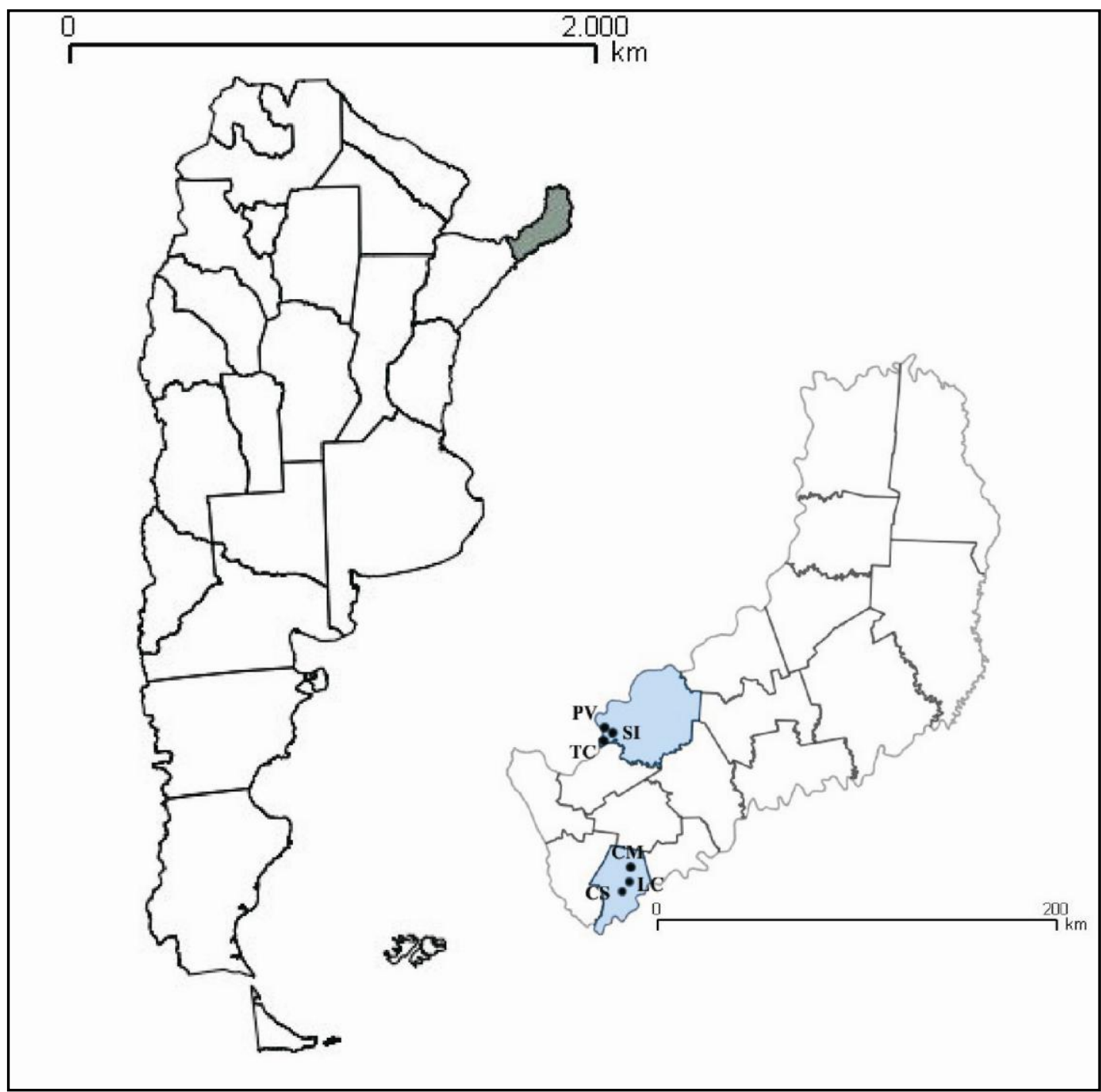




\subsection{FITOGEOGRAFÍA}

La provincia de Misiones es la región de mayor diversidad biológica de Argentina (Placci \& Di Bitetti, 2006) y sus ambientes están incluidos dentro de los puntos calientes (hotspots) de la conservación mundial (Myers et al., 2000; Mittermeier et al., 2004) siendo una de las ecorregiones prioritarias de conservación de acuerdo al criterio de la WWF (Olson \& Dinerstein, 2002). A lo largo de la historia de uso, sus paisajes se fueron reconvirtiendo en sistemas agrícolas, agrosilvícolas y/o forestales (Laclau, 1994; Colcombet \& Noseda, 2000; Chebez \& Hilgert, 2003; Grau \& Aide, 2008; Izquierdo et al., 2008, 2010).

Todos los enclaves estudiados pertenecen a la Región Neotropical, Dominio Amazónico, Provincia Fitogeográfica Paranense, más específicamente a la zona de transición entre los distritos de "las Selvas Mixtas" y de "los Campos" (Cabrera, 1976). En esta región las áreas boscosas se extienden en galerías a lo largo de los ríos Paraná y Uruguay, siguiendo el curso de los arroyos más importantes y cubriendo las laderas de las serranías bajas como Santa Ana, San Juan o San José, definiéndose como una selva empobrecida que avanza sobre las sabanas, en las cuales se observan isletas boscosas (capones) dentro de una matriz de pastizales (Chebez, 2005).

Esta área transicional es descripta con más detenimiento por Martínez-Crovetto (1963) en su "Esquema Fitogeográfico de la provincia de Misiones", ahondando en aspectos relativos al clima, suelo, vegetación "natural" y de las "capueras" ( sitios modificados con vegetación secundaria o sucesional). Así, el Sector "Misionero" - establecido por oposición al Sector "Planaltense", que ocupa las "tierras altas" del nordeste misioneroestá representado en el área de estudio por cuatro Distritos:

1. "de los Campos", al sur, con dominancia de comunidades herbáceas, siendo característica la presencia de las gramíneas: Aristida pallens Cav., Andropogon lateralis Nees y los “espartillos amargos", Elionurus tripsacoides Humb. \& Bonpl. ex Willd. y E. muticus (Spreng.) Kuntze. Este distrito se encuentra altamente modificado por la actividad ganadera intensiva desde época jesuítica, hecho que lleva a Fontana (1998) a plantear su origen antrópico en la zona. En la zona estudiada, es característico de Concepción de la Sierra y La Corita, aunque suelen aparecer "campos" o "potreros" (“campos” destinados a la cría de 
ganado) de extensión considerable en Teyú Cuaré, Cerro Mártires (Figura 4) y San Ignacio.

2. "del Urunday", transicional, caracterizado por la presencia dominante de Astronium balansae Engl. (actualmente diezmados), "espinillo" [Acacia caven (Molina) Molina], “niño rupá” o “cedrón” [Aloysia virgata (Ruiz \& Pav.) Pers.], "aruera” [Lithraea molleoides (Vell.) Engl. y Schinus weinmaniifolius Engl.], "chichita" (S. molle L.), "talera" [Celtis iguanaea (Jacq.) Sarg.], que suelen ingresar al distrito "de los campos" por las faldas de las sierras, asociados a afloramientos rocosos (denominados localmente pedreras). Puede observarse en La Corita, parte de Cerro Mártires (Figura 5) y de Teyú Cuaré.

3. "de los Laureles", con dominancia de "laurel negro" [Nectandra megapotamica (Spreng.) Mez] y "laurel amarillo" (N. lanceolata Nees \& Mart. ex Nees), destacándose además “anchico" [Parapiptadenia rigida (Benth.) Brenan], "cedro" (Cedrela fissilis Vell.), "guayubira” [Cordia trichotoma (Vell.) Arráb. ex Steud.], "cancharana" [Cabralea canjerana (Vell.) Mart.], entre otros, siendo característico de la mayor parte de la provincia. Puede apreciarse en San Ignacio, muy modificado en Puerto Viejo (plantaciones forestales) y cerca del cerro Mártires en el enclave homónimo (Figura 6).

4. "Fluvial", propio de las selvas hidrófilas ribereñas y afluentes, a su vez diferenciado en "Paranense" y "Uruguayense", variando su composición florística de acuerdo al río al cual se encuentra asociado. Es característico de las zonas ribereñas de Puerto Viejo y Teyú Cuaré.

Figura 4. Distrito de los Campos, modificado por la actividad ganadera. La Corita.

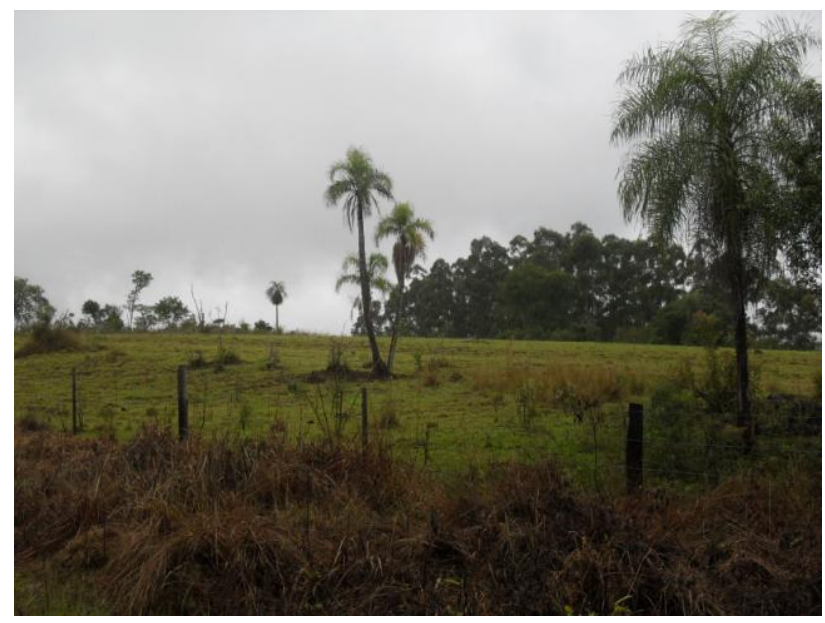


Figura 5. Distrito del Urunday, a un costado del camino al cerro Mártires.

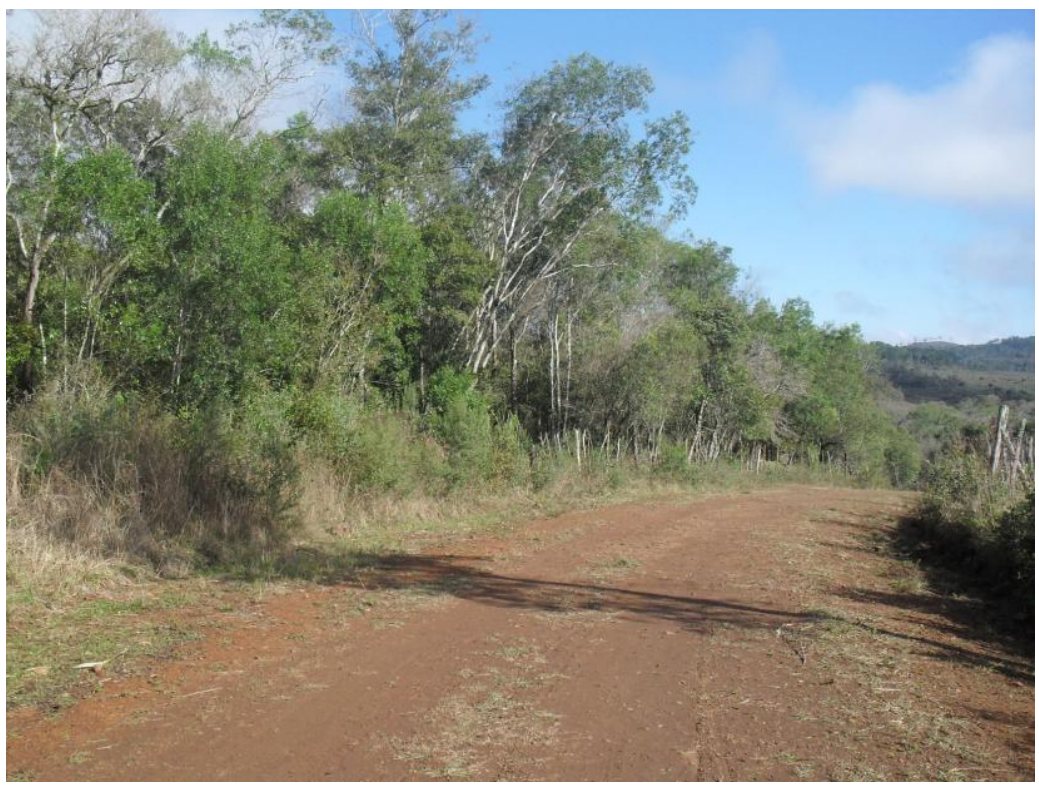

Figura 6. Distrito de los Laureles. Paraje Cerro Mártires.

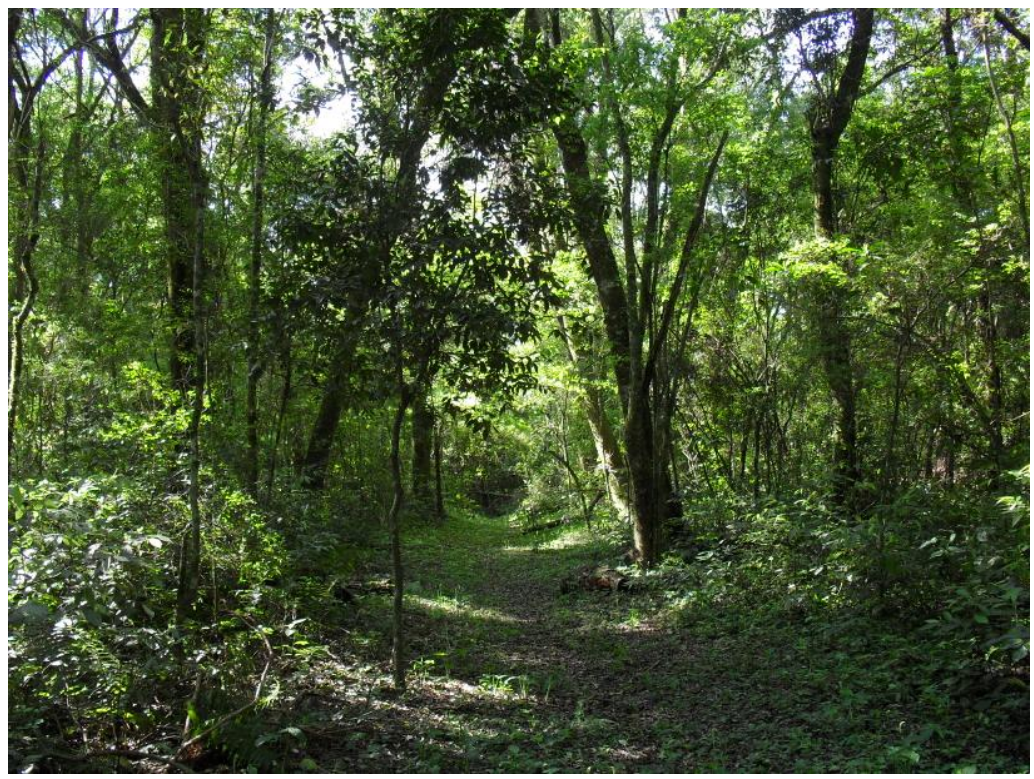

Recientemente, Morello et al. (2012) caracterizaron a la zona de estudio, como de transición entre 2 ecorregiones: "Selva Paranaense" y "Campos y Malezales". Esta propuesta toma en cuenta, además de factores climáticos y de vegetación, factores ecológicos, históricos y económicos. A la vez, estos autores diferencian distintas subregiones y complejos de acuerdo a características meso-micro-climáticas, edafológicas y de vegetación. Así, mientras Concepción de la Sierra y parte de La Corita se encuentran incluidos en la ecorregión de Campos y Malezales (más 
específicamente en la subregión de los Campos), Cerro Mártires, parte de La Corita y todo el departamento de San Ignacio pertenecen a la ecorregión de la Selva Paranense (subregiones Pediplanos del Paraná y Serranías y Mesetas) (Tabla 3).

Tabla 3. Ecorregiones, Subregiones y complejos presentes en los enclaves estudiados, según Morello et al. (2012).

\begin{tabular}{|l|l|l|l|l|l|l|}
\hline & Concepción & La Corita & $\begin{array}{l}\text { Cerro } \\
\text { Mártires }\end{array}$ & $\begin{array}{l}\text { San } \\
\text { Ignacio }\end{array}$ & $\begin{array}{l}\text { Puerto } \\
\text { Viejo }\end{array}$ & $\begin{array}{l}\text { Teyú } \\
\text { Cuaré }\end{array}$ \\
\hline Ecorregión & $\begin{array}{l}\text { Campos y } \\
\text { Malezales }\end{array}$ & $\begin{array}{l}\text { Campos y } \\
\text { Malezales; } \\
\text { Selva } \\
\text { Paranaense }\end{array}$ & $\begin{array}{l}\text { Selva } \\
\text { Paranaense }\end{array}$ & $\begin{array}{l}\text { Selva } \\
\text { Paranaense }\end{array}$ & $\begin{array}{l}\text { Selva } \\
\text { Paranaense }\end{array}$ & $\begin{array}{l}\text { Selva } \\
\text { Paranaense }\end{array}$ \\
\hline Subregión & Campos & Campos & $\begin{array}{l}\text { Cerranías y } \\
\text { Mesetas; } \\
\text { Pediplanos } \\
\text { del Paraná }\end{array}$ & $\begin{array}{l}\text { Pediplanos } \\
\text { del Paraná }\end{array}$ & $\begin{array}{l}\text { Pediplanos } \\
\text { del Paraná }\end{array}$ & $\begin{array}{l}\text { Pediplanos } \\
\text { del Paraná }\end{array}$ \\
\hline Complejos & $\begin{array}{l}\text { Colinas y } \\
\text { llanuras } \\
\text { onduladas; } \\
\text { Valles } \\
\text { fluviales }\end{array}$ & $\begin{array}{l}\text { Colinas y } \\
\text { Pedinuras; } \\
\text { con } \\
\text { Paleocauces }\end{array}$ & $\begin{array}{l}\text { Pediplanicie } \\
\text { con } \\
\text { Paleocauces; } \\
\text { Estribaciones } \\
\text { de la Meseta }\end{array}$ & $\begin{array}{l}\text { Lomeríos } \\
\text { del ecotono } \\
\text { al } \\
\text { pediplano } \\
\text { Paraná }\end{array}$ & $\begin{array}{l}\text { Lomeríos } \\
\text { del ecotono } \\
\text { al } \\
\text { pediplano } \\
\text { Paraná }\end{array}$ & $\begin{array}{l}\text { Pediplanicie } \\
\text { con } \\
\text { Paleocauces }\end{array}$ \\
\hline
\end{tabular}

\subsection{LA POBLACIÓN}

Las poblaciones estudiadas son expresivas de la historia regional. Si bien se destacan algunas colonias con alta proporción de descendientes polacos o ucranianos -como las relevadas en el norte de la provincia por Kujawska \& Hilgert (2014)-, la población de las ciudades, parajes y picadas, se corresponde con un entramado diverso y complejo proveniente de distintos orígenes y oleadas, agrupando ciudadanos argentinos (especialmente correntinos), descendientes de las inmigraciones de los siglos XIX y XX (españoles, italianos, polacos, ucranianos, suecos, suizos, alemanes), "paisanos" -como se designa localmente a los M'bya, parcialidades de los guaraníes- e inmigrantes paraguayos y brasileños de fines del siglo pasado (Belastegui, 2006; Bartolomé, 2007; Zamudio, 2012).

Asimismo, en determinados parajes y picadas suele apreciarse un "mestizaje" de toda esta diversidad, conformando grupos "criollos" con alta proporción de paraguayos 
(Teyú Cuaré y Puerto Viejo) y de brasileños (Cerro Mártires, La Corita) con aportes M'bya (Figura 7). Es de destacar que en estos parajes conformados por UD dispersas, cuyos miembros se encuentran relacionados por lazos de parentesco, los mismos constituyen la fuerza de trabajo y por eso pueden asimilarse a "campesinos" (Bartolomé y Schiavoni, 2008), "productores familiares" o "pequeños productores" (Granitto \& Sarandón, 2002), casos concretos de los parajes Teyú Cuaré y Cerro Mártires, y en parte Puerto Viejo. Ellos mismos se definen como "criollos", sean de descendencia paraguaya, brasileña o M'bya. Es de destacar que estas categorías de campesinos y productores se refieren a la forma de producción mientras que la última es de carácter étnico.

Figura 7. Familia Bueno-Fleitas. Paraje Cerro Mártires.

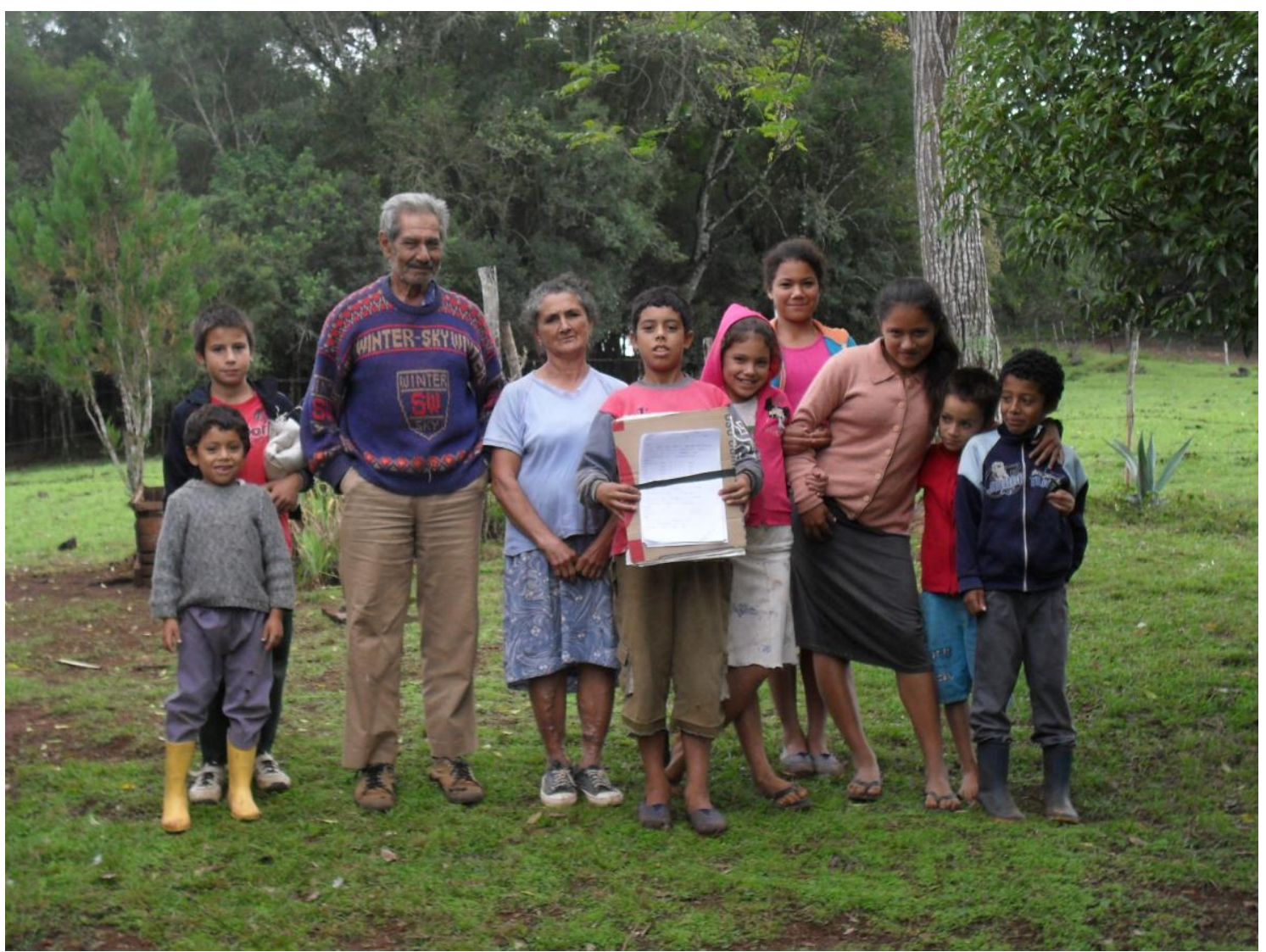

En los enclaves rurales - cercanos al monte- los M'bya y los "criollos" derivan su economía del monte a través de la caza, pesca, recolección y horticultura de "mandioca" (Manihot esculenta Crantz), "batatera” [Ipomoea batatas (L.) Lam.], "maíz” (Zea mays L.), varias especies de "porotos" (Phaseolus), “zapallos" (Cucurbita) y otros productos de tierras bajas mediante el sistema de roza y quema (Cadogan, 1969; Susnik, 1979- 
1980; Chase-Sardi, 1989, Schaden 1998). Asimismo, son cultivados el "arroz" (Oryza sativa L.), la "soja” [Glycine max (L.) Merr.], la "caña dulce” (Saccharum officinarum L.), adoptados luego del contacto hispano-indígena y la cría de ganado vacuno, ovino, porcino y de animales de corral (gallinas, patos), en coincidencia con lo citado para el norte de la provincia (Chifarelli, 2010).

$\mathrm{Si}$ atendemos a las descripciones de cronistas y etnógrafos, la horticultura y la caza son resaltadas como actividades que proveen la mayor cantidad y variedad de recursos necesarios para la subsistencia de los M’bya (Bartolomé, 1978; Schaden, 1998). En este sentido, Beate Lehner (en Chase-Sardi, 1989: 37) plantea que los “...Mbya-Guaraní constituyen una etnia cuya base económica está sustentada, en regular proporción, sobre la horticultura de roza, la caza, la recolección y la pesca, predominando la primera de estas actividades, que con la tercera es fuente de hidratos de carbono, siendo la segunda y en menor medida la cuarta, las que proporcionan proteínas a una rica y bien balanceada alimentación", definición que podría ampliarse hacia algunos grupos de "criollos" que se apropian del entorno mediante una estrategia de uso múltiple. De esta manera, en la caracterización de los modos de subsistencia de estas etnias, la recolección es subestimada o se le asigna un carácter secundario a la hora de su descripción y análisis (Bartolomé, 1978; Chase-Sardi, 1989, Schaden, 1998).

Las actividades económicas más importantes de la región son la silvicultura, la agricultura y la ganadería (Reboratti, 1983; Izquierdo et al., 2008, 2010). La primera se basa en las plantaciones de monocultivos de pino (Pinus spp.) y eucalipto (Eucalyptus spp.) para la industria del papel y la madera con sede en la zona. Esta industria es fuente de trabajo temporal de varios pobladores (changueros, jornaleros, tareferos) que en la zona trabajan en distintos momentos productivos, muchas veces bajo condiciones inhumanas que recuerdan a los "mensúes" -trabajadores temporarios en la extracción forestal iniciada hacia fines del siglo XIX- que describe Horacio Quiroga (Quiroga, 1967). Los principales cultivos son el "tabaco" (Nicotiana tabacum L.), la "yerba mate" (Ilex paraguariensis A. St.-Hil.), el "té” [Camellia sinensis (L.) Kuntze] y las plantaciones de frutales, principalmente cítricos: "mandarinas" (C. reticulata), "naranjas" $(C . \times$ aurantium $)$ y "limas ácidas" $(C . \times$ aurantiifolia $)$. La economía de la provincia se basa en la extracción de materias primas con poco desarrollo industrial (Schiavoni, 1995, 1998). La ganadería se practica a cielo abierto predominando el ganado de tipo índico, de a poco reemplazado por cruzas Cebú-Hereford, Braford, Angus y Criolla (Pantiu et al., 2010). Actualmente, se observa una leve tendencia a la 
adopción - muchas veces infructuosa en la zona en estudio- de cultivos asociados (pinoyerba mate) y sistemas silvopastoriles (pino-ganado vacuno) simplificados o poco diversificados. La totalidad de las familias estudiadas en los ámbitos rurales se caracterizan por sistemas productivos tradicionales de subsistencia o venta a pequeña escala en las ferias francas urbanas.

Los idiomas hablados son español, guaraní y portugués, y lenguas francas derivadas de la mezcla, tales como "guaraniol” (en la cuenca del Paraná principalmente) y “portuñol” (sobre todo en la cuenca del Uruguay).

\subsection{HISTORIA LOCAL EN RELACIÓN A LA POBLACIÓN DEL ÁREA DE ESTUDIO}

Poblamiento prehispánico y contacto hispano-indígena, las primeras ciudades españolas en las cuencas de los ríos Paraná y Paraguay

La presencia humana en el área de estudio data de 6000 años A.P., a través de evidencias arqueológicas correspondientes a la cultura "Uruguay II" cuando las condiciones climáticas comienzan a ser muy semejantes a las actuales (Rodríguez \& Ceruti, 1999). La presencia de los grupos Tupí-Guaraní en Misiones ha sido datada en 1200 años, correspondiendo a pueblos horticultores amazónicos que descendieron por los afluentes del río Amazonas (Poujade, 1995) extendiéndose hasta la desembocadura del río de La Plata en el momento del contacto hispano-indígena.

Los primeros contactos entre los conquistadores españoles y los pueblos originarios se remontan a los sobrevivientes del frustrado viaje de Solís, hacia 1516. Alejo García, quien luego de la muerte del capitán habría naufragado en las cercanías de la actual Santa Catarina (Brasil), emprendió un viaje sin precedentes junto a guerreros guaraníes hacia el oeste hasta llegar a la pre-cordillera a la altura de Cochabamba (Bolivia) siendo asesinado al regreso en algún lugar del actual Paraguay. Esta historia, comentada en las crónicas tempranas de Schmidl (1944) y de Díaz de Guzmán (2000), precedió al establecimiento de los Chiriguanos (guaraníes establecidos en la precordillera) que ingresan por las yungas al noroeste argentino. De mayor importancia es la fundación del Fuerte Sancti Spiritus (1526) en la confluencia del río Carcarañá con el Paraná, por Sebastián Caboto que significó el primer núcleo de dispersión de plantas exóticas que 
posteriormente cubrieron la llanura platense: Crucíferas, Compuestas, Umbelíferas y Gramíneas (Báez, 1944: 284).

Pero es con el viaje de Pedro de Mendoza (1536) cuando se fundan los primeros núcleos permanentes de la conquista pertenecientes a la corriente Asunceña-Rioplatense. Luego de fundar Buenos Aires (1936), remontando el Paraná -en busca de tesoros derivados de las historias fantásticas del "Cerro de Plata" o del "Rey Blanco", de "El dorado" y de "las Amazonas" (Cabeza de Vaca, 1947)-, Juan Salazar de Espinosa funda el fuerte de "Nuestra Señora de la Asunción" (1537, y refundada como ciudad en 1541 por Irala). A partir de dicha fecha comienza la navegación exploratoria de los ríos Paraguay, Paraná, Pilcomayo y Bermejo, y la fundación de puertos, fuertes y ciudades en todo el territorio comprendido por el actual este de Paraguay, nordeste de Argentina y sur de Brasil, siempre con dirección hacia el norte y oeste.

Las relaciones entre los conquistadores y las parcialidades Guaraníes se mantuvieron "recíprocas" durante la primera década y media, tratándose mutuamente como "tobaya" (cuñados) (Gálvez, 1995). Pero es entrada la segunda mitad del siglo XVI cuando los conquistadores dan cuenta de que el Cerro de Potosí (Bolivia) había sido apropiado por los españoles de la corriente colonizadora Andina, comandada por Francisco Pizarro y Diego de Almagro. En ese momento, los pueblos de guaraníes cercanos a Asunción comienzan a repartirse en encomiendas resultando en un cambio significativo en el uso de la tierra, cultivo de la misma, en el ingreso de germoplasma exótico y de prácticas y conocimientos relacionados a los mismos. Durante la segunda mitad del siglo varias ciudades se fundan con duraciones variables: Villa de Ontiveros (1554, al $\mathrm{N}$ de las cataratas del Iguazú), Ciudad Real (1557, a pocos kilómetros al norte de la anterior), Santa Cruz de la Sierra (1561, actual ciudad boliviana), Villa Rica del Espíritu Santo (1570, al norte de Ciudad Real), Santa Fe de la Vera Cruz (1573, actual ciudad argentina), Buenos Aires (1580, segunda fundación), Santiago de Jerez (1583, cerca de la "Laguna de los Jarayes" o "gran pantanal”), Concepción del Bermejo (1585, cerca del actual Fortín Lavalle, norte de la provincia de Chaco), San Juan de la Vera de las Siete Corrientes (1588, actual ciudad conocida como Corrientes), entre otras (Díaz de Guzmán, 2000; Lobos, 1999) (Figura 8). Cada una de ellas significó a la vez un núcleo de dispersión de plantas introducidas, de prácticas de manejo sobre las mismas y sobre el ambiente y de los conocimientos y creencias asociados a las mismas. Todas estas 
ciudades conformaron la Gobernación del Río de La Plata hasta principios de siglo XVII, con cabecera en Asunción.

Figura 8. Exploraciones y fundaciones durante el siglo XVI. Tomado de Lobos (1999).

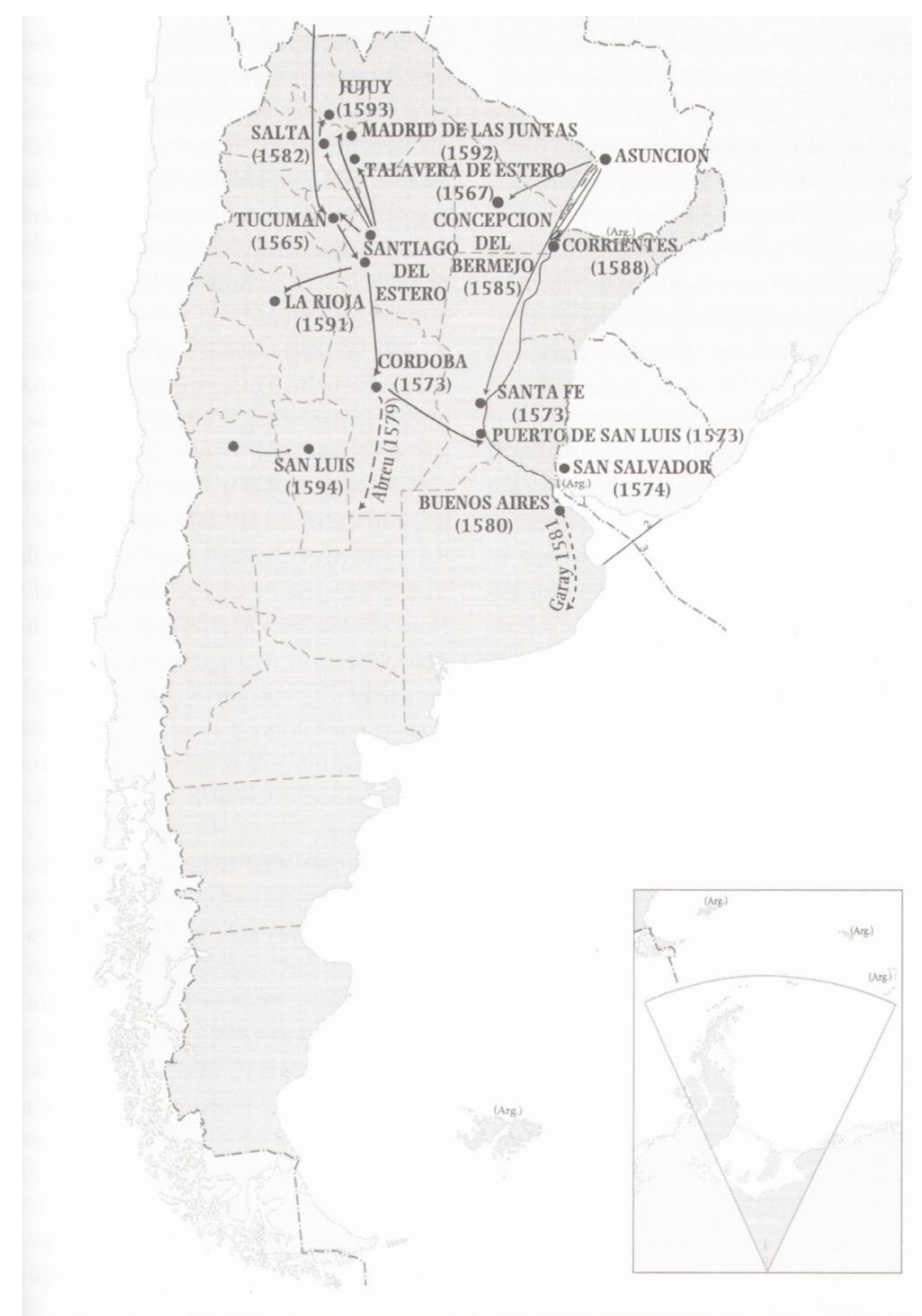


A principios del siglo XVII, la colonización se extiende hacia el sur de la actual provincia de Misiones. Es también cuando se separan las gobernaciones de Paraguay (territorio comprendido entre los ríos Paraguay y Paraná, desde Corrientes hasta los límites con Brasil al norte) y la del Río de La Plata (Buenos Aires, Santa Fe, Corrientes, Concepción del Bermejo, Misiones) por petición de Hernández Arias de Saavedra (más conocido como Hernandarias) en 1617. La Compañía de Jesús, establecida en América desde mediados del siglo XVI, funda la Provincia Jesuítica del Paraguay por orden de Hernandarias. Hacia 1609, se establecen 3 expediciones fundacionales: 1. hacia el sudeste, cruzando el río Tebicuary más allá de los pueblos Franciscanos establecidos a finales del siglo XVI, zona conocida como "Paraná", extendiéndose con los años al "Uruguay” y luego al "Tape” (actual Rio Grande do Sul, Brasil); 2. Hacia el "Guairá”, actual noroeste del estado brasileño de Sao Paulo; y 3. Hacia el oeste, cruzando el río Paraguay frente a Asunción, esta última fracasada por la belicosidad de los Guaycurues (Figura 9) (Furlong, 1962; Gálvez, 1995). La primera de estas corrientes ingresa a Misiones, hacia mediados de la segunda década y sigue hacia el "Tape" en dirección a las costas atlánticas.

Las reducciones significaron un cambio rotundo en el modo de vida de los pueblos guaraníes. La sedentarización significó un cese en la búsqueda de la "tierra sin mal" y trajo aparejado el incremento poblacional al agrupar distintos cacicazgos, y la necesidad de talar grandes áreas para los cultivos individuales (Abambae) y colectivos (Tupambae), además de la cría de ganado vacuno, principal abastecimiento de proteínas de las misiones (Hernández, 1913). Además, este cambio trajo consigo nuevas rutinas, deidades y cultivos.

Posteriormente, hacia la tercera década, el ataque de los bandeirantes paulistas buscadores de esclavos para la industria minera y azucarera-replegó obligadamente las misiones establecidas en el "Tape", "Itatines" y "Guairá" hacia la porción sur de la actual provincia de Misiones. De esta manera, a las reducciones de Concepción, San Javier y Corpus - establecidas en el sur de la actual provincia argentina de Misiones, durante la segunda década-, se sumaron las de San Ignacio Miní y Nuestra Señora de Loreto (actualmente Patrimonio UNESCO) antes establecidas en el "Guairá"; Apóstoles, San José, Santa Ana, La Candelaria y Mártires, provenientes del "Uruguay" 
y "Tape", y Santa María la Mayor, proveniente de las inmediaciones de las Cataratas del Iguazú (Furlong, 1962; Carbonell, 1992; Gálvez, 1995). Esta reorganización y concentración de las reducciones en el sur de la actual provincia de Misiones significó la convergencia de distintas etnias como también el uso intensivo del paisaje, especialmente de actividades de cría de ganado (Carbonell, 1992).

Figura 9. Expediciones fundadoras de la Compañía de Jesús salidas desde Nuestra Señora de la Asunción en las primeras décadas del siglo XVII. Tomado de Gálvez (1995).

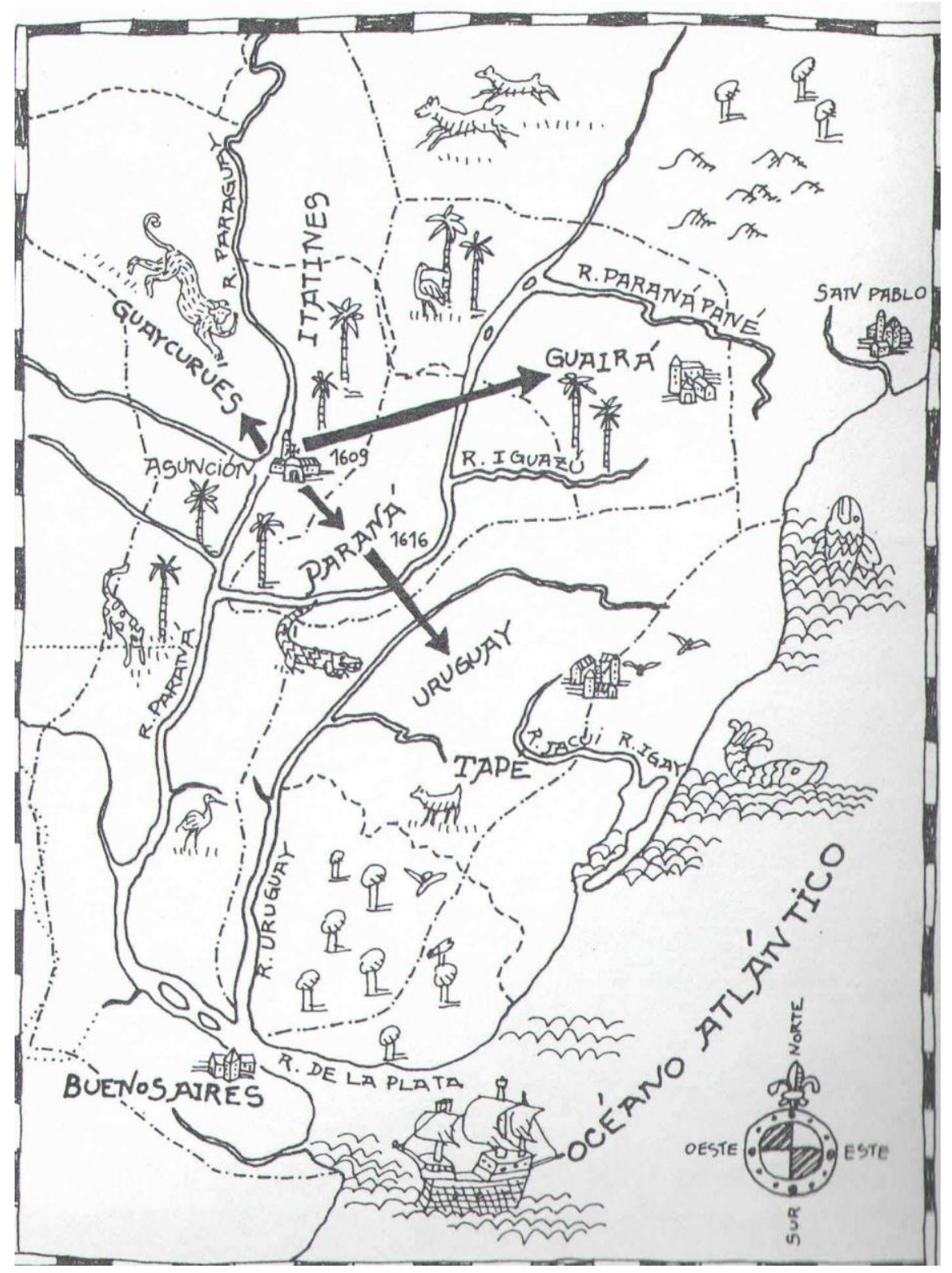

Hacia finales del siglo XVII y primeras décadas del XVIII las misiones van logrando una configuración estable. Se vuelven a explorar el "Guairá", el "Tape" e "Itatines" y se 
fundan nuevas misiones de etnias chaqueñas hacia mediados de este último siglo, proceso bien documentado por Sánchez Labrador (1910), Paucke (1942-1944) y Dobrizhoffer (1967). Las construcciones que actualmente conforman las ruinas jesuíticas de guaraníes pertenecen a dicha época.

Expulsión de los Jesuitas, Guerras de Independencia, invasiones paraguayas y portuguesas y anexión a la provincia de Corrientes

Al tiempo de la expulsión de los Jesuitas de América (1767) las misiones permanecieron mal administradas por el Gobernador Bruno de Zavala, quedando varias de ellas abandonadas. Hacia 1782, las misiones de ambas costas del río Paraná pertenecían a Paraguay y las demás (del Uruguay y las Misiones Orientales) al Gobierno de Buenos Aires; y hacia 1801, los portugueses ocupan las misiones orientales (aquellas establecidas al este del río Uruguay) (Machón, 2004) y pocos años después por orden de cédula Real, Bernardo Velasco separó las Misiones de las Gobernaciones de Paraguay y del Río de La Plata, redactando Manuel Belgrano hacia 1810 el "Reglamento para la administración de la provincia de Misiones". Fue también en esta época cuando la población de las misiones sufrió terribles bajas durante las guerras de independencia destacando que "los hijos de Misiones fueron de los primeros en responder al grito de ;libertad! de Buenos Aires" (Fernández Ramos, 1929: 146). Pero sólo un año después los pueblos misioneros se separaron nuevamente quedando las doctrinas repartidas entre Paraguay y Buenos Aires. Pocos años después se fundaron las provincias argentinas de Corrientes y Entre Ríos, anexándose Misiones a la primera de éstas en 1814, aunque esto fue ignorado hasta 1830, fecha en la cual Corrientes intentó la refundación de las misiones de la orilla occidental del Uruguay, por entonces ocupada por paraguayos, principalmente con fines de explotación tanto de los yerbales asociados a las ruinas como de los silvestres (Schaller, 1994). Hacia 1817 ocurrió la primera invasión portuguesa destruyendo casi la totalidad de los pueblos misioneros del norte de Corrientes y de la orilla occidental del Uruguay, escapando los guaraníes a los bosques y los españoles a Brasil (Machón, 1994). Simultáneamente, el dictador José de Francia (Paraguay) destruyó los pueblos de la orilla oriental del Paraná, y luego fueron destruidas por los portugueses las misiones de San Carlos, San José y Apóstoles, desde donde comandaba la resistencia Andresito Guazurary (Fernández Ramos, 1929). Hacia 
1841, durante el gobierno de Rosas, se firmó el tratado de comercio y límites entre Argentina y Paraguay, por lo cual la zona de Misiones constituía un área clave en la nueva ruta comercial de Paraguay (Itapúa) hasta San Borja (Brasil), y posteriormente Juan M. de Rosas cerró el tránsito fluvial del río Paraná (Barreyro, 1979; Belastegui, 2006) lo que inició la Guerra de la Triple Alianza. En este período las misiones nuevamente fueron saqueadas y destruidas (Concepción y Santa María la Mayor), hasta la Guerra de la Triple Alianza contra Paraguay (1865) cuando se recuperaron las misiones ubicadas en el margen oriental del Paraná. Es de destacar que durante tal guerra el ejército brasileño encontró los yerbales vírgenes de San Pedro. A partir de esa fecha comenzaron a llegar los pobladores, comerciantes y estancieros uruguayos, brasileños, argentinos (correntinos), franceses, españoles e italianos (Barreyro, 1979; Belastegui, 2006) y para esa fecha se dispone de los primeros datos poblacionales de Misiones, estimándose su población en 3000 nativos de diversas parcialidades (Meichtry, 1994). Durante esta época la navegación del río Uruguay fue intensa, llegando hasta Concepción de la Sierra, comenzando a declinar hacia principios del siglo XX con el establecimiento del FF.CC. argentino (Abadie, 1998). La explotación de los "yerbales silvestres" -es decir espontáneos- fue también intensa en esta época, especialmente siguiendo el curso del Paraná y luego la picada de San Pedro, llevando al exterminio de los Cainguá. Hacia fines de la década de 1870 se destinaron para la formación de pueblos agrícolas las misiones de Santa Ana, San Javier, Concepción, San Carlos, Corpus, Apóstoles, Mártires, San Ignacio y San José, fundándose los departamentos de Candelaria y San Javier hacia principios y finales de 1870, respectivamente; éste último como desprendimiento de Santo Tomé (antigua misión jesuítica, actual ciudad correntina). Los pueblos jesuíticos se repoblaron "atraídos por las ventajas del sitio, la facilidad de obtener materiales para sus viviendas extrayéndolos de las construcciones antiguas y la posibilidad de explotar los yerbales y naranjales cercanos" (Schaller, 1994: 436). Pero hacia mediados de 1881 Corrientes vendió casi la totalidad del territorio misionero (poco más de 2 millones de hectáreas, con excepción del municipio de Posadas y de los pueblos agrícolas) a 27 personas (funcionarios de la provincia y oficiales del Ejército Nacional) (Belastegui, 2006) cuyas identidades pueden consultarse en Schaller (1994: 446). 
Federalización y colonización oficial y privada

Recién hacia fines de 1881 se federalizó Misiones creando el Territorio Nacional de las Misiones, con Rudecindo Roca como Gobernador, y a mediados de 1884 la actual Posadas (llamada por entonces Trincheras de San José), perteneciente a Corrientes hasta ese entonces, se anexó al territorio. Dado que sólo estaba poblada la porción sur del territorio, en este período comenzaron las grandes inmigraciones en el marco de la colonización oficial. Así, se sucedieron un gran número de colonias agrícolas pobladas por inmigrantes polacos y ucranianos, principalmente, muchas veces naciendo como parajes en las picadas hacia los yerbales silvestres y tierras potencialmente cultivables (Belastegui, 2006; Gallero \& Krautstofl, 2010). 
5. RESULTADOS 


\subsection{LOS CÍTRICOS INTRODUCIDOS EN EL SUBTRÓPICO ARGENTINO: HISTORIA E IMPORT ANCIA LOCAL}

\subsubsection{INTRODUCCIÓN}

Los grupos nativos que desde tiempos prehispánicos habitan los distintos enclaves ecológicos del país construyeron cosmovisiones particulares. Éstas acompañaron prácticas de manejo y uso de los recursos vegetales que definían el paisaje local, diseñando un espacio físico dinámico donde se manifestaban significados y valoraciones propias de cada pueblo (Capparelli et al., 2011; Ochoa \& Ladio, 2011). En el escenario de las misiones jesuíticas del $\mathrm{NE}$ argentino esto está representado por la diversidad de ambientes productivos relacionados a esta interacción jesuítica-guaraní, siendo los más importantes el Tupambae (con toda la diversidad que significa: "yerbales", "naranjales", "algodonales", estancias de ganado vacuno, ovino y equino), el Abambae y el huerto de los padres [jesuitas] (Capparelli et al., 2011).

A partir del proceso de asentamiento y población europea en América, como fueron las reducciones Jesuíticas y las diversas fundaciones colonizadoras en el territorio argentino, estos paisajes cambiaron, al igual que los modos de vida característicos de dichos grupos humanos. Es así que se produjo la desestructuración de los espacios nativos y la instauración forzada de un nuevo régimen de explotación y producción -muchas veces sangriento- el cual implicó la introducción de objetos y productos del Viejo Mundo, como el ganado y algunos cultivos, que modificaron la conformación y representación del paisaje (Capparelli \& Raffino, 1997; Pochettino et al., 2002; Giovannetti \& Lema, 2005; Lema, 2009; Capparelli et al., 2011).

El establecimiento de colonias españolas en América, supuso el inicio de un intercambio de especies vegetales que afectaría múltiples aspectos de la realidad cotidiana de ambos continentes. Pocas veces los estudios atendieron los cambios que se produjeron a partir de 1492, si consideramos las particularidades de cada grupo cultural, en el terreno de la agricultura, la alimentación e incluso en los hábitos o costumbres locales, como la medicina, los rituales y celebraciones religiosas. Son numerosos los ejemplos que hacen referencia a la expansión de los vegetales desde épocas muy anteriores a la llegada de las 
oleadas españolas hacia América que ponen de manifiesto situaciones semejantes para otras zonas del mundo, en particular desde Oriente o el sur (África) hacia el Mediterráneo clásico. Entre ellos se puede mencionar, la caña de azúcar; el avance del Imperio Islámico provocó su instauración en poco tiempo en el sur de Europa. Asimismo el contacto europeo con África, a mediados del siglo XV en parte es promovido por el deseo de adquirir especies condimenticias. La ruta de la seda establecida en el siglo I y II, constituyó una vía comercial de importancia para el intercambio de especias cultivadas. Muchas de ellas llegaron América como parte constitutiva de la cultura e idiosincrasia del pueblo Ibérico. Entre este elenco de especies se puede mencionar: trigo (varias especies de Triticum), cebada (Hordeum vulgare L.) y centeno [Secale cereale (L.) M. Bieb.], habas (Vicia faba L.) y otras leguminosas; mientras que para los frutales se destacan los de pepita (Cydonia, Malus y Pyrus), de hueso (Prunus), y cítricos (Webber, 1943a; Kiple \& Ornelas, 2000; Ramón-Laca, 2003; Arias \& Ramón-Laca, 2005; Prance \& Nesbitt, 2005). También se incorporaron al seno de las comunidades especies aromáticas y flores (Sepp, 1971; García Paris, 1991).

Embarcaciones de todo tipo constantemente intercambiaban germoplasma vegetal entre ambos hemisferios $\mathrm{y}$, además de semillas, frutos y plantas adultas, era común el transporte de "ramas, retoños, varetas y mugrones (ingertos) de algunos árboles (...)" en toneles para vino (Anglería, 1516 en Puente y Olea, 1900: 386, 393) e incluso verdaderos “jardines de plantas útiles” en algunos sectores de las embarcaciones (Sepp, 1971). El destino principal de estos viajes fueron Las Antillas y posteriormente el continente (México, Perú), para luego, según citan las crónicas, seguir diferentes ruta de ingreso e instauración. A esta ruta Caribeña-Andina pueden añadirse la Asunceña-Rioplatense y la Brasileña, cada una con sus particularidades de relaciones interétnicas, origen del germoplasma introducido y conocimientos asociados a cada una de las plantas y al manejo de las mismas (Figura 10).

\section{Los frutales y la medicina local}

Muchas fueron las plantas cultivadas con propiedades medicinales que llegaron a América, propagándose con ellas los conocimientos asociados a las mismas por las poblaciones españolas y criollas. Su incorporación -y apropiación- involucró un proceso 
de asignación de propiedades, una progresiva percepción y búsqueda en las alternativas de obtención, producción y aplicación del uso medicinal de las mismas.

Figura 10. Conquista y colonización ibérica del continente americano: las rutas a Tierra Firme del siglo XVI. Extraído de Stampella et al. (2013c).

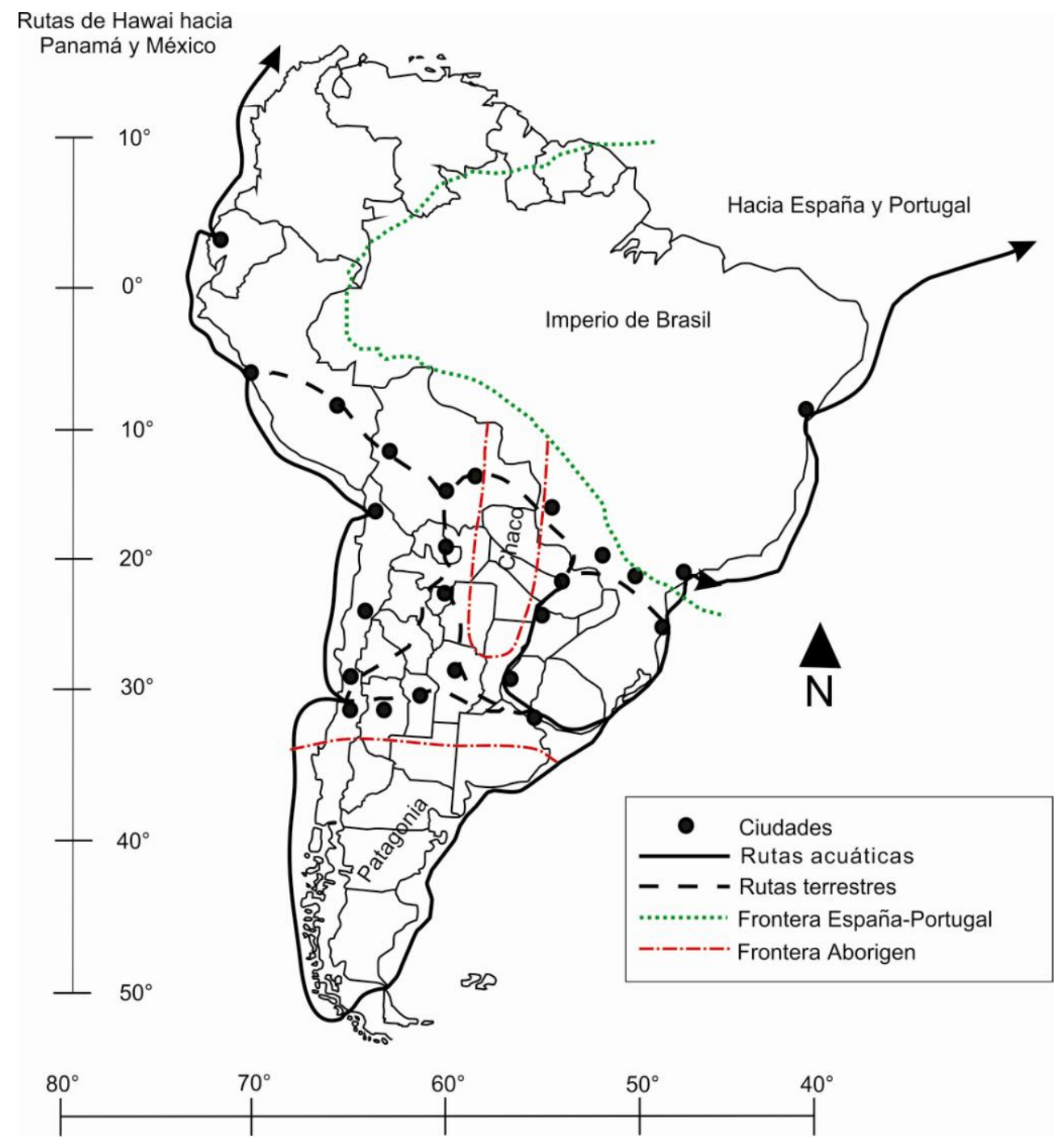

De los primeros tiempos existen referencias sobre estas especies medicinales en la obra de Puente y Olea (1900) -que reúne información geográfica, botánica, agronómica y zoológica de los Archivos de la Casa de la Contratación, organismo español encargado de fiscalizar los ingresos y salidas de América-, en las descripciones de los huertos de los padres de dos misiones jesuíticas que realizan Sepp (1971) y Paucke (1942-4), aunque también algunas menciones aisladas en la obra de Montenegro (1945). Además, varios libros de plantas medicinales y sobre medicina fueron encontrados en poder de los jesuitas al momento de su expulsión [Galeno de Pérgamo (siglo II), Rivero, Johann 
Dolaeus (siglo XVII), Suárez de Rivera, y Fuente Piérola (siglo XVIII)], y se supone la presencia de las obras de Andrea Mattioli, Andrés de Laguna, Dioscórides y los Tratados (Materia Médica) de los Padres Pedro de Montenegro y Segismundo Asperger (Vera de Flachs \& Page, 2010). Por otra parte, es de destacar el valor medicinal que diversas poblaciones asignan a los alimentos, y en este sentido las especies aquí tratadas (todas ellas de origen asiático o del este de Europa) fueron incorporadas al repertorio de las plantas útiles mediterráneas también por su importancia como biodinámicas: los cítricos como repelentes de insectos, antídotos contra envenenamientos, y como medicinales contra diversas afecciones y síntomas (náuseas, mareos, infecciones) (Morton, 1987). Estas aplicaciones terapéuticas, si bien no permanecieron inalteradas a lo largo del tiempo reflejan una menor incidencia de aspectos comerciales que los usos alimenticios, y manifiestan también la apropiación de estos vegetales a través de la generación de usos novedosos.

Por lo expuesto, este capítulo pretende brindar información referida a la diversidad histórica de cítricos a partir del contacto hispano-indígena, de sus usos medicinales, cuya historia de introducción, apropiación y reconocimiento local permite relacionarlas y definirlas como elementos representativos del paisaje que integran. Desde una aproximación etnobotánica histórica se presenta una descripción, análisis y comparación de las rutas de ingreso, de las variedades ingresadas y los usos de los cítricos en el pasado. Un estudio de este tipo permitirá realizar una proyección temporal con los datos históricos e información etnobotánica acerca del uso medicinal asignado y la significancia de su apropiación.

\subsubsection{MATERIALES Y METODOS}

Mediante la revisión de un total de 46 fuentes bibliográficas y de documentación histórica de distintas disciplinas, abarcando el período de 1500 hasta la actualidad, se amplió la búsqueda acerca de los usos medicinales y se obtuvo información referida al ingreso de estos cultivos en América. Debido a la escasez de fuentes Guaraníes exceptuando las presentadas por Melià (2005), que no contienen información referida a estos frutales- la interacción pasada se remite a la documentación derivada de los colonizadores y evangelizadores, aparte de la evidencia arqueológica, también escasa en la zona. Cada tipo de fuente posee sus limitaciones y sesgos de acuerdo al contexto 
histórico-cultural, por lo cual no pueden interpretarse de la misma manera los documentos jesuíticos del siglo XVII-XVIII, cuyas explicaciones remiten a la obra de un "creador supremo" o el sesgo debido al paternalismo hacia los guaraníes; que los viajeros naturalistas de la generación del '80, influenciados por teorías evolutivas culturales: "testigos del grado de civilización a que los jesuitas hicieron llegar a aquellos indios..." (Burmeister, 1899: 4).

Sin embargo, las descripciones de algunos jesuitas, en especial de los padres Anton Sepp, José Sánchez Labrador, Florian Paucke y Martín Dobrizhoffer, constituyen relatos riquísimos en la diversidad histórica de frutales, prácticas hacia los mismos y sobre el entorno, como también rutas de introducción y lugar de procedencia. La información de estos relatos puede ampliarse con los catálogos de plantas medicinales y de citricultura de acuerdo al lugar y época. Por ejemplo, para los relatos de los jesuitas (principalmente siglo XVIII, pertenecientes a diversos orígenes) son muy útiles las obras de Ferrari (1646, Italiano) -que además pertenecía a la misma orden religiosa-, Volkamer (1708-1714, Alemán) y Commelyn (1683, Países Bajos). Además de descripciones estas obras abundan en imágenes con detalles minuciosos de las variedades de cítricos, procedencias, nombres, formas de cultivo, propiedades medicinales, entre otros (Figura 11).

Las fuentes consultadas fueron: Acosta, 1590; Ferrari, 1646; Commelyn, 1683; Volkamer, 1708-1714; Azara, 1847; Casas, 1875; Hieronymus, 1882; Lista, 1883; Holmberg, 1887; Burmeister, 1899; Bertoni, 1927; Cobo, 1890-1892 [1580-1657]; Gambón, 1904; Lizárraga, 2002 [1607?]; López de Gómara, 1922 [1552]; Schmidl, 1944; Cabeza de Vaca, 1947 [1490-1558]; Vázquez de Espinosa, 1948 [1630]; Díaz de Guzmán, 2000 [1602] y Ambrosetti, 2008a, b [1892, 1896, 1898]. Para el período colonial se consultaron, además, obras de los Jesuitas publicadas entre los siglos XVII y XVIII (Ruíz de Montoya, 1892 [1639]; Sánchez Labrador, 1910 [1770]; Paucke, 1944 [1749-1767]; Dobrizhoffer, 1967 [1784]; Sepp, 1971 [1696]; Cardiel, 1994 [1771]; Montenegro, 1945). Para contextualizar el período estudiado se consultaron publicaciones y tesis de historia, etnohistoria y botánica histórica: Brabo, 1872; Puente y Olea, 1900; Storni, 1944; Báez, 1949; Gade, 1976; Susnik, 1979-1980; Mörner, 1985; Kumamoto et al., 1987; Cadogan, 1992; Carbonell, 1992; Ramón-Laca, 2003 y Giovanetti, 2005. De la misma manera, para caracterizar las variedades introducidas durante la segunda mitad del siglo XX (variedades comerciales y portainjertos) se 
consultaron los trabajos de Webber (1943a), Palacios (1978), Banfi (1954), Banfi \& Beñatena (1954) y Citrus Pages (2014). El trabajo de Puente y Olea (1900) permitió contextualizar el proceso de ingreso de estos frutales, ya que presenta una descripción de lo que ocurría en el continente Americano en el momento del ingreso de la población colonial.

Figura 11. Portadas de algunas obras de Agricultura y Tratados de cítricos de los siglos XVI a XIX. A. Commelyn (1683); B. Herrera (1513); C. Ferrari (1646); D. Volkamer (1708-1714); E. Gallesio (1811); F. Risso \& Poiteau (1818-1822).
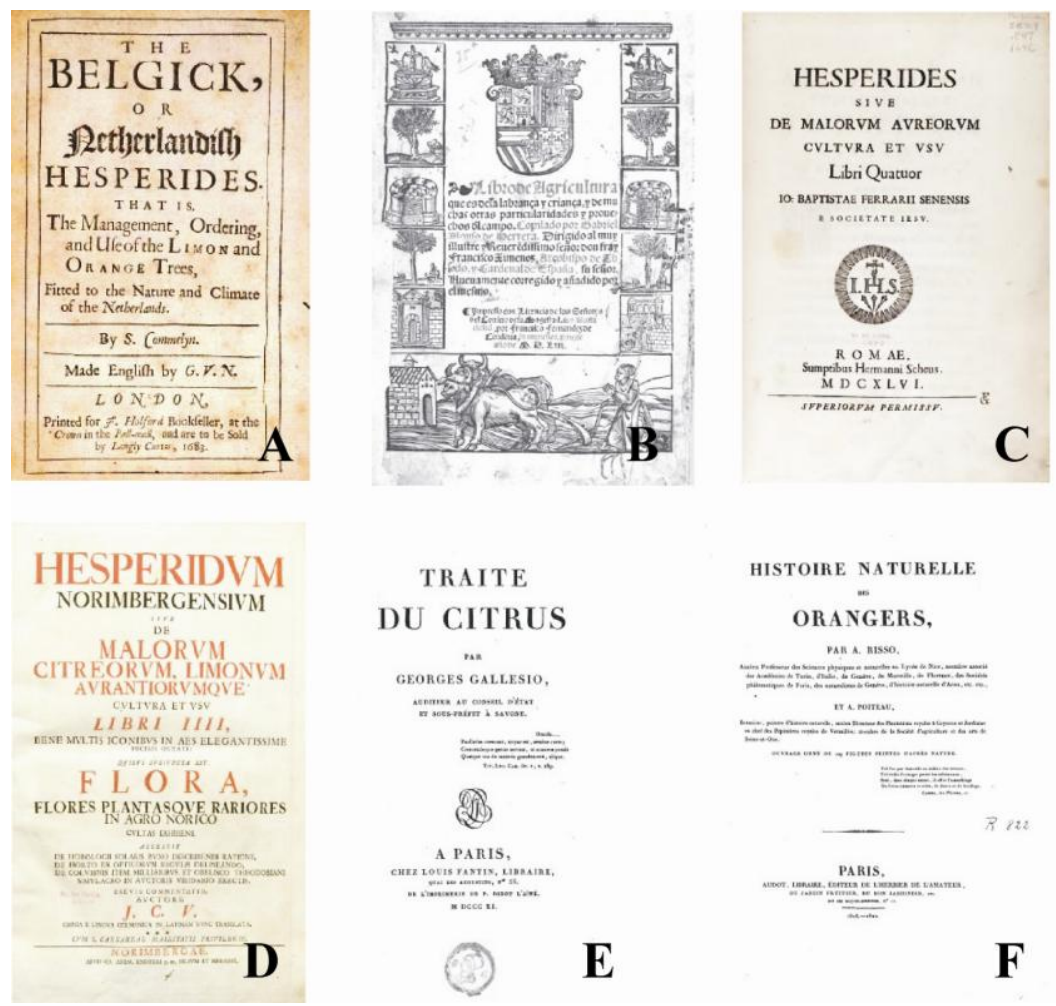

\subsubsection{RESULTADOS}

\subsubsection{Historia de ingreso y de uso de Citrus en el NEA durante el período colonial}

INGRESO A EUROPA Y A AMÉRICA

Los cítricos son originarios del Este, Sur y Sudeste Asiático, Australia y Sudoeste de las Islas del Pacífico (Zhang \& Mabberley, 2008). Exceptuando el “cidro" (Citrus medica L.) 
que ya era conocido por Griegos y Romanos, y la "naranja dulce", "mandarina" y "pomelo" (de introducción posterior) la mayoría de los cítricos ingresan a Europa siguiendo las rutas conquistadoras de los Musulmanes durante los siglos X y XI (RamónLaca, 2003), siendo cultivados principalmente en el sur de la península ibérica (bajo influencia musulmana) y en las costas del Mar Mediterráneo. Son llevados a América durante el segundo viaje de Cristóbal Colón en 1493, la mayoría de ellos ("naranja", "limón", "lima" y "toronja") luego de pocos siglos de ser conocidos en Europa. Los historiadores naturales de la época citan: pepitas y simientes de naranjas, limones y cidras, [además de] melones y de toda hortaliza (Casas, 1875, II, LXXXIII: 3) llevados a Centroamérica desde la Isla de la Gomera (perteneciente al grupo de las Canarias). Estas referencias corresponderían respectivamente a $C . \times$ aurantium $\mathrm{L} ., C . \times$ limon, $C$. medica L. y Cucumis melo L. A estas "especies", Puente y Olea (1900) agrega "toronjas" y "limas" que corresponderían a C. maxima y al grupo de $C$. $\times$ aurantiifolia y $C$. $\times$ limon (C. $\times$ limettioides Tanaka). También destaca que las primeras rutas de ingreso de plantas cultivadas fueron Andalucía y Castilla (en España), Guinea (África) y del Asia como “ciertos naranjos de fruta grande, llevados desde Filipinas" (1900: 375).

\section{LOS CÍTRICOS ESPONTÁNEOS EN AMÉRICA}

Es muy probable que la "naturalización" o "asilvestramiento" de varias especies de frutales haya sido inmediata, o por lo menos en lo que respecta a variedades menos domesticadas, denominadas "comunes", "silvestres", "ordinarios" o "vulgares" en los tratados de cítricos de Ferrari (1646), Commelyn (1683) y Volkamer (1708-1714) (Figura 12A, B). En las obras de los cronistas tempranos -siglos XVI y XVII- ya aparecen referencias acerca del escape de cultivo de estos frutales. El Padre José de Acosta (que llega a Perú en 1572), extrañado ante el comportamiento de los cítricos en el Nuevo Mundo, se asombra ante la abundancia en campos y bosques:

"De árboles, los que mas generalmente se han dado allá, y con mas abundancia, son naranjos, limas, cidras y fruta de este linage. Hay ya en algunas partes montañas y bosques de naranjales, lo qual haciendome maravilla, pregunté en una Isla, ¿quien había llenado los campos de tanto naranjo? Respondieronme, que acaso se había hecho porque cayéndose algunas naranjas, y pudriéndose la fruta, habian brotado de su simiente, y 
de la que de estos y de otros llevaban las aguas á diversas partes, se venían á hacer aquellos bosques espesos: parecióme buena razón" (Acosta, 1590, I, XXXI: 261).

Durante el siglo siguiente, el jesuita Bernabé Cobo, señala la afinidad de estos frutales con América incluso en "lugares desiertos e incultos", refiriéndose seguramente a distintos ambientes boscosos. Es uno de los primeros cronistas que destaca el origen doméstico de los frutales silvestres:

“(...) parece haber estado todas estas plantas (los cítricos) en las demás regiones del mundo como desterradas y fuera de su naturaleza, hasta que llegaron á esta tierra; la cual les es tan natural, que ninguna otra planta, así de las propias y naturales de acá como de las extranjeras y peregrinas, abraza mejor y conserva más tenazmente. Lo cual, cuánta verdad tenga testifican las grandes montañas y bosques que se han hecho en estas Indias de Naranjos, Limones y de los demás árboles deste género, naciendo en lugares desiertos é incultos, como si fueran plantas silvestres las que de suyo son tan domésticas y hortenses, que se plantan y cultivan en todo el mundo con gran diligencia y regalo." (Cobo, 1890, VIII, XXI: 396).

Azara (1847), en su paso por las Misiones recientemente abandonadas luego de la expulsión de los Jesuitas nota los "bosques de naranjos casi puros cercanos a los pueblos o dónde los ha habido", juzgando que se "agriaron por falta de cultivo". Puente y Olea (1900: 388) dispara una frase que puede servirnos de base en este trabajo: "la reproducción en las condiciones naturales de que habla el P Acosta conduce, en efecto, y rápidamente, á variedades silvestres". Este autor lo contrasta con lo que pasa en Andalucía, donde ocurre lo mismo pero "aunque no se utilice porque además de la lentitud, el naranjo resulta generalmente basto, agrio, ó agridulce, y en general exige el injerto".

Al parecer el ingreso (así como el egreso) de germoplasma vegetal fue continuo y cuantioso, diversificándose a medida que los diversos enclaves mundiales fueron poniéndose en contacto. 
Figura 12. Láminas de algunas de las variedades históricas de la obra del jesuita Ferrari (1646). A. Limón vulgaris. B. Naranja agria de médula dulce vulgar. C. Lima dulce y lima agria. D. Naranja dulce de la China. E. Naranja de ombligo. F. pampelmusa.
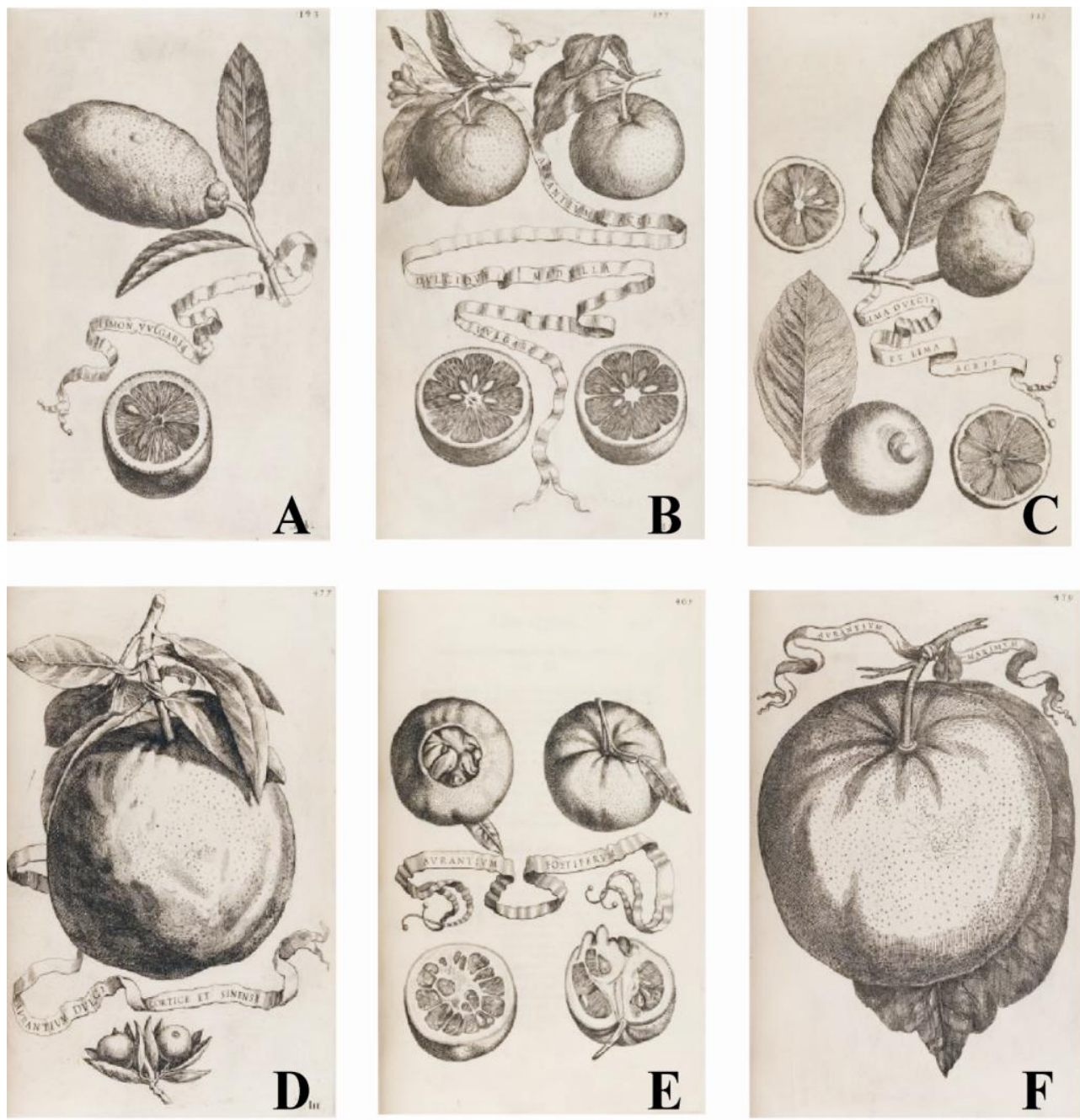

\section{Misiones Jesuíticas de GuaraníEs}

Durante el siglo XVIII las misiones jesuíticas adquieren la conformación final de sus reducciones (Figura 13). Los ambientes productivos definidos en base a la presencia de frutales fueron: el arbolado urbano y los jardines, el cementerio, el huerto de los padres jesuitas, el Abambae - predios asignados a cada familia para la producción de autoconsumo- y la gran diversidad de Tupambae comunales, que incluían "huertos frutales" (naranjales, duraznales), "yerbales", “algodonales” y cultivos de caña de azúcar y tabaco (Paucke, 1944; Capparelli et al., 2011). De esta manera, las variedades más domesticadas se hallaban en los jardines de los jesuitas y en los Colegios de la orden religiosa (Capparelli et al., 2011). 
El arbolado urbano estaba conformado por varias especies frutales, entre ellas cítricos ("naranjos" y "limoneros"), "duraznos" e "higueras" (Ficus carica L.) y en el cementerio de las misiones abundaban especies vegetales con aromas dulces, como los “naranjos" (azahares) y “narcisos” (Narcissus spp.) (Cardiel, 1994; Gálvez, 1995). Pero entre los ambientes domésticos es el huerto de los jesuitas el que alcanza mayor complejidad y diversidad. Las fuentes históricas documentan la presencia de especies herbáceas, arbustivas y arbóreas, nativas y exóticas; cultivadas con fines ornamentales, medicinales y alimenticios, entre otros. Este espacio también era destinado a la aclimatación de las especies introducidas y, quizás, a la experimentación ya que se trataba de un espacio vedado a la mayoría de los guaraníes. Desde estos huertos se dispersaron las primeras plantas introducidas y los portainjertos destinados a portar las yemas de las variedades seleccionadas (Figura 14).

Los cítricos eran empleados en preparaciones medicinales contra fiebres pútridas, parásitos intestinales, males del estómago, para levantar el apetito ("apetito postrado") y como remedio para las mordeduras de víboras y animales venenosos ("animales que arrojan de sí ponzoña"); los jugos de las variedades ácidas poseían propiedades agudas frías en medicina templaria; además eran usados como excipientes y endulzantes [jarabe y corteza de "cidra" $(C$. medica $)$ o de "limón" $(C . \times$ limon $)]$. El vino de naranjas es citado como el licor más saludable de todos, además de ser usados, al igual que otros aguardientes de frutas, como remedio para "frialdades" de los guaraníes, uno de las principales dolencias en las misiones. El agua de azahar (extracto acuoso de las flores de $C$. $\times$ aurantium, naranja amarga') se empleaba en repostería y el agua de bergamotas (C. × aurantium „Bergamota ${ }^{\circ}$ ) en perfumería (Sepp, 1971: 135; Cardiel, 1994; Montenegro, 1945).

Posteriormente a la expulsión de los jesuitas (1767) se citan otros usos: las cáscaras de "naranja amarga" $(C . \times$ aurantium $)$ usadas para calmar el dolor de las disenterías, como tónicas; el jugo de la "lima sutí" $(C . \times$ aurantiifolia $)$ para cortar las fiebres del paludismo ("chucho") y para combatir la enfermedad llamada "sudamina" o "zarpullido" (Bertoni, 1927). Algunas de estas propiedades ya eran comentadas por W. Piso (siglo XVI). 
Figura 13. El resultado de la conquista y colonización ibérica en el continente americano: Misiones jesuíticas en Sudamérica (mediados de siglo XVIII). Tomado de Stampella et al. (2013c).

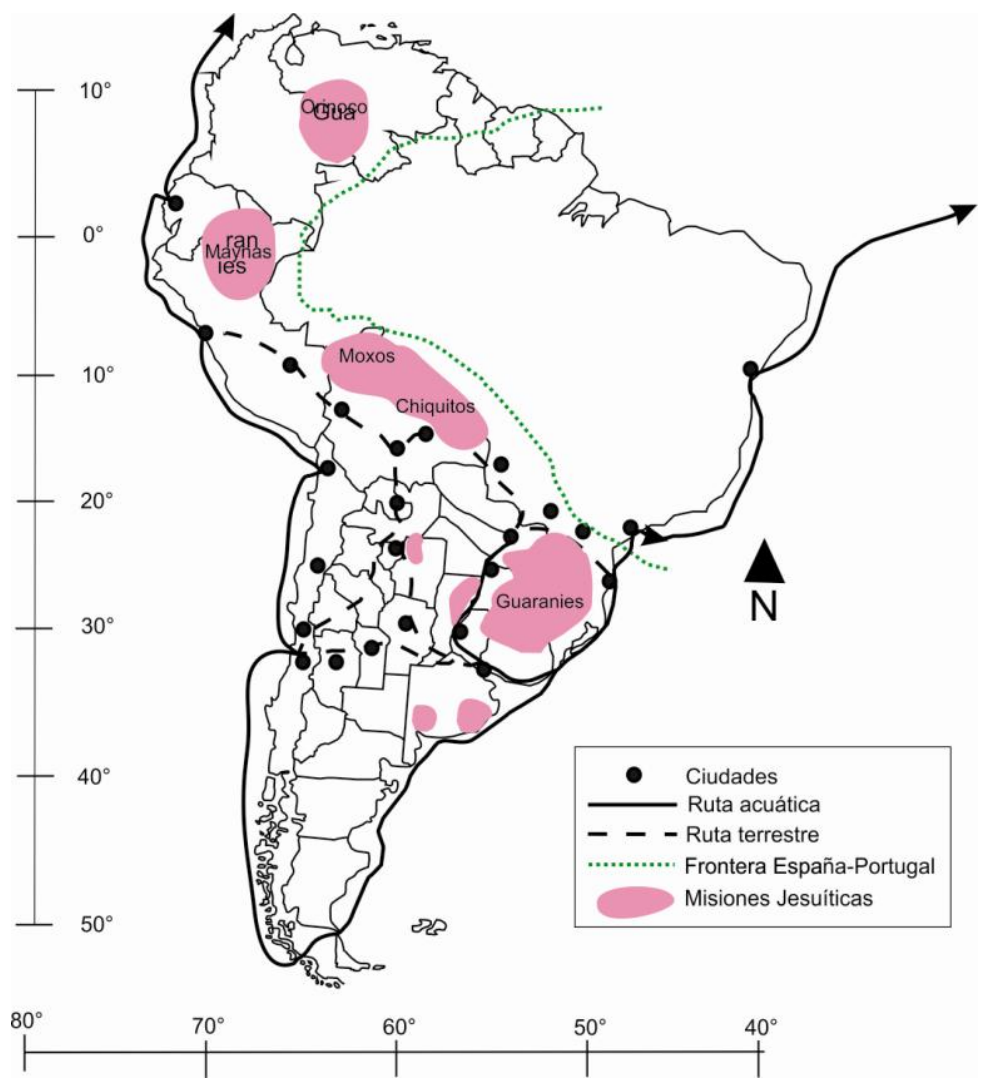

Figura 14. Esquema del huerto de los jesuitas de la reducción de San Javier (actual N de la provincia de Santa Fe. Modificado de F. Paucke (1942-1944).

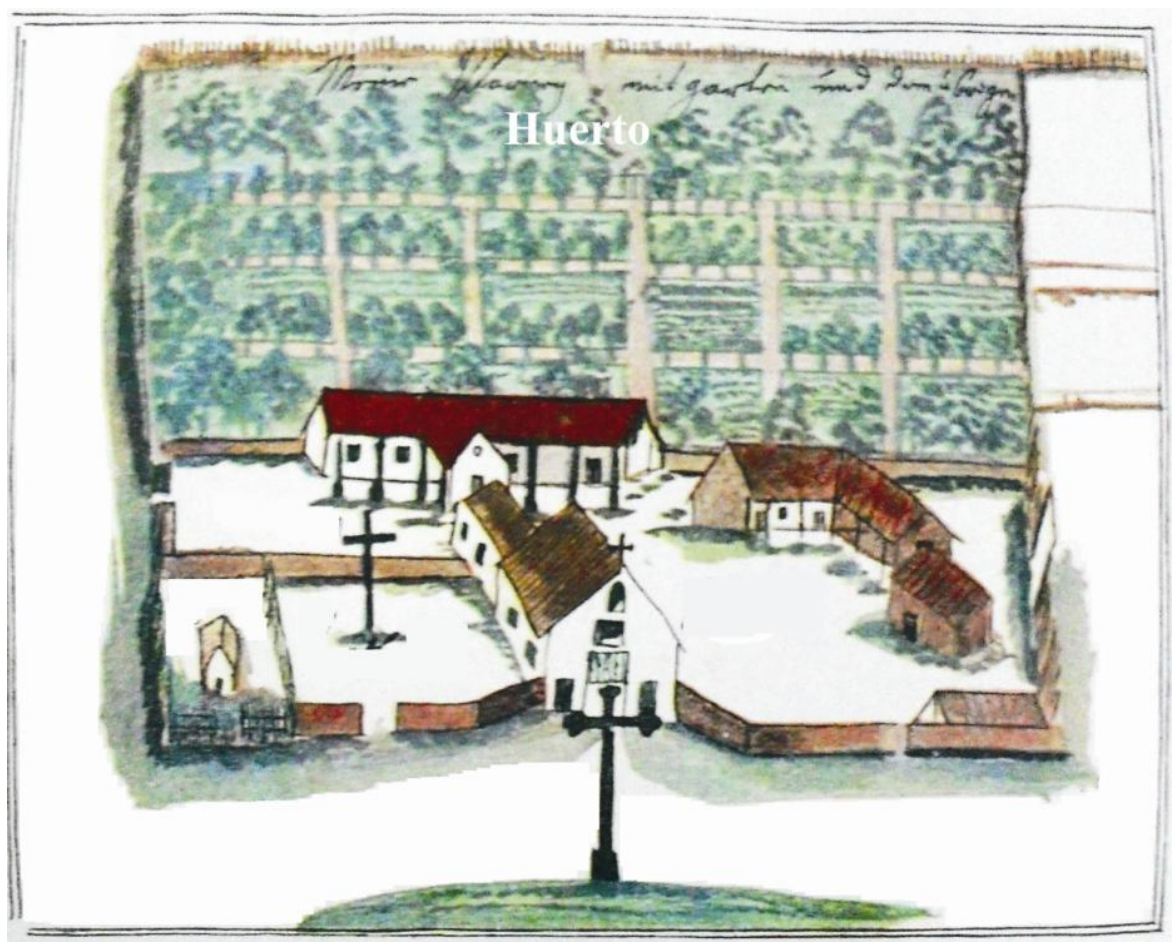




\section{VARIEDADES HISTÓRICAS DE LAS MISIONES}

Tomando como referencia las obras de Paucke (1944), Sepp (1971) y los inventarios de la expulsión de los jesuitas de Brabo (1872), podemos acercarnos a cuáles eran los cultivares que crecían en las misiones jesuíticas. Los relevados fueron: "limones comunes o ácidos", "limones dulces", "limones ceutíes", "limas dulces", "cidros", “toronjas", "naranjos dulces y agrios", "naranjos de cáscara fina” y "naranja de la China” (Figura 12). Las variedades selectas frecuentemente eran cultivadas en los huertos y jardines de los jesuitas (a los cuales sólo tenían acceso los padres y pocos guaraníes horticultores) y en los Colegios de Buenos Aires, Córdoba, Santa Fe y Asunción. Las variedades "comunes" o "vulgares" se hallaban frecuente cultivados en el Tupambae y ocasionalmente en algún Abambae, además de las variedades "silvestres" seguramente espontáneas en los bosques más o menos modificados según el manejo agroforestal o intensivo.

Las variedades históricas anteriores se diversifican si tenemos en cuenta la obra del jesuita italiano J. Ferrari (1646) en la cual se describen e ilustran tres grupos principales de cítricos denominados: malo citreo ("cidros"), malo limonio ("limones", "limas" y "lumias") y malo aurantio (“naranjas", "pampelmusas" y i”mandarina”?). A lo largo de la obra se pueden evidenciar variedades injertadas de "limones" y "naranjas" con pulpa (endocarpo) ácida y dulce ("dulci medulla"), con semillas y aseminadas ("semine carens"), de epicarpo comestible y dulce (“dulci cortice"), con flores (y frutos) dobles ("flore duplici", "geminatum"), como también indicando la presencia de ombligos (“foetiferum”) y “cuernos" (“corniculatum”), entre otras características (Figura 12).

EXPULSIÓN DE LOS JESUITAS Y APROVECHAMIENTO/EXTRACCIÓN DE LOS AMBIENTES PRODUCTIVOS

Con el extrañamiento de la orden religiosa en 1768 las misiones son abandonadas y durante los años posteriores ocurren múltiples migraciones de los guaraníes misioneros a los "montes" vecinos, a Corrientes, Santa Fe, Buenos Aires y Asunción, entre otros, especialmente aquellos que contaban con una profesión (Gálvez, 1995). Los naranjales son recordados por los pobladores entrevistados hasta pocos años atrás y observados y elogiados por los viajeros de Misiones de fines de siglo XIX y principios del XX (Lista, 
1883; Holmberg, 1887; Gambón, 1904; Ambrosetti, 2008a, b). Al respecto, Holmberg (1887: 121, 191) le dedica unos versos a los naranjales y diserta acerca de la estética de los naranjos en el monte; mientras que Azara (1847), Ambrosetti (2008: 86-87, 97) у Lista (1883: 66) se detienen en la descripción de diferentes aspectos relacionados a la "naturalización" de estas plantas y su relación con la fauna local y las poblaciones humanas.

5.1.3.2. Inmigraciones, inicios de la citricultura argentina y situación actual de los Citrus

\section{INMIGRACIONES}

Hacia finales del siglo XIX, Burmeister (1899: 11-12) cita "naranjos mandarinos" ( $C$. reticulata) para la provincia de Corrientes, recomendándolos junto a los "naranjos comunes" y el "chirimoyo" (Annona cherimola Mill.) en cultivos intensivos para la exportación a grandes ciudades. Poco antes fueron incorporados por Hieronymus (1882) en su obra bajo la denominación de "naranjo fino" o "mandarino" (Citrus deliciosa Tenore) reportando sus usos idénticos a los del "naranjo dulce" [antiescorbútico, béquico (tos) y contra enfermedades de la bilis].

Los "pomelos" o "grapefruit" $(C . \times$ aurantium $)$ ingresan posiblemente junto con la "mandarina” o quizá poco antes. Su origen es discutido, si por mutación o hibridación, aunque se acepta Barbados como lugar geográfico, hacia principios del siglo XVIII, dispersándose hacia otras islas recién poco menos de un siglo después (Kumamoto et al., 1987; Citrus Pages, 2014). Posiblemente fueran confundidos con "pampelmusas" o "toronjas" (C. maxima).

Estas introducciones coinciden con la reconfiguración de las poblaciones locales a través del proceso migratorio que tuvo lugar en los primeros años del siglo XX. Los inmigrantes que llegan a territorio misionero lo hacen en un primer momento con la colonización oficial la cual se inicia en 1898 con el arribo de polacos y ucranianos de la zona de la Galitzia - una de las comarcas más pobres de la Europa campesina- al pueblo de Apóstoles y alrededores. El Estado también es responsable del poblamiento de las tierras localizadas sobre la dorsal central (Além, Oberá, Cainguás). Por su parte la colonización privada incorpora principalmente inmigrantes alemanes provenientes de 
Brasil o directamente de Europa, extendiéndose principalmente por la zona del Alto Paraná. Posteriormente a esta zona arribarán inmigrantes criollos y paraguayos en busca de trabajo (Gallero \& Krautstofl, 2010). Con estos inmigrantes llegan nuevos saberes y prácticas sobre el entorno, así como diferentes valoraciones de las plantas con las que iban a interactuar.

\section{INICIOS DE LA CITRICULTURA EN EL NEA}

Otra fuente de variabilidad fue la industrialización de los cultivos. Luego del primer cuarto del siglo XX, con el inicio de la citricultura en el NEA, se diversifican las introducciones de los cultivares de distintos enclaves del mundo (África, India, EE.UU., China, Japón). El modelo de industria citrícola es EE.UU. (Florida y California) cultivándose variedades injertadas principalmente sobre "naranjo amargo", que luego es reemplazado debido a la epidemia del virus de la tristeza, por portainjertos de "naranjo dulce”, “mandarino Cleopatra” (C. reticulata cv. „Cleopatra"), "lima de Rangpur" (C. × taitensis) y "lima dulce” (C. × limon ,lima dulce"), entre otros (Webber, 1943a; Banfi, 1954; Banfi \& Beñatena, 1954; Palacios, 1978).

Hacia los ${ }^{~} 70$ se produce una homogeneización de los cultivares debido a la creciente globalización agraria y la demanda del mercado de frutos uniformes en cuanto a tamaño, forma, color y sabor, como también la carencia de semillas. Actualmente, de los cítricos cultivados en la provincia, el 78\% corresponde a "mandarinas" ( C. reticulata cV „Satsumae, „Clementina"e y „Murcott"), el 17\% a "naranjas” $(C . \times$ aurantium „Valencia Late aurantiifolia cv „Tahitiee y C. × limon cv „Eureka“) (Compañía Tabacalera de Misiones Ltda., 2014).

\subsubsection{DISCUSIÓN}

El camino que han recorrido los cítricos desde su área de origen hasta los distintos enclaves del mundo constituye un párrafo oculto en la historia de introducción de los frutales euroasiáticos a América y que ha sido abordado, mediante el empleo de documentación histórica (y evidencias filológicas), por Webber (1943a) y Ramón-Laca 
(2003). La historia de introducción en Argentina incluye múltiples rutas de ingreso, desde distintos orígenes y a lo largo de los cinco siglos de historia. Tempranamente, para la zona en estudio convergen dos corrientes principales: la Asunceña-Rioplatense, proveniente de España y sus dominios, con marcada influencia andaluz; y la Portuguesa, con aportes de los viajes hacia África, India y Lejano Oriente.

El germoplasma ingresado incluye variedades dulces y agrias de "cidras", "naranjas", "limones", "limas", "toronjas", entre otras. Un trabajo reciente de los oasis de Baja California, pertenecientes a las misiones jesuíticas durante el siglo XVIII, cita prácticamente las mismas variedades en base al análisis documental (De Grenade et al., 2014). Estos oasis, ricos en humedad y vegetación, contrastan con el clima propio de la región, caracterizado por precipitaciones que no superan los $200 \mathrm{~mm}$ anuales. En ambos sitios las variedades introducidas en época histórica representan un problema para su identificación ya que son mencionadas simplemente como "cidras", "toronjas", "limones", "limas", "naranjas", a lo sumo con epíctetos que hacen referencia al dulzor o acidez del endocarpo o, bien, a su origen.

Pues bien, los libros de geóponos como Agricultura General de Herrera (1818) [1513] y Agricultura de Jardines de G. de los Ríos [1592] y Tratado de citricos de Monardes [1540] (en Fernández González \& Ramón-Laca, 2002) abundan en prácticas, calendarios, descripciones. Los Tratados de J. Ferrari (1646), S. Commelyn (1683), J. C. Volkamer (1708-1714), G. Gallesio (1811) y A. Risso \& A. Poiteau (1818-1822) son abundantes en descripciones de las variedades agrupadas de acuerdo a criterios de afinidad propios de su época, con variedades locales que se iban poniendo en contacto entre sí por la incipiente Globalización, origen geográfico, formas de cultivo y por cierto, ilustraciones (Figura 19). Estas obras indican además una alta diversidad de variedades propagadas mediante injertos y unas pocas variedades "comunes", "vulgares" o "silvestres", propagadas mediante semillas, también espontáneas.

Asimismo, las referencias acerca de su temprana "naturalización" (Acosta, 1590; Cobo, 1890-1892) en el trópico y subtrópico americano, y de Gade (1976) en Paraguay, dan cuenta no sólo de la afinidad climática de este género sino también de las prácticas culturales sobre los paisajes selváticos y boscosos que favorecen la "naturalización" de estos frutales, diversificando asimismo el paisaje donde las variedades prosperan (Grant, 1989). 
En cuanto a la diversidad ingresada a América, sólo las variedades comunes se "naturalizaban", coincidiendo quizá con las empleadas como portainjertos en los huertos jesuíticos. Este proceso de "naturalización" es descripto muchas veces como un proceso "biológico" despojado de las prácticas humanas. Así, muchos autores se refieren a la dispersión por la fauna local (aves y mamíferos), por cursos de agua (hidrocoria) o simplemente por caída de los frutos, entre otros (Acosta, 1590; Cobo, 1890-1892) pero, exceptuando las descripciones de Azara (1847) y Gade (1976), las explicaciones acerca de la naturalización de estos frutales excluyen a los humanos.

La estrategia de subsistencia por recolección, caza y pesca de los grupos guaraníes, caracterizada por prácticas de manejo de paisajes, como también de escasas especies individuales (mandioca, poroto, maíz, batata) (Bartolomé, 1978; Susnik, 1979-1980), fue alterada durante los siglos XVII y XVIII con la formación de diversas Reducciones Guaraníticas en el sur de la provincia, cambiando los patrones de apropiación del entorno hacia la formación de paisajes relacionados a la vida sedentaria (incremento de los campos para el ganado y la explotación intensiva por roza y quema), y la producción para un mercado regional y mundial (Mörner, 1985; Carbonell, 1992). En las áreas cercanas a las reducciones se configuran como modelos hegemónicos de producción el Abambae y el Tupambae, separándose la propiedad privada de la colectiva o comunitaria. Además, los huertos de los Jesuitas, abordados en trabajos previos (Capparelli et al., 2011; Rosso, 2013; Stampella et al., 2013c; Hilgert et al., 2014), se configuraron como ambientes donde las prácticas estaban dirigidas a plantas individuales o pequeños grupos de plantas, mayoritariamente exóticas, empleadas como medicinales, ornamentales, condimenticias y frutales, entre otras. Desde estos espacios, vedados para el común (para la mayoría de los guaraníes reducidos), las variedades de cítricos comunes se escapan de cultivo hacia los ambientes con menor intervención (montes y capueras). Durante este período la planificación del paisaje en la interacción jesuítica-guaraní incluyó tanto a los cítricos como a otras especies de frutales euroasiáticos ["duraznos", "granados" (Punica granatum L.), "bananos"] como componentes conspicuos con fines ornamentales, medicinales, alimenticios y productivos, entre otros. De la misma manera, las plantas nativas también estaban presentes en esta planificación. En la reducción de San Javier (de Mocovíes) eran frecuentes los frutales como Ziziphus mistol Griseb., Geoffroea decorticans (Gillies ex 
Hook. \& Arn.) Burkart, Cynophala retusa (Griseb.) X. Cornejo \& H.H. Iltis, Prossopis spp., Opuntia spp., Cleistocactus baumannii (Lem.) Lem., entre otros (Rosso, 2013).

La presencia de los cítricos en diversos espacios productivos y cotidianos, como también su representación en los bosques por "naturalización", contrastan con la introducción de otros cultivos euroasiáticos durante la conquista y colonización americana (Del Río Moreno \& López y Sebastián, 1996; Giovannetti, 2005). Así, los cítricos en el NE de Argentina se presentan como patrimonio natural-cultural ya que no se trata sólo de variedades ingresadas por los jesuitas y colonizadores lusohispánicos sino de etnovariedades o variedades locales seleccionadas a lo largo de 5 siglos de historia, una de ellas "apepú” o "naranja jhai”, con denominación guaranítica.

$\mathrm{Al}$ respecto, los escritos del período jesuítico constituyen un corpus documental diverso y detallado para el NE de argentina que, de alguna manera, suplen la pobreza del registro arqueológico en zonas subtropicales.

En todo caso, el huerto de los jesuitas se erige como el ámbito de cultivo donde los cítricos presentaban mayor diversidad. Esto pudo deberse quizá a la presencia de cítricos injertados e híbridos correspondiéndose con algunos de los presentados por Ferrari (1646). Esto puede ser criticado debido a que estas fuentes documentales, escritas por los jesuitas, resaltan los ambientes con mayor control sobre la vegetación de los considerados "silvestres".

Los cultivos son abandonados entrando en un proceso de regeneración forestal en varios parches antes cultivados. Es de esperar que los más cercanos a las construcciones algunas aún habitadas por pocos años más, a pesar de las invasiones portuguesas y paraguayas de 1917 y 1818- fueran sometidos a manejo de la cobertura arbórea superior, como también de los "montes frutales", yerbales y algodonales abandonados, los remanentes visitados a principios del siglo XIX por Aimé Bonpland (Domínguez, 1928; Machón, 2004). 


\subsection{VARIABILIDAD DE CÍTRICOS (CITRUS, RUTACEAE) LOCALMENTE RECONOCIDA EN EL SUR DE MISIONES (ARGENTINA): DIVERSIDAD LOCAL, PERCEPCIÓN DE LA VARIABILIDAD Y USOS.}

\subsubsection{INTRODUCCIÓN}

La agrodiversidad actual es el resultado de múltiples procesos biológicos y culturales, construidos históricamente, donde se hallan imbricadas diferentes dimensiones socioculturales locales y determinantes macroeconómicos (Emperaire et al., 2001; Emperaire, 2010). La importancia de estos procesos está bien representada en los enclaves tradicionales, definidos como sociedades rurales con sistemas de producción de subsistencia o para venta a pequeña escala, relacionados al entorno con prácticas de manejo no industriales (Toledo \& Barreras-Bassols, 2008). Lejos de representar definiciones estáticas, estos parajes están conformados por UD que incluyen varias vertientes culturales mestizadas, fruto de 5 siglos de historia, que confluyen en el modo de vida tradicional de la zona.

En relación a los procesos locales de selección cultural, la diversidad de prácticas sobre una misma especie permite la aparición y conservación dinámica -es decir, in situ- de taxa locales. Estos procesos han sido abordados desde diferentes ópticas. Por ejemplo, en distintos niveles de inclusión, estas agrupaciones o etnoespecies son definidas por Zamudio \& Hilgert (2012) como “identidades folclóricas" reconocidas por las comunidades locales y, en la mayoría de los casos, referidas mediante un nombre vernáculo. De manera similar las etnovariedades son entendidas como "cultivariedades definidas en un contexto cultural tradicional concreto, caracterizadas por atributos, siendo diferenciables, uniformes y estables" (Rivera Núñez et al., 1998). Estas etnovariedades -también denominadas landraces (razas locales)- están caracterizadas por sus adaptaciones a las condiciones climáticas y edáficas locales, y a las prácticas culturales; lo que redunda en características morfo-fisiológicas particulares (Harlan, 1992).

La clasificación local de esta variabilidad, caracterizada por los múltiples criterios de evaluación tenidos en cuenta (Nazarea, 1998) y por los matices que relacionan a dos 
categorías opuestas de un mismo descriptor, contrasta con los principios ordenadores reduccionistas de la ciencia occidental (Lema, 2009). Esta serie de discontinuidades percibidas diferencialmente configura la riqueza de etnovariedades sobre la cual se basa la selección cultural (Berlin, 1992; Lambaré \& Pochettino, 2012).

En este sentido, el género Citrus constituye un buen ejemplo ya que su sistemática intragenérica es compleja y ha generado controversias, como lo expresa el número variable de especies que se le han asignado (ver apartado 2.4). Este género botánico surge en las regiones tropicales y subtropicales del SE asiático, hace 20 millones de años, antes de que Asia y Nueva Guinea se separaran de Australia. Al parecer, durante el siglo VII es dispersado desde China hacia el NE de India donde se originan las especies "modernas" (Gmitter \& Hu, 1990; Ramón-Laca, 2003). La expansión del imperio Árabe (siglos VII a X) dispersó el cultivo de estos frutales por el N de África y $\mathrm{S}$ de Europa, ingresando a la Península Ibérica hacia el final de dicho período. Su ingreso al Nuevo Mundo es más bien temprano ya que en el segundo viaje de Cristóbal Colón se hallaban entre las plantas llevadas en las carabelas (Ramón-Laca, 2003; Stampella et al., 2013c; Hilgert et al., 2014). Las diversas rutas de ingreso, relacionadas a la vez con diferentes cosmovisiones y prácticas de cultivo, finalmente van a dar lugar a distintas dinámicas en relación al clima de la zona en cuestión. Así, en el sur de la provincia de Misiones la rica y diversa historia relacionada a los cítricos ha sido estudiada en algunos trabajos previos desde la conquista hasta el ingreso de los portainjertos empleados actualmente hacia mediados del siglo pasado (Capparelli et al., 2011; Stampella et al., 2013c).

De lo expuesto se desprende que el relevamiento de la variabilidad de este género de frutales en un contexto local, relacionando la diversidad de usos y la manera en que son percibidos y socializados puede arrojar nuevas problemáticas en procesos de generación de variabilidad, selección y conservación in situ de etnovariedades y comunidades locales como también en la articulación con proyectos a nivel regional.

El objetivo del presente trabajo es relevar la diversidad local de cítricos, los criterios locales (emic) que intervienen en la percepción y en la selección de la variabilidad de los mismos, los usos asignados a dicha variabilidad y discutir aspectos relacionados a su taxonomía local. Asimismo, indagar acerca de las estrategias de apropiación del 
ambiente por los "criollos" de esta área y elaborar una reseña histórica del desarrollo de estos enclaves.

\subsubsection{MATERIALES Y MÉTODOS}

\section{Área de estudio}

Los trabajos de campo fueron llevados a cabo en los dos enclaves rurales mencionados en los apartados 3.2 y 3.3: Teyú Cuaré (Municipio de San Ignacio del departamento homónimo) y paraje Cerro Mártires (Municipio de Santa María, departamento de Concepción de la Sierra) (Figura 15).

Figura 15. Área de estudio. Se indica en celeste los departamentos de San Ignacio (arriba) y de Concepción de la Sierra (abajo), señalando Teyú Cuaré (TC) y Cerro Mártires (CM).

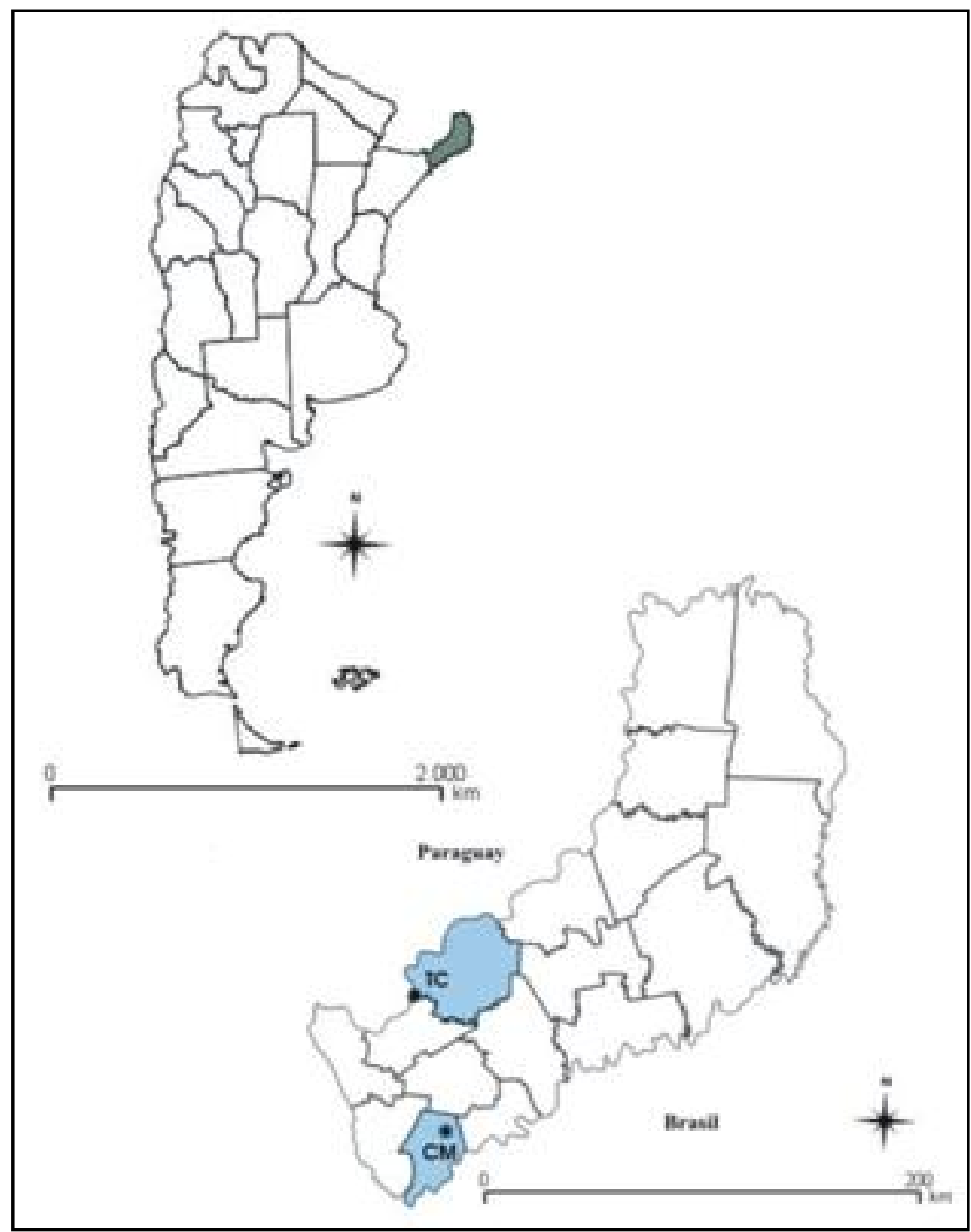




\section{Metodología}

Los trabajos de campo fueron realizados en 8 campañas durante los años 2010 a 2013. La metodología empleada fue propia de la etnobotánica cualitativa (observación participante, entrevistas abiertas y semiestructuradas y caminatas con los informantes) (Cotton, 1998; Martin, 2001; Albuquerque et al., 2014). Para la reconstrucción de la historia local se empleó la técnica de historia de vida relatada por informantes con varios años de residencia en la zona; mientras que para conocer la importancia de las etnovariedades de cítricos entre los frutales locales se empleó la técnica "ranking de preferencia" (Bernard, 2000), consistente en el ordenamiento de los 5 frutales más mencionados en las entrevistas previas, de acuerdo al orden de preferencia. Se relevaron un total de 18 UD visitadas en reiteradas oportunidades, en las cuales se entrevistaron 25 actores sociales con edades entre 12 y 88 años. Para la realización de las entrevistas se obtuvo el consentimiento de los participantes, previamente informado mediante explicitación de los objetivos y alcances de la investigación, y conformidad por su parte para el registro y difusión de la información (Capítulo 3.1; Anexo 8.1).

Cuando fue posible, por disposición y disponibilidad de su tiempo, se trabajó con pobladores que mantienen contacto cotidiano con las plantas estudiadas a través del manejo del cultivo. La selección de los entrevistados se realizó en primera instancia al azar y luego se empleó el método "Bola de Nieve" (Bernard, 2000). Durante las entrevistas y caminatas a los distintos espacios y en diferentes etapas, se indagó acerca de la diversidad cultivada y espontánea, los usos, y descriptores empleados para diferenciarlos. Se obtuvieron, de ese modo, las apreciaciones locales de la variabilidad y las prácticas de manejo presentes en la actualidad.

El material de herbario constituido por partes aéreas de plantas (ramas con hojas, y eventualmente flores), resultado del trabajo realizado en la zona, fue identificado empleando bibliografía especializada (Webber, 1943b; Swingle \& Reece, 1967; Palacios, 1978; Anderson, 1996; Zhang \& Mabberley, 2008; Citrus Pages, 2014; NSW, 2014; USDA, 2014) y depositado en el Herbario de Plantas Útiles y en la Colección de Frutos y Semillas del Laboratorio de Etnobotánica y Botánica Aplicada (CFS, LEBA) de la Facultad de Ciencias Naturales y Museo, Universidad Nacional de La Plata y en el Herbario del Museo de La Plata (LP), con la asignación de siglas y número de registro personal. Los frutos colectados fueron conservados en alcohol $70^{\circ}$ con agregado de ácido acético confeccionándose de esta manera una carpoteca de referencia. 
Las palabras en cursiva -exceptuando los géneros y nombres específicos- indican denominación local (o emic), aclarándose su significado entre paréntesis a continuación de la primera mención. El nombre de las etnoespecies y etnovariedades -tanto de Citrus como de otras plantas y/o animales- se menciona entre comillas (“")).

\subsubsection{RESULTADOS}

5.2.3.1. Características socioculturales e historia local de los enclaves estudiados

\section{Los parajes de la cuenca del río Uruguay}

\section{CONCEPCIÓN}

Concepción de Nuestra Señora del Ibitiracuá fue la segunda reducción erigida en actual territorio misionero, si consideramos que Nuestra Señora de la Encarnación (actual ciudad paraguaya de Encarnación) fue fundada en 1615 en la margen izquierda del Paraná, cerca de la actual ciudad de Posadas. Concepción fue fundada a fines de 1619 por el jesuita Roque González de Santa Cruz en el avance hacia el "Tape" (actual Rio Grande do Sul, Brasil, ver Figura 4, capítulo 4.3), una zona de pastizales intercalados con selvas en galerías de los cursos de agua. La refundación fue llevada a cabo por el gobernador Juan Balestra en 1895. Actualmente, la ciudad se halla emplazada sobre las ruinas de la misión, manteniéndose sólo restos del "cotyguazú" (construcción destinada al alojamiento de viudas, huérfanas y abandonadas, Gálvez, 1995). En varios puntos de la ciudad pueden observarse las rocas de las construcciones jesuíticas formando parte de diversas construcciones particulares.

\section{LA CORITA}

El pueblo de La Corita pertenece al Municipio de Santa María, departamento de Concepción de la Sierra. Su nombre proviene de la esposa de un hacendado de la zona, llamada Cora (Stampella, 2012). Hacia mediados del siglo XX la zona era denominada "Santa María" o "Pueblo Viejo" -aludiendo a los caseríos dispersos asociados a las ruinas de Santa María la Mayor- pero cuenta un residente de la zona que “...la gente venía de Concepción o de San Javier y decían [al chofer del colectivo] bájeme en el portón de la Corita ... y fue quedando... La Corita". Fue trazado a $2 \mathrm{~km}$ del casco de la 
reducción antes mencionada, establecida en la zona luego del éxodo del Tape, hacia 1633.

\section{CERro MÁrtires}

El paraje Cerro Mártires está ubicado a poco menos de $2 \mathrm{~km}$ al sur de las ruinas de Santos Mártires del Japón, establecida hacia inicios del siglo XVII en las cercanías de Santa María la Mayor. La zona donde se encuentran las ruinas pertenece a un particular y está propuesta su expropiación (Kuna, 2005), mientras que los alrededores y la Ruta Provincial 30 están propuestos para el turismo cultural (Cambas, 2005; Ribero, 2005) aún sin acciones al respecto. Para el caso de Cerro Mártires las características de las fincas y de los pobladores se asemejan a las descriptas por Granitto \& Sarandón (2002) para el paraje de San Juan de la Sierra, situado a 10 kilómetros al O-NO, con quienes los pobladores de Cerro Mártires mantienen relaciones familiares y laborales.

\section{Los parajes de la cuenca del río Paraná}

\section{SAN IGNACIO}

La fundación de San Ignacio Miní - para diferenciarlo de San Ignacio Guazú, fundado en el territorio comprendido entre el río Tebicuary y Paraná (actual Paraguay)- se remonta hacia principios del siglo XVII en el Guairá, en las costas del río Paranapanema, al noroeste del actual estado de São Paulo (Brasil). Luego de varios ataques de bandeirantes paulistas, se lleva a cabo el éxodo del Guairá (junto a Nuestra Señora de Loreto), hecho relatado extensamente en las Cartas Anuas del período 16151637 compiladas por Leonhardt (1929), y por el jesuita Ruíz de Montoya (1892). Luego de un largo viaje se ubican en 1631 en la cuenca del río Yabebirí, cerca de la reducción de Corpus, en la porción sur de la actual provincia de Misiones. Luego de la expulsión de la Compañía de Jesús, San Ignacio es refundado hacia 1895, aunque a partir de 1877 ya se realiza el trazado del ejido a cargo de Juan Queirel (Gran Atlas de Misiones, 2012).

\section{PUERTO VIEJO}

El paraje Puerto Viejo es un asentamiento en terrenos fiscales situado a $1 \mathrm{~km}$ al NE de la ciudad de San Ignacio. Se accede por la avenida Sarmiento en dirección norte, que 
lleva al antiguo puerto. Hacia las costas del Paraná se encuentran varios afloramientos de arenisca rojiza, conocida en la zona como laja de San Ignacio, que pertenece a la Formación Solari, correlacionada con las Formaciones Botucatú (Brasil) y Misiones (Paraguay), correspondiendo su base al Triásico tardío. Son indicadoras de ambientes eólicos y constituyen evidencias del régimen árido que predominó durante el Pérmico conformando uno de los desiertos más grandes de la historia geológica (Teruggi, 1970; Marengo et al., 2005).

\section{TEYÚ CUARÉ}

Teyú Cuaré (Teju kuare, en guaraní) significa "cueva del lagarto". La zona se halla cercana a las ruinas de dos misiones jesuíticas: San Ignacio Miní y Nuestra Señora de Loreto. Las UD están ubicadas en un área propuesta como zona de ampliación del Parque Provincial Teyú Cuaré (Soria, 1996 en Biganzoli \& Múlgura de Romero, 2004), cercanos también a 3 ó 4 comunidades M'bya. La flora local ha sido estudiada por Biganzoli \& Múlgura de Romero (2004) y Fontana (2005), su geología por Marengo et al. (2005); y Bertolini (2005) ha publicado un documento base para el manejo del Parque Provincial.

\subsubsection{Observaciones acerca de la zona en estudio y subsistencia de los criollos}

Ambos parajes están conformados por UD más condensadas en las cercanías de las escuelas primarias. Particularmente, en Cerro Mártires la zona estuvo ocupada por Guaraníes, que luego de las plagas de langostas de principios de siglo XX migran hacia el norte, estableciéndose en las cercanías de Arroyo Bonito (Departamento L. N. Além). En la década del 30 la Compañía Tabacalera Nobleza-Piccardo lotea la zona desde el Uruguay hasta el límite con Arroyo del Medio (Departamento L. N. Além), vendiéndoles los terrenos a familias de "criollos" descendientes de españoles, italianos y brasileños, que ya estaban instalados en la zona y que comenzaron a pagar sus tierras con la producción de tabaco. Por esa época también llegan los "polacos" que se instalan en los bañados y zonas cercanas a los cursos de agua: "Al polaco le gusta el bajo, ahi donde puede plantar verdura, fruta y arroz" (M. D., La Corita, 73 años). Hacia fines del '70 y principios del ' 80 se instalan masivamente en la zona productores migrados de Rio Grande do Sul (Brasil), del otro lado del río Uruguay. Posteriormente casi el 80\% de la población migra hacia Virasoro (Corrientes), Apóstoles y otras localidades con la 
crisis económica de los '90. Actualmente la zona está poco poblada presentando varios parches de vegetación espontánea y en proceso de regeneración ecológica, consecuencia de la desocupación de la zona, donde se evidencian "naturalizaciones" de varios frutales remanentes de las antiguas colonias. Este abandono (y regeneración de la selva) de más de 20 años aporta evidencias concretas acerca de la "naturalización" de plantas cultivadas que pudo haber ocurrido siglos antes con el despoblamiento de la zona luego de la expulsión de los Jesuitas.

Al establecerse en la zona, las familias construyen casas de madera con techos de chapa y luego algunas familias construyen otra casa de ladrillos y cemento, cerca de la anterior (Figura 16).

Figura 16. Casa de un informante de Cerro Mártires. Hacia la derecha puede apreciarse la casa de madera, a la cual se le ha adosado, hacia la izquierda, la construcción de cemento. Rodeando a ambas puede apreciarse el jardín.

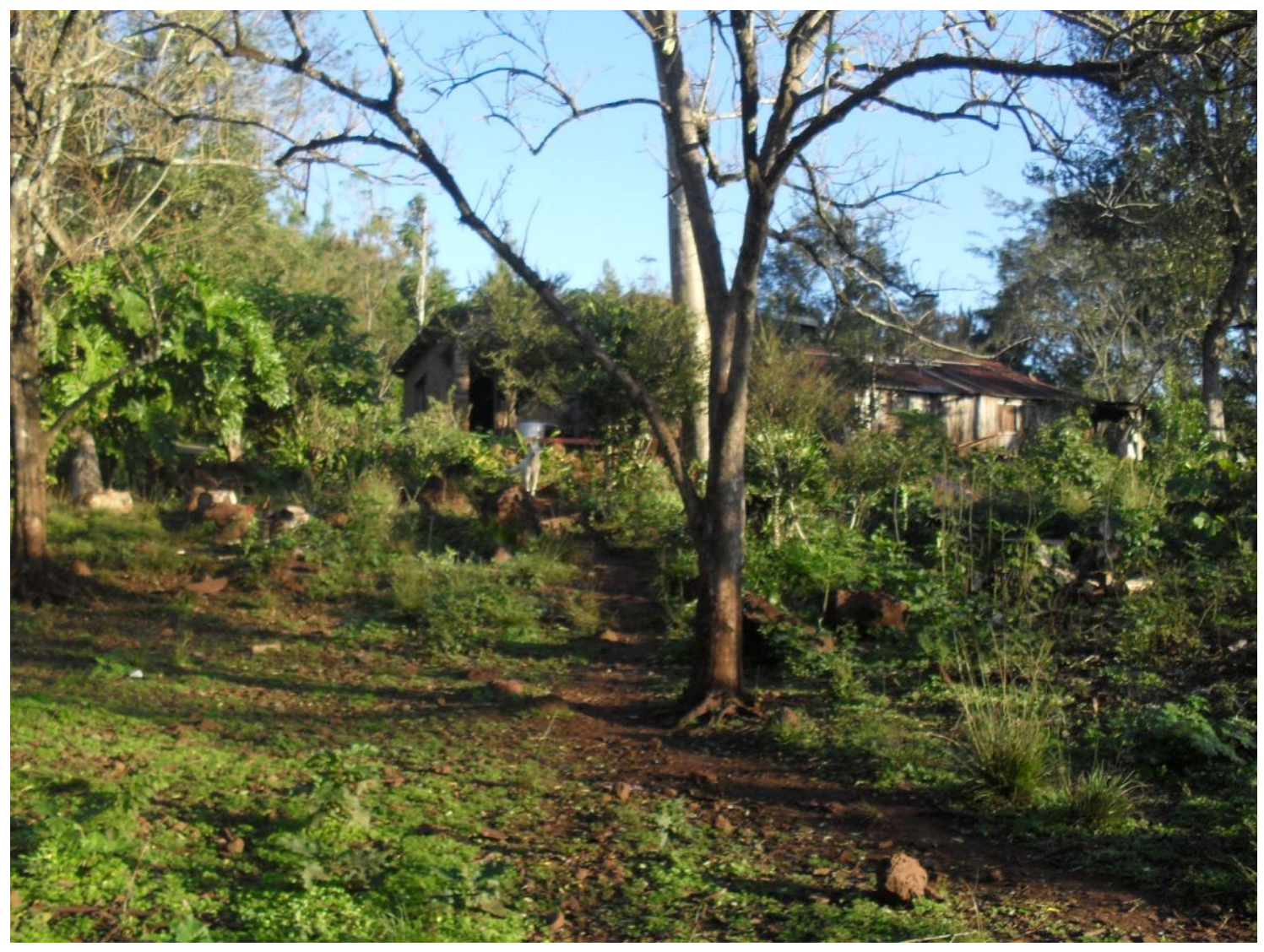

Los campesinos se apropian del paisaje mediante la estrategia de uso múltiple, combinando de esta manera prácticas agroforestales, ganaderas, hortícolas y de caza en 
algunos sectores, casi siempre de subsistencia. Esta estrategia está presente a nivel de las diferentes zonas ecológicas locales como también en la diversidad de especies y variedades cultivadas. Unos pocos venden su cosecha y productos elaborados (conservas, dulces, mermeladas) en las ferias francas de San Ignacio y Concepción, principalmente descendientes de colonos, los demás practican agricultura de subsistencia con eventuales trueques de los excedentes. Generalmente los rozados (zonas de cultivos anuales) se encuentran alejados, por lo cual se construyen casas temporales de madera, ramas y adobe que, luego de abandonadas, devienen en taperas.

5.2.3.3. Los citricos y las discontinuidades de la variabilidad localmente reconocidas

Se relevaron 9 etnoespecies de cítricos que incluyen 30 etnovariedades, con diferente tipo de manejo. Las etnoespecies involucradas son "cidra", "pomelo", “apepú", "naranja", "mandarina", "limón", "lima", "quinoto" y "trifoliata" (Tabla 4). Esta variabilidad local se corresponde con 4 especies biológicas: $C$. maxima, $C$. reticulata, $C$. trifoliata y Citrus japonica Thunb.; y 4 taxa híbridos: $C$. $\times$ aurantium $(C$. maxima $\times C$. reticulata, $C . \times$ taitensis $(C$. medica $\times C$. reticulata $), C . \times$ limon $(C$. medica $\times ?)$, y $C$. $\times$ aurantiifolia (C. medica × "papeda"). "Papeda" es un subgénero de Citrus conformado por especies "primitivas" de frutos no comestibles debido a la presencia de gotas de aceite ácrido en los pelos jugosos del endocarpo (ver Swingle, 1943).

La diversidad de etnovariedades cambia de acuerdo a la etnoespecie considerada. "Mandarina", "limón” y "naranja" son las más ricas en etnovariedades, con 7, 6 y 6, respectivamente; luego "apepú" y "pomelo" con 3 cada una; "quinoto" con 2; y con 1 única variedad "cidra", "lima” y "trifoliata”. Según la taxonomía botánica, las etnovariedades se agrupan de la siguiente manera: 12 en $C$. $\times$ aurantium, 7 en $C$. reticulata, 3 en $C$. $\times$ limon, 2 en $C$. $\times$ aurantiifolia y $C$. trifoliata, y los demás taxa antes mencionados con 1 cada uno. 


\subsubsection{Descriptores, la percepción de la variabilidad}

Se relevaron 25 descriptores empleados cotidianamente para diferenciar la variabilidad de etnoespecies y etnovariedades, 14 de los cuales son empleados con mayor frecuencia (Tabla 5). Dichos descriptores, aluden a variables de la planta y de partes de las mismas (frutos y hojas), y pueden ser organolépticos (morfológicos y sensoriales) y agronómicos (fisiológicos y ecológicos).

Durante la época de fructificación el reconocimiento de las etnovariedades se realiza mediante la forma, tamaño, color y sabor de los frutos de una manera inequívoca a excepción de algunos cultivares comerciales poco conocidos localmente. En cambio, al estado vegetativo, las plantas adultas y las muditas (plántulas) son reconocidas por su porte (hábito de crecimiento) y por el tamaño, forma $\mathrm{y}$, fundamentalmente, por el olor (aroma) de las hojas.

Tabla 5. Descriptores empleados en la diferenciación de las distintas etnovariedades según la parte de la planta.

\begin{tabular}{|cc}
\hline FRUTOS & PLANTA \\
Tamaño & Maduración de los frutos \\
Forma & Presencia de espinas \\
Presencia de ombligo & \\
Color de la cáscara & HOJAS \\
Grosor de la cáscara & Tamaño \\
Textura de la cáscara & Forma \\
Sabor del endocarpo & Ancho del ala del pecíolo \\
Sabor del mesocarpo & Aroma \\
\hline
\end{tabular}


Tabla 4. Etnoespecies y etnovariedades de cítricos diferenciadas según los caracteres relevados.

\begin{tabular}{|c|c|c|c|c|}
\hline & & HOJA & FRUTO & PLANTA \\
\hline CIDRA & $\begin{array}{l}\text { Cidra, Citrus maxima } \\
\text { (Burm.) Merr.; } \\
\text { Stampella } 34 \text { (LP) } \\
\text { (Figura 25) }\end{array}$ & $\begin{array}{l}\text { Muy grande, redondeada, } \\
\text { pecíolo muy grande, } \\
\text { aroma no especificado } \\
(\mathrm{n} / \mathrm{e})\end{array}$ & $\begin{array}{l}\text { Fruto muy grande, redondo, sin } \\
\text { ombligo; Cáscara amarillo pálida, muy } \\
\text { gruesa, lisa; Gomo desabrido, seco y } \\
\text { poco dulce, amargo; Mesocarpo poco } \\
\text { amargo }\end{array}$ & $\begin{array}{l}\text { Muy pocas espinas; } \\
\text { Maduración: mayo } \\
\text { a julio }\end{array}$ \\
\hline \multirow{3}{*}{ POMELO } & $\begin{array}{l}\text { Pomelo cidra, Citrus } \\
\text { maxima } \times \text { Citrus } \times \\
\text { aurantium } \mathrm{L} . ; \text { no } \\
\text { colectado }(\mathrm{n} / \mathrm{c})\end{array}$ & $\begin{array}{l}\text { Grande, redondeada, } \\
\text { pecíolo mediano a } \\
\text { grande, aroma } \mathrm{n} / \mathrm{e}\end{array}$ & $\begin{array}{l}\text { Fruto grande a muy grande, redondo, sin } \\
\text { ombligo; Cáscara amarilla, gruesa, lisa; } \\
\text { Gomo amargo y dulce; Mesocarpo } \\
\text { amargo }\end{array}$ & $\begin{array}{l}\text { Pocas espinas; } \\
\text { Maduración: mayo } \\
\text { a julio }\end{array}$ \\
\hline & $\begin{array}{l}\text { Pomelo blanco, C. } \times \\
\text { aurantium [grupo } \\
\text { pomelo]; Stampella } 19 \\
\text { (LP) (Figura 24) }\end{array}$ & $\begin{array}{l}\text { Grande, redondeada, } \\
\text { pecíolo grande, aroma } \\
\text { dulce }\end{array}$ & $\begin{array}{l}\text { Fruto grande, redondo, sin ombligo; } \\
\text { Cáscara amarilla, mediana a gruesa, lisa; } \\
\text { Gomo amargo y dulce; Mesocarpo } \\
\text { amargo }\end{array}$ & $\begin{array}{l}\text { Pocas espinas; } \\
\text { Maduración: mayo } \\
\text { a julio }\end{array}$ \\
\hline & $\begin{array}{l}\text { Pomelo rosado, } C . \times \\
\text { aurantium [grupo } \\
\text { pomelo]; Stampella } 78 \\
(\mathrm{CFS})\end{array}$ & $\begin{array}{l}\text { Mediana a grande, } \\
\text { redondeada, pecíolo } \\
\text { mediano a grande, aroma } \\
\text { dulce }\end{array}$ & $\begin{array}{l}\text { Fruto grande, redondo, sin ombligo; } \\
\text { Cáscara amarillo anaranjada, mediana a } \\
\text { gruesa, lisa; Gomo amargo y dulce; } \\
\text { Mesocarpo poco amargo }\end{array}$ & $\begin{array}{l}\text { Muy pocas espinas; } \\
\text { Maduración: mayo } \\
\text { a julio }\end{array}$ \\
\hline APEPÚ & $\begin{array}{l}\text { Apepú de monte, } C . \times \\
\text { aurantium [grupo }\end{array}$ & $\begin{array}{l}\text { Grande, redondeada, } \\
\text { pecíolo grande a muy }\end{array}$ & $\begin{array}{l}\text { Fruto grande, redondo achatado, sin } \\
\text { ombligo; Cáscara naranja fuerte, }\end{array}$ & $\begin{array}{l}\text { Abundantes } \\
\text { espinas; }\end{array}$ \\
\hline
\end{tabular}




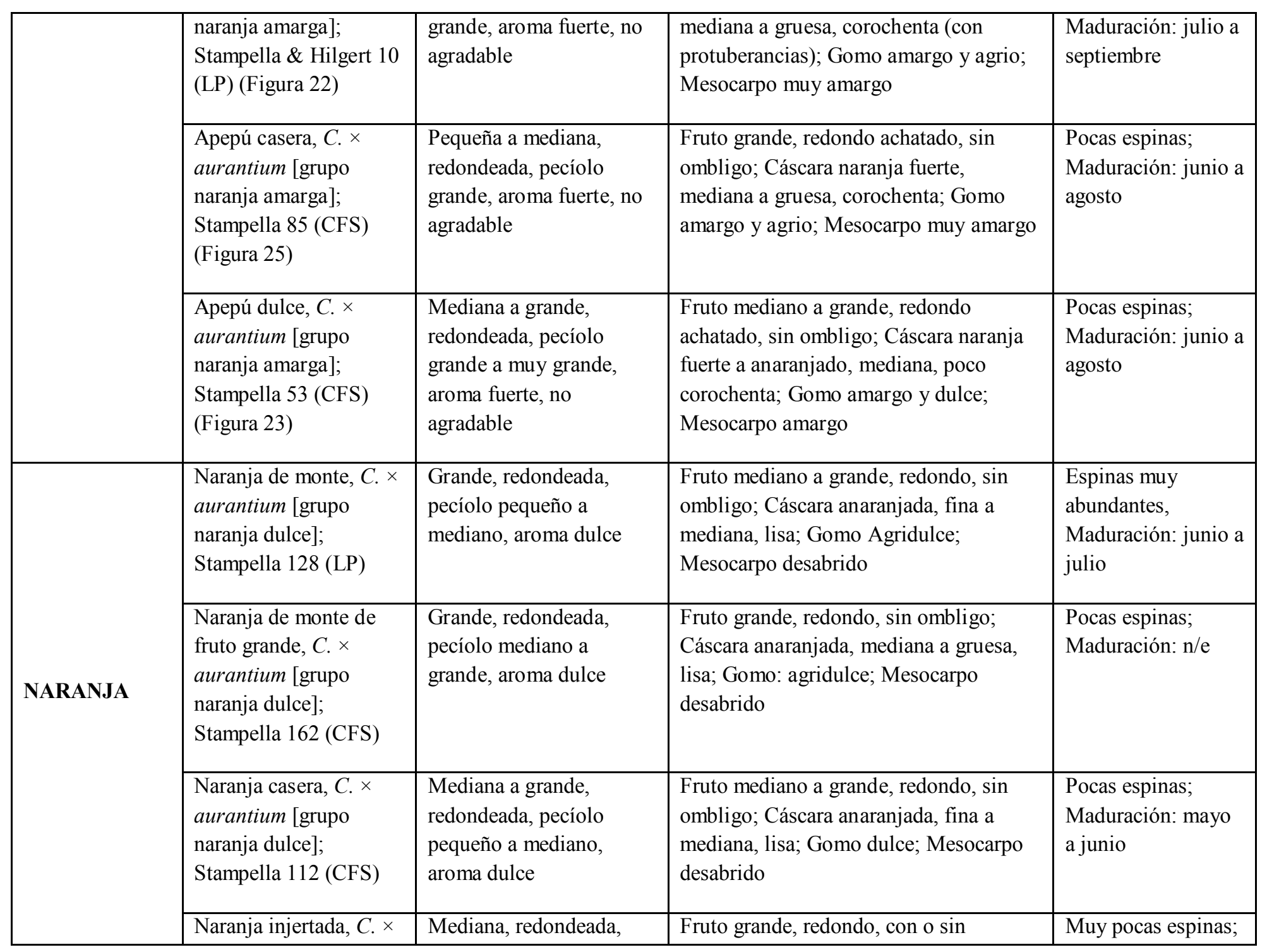




\begin{tabular}{|c|c|c|c|c|}
\hline & $\begin{array}{l}\text { aurantium } \text { [grupo } \\
\text { naranja dulce] + Citrus } \\
\text { trifoliata } \mathrm{L} . * ; \mathrm{n} / \mathrm{c} \\
\text { cultivar comercial }\end{array}$ & $\begin{array}{l}\text { pecíolo pequeño, aroma } \\
\text { dulce }\end{array}$ & $\begin{array}{l}\text { ombligo; Cáscara anaranjada, fina, lisa; } \\
\text { Gomo muy dulce; Mesocarpo desabrido }\end{array}$ & $\begin{array}{l}\text { Maduración: } \\
\text { variable }\end{array}$ \\
\hline & $\begin{array}{l}\text { Naranja de ombligo, } C \text {. } \\
\times \text { aurantium } \mathrm{cv} \text {. } \\
\text {,Navel }{ }^{\mathrm{ee}}+C \text {. } \text { trifoliata; } \\
\text { n/c, cultivar comercial }\end{array}$ & $\begin{array}{l}\text { Mediano, redondeada, } \\
\text { pecíolo pequeño, aroma } \\
\text { dulce }\end{array}$ & $\begin{array}{l}\text { Fruto grande, redondo alargado, con } \\
\text { ombligo; Cáscara naranja, mediana a } \\
\text { gruesa, lisa; Gomo muy dulce; } \\
\text { Mesocarpo desabrido }\end{array}$ & $\begin{array}{l}\text { Muy pocas espinas; } \\
\text { Maduración: } \\
\text { variable }\end{array}$ \\
\hline & $\begin{array}{l}\text { Naranja que guía, } C . \times \\
\text { aurantium } \mathrm{cv} . \\
\text { indeterminado; } \mathrm{n} / \mathrm{c} \text {, } \\
\text { cultivar ornamental }\end{array}$ & $\begin{array}{l}\text { Mediana, redondeada a } \\
\text { algo alargada, pecíolo } \\
\text { pequeño, aroma n/e }\end{array}$ & $\begin{array}{l}\text { Fruto mediano, sin ombligo. Los demás } \\
\text { descriptores sin datos. El ejemplar fue } \\
\text { visto por única vez antes de secarse }\end{array}$ & $\begin{array}{l}\text { Pocas espinas; } \\
\text { Maduración } n / \mathrm{e}\end{array}$ \\
\hline \multirow[t]{2}{*}{ MANDARINA } & $\begin{array}{l}\text { Mandarina casera, } \\
\text { Citrus reticulata } \mathrm{cv} \text {. } \\
\text { „Común de Concordia }{ }^{\text {ec; }} \\
\text { Stampella } 121 \text { (CFS) }\end{array}$ & $\begin{array}{l}\text { Pequeña, alargada, } \\
\text { pecíolo pequeño, aroma } \\
\text { fuerte, agradable (delator) }\end{array}$ & $\begin{array}{l}\text { Fruto pequeño a mediano, achatado, sin } \\
\text { ombligo; Cáscara naranja amarillenta, } \\
\text { fina, lisa; Gomo dulce; Mesocarpo } \\
\text { desabrido }\end{array}$ & $\begin{array}{l}\text { Espinas medias, } \\
\text { Maduración: } \\
\text { principios de mayo } \\
\text { a junio }\end{array}$ \\
\hline & $\begin{array}{l}\text { Mandarina injertada, } C \text {. } \\
\text { reticulata } \text { cv. ,Okitsu } \\
\text { o cv. ,Encore } \\
\times \text { limon }(\text { L. }) \text { Osb.; } \\
\text { Stampella } 116 \text { (LP) }\end{array}$ & $\begin{array}{l}\text { Pequeña a mediana, } \\
\text { redondeada a algo } \\
\text { alargada, pecíolo } \\
\text { pequeño a mediano, } \\
\text { escaso aroma }\end{array}$ & $\begin{array}{l}\text { Fruto mediano a grande, achatado, sin } \\
\text { ombligo; Cáscara naranja, fina a } \\
\text { mediana, lisa; Gomo muy dulce; } \\
\text { Mesocarpo desabrido }\end{array}$ & $\begin{array}{l}\text { Pocas espinas, } \\
\text { Maduración: } \\
\text { febrero („Okitsu') y } \\
\text { julio a agosto } \\
\text { (,Encore") }\end{array}$ \\
\hline
\end{tabular}




\begin{tabular}{|c|c|c|c|c|}
\hline & $\begin{array}{l}\text { apepú, C. reticulata cv. } \\
\text { „Encore } \text {; Stampella, } \\
\text { Cabanillas \& Hilgert } \\
172 \text { (CFS) }\end{array}$ & $\begin{array}{l}\text { redondeada a algo } \\
\text { alargada, pecíolo } \\
\text { pequeño a mediano, } \\
\text { escaso aroma }\end{array}$ & $\begin{array}{l}\text { ombligo pequeño; Cáscara naranja, } \\
\text { mediana, poco corochenta; Gomo dulce; } \\
\text { Mesocarpo desabrido }\end{array}$ & $\begin{array}{l}\text { Maduración: julio a } \\
\text { agosto }\end{array}$ \\
\hline & $\begin{array}{l}\text { Mandarina colorada o } \\
\text { mandarinola, } C \text {. } \\
\text { reticulata } \text { cv. } \\
\text { „Cleopatrac; Stampella, } \\
\text { Cabanillas \& Hilgert } \\
170 \text { (CFS) (Figura 29) }\end{array}$ & $\begin{array}{l}\text { Pequeña a mediana, } \\
\text { alargada a algo } \\
\text { redondeada, pecíolo } \\
\text { pequeño, aroma n/e }\end{array}$ & $\begin{array}{l}\text { Fruto pequeño a mediano, achatado, sin } \\
\text { ombligo; Cáscara naranja oscura, fina a } \\
\text { mediana, lisa; Gomo agridulce (bien } \\
\text { maduras); Mesocarpo desabrido }\end{array}$ & $\begin{array}{l}\text { Pocas espinas, } \\
\text { Maduración: julio a } \\
\text { agosto }\end{array}$ \\
\hline & $\begin{array}{l}\text { Mandarina colorada } \\
\text { chica o japonesa, } C \text {. } \\
\text { reticulata } \text { cv. „Dancy“; } \\
\text { Stampella, Cabanillas } \\
\& \text { Hilgert } 175 \text { (CFS) } \\
\text { (Figura 28) }\end{array}$ & $\begin{array}{l}\text { Pequeña a mediana, } \\
\text { alargada a algo } \\
\text { redondeada, pecíolo } \\
\text { pequeño, aroma dulce } \\
\text { alimonado }\end{array}$ & $\begin{array}{l}\text { Fruto pequeño a mediano, achatado, sin } \\
\text { ombligo; Cáscara naranja, fina, lisa; } \\
\text { Gomo dulce; Mesocarpo desabrido }\end{array}$ & $\begin{array}{l}\text { Pocas espinas, } \\
\text { Maduración: junio a } \\
\text { julio }\end{array}$ \\
\hline & $\begin{array}{l}\text { Mandarina bergamota, } \\
\text { C. reticulata cv. } \\
\text { „Campeona } \text {; Stampella } \\
86 \text { (CFS) (Figura 27) }\end{array}$ & $\begin{array}{l}\text { Mediana, alargada, } \\
\text { pecíolo pequeño, aroma } \\
\text { n/e }\end{array}$ & $\begin{array}{l}\text { Fruto grande, achatado, sin ombligo; } \\
\text { Cáscara naranja, mediana, corochenta; } \\
\text { Gomo dulce y seco; Mesocarpo } \\
\text { desabrido }\end{array}$ & $\begin{array}{l}\text { Pocas espinas, } \\
\text { Maduración: julio a } \\
\text { agosto }\end{array}$ \\
\hline LIMÓN & $\begin{array}{l}\text { Limón o limón } \\
\text { mandarina, Citrus } \times \\
\text { taitensis Risso; } \\
\text { Stampella } 80 \text { (LP) } \\
\text { (Figura 17) }\end{array}$ & $\begin{array}{l}\text { Mediana, redondeada a } \\
\text { algo alargada, peciolo } \\
\text { muy pequeños, aroma } \\
\text { alimonado }\end{array}$ & $\begin{array}{l}\text { Fruto pequeño a mediano, achatado, sin } \\
\text { ombligo; Cáscara naranja oscura a } \\
\text { anaranjada, fina, lisa; Gomo muy agrio; } \\
\text { Mesocarpo desabrido }\end{array}$ & $\begin{array}{l}\text { Espinas medias a } \\
\text { abundantes, } \\
\text { maduración: casi } \\
\text { todo el año } \\
\text { (excepto en verano) }\end{array}$ \\
\hline
\end{tabular}




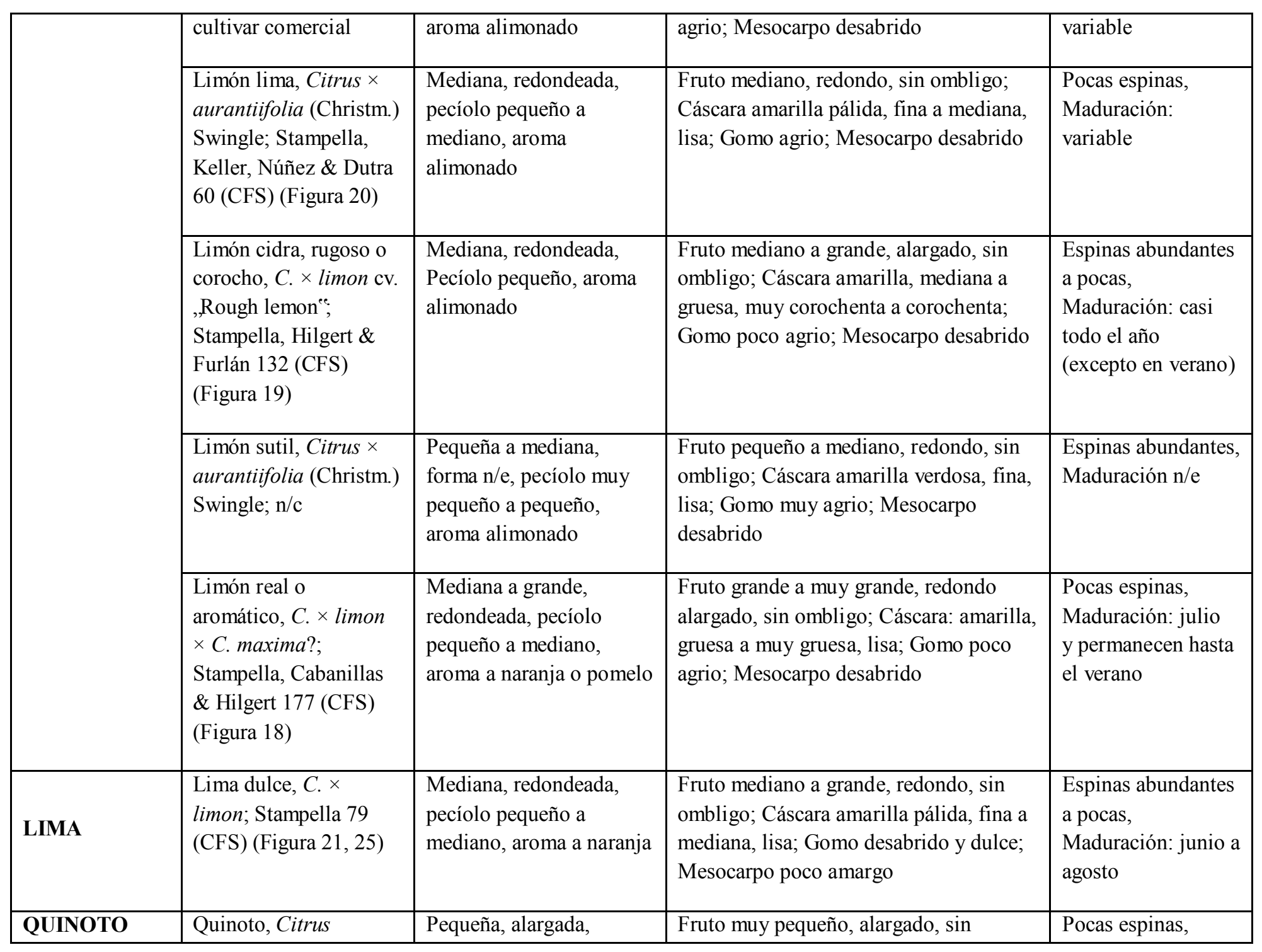




\begin{tabular}{|l|l|l|l|l|}
\hline & $\begin{array}{l}\text { japonica } \text { Thunb.; } \\
\text { Stampella, Hilgert \& } \\
\text { Furlán 150 (CFS) }\end{array}$ & $\begin{array}{l}\text { pecíolo muy pequeño, } \\
\text { aroma n/e }\end{array}$ & $\begin{array}{l}\text { ombligo; Cáscara naranja, fina a } \\
\text { mediana, lisa; Gomo agrio; Mesocarpo } \\
\text { algo dulce }\end{array}$ & $\begin{array}{l}\text { Maduración: mayo } \\
\text { a julio }\end{array}$ \\
\cline { 2 - 5 } & $\begin{array}{l}\text { Quinoto dulce, } C . \\
\text { japonica Thunb. } \\
\text { (Figura 30) }\end{array}$ & $\begin{array}{l}\text { Pequeña, alargada, } \\
\text { pecíolo muy pequeño, } \\
\text { aroma n/e }\end{array}$ & $\begin{array}{l}\text { Fruto muy pequeño, alargado, sin } \\
\text { ombligo; Cáscara naranja, fina a } \\
\text { mediana, lisa; Gomo dulce; Mesocarpo } \\
\text { algo dulce }\end{array}$ & $\begin{array}{l}\text { Pocas espinas, } \\
\text { Maduración: junio a } \\
\text { agosto }\end{array}$ \\
\hline TRIFOLIATA & $\begin{array}{l}\text { Trifoliata, C. trifoliata; } ; \mathrm{c} \\
\mathrm{n} / \mathrm{c}\end{array}$ & $\begin{array}{l}\text { Pequeña, forma como } \\
\text { trébol, pecíolo n/e, aroma } \\
\mathrm{n} / \mathrm{e}\end{array}$ & $\begin{array}{l}\text { Fruto muy pequeño a pequeño, redondo, } \\
\text { sin ombligo; Cáscara amarilla, fina, } \\
\text { peluda; Gomo agrio; Mesocarpo n/e }\end{array}$ & $\begin{array}{l}\text { Espinas muy } \\
\text { abundantes, } \\
\text { Maduración n/e }\end{array}$ \\
\hline
\end{tabular}


Este último carácter presenta categorías muy variables entre los distintos informantes resultando fuerte, suave, feo, lindo, agrio, dulce, alimonado, parecido a una etnovariedad reconocida, o la mayoría de las veces inexpresable, incomunicable). Sin embargo, el olor de las hojas es el carácter más empleado para la identificación de las muditas colectadas del monte (áreas de vegetación espontánea) a mediados del otoño. Cada planta posee un aroma particular que prácticamente todos conocen, relacionado a la cantidad y composición de los aceites esenciales. Algunas de ellas suelen confundirse entre sí, como por ejemplo la "naranja común" con la "lima" o las diversas variedades de "mandarina injertada", exceptuando a la "mandarina común", de aroma fuerte y particular.

En general, para la caracterización de las etnoespecies y etnovariedades, los descriptores son también diversos y están focalizados en el porte de la planta, especialmente en características de frutos y hojas, como también los ambientes donde crecen y la época de maduración (o de disponibilidad) de los frutos. Todas las partes del fruto intervienen en el reconocimiento. El olor del epicarpo, el sabor del mesocarpo y del gomo (endocarpo), la presencia y cantidad de semillas como también la época de maduración y disponibilidad de los frutos.

\section{LIMÓN}

El "limón" fue caracterizado por sus frutos agrios que nunca se tornan dulces al madurar, la forma y el olor de las hojas, y por la coloración violácea de sus brotos (brotes) y flores (pétalos). Esto los diferencia de la "mandarina limón" (que endulza su endocarpo al madurar el fruto) y del "apepú común”, de endocarpo agrio, empleados como acidificantes o condimento y luego como frutas al endulzar el gomo. 
Figura 17. Limón mandarina (Citrus $\times$ taitensis). Ruinas de Santa María la Mayor.

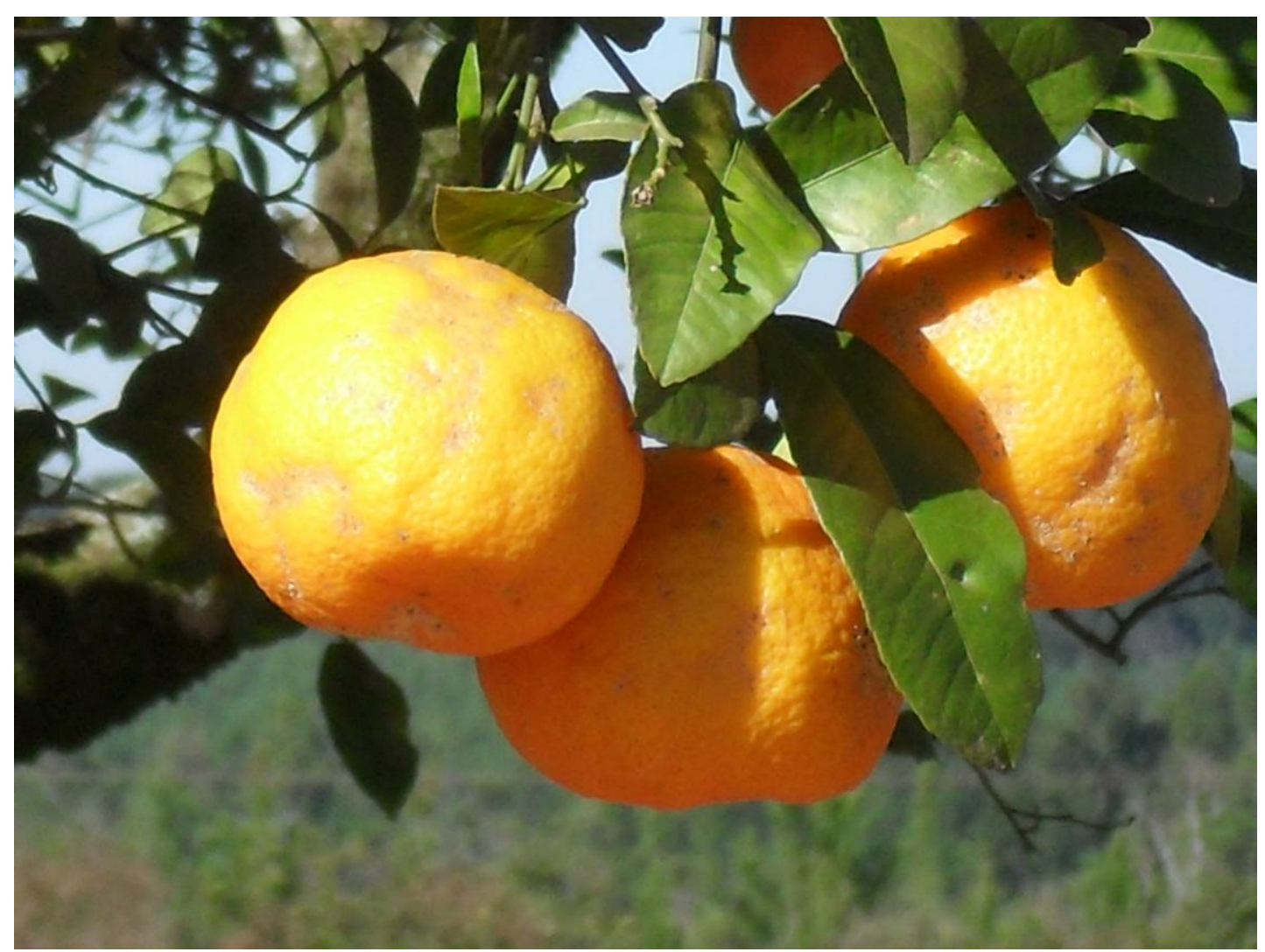

Figura 18. Limón real. Híbrido de Citrus × limon. Teyú Cuaré.

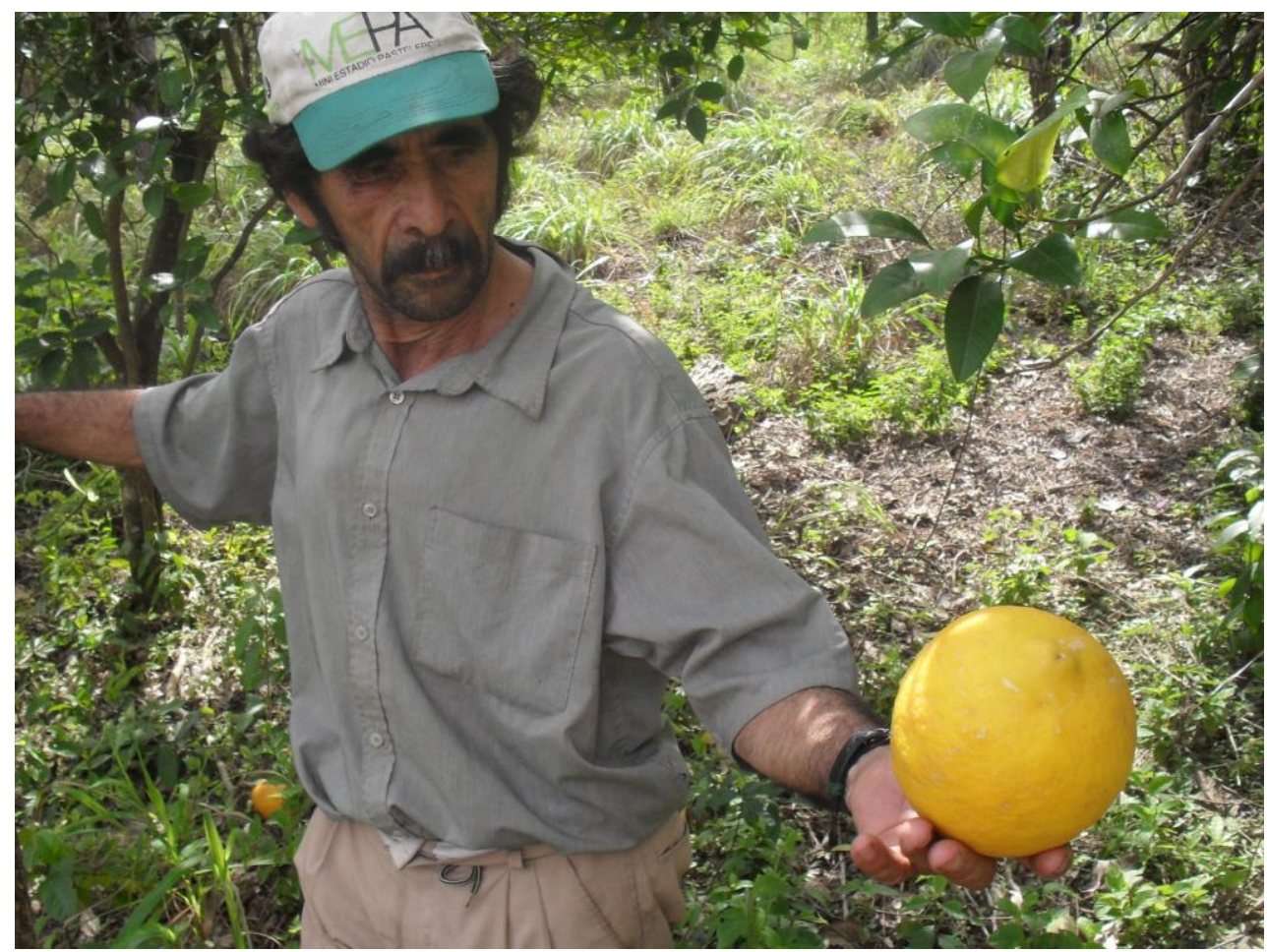


Figura 19. Limón cidra (Citrus $\times$ limon cv. ,Rugoso $)$. Concepción de la Sierra

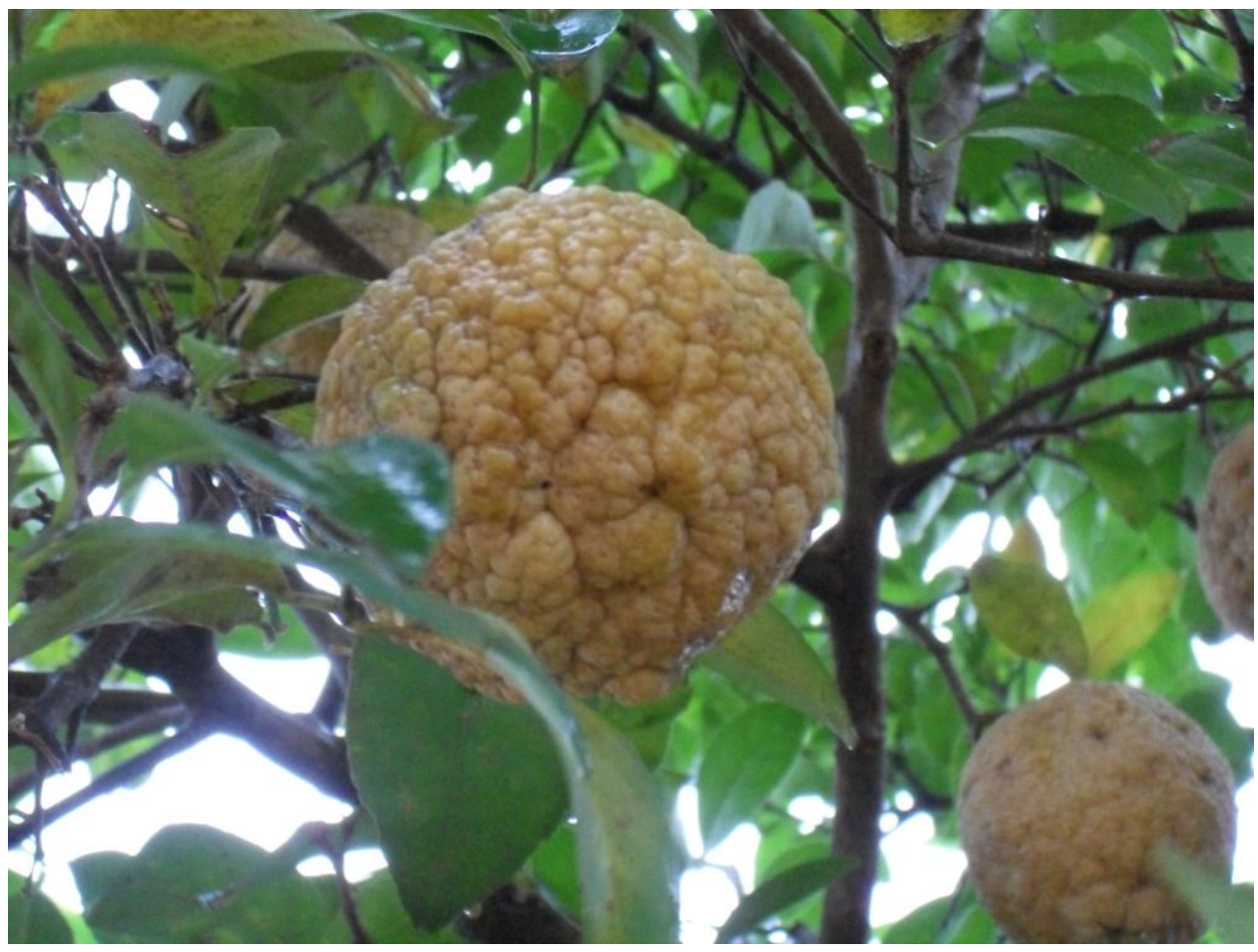

Figura 20. Limón lima (Citrus $\times$ aurantiifolia cv. „Persa“). Nótese el estilo persistente en los frutos. San Ignacio.

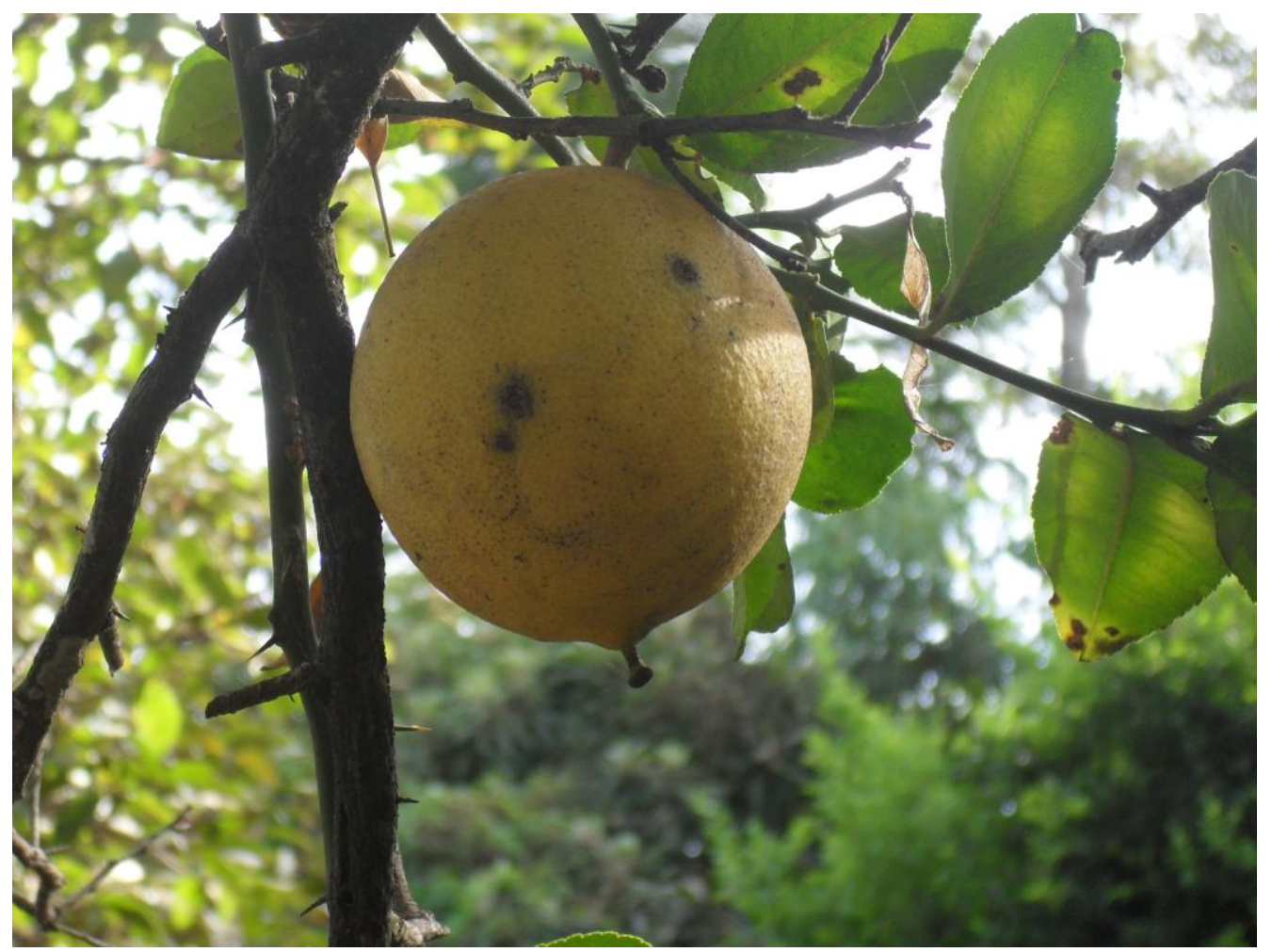


El término "lima", en cambio, es reservado para aquellos cítricos de porte similar al "limón" y con características de "naranja", con olor del follaje confundible con ésta, frutos redondeados, de cáscara amarilla, lisa, y gomo pálido y desabrido a levemente dulce (incluso amargo en algunos ejemplares de mesocarpo adherido). De esta manera, las "limas” de pulpa ácida, pequeñas y grandes $\left(C\right.$. $\times$ aurantiifolia $\mathrm{cv}$. „Key lime ${ }^{\text {ee }}$ „Mexicana ${ }^{e e}$ y cv. „Persa ${ }^{e e}$ (también conocida como C. × latifolia, respectivamente), localmente quedan agrupadas junto a los "limones" debido a su pulpa ácida.

Figura 21. Lima (Citrus $\times$ limon cv. „Lima Palestina“). Cerro Mártires.

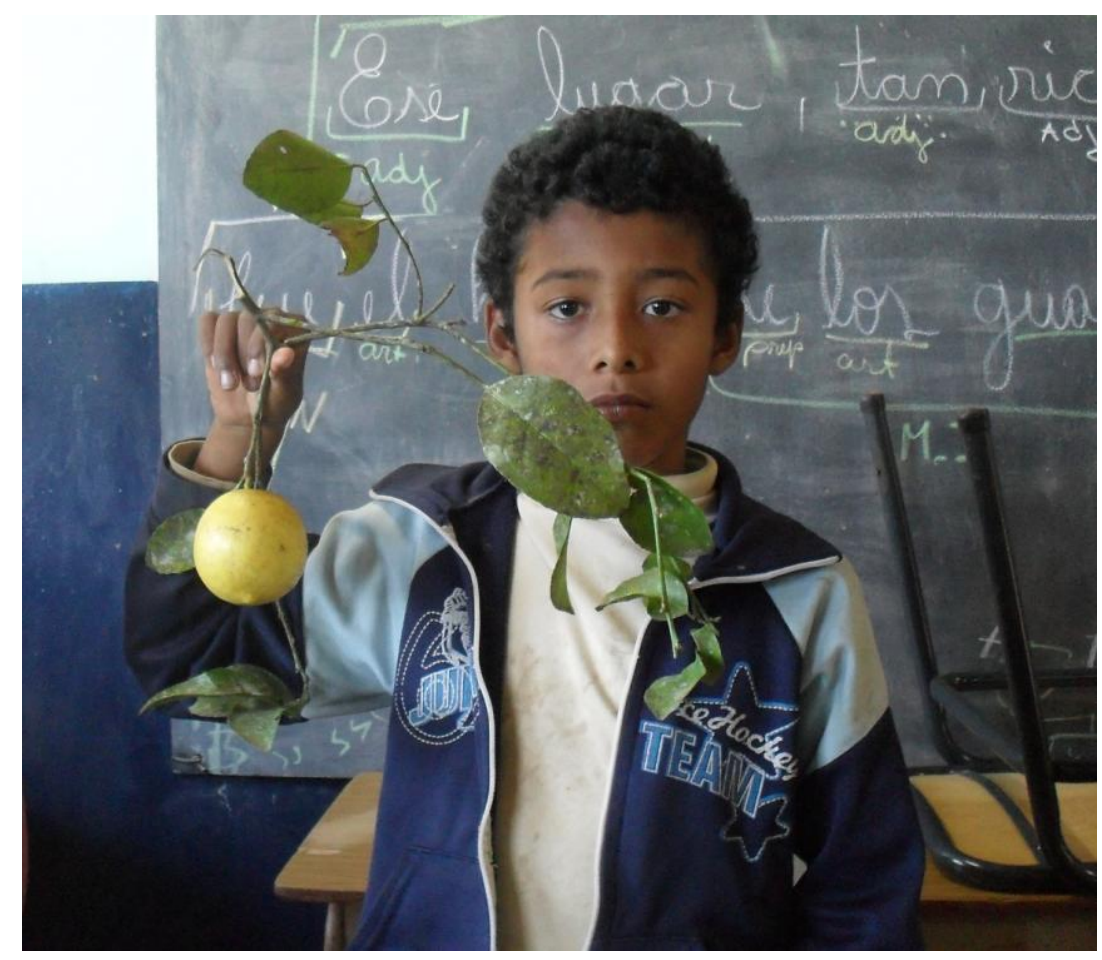

NARANJA

La "naranja" quizá sea la etnoespecie más importante. Es caracterizada por su porte arbóreo, la presencia de espinas largas y abundantes en los ejemplares nacidos de semilla (comunes), el pecíolo levemente alado, y por sus frutos dulces a agrios, de cáscara anaranjada a amarillenta. 
APEPÚ

El "apepú" es caracterizado por el sabor amargo del mesocarpo, el olor fuerte del epicarpo y hojas, y la morfología foliar donde el tamaño de la lámina y el ala del pecíolo son mayores que en la "naranja". El aroma fue descripto como fuerte o catingudo (oloroso) casi siempre en contraposición a la "naranja". El agente emanado del follaje y fruto es referido como gas.

Figura 22. Apepú de monte $($ Citrus $\times$ aurantium $)$. Cerro Mártires.

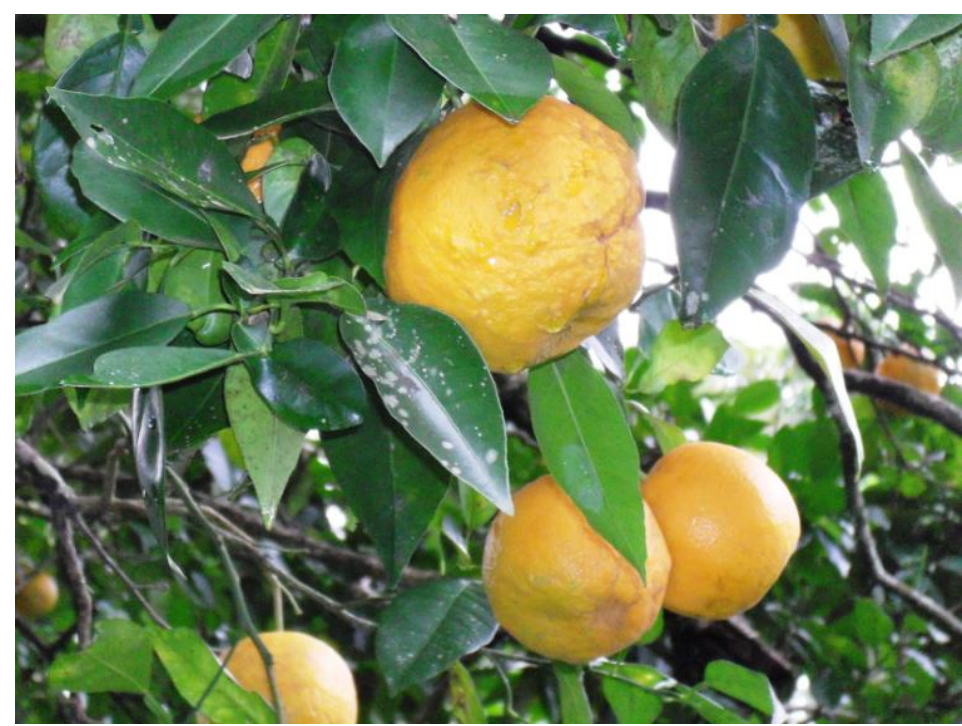

Figura 23. Apepú dulce. Consumida como fruta por los niños en Cerro Mártires.

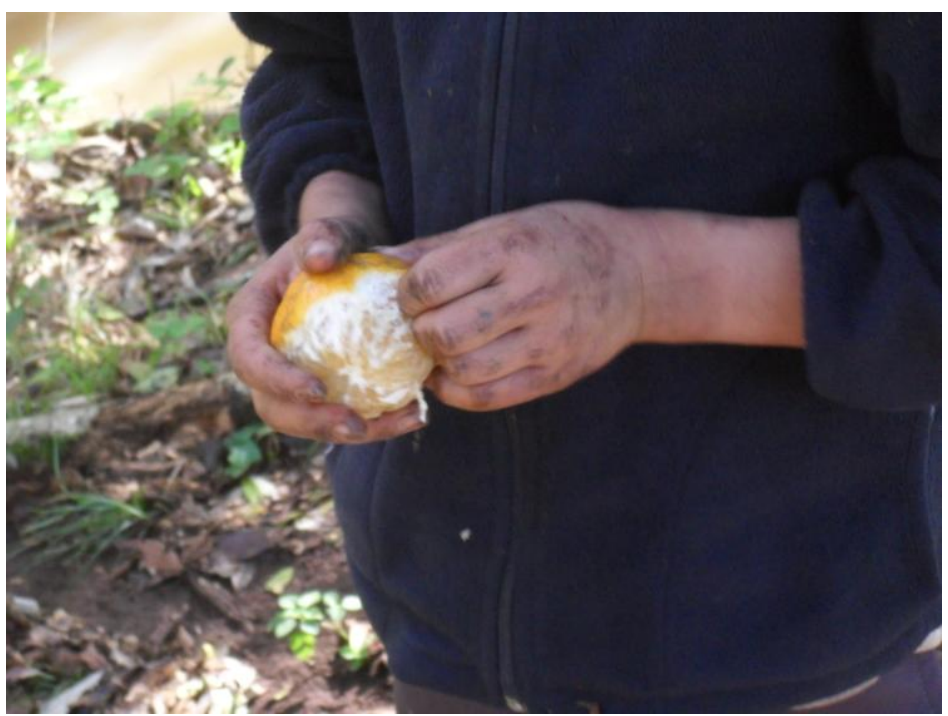


El "pomelo" es asociado a la "naranja" y al "apepú". El porte es un poco mayor al de la "naranja", con hojas, pecíolos y frutos mayores a los de la "naranja" y apepú. El amargor de los frutos (mesocarpo y hollejo) y el grosor del mesocarpo recuerdan al “apepú”.

Figura 24. Pomelo blanco (Citrus $\times$ aurantium). Cerro Mártires.

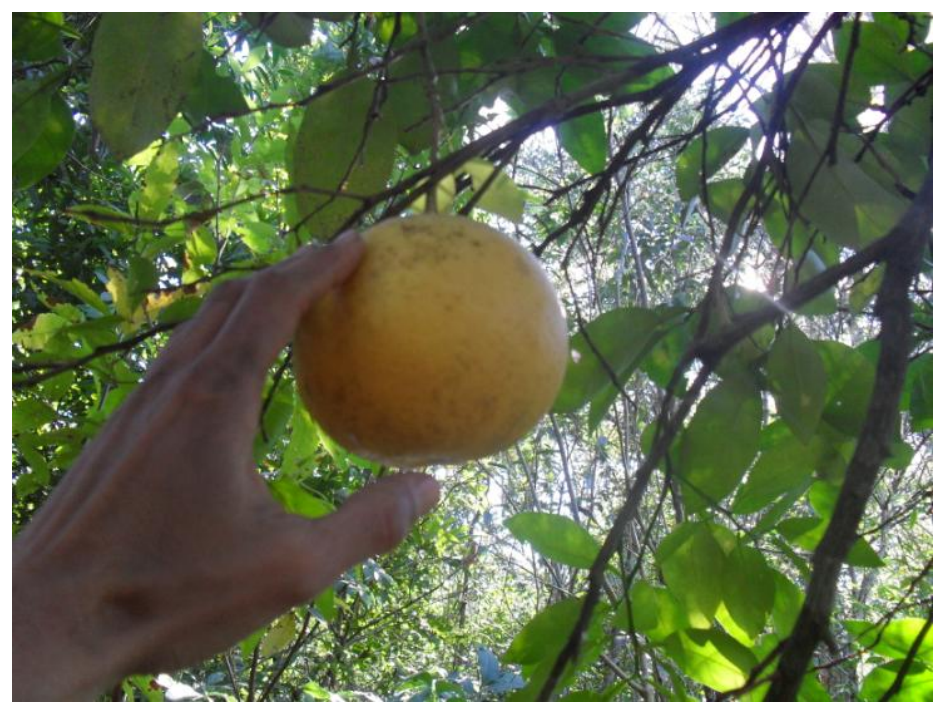

CIDRA

Es similar al pomelo, de porte arbóreo, con flores grandes y blancas. Los frutos son los de mayor tamaño de este género, presentando mesocarpo muy engrosado, amargo, y endocarpo poco jugoso y desabrido.

Figura 25. Frutos varios. De izquierda a derecha: Lima, apepú y Cidra (Citrus maxima).

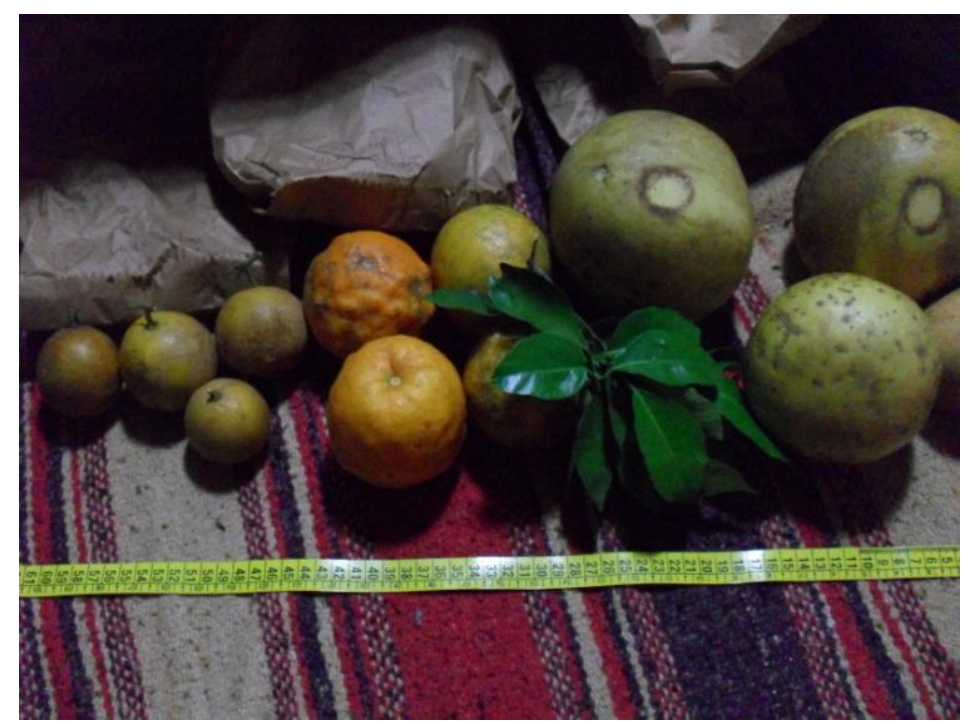


La "mandarina", de porte arbustivo y follaje más denso, presenta hojas más pequeñas y frutos mayormente achatados. Son más resistentes en sitios rocosos, comunes en la zona. El gusto de los frutos fue referido como más dulces que los de "naranja".

Figura 26. Mandarina común (Citrus reticulata). Ruinas de Santa María la Mayor.

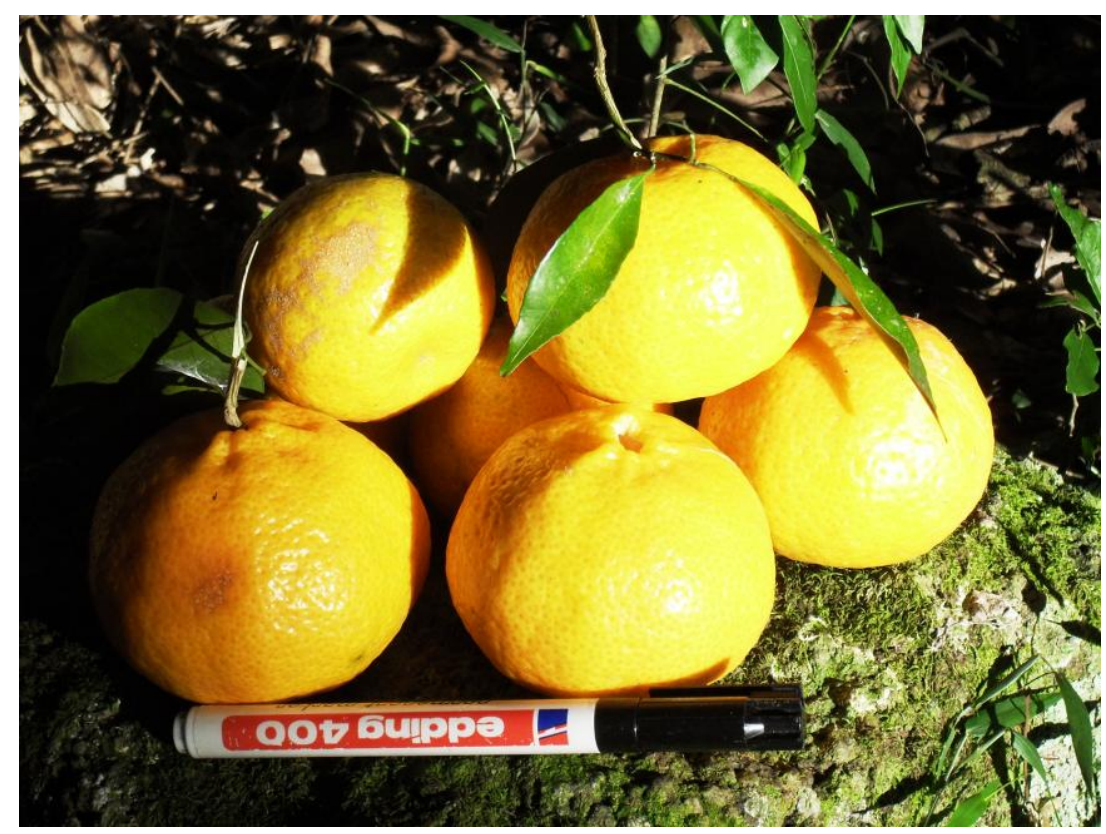

Figura 27. Mandarina bergamota (Citrus reticulata). Caá Guazú, camino a Cerro Mártires.

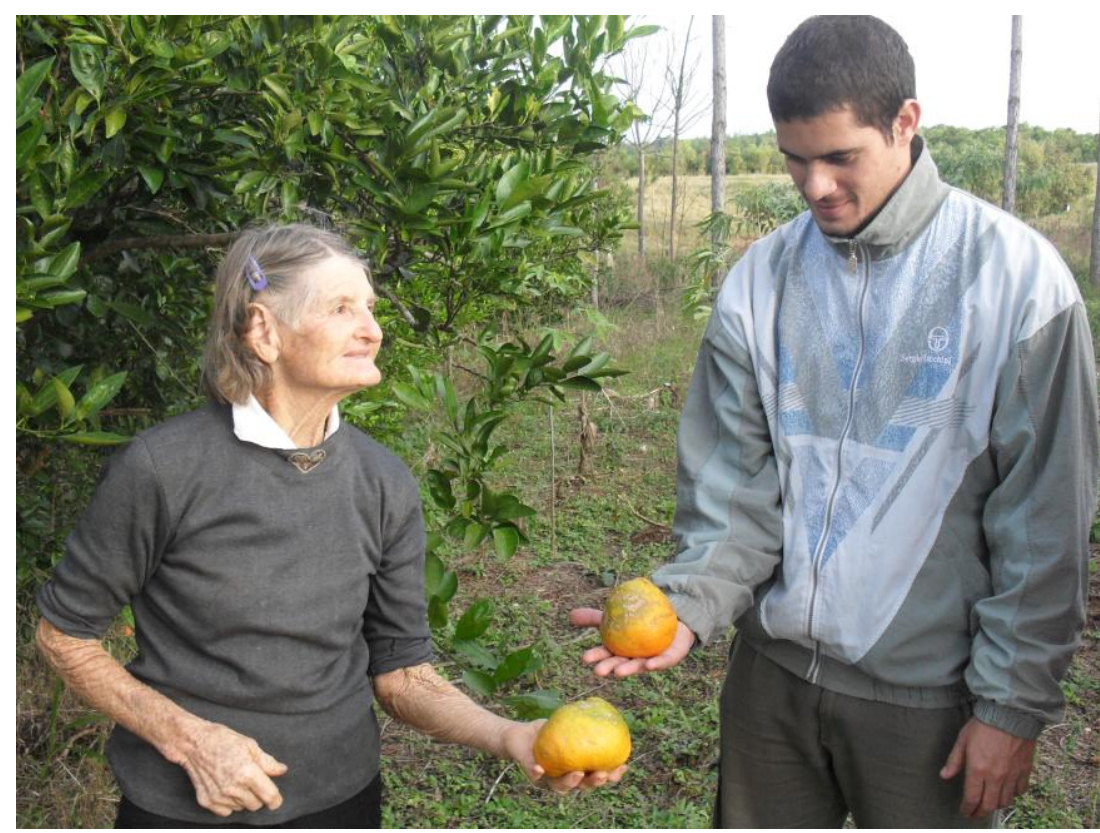


Figura 28. Mandarina colorada japonesa (Citrus reticulata cv. „Dancy“). La Corita.

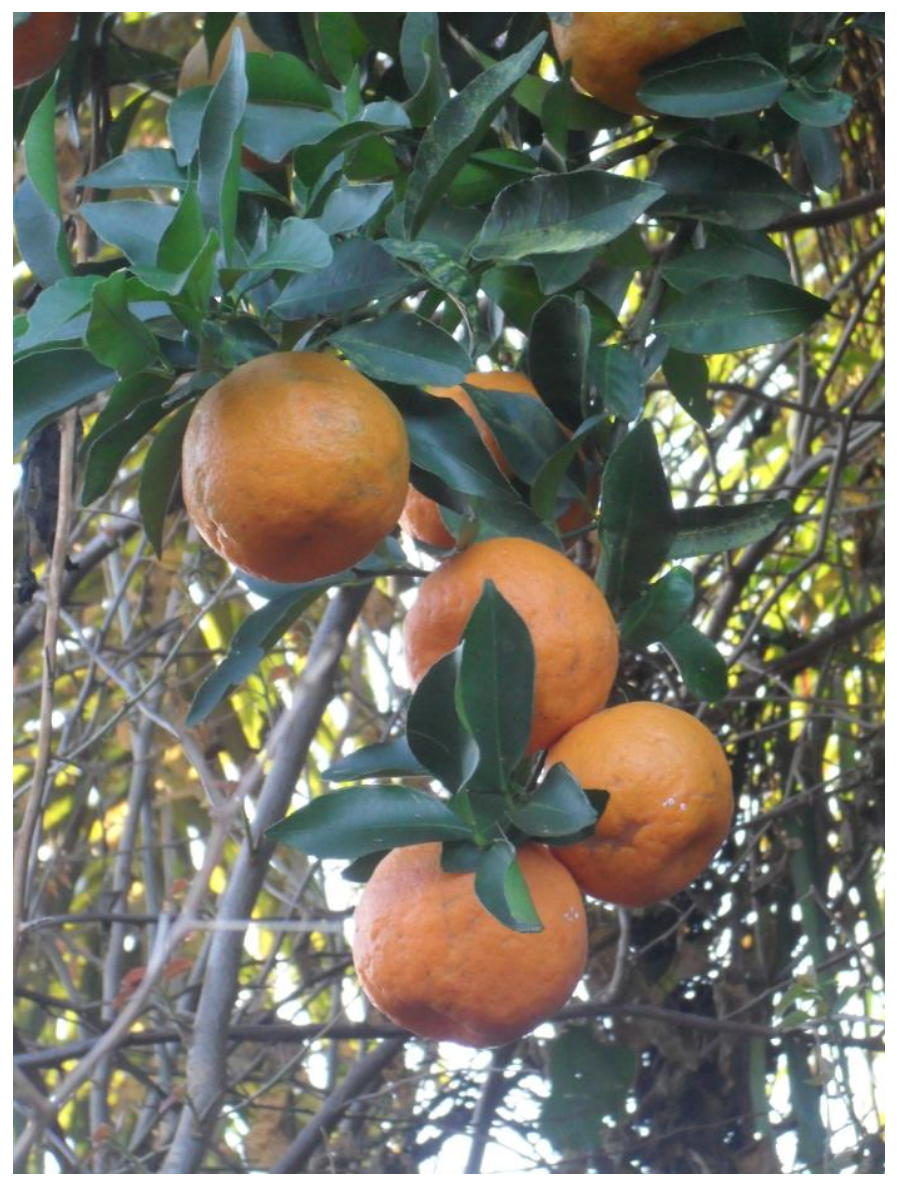

Figura 29. Mandarina colorada o mandarinola (Citrus reticulata cv. „Cleopatra“). Teyú Cuaré

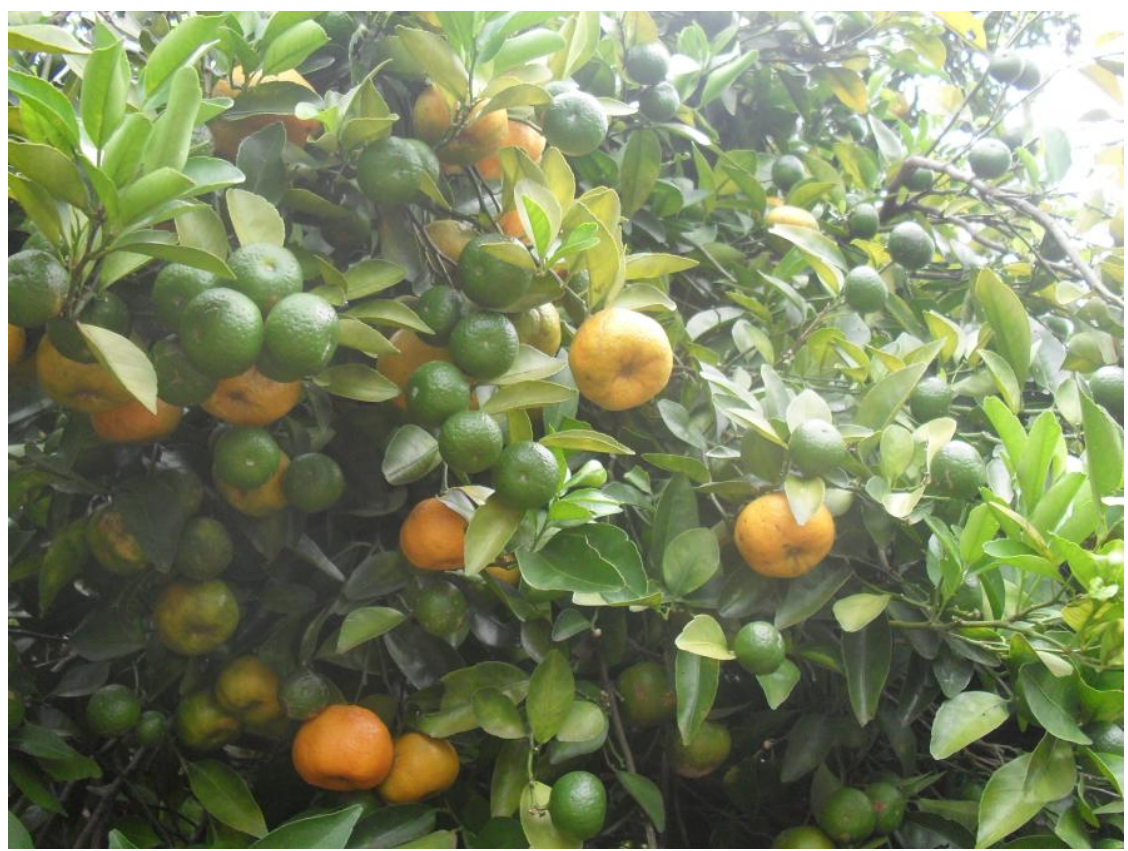


Figura 30. Quinoto dulce (Citrus japonica). Caá Guazú, camino a Cerro Mártires.

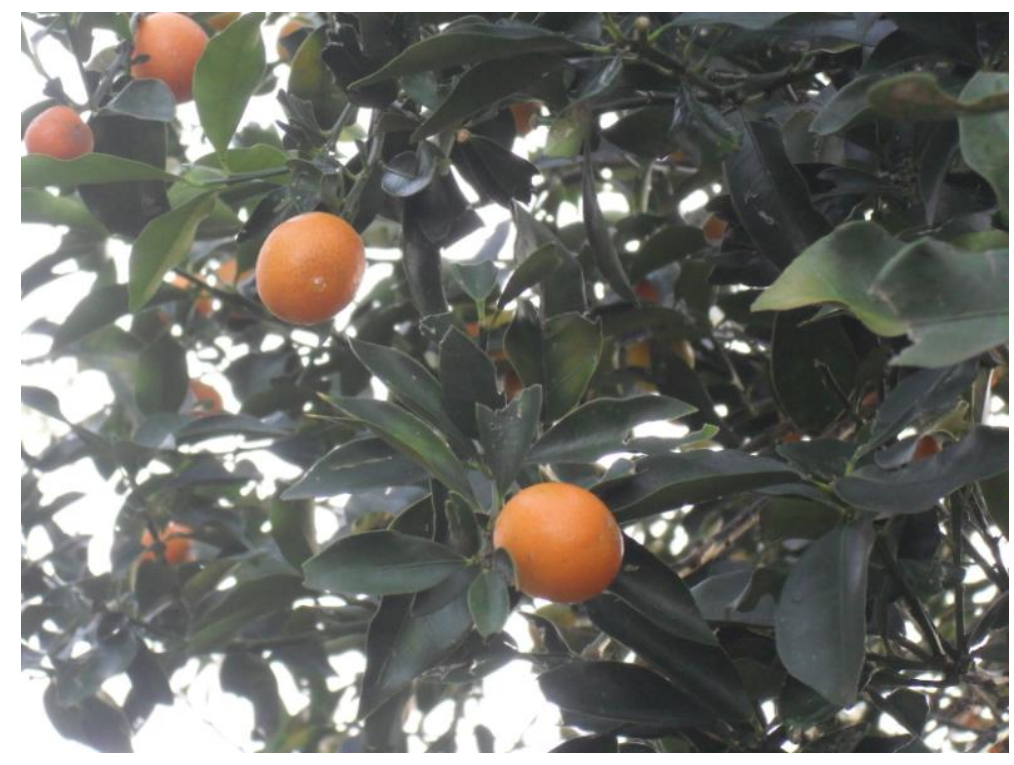

A su vez, estas etnoespecies se suelen agrupar por similitudes. "Naranja”, "apepú", "pomelo", mandarina" y "cidra" se reconocen como familiares -haciendo referencia con este término a su parecido morfológico-organoléptico- y "limón" y "lima" se suelen agrupar por otro lado, difiriendo ambos grupos principalmente en el porte de la planta, coloración de las flores, aroma del follaje y características de los frutos. El "quinoto" y el "trifoliata" constituyen etnoespecies poco conocidas en la zona, lo mismo que la "cidra", asociadas a las familias de colonos.

\subsubsection{Prácticas de manejo y espacialidad en la clasificación de los cítricos}

Transversalmente a los criterios para diferenciar las etnoespecies, todas las etnovariedades son estructuradas en 3 grupos en función a su forma de propagación (rol en el injerto) y luego a su grado de relación con los seres humanos.

Debido a que muy pocos cítricos prosperan mediante esquejes (entre ellos $C$. medica, no relevado en la zona), para la propagación vegetativa de fenotipos con características seleccionadas se realizan injertos. En esta técnica, ampliamente descripta en los libros de citricultura, intervienen la planta que se quiere propagar vegetativamente (de la que se toma una yema o injerto) y el portainjerto. Este último es variable, según el microclima y las características locales del suelo y son obtenidos por germinación de semillas que se siembran en vivero. Con este término se refiere también a varias 
plántulas creciendo bajo la protección de otras plantas arbóreas o de una capuera herbácea y no sólo a una construcción destinada a la cría de plantas. El desarrollo de esta técnica se observó fundamentalmente entre los polacos (término local que refiere en su conjunto a los colonos, sean descendientes de polacos, ucranianos, alemanes, suizos), los operarios de viveros y, con menor frecuencia, entre los criollos. Localmente muy pocos conocen el procedimiento para injertar plantas. Así, el término injerto es empleado indistintamente para referir a la técnica descrita como a los procesos de hibridación (en los cuales se percibe que las abejas son quienes casan o mesturan polinizan $\mathrm{y}$, por lo tanto, muchas veces hibridan- a las plantas). Por lo tanto la etnovariedad “mandarina injerto con apepú” (C. reticulata cv. „Encore") se refiere a una "mandarina" que adquiere características del "apepú" mediante el casamiento (polinización), pero manteniéndose dentro de la etnoespecie "mandarina" debido a la mayor concordancia fenotípica con ésta.

Las plantas propagadas a partir de semillas, que no participan en el injerto, son denominadas comunes (de pie franco, como suelen llamarlas los citricultores) y pueden ser de monte o caseras. Las primeras pertenecen al monte y a los capuerones sucesiones ecológicas que tienden al monte- mientras que las otras al ámbito doméstico (inmediaciones del hogar y zonas de cultivos o cría de ganado). De esta manera, las muditas de "mandarina de monte" colectadas en ese ambiente y plantadas en el jardín pasan a llamarse "mandarina casera".

Dentro del grupo de plantas provenientes de injertos se distinguen dos grupos: los cítricos injertados y los de injerto. Los cítricos injertados son aquellos que han sido injertados por especialistas $-\mathrm{o}$ conocedores de dicha técnica- sobre un portainjerto determinado (usualmente C. trifoliata, $C . \times$ taitensis, $C . \times$ limon, lima dulce ${ }^{e}$ ). Estos ejemplares se adquieren en viveros urbanos, en chacras vecinas o por distribución del INTA.

En cambio, se denomina cítricos de injerto a aquellos empleados como portainjerto de variedades injertadas. Por lo tanto, estos cítricos de injerto, al igual que las etnovariedades comunes, se propagan mediante semillas y comúnmente se vuelven espontáneas. No obstante, las denominaciones de injerto e injertado frecuentemente se emplean indistintamente resultando sinónimos antes que denotadores 


\subsubsection{Usos}

Entre los frutales locales -incluyendo nativos y exóticos, ya que no se ha relevado tal diferenciación en ámbitos rurales y periurbanos- los cítricos ocupan un lugar destacado. El ranking de preferencia acerca de las frutas locales evidencia que dos etnoespecies -la "naranja" y la "mandarina", especialmente las etnovariedades comunes o de gomo dulce- se hallan entre los cuatro frutales preferidos junto a la "banana" (Musa $\times$ paradisiaca L.) y la "ciruela" (Prunus domestica L.), éstas últimas cultivadas y adquiridas en las ferias y mercados de las ciudades, respectivamente.

La palabra fruta es empleada, en general, para los productos de la tierra, sean recolectados o cosechados. Así, varios órganos del cormo de diferentes plantas son denominados fruta. Ejemplos de lo anterior son las raíces de "mandioca" y de "batatera", los frutos de los cítricos y las semillas de "arroz" (Oryza sativa L.), "poroto" (Phaseolus vulgaris L.) y “soja” [Glicine $\max ($ L.) Merr.].

Los cítricos son principalmente empleados como fruta por los niños y jóvenes (la gurisada). Este término gurisada está íntimamente relacionado con la niñez y juventud, las frutas y las agrupaciones. Quienes comen frutas son gurisada, más aún si se movilizan en grupos y tienen por costumbre trepar a los frutales. Comúnmente, la adultez viene acompañada del abandono del consumo de frutas muchas veces adjudicado a dolencias estomacales (úlceras) y dentarias (adormece las encías o afloja los dientes) o a que se trata de cosas de gurisada.

La maduración de los cítricos comunes comienza hacia fines de abril o principios de mayo (mediados del otoño) con la "lima", el "limón", la "mandarina" y la "naranja", y luego continúan el "pomelo" y el "apepú” y por último las "mandarinas coloradas". Para la cuenca paranaense se recomienda consumir las "naranjas" después de Semana Santa, asegurando que luego de esta festividad "se mata un diablito" (Keller, com. pers.). Esta restricción es poco cumplida ya que mucho antes de tal festividad puede observarse a la gurisada sacando mandarinas pintonas -es decir casi maduras, aunque con cáscaras verdosas y aún ácidas- de las plantas cercanas al hogar (Figura 31), práctica condenada por algunos adultos, a la que adjudican diversas dolencias estomacales. 
Figura 31. Consumo de mandarinas inmaduras. Cerro Mártires.

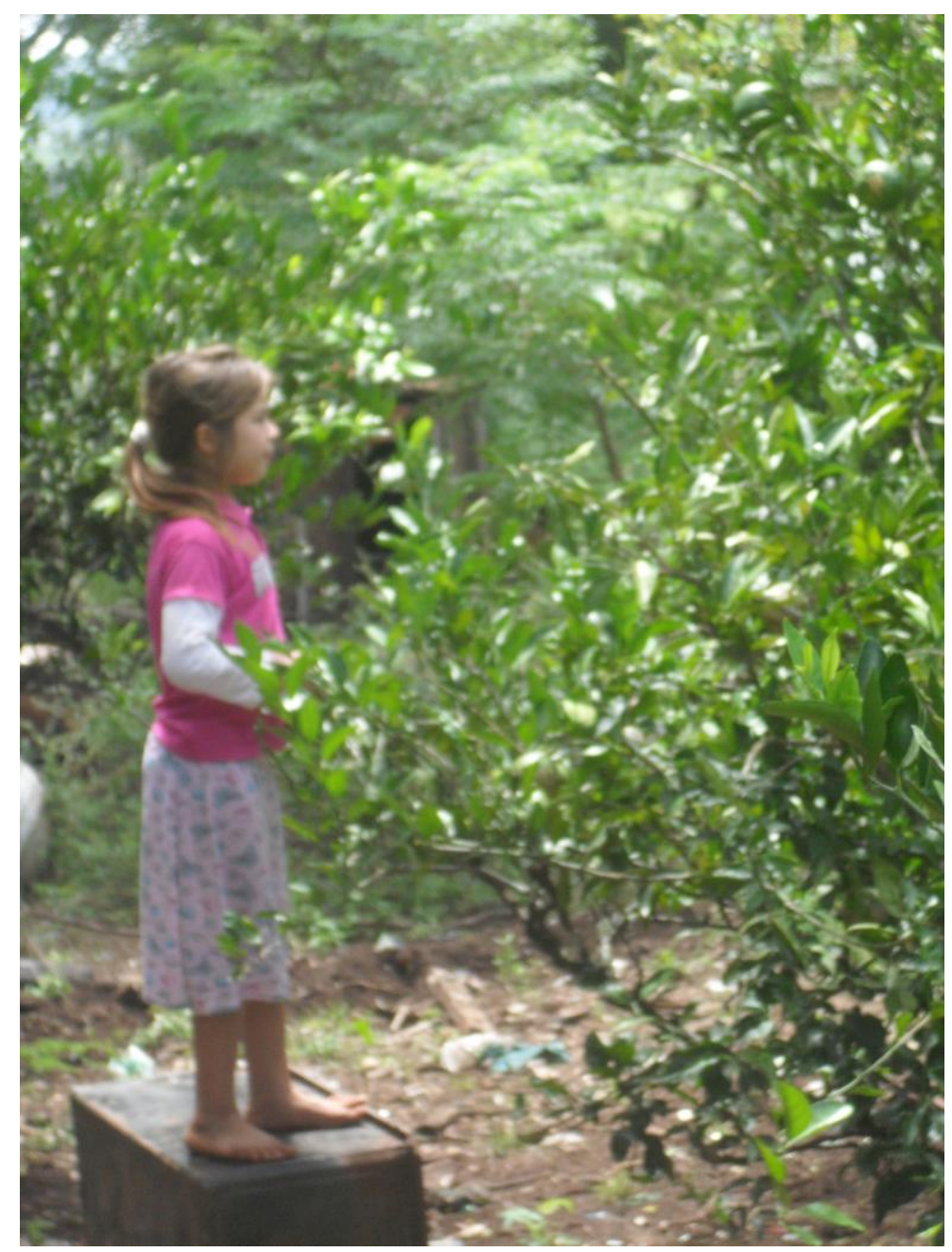

Los cítricos presentan una gran diversidad de usos en la zona. El gomo de las variedades dulces y agridulces es empleado como fruta y golosina por los niños, quienes conocen la ubicación de las plantas más preciadas así como su marcha de maduración en los distintos ambientes. El jugo exprimido se emplea como bebida refrescante, siendo más comunes los de "naranja" (naranjada), "limón" (limonada), "mandarina", "lima” y "pomelo". La misma preparación es empleada para cebar tereré, una bebida refrescante (fría o no) típica de la región preparada en un recipiente con "yerba mate" (Ilex paraguariensis) y hierbas medicinales, con pequeñas variantes a las descriptas por Amat \& Yajía (1991). Suelen emplearse localmente, especialmente en Teyú Cuaré, los tallos y hojas de "capiquí" (Parietaria debilis G. Forst.), hojas de "pitanga" (Eugenia uniflora L.), “bacún” o "cocú” [Allophyllus edulis (A. St.-Hil., A. Juss. \& Cambess.) Hieron. ex Niederl. y A. guaraniticus (A. St.-Hil.) Radlk.], “cangorosa” (Maytenus ilicifolia Mart. ex Reissek), y hojas y flores de "cedrón” o "niño rupá” [Aloysia 
gratissima (Gillies \& Hook. ex. Hook.) Tronc. y A. virgata (Ruiz \& Pav.) Pers.]. Los adultos suelen agregar "sipó milome" o "milhombres" (Aristolochia sp.), famosa por su amplia gama de atributos que varían desde la limpieza de la sangre a su empleo como anticonceptivo y abortivo. El jugo del limón es empleado para conservar "duraznos". Debido a la rápida maduración de estas frutas, los mismos son cosechados, pelados y guardados en el freezer con azúcar y jugo de limón para que no se oxiden.

Los frutos de "cidra", "pomelo cidra" y "pomelo" son empleados como recipiente para tomar tereré. Para ello, se corta la parte superior del fruto (donde está el cabito o pedúnculo) y se ahueca parcialmente el gomo con un cuchillo. Se vierte "yerba" y se ceba con agua fría o caliente - esta última más empleada con fines medicinalesapretando de vez en cuando para que suelte el jugo.

La piel (epicarpo) del "limón cidra" y del "limón amarillo" es empleada como saborizante para tortas y budines, se incorpora la ralladura en la preparación. La cáscara (epicarpo y mesocarpo) de los frutos de "naranja", "apepú", "limón real”, "cidra" y "pomelo" es empleada por los descendientes de colonos polacos y ucranianos en la elaboración de confituras para pan dulce y tortas. Más popular y difundido en la zona es el dulce de oreja, elaborado con la pelusa (albedo o mesocarpo) de la cáscara de los frutos de "apepú" y a veces con los de "cidra", "pomelo cidra" y "limón cidra". Las recetas relevadas varían en unos pocos aspectos pero en general se trata de la separación de las orejas (la pelusa cortada en dos planos perpendiculares radiales) de la piel y del gomo; la extracción acuosa de los compuestos amargos del gomo (flavonoides) y la cocción en una solución azucarada. Estos procesos varían según los enclaves y las familias. Se seleccionan los frutos de cáscara más gruesa, no demasiado maduros, ya que la maduración va agotando la pelusa, principal materia prima. La eliminación de la piel se efectúa mediante un cuchillo afilado o por raspado en un rallador o superficie abrasiva, mientras que el gomo es quitado fácilmente debido a la poca adherencia del mismo a la cáscara en los frutos de esta etnoespecie. La extracción de los compuestos amargos es realizada ya sea colocando las orejas en bolsas arpilleras en un curso de agua, o dejándolas en un recipiente con agua la cual se cambia todos los días. Ambos métodos se extienden por un lapso de 3 a 7 días, según las familias. La cocción se realiza en una olla con guarapa (miel de caña) o almíbar durante algunas horas sin revolver demasiado para que no se rompan las orejas. Se almacenan en frascos o toneles pudiendo agregársele clavo o canela como saborizantes y conservantes. Los informantes 
más añosos se refirieron al dulce de oreja como un postre muy común en otros tiempos en fiestas y reuniones como bodas o cumpleaños.

La piel y el jugo son empleados en la preparación de bebidas alcohólicas. El yaquico, de amplia distribución entre los tareferos (empleados temporarios en la cosecha de la yerba mate), es una bebida elaborada con caña o alcohol medicinal, agua, cáscaras de "limón" o "apepú" y azúcar. Estas bebidas espirituosas, especialmente los licores, también son elaboradas por los descendientes de los colonos para la venta artesanal. No se han relevado bebidas destiladas en base a frutos de cítricos como las descriptas por Horacio Quiroga en el cuento "Los destiladores de naranja" publicado hacia fines de 1923, quedando este proceso relegado fundamentalmente al espíritu de caña (alcohol de azúcar) y a la "citronella" o "cedrón” [Cymbopogon citratus (DC.) Stapf].

El jugo de las variedades ácidas es empleado como condimento para ensaladas y carnes asadas. En la cuenca del río Paraná, el jugo de "apepú" es empleado para condimentar carnes de cerdo, confiriéndole un tostado y sabor característico (Keller, com. pers.). El "limón mandarina", en cambio tiene un uso más generalizado en carnes vacunas, de caza y pescados.

Prácticamente todos los cultivares comunes son empleados con fines medicinales para prevención y tratamientos de distintas dolencias, principalmente gripales, digestivas y respiratorias; siendo las partes de las plantas, formas y vías de administración también variadas (Hilgert et al., 2013). Estos aspectos relacionados al uso medicinal de los cítricos serán abordados en el capítulo 5.4.

Los cítricos también son empleados en la planificación del jardín inmediato al hogar donde cumplen múltiples funciones a la vez. Su sombra fresca es aprovechada durante el obligado descanso de la siesta, para reposar y tomar tereré, constituyendo -al igual que el "araticú" (Rollinia emarginata Schltdl.)- verdaderos microambientes donde la sensación térmica desciende varios grados y que, para refrescarse, sólo basta alzar el brazo y alcanzar algunos frutos. Casi en desuso pueden apreciarse algunos montes frutales donde se cultivan las variedades comunes e injertadas de cítricos junto a "durazno", "mango" (Mangifera indica L.), "palta" (Persea americana Mill.), "banana", “mamón” (Carica papaya L.), "guayaba” (Psidium guajaba L.), y frutales de monte como "pitanga", "guabiyú" [Myrcianthes pungens (O. Berg) D. Legrand], "guabirova" (Campomanesia xanthocarpa O. Berg), "siete capotes" [C. guazumifolia 
(Cambess.) O. Berg], "guayaba de monte" [Hexachlamys edulis (O. Berg) Kausel \& D. Legrand] y "araticú".

En las costas del Paraná, en Teyú Cuaré se ha relevado el uso de las cáscaras de "naranja", "apepú" y "mandarina" como cebo en anzuelos para pescar "pacú" (Piaractus mesopotamicus E. Holmb.). Para cazar "paca" (Cuniculus paca L.), “cutiá" (Dasyprocta azarae Lichtenstein) y "tatú” (varias especies de Dasypodidae), se colectan frutos de "apepú" o "naranja" y se hace un montículo en un lugar cercano a un arroyo. La presa es esperada a cierta distancia sobre un árbol o enramada desde donde se dispara.

\subsubsection{DISCUSIÓN}

Los "criollos" de los enclaves rurales del sur de Misiones pueden ser incluidos en el repertorio de sociedades tradicionales en el sentido de la riqueza de conocimientos, creencias y prácticas que se ponen en juego en la vinculación con el entorno, plasmados en la estrategia de uso múltiple de los bienes comunes (Toledo, 2002). Su profundidad histórica en la zona se pierde en el tiempo ya que reflejan una síntesis de diferentes culturas, de las cuales toman conocimientos, prácticas y algunas creencias. Asimismo, mantienen prácticas sustentables no ligadas al uso de derivados de hidrocarburos y caracterizadas por la alta agrobiodiversidad tanto a nivel específico como de variedades, siendo la fuerza de trabajo los habitantes de la UD.

Las etnovariedades más frecuentes en la zona en estudio son el "limón mandarina", la "mandarina común", la "naranja común", y luego el "pomelo blanco", la "lima" y el "apepú". Según los relatos de los informantes, las etnoespecies "cidra" y "apepú" actualmente son menos variables que en el pasado debido a su desuso. El empleo preponderante del "trifoliata" como portainjerto "universal" y el cambio en las tradiciones culinarias, medicinales locales y de mercado -la baja en la producción de aceites esenciales de "petit-grain" y "nerolí" para exportación- son algunas de las causas. Otras etnovariedades como el "limón mandarina" y la "mandarina colorada", tienen una historia relativamente reciente en la zona, no obstante se encuentran apropiadas, resignificadas (nuevas denominaciones locales) y ampliamente representadas en los saberes locales (Stampella et al., 2013b, d). 
Algunas denominaciones pueden llevar a confusión al comparar con la nomenclatura citrícola. La etnoespecie "cidra" referida a C. maxima puede confundirse con el "cidro", no presente en la zona como tal sino "diluido genéticamente" en el "limón cidra", siendo más conocida en otros enclaves hispanohablantes como "pampelmusa", "toronja" o "zamboa". De hecho, hacia principios del siglo XVI, C. medica y $C$. maxima eran llamados "toronja" indistintamente (Ramón-Laca, 2003) pudiendo esta confusión persistir desde el siglo XVI o siendo traída por los inmigrantes del siglo XIX. El "apepú" es también llamado "naranja amarga" o "naranja agria", aludiendo al sabor del mesocarpo y endocarpo, respectivamente, pero no considerado como una nominación secundaria sino como una categoría primaria compleja y por lo tanto diferente a "naranja" (Berlin, 1992: 27-28). Con respecto a las "limas", comúnmente diferenciadas en la literatura citrícola en "agrias" y "dulces" -y las primeras por tamaño- (Swingle \& Reece, 1967; Palacios, 1978), se reservan sólo para las variedades "dulces" (en realidad carentes de ácido cítrico) quedando las "ácidas" agrupadas en la etnoespecie "limón" debido a la acidez de sus frutos, evidenciando la importancia de la percepción gustativa en la caracterización de la etnoespecie "limón".

La clasificación de la variabilidad es difusa y generalmente se emplean conjuntamente varios descriptores que varían entre las distintas UD y épocas del año. Esto puede relacionarse a la gran variabilidad fenotípica debida a procesos de hibridación entre la mayoría de las etnovariedades, como también a los diferentes contextos en que se realizan las agrupaciones y por los conocimientos individuales de los pobladores (Capparelli et al., 2011; Zamudio, 2012). Las clasificaciones son construidas jerárquicamente (dimensión vertical), en reglas generales de acuerdo a los principios propuestos por Berlin (1992), ya que todas las etnoespecies pertenecen a los "citrus", "cítricos" o "parientes de la naranja", luego las etnovariedades son agrupadas en las distintas etnoespecies, y así sucesivamente. De esta manera, podemos ver que la "naranja" es la etnoespecie que agrupa y relaciona a las demás. Al interior de las etnoespecies desaparecen los límites precisos entre las mismas -en los cítricos más agudizado debido a las particularidades reproductivas mencionadas- conglomerando una amplia variabilidad de formas alrededor de una etnovariedad prototípica. En el sentido de Rosch (1978), un prototipo es un ejemplar que mejor expresa los atributos que definen al dominio, al cual los demás ejemplares son asociados, es decir, un punto de referencia cognitivo. De esta manera, al interior de las etnoespecies las variedades 
comunes son consideradas prototípicas, presentando dicha distinción en su nomenclatura al igual que algunos himenópteros como el "exú-verdadeiro", Brachygastra lecheguana (Vespidae: Epiponini) de los Pankararé del NE de Brasil (Costa-Neto, 1998). Sin embargo, no siempre la nomenclatura refleja a los taxa prototípicos, tal como ha sido descripto por Zamudio (2012) en la clasificación de las abejas sin aguijón por los criollos del norte de Misiones.

Asimismo, es de destacar la convergencia entre la clasificación relevada localmente y la propuesta por Scora (1975), ampliada luego por Mabberley (1997, 2004), especialmente en lo que refiere al grupo de $C$. $\times$ aurantium y parentales $(C$. maxima y $C$. reticulata). Sin embargo, C. maxima y C. reticulata son percibidos localmente como variaciones de este grupo antes que parentales, reflejando quizá la mayor importancia de la "naranja" en la cotidianeidad. Hacia fines de siglo XIX la "mandarina", inclusive, es denominada "naranja mandarina" por los naturalistas que recorrieron el NE argentino (Hieronymus, 1882; Burmeister, 1899).

El modelo de "Pool de Genes" presentado por Harlan (1992) resulta de suma utilidad al contemplar los distintos grados de barreras al cruzamiento de las variedades. En el mismo se contemplan tres Pooles de Genes (PG): PG Primario, que se corresponde con el concepto de especies biológicas y está caracterizado por plantas con cruzamientos frecuentes, híbridos fértiles y segregación génica normal; PG Secundario, que incluye las especies biológicas que pueden cruzarse con el cultivo pero los híbridos tienden a ser estériles y con segregación génica pobre; y PG Terciario, donde las cruzas tienden a ser anómalas, letales o completamente estériles, siendo característico de los híbridos complejos. Para los cítricos, esto puede ejemplificarse con la "mandarina común" ( $C$. reticulata) de la siguiente manera. El PG-1 correspondería a las etnovariedades cultivadas (caseras) y espontáneas (de monte); mientras que el PG-2: estaría representado por los taxa híbridos producto de la hibridación entre C. reticulata con $C$. medica $(C . \times$ taitensis $)$ y con $C . \times$ aurantium [naranja, pomelo, apepú]. Por último, el PG-3: está representado por cruces híbridos complejos o híbridos generados mediante ingeniería genética, como el "quinoto mandarina", Citrus $\times$ georgiana Mabberley "Citrangequat ${ }^{e e}[$ C. trifoliata $\times C$. $\times$ aurantium $\times$ C. japonica Thunb.], que deben propagarse obligadamente mediante injertos. 
Los caracteres organolépticos sensoriales constituyen un campo poco estudiado debido a la disparidad de categorizaciones locales e incluso personales, lo cual dificulta los estudios comparativos. No obstante son ampliamente empleados en contextos tradicionales y en trabajos científicos donde prima la determinación a campo o proveniente de materiales vegetales estériles (Cunningham, 2001; Molares, 2010). En este caso, el gusto ácido caracteriza la etnoespecie "limón", agrupando variedades que más se asemejan a "mandarinas" de endocarpo ácido $(C . \times$ taitensis $)$ e incluso a las "limas ácidas" (pequeña y grande, $C . \times$ aurantiifolia). El gusto también está presente en la diferenciación de las etnovariedades: "apepú" (casera y dulce) y "quinoto" (común y dulce). Estudios sobre la taxonomía Aymara de "papas" (Solanum spp.) y de variedades tradicionales sudamericanas de "cassava" (o "mandioca", M. esculenta) da como resultado la diferenciación en dos grupos de variedades en base al gusto. Los Aymara designan lug 'i (amargas) y ch'oke (no amargas), a las variedades de "papa" en relación al contenido de glucoalcaloides (Johns, 1989), y las "mandiocas" en amargas (también brava) y dulces (macaxeira), en relación al contenido de glucósidos cianogenéticos (Elias et al., 2004; Peroni et al., 2007).

La imposibilidad de describir y comunicar las categorías organolépticas no morfológicas (sabor y aroma) parece estar relacionada al aprendizaje a temprana edad en prácticas compartidas (observación, imitación) junto a padres, abuelos y otros adultos. Algunos autores se refieren al "saber cómo" (know how) como la manera en que operamos (espontaneidad) ante una situación dada no estando constituido por abstracciones o juicios racionales (Eyssartier, 2011). El gusto y el olfato constituyen valiosas herramientas para la prospección de nuevas plantas medicinales, como elementos nemotécnicos importantes -junto a factores ecológicos y culturales- en la transmisión del conocimiento etnomédico (Molares, 2010) y, para el caso de los cítricos y otros frutales aromáticos, en el reconocimiento de etnoespecies e incluso etnovariedades al estado de plántula o en ejemplares desprovistos de frutos.

En los tratados de cítricos de los siglos XVII-XIX puede rastrearse el empleo de los términos "vulgare", "vulgaris", "franc", "ordinaire", "sauvage" y "silvestre" (Ferrari, 1646; Commelyn, 1683; Volkamer, 1708-1714; Risso \& Poiteau, 1818-1822), empleados indistintamente para designar a los cítricos prototípicos, que no han sido seleccionados. Las demás variedades, mucho más cuantiosas, son detalladas con epítetos que aluden a su origen geográfico (de la China, de Malta, Calabrés) y a 
características organolépticas específicas (bicolor, de flores dobles, de fruto dulce), entre otros.

Al comparar las características entre las etnovariedades comunes y las de injerto, se observa que se diferencian principalmente por la profundidad temporal -introducidas a partir del siglo XVI y hacia mediados del siglo pasado, respectivamente- seguido luego en menor importancia el modo de propagación y los ambientes donde prosperan. El uso indistinto de los términos "hibridación" e "injerto", indagados en las historias locales, pueden rastrearse en los escritos de Nicolás Monardes en el siglo XVI -traducidos por Fernández González \& Ramón-Laca (2002: 161) donde él mismo explica en una carta a un amigo la diversificación de los cítricos mediante el injerto.

Estos grupos de etnovariedades definidos en base a su participación en el injerto, se asemejan a los propuestos por Lambaré \& Pochettino (2012) para P. persica en base a caracteres comunes y seleccionados de acuerdo a distintos criterios morfológicos, organolépticos y fenológicos. Sin embargo, a diferencia de lo planteado por estas autoras no se hallan caracterizados por criterios de semejanza morfológica sino por prácticas de manejo que inciden en la propagación de las variedades. La diversidad de usos y de variedades es menor debido, quizá, a que la Quebrada Humahuaca no es propicia a la "naturalización" de los "duraznos", por lo cual la variabilidad representada se remite a la cultivada en los "rastrojos" y alrededores del hogar.

Las etnovariedades injertadas incluyen varios cultivares comerciales que han sido redefinidos localmente en su denominación. Por ejemplo, C. reticulata cv. „Encore es conocida como "mandarina injerto con apepú" debido a la forma del fruto, color y rugosidad de la cáscara. La “mandarina japonesa” se trata de C. reticulata cv. „Okitsu“ perteneciente a las mandarinas tempranas aseminadas (,Satsuma'), usualmente cultivadas por comunidades japonesas en Misiones, aunque también se designa con ese nombre a C. reticulata cv. „Dancy ${ }^{e e}$ En cambio, las etnovariedades comunes y de injerto son más variables, coincidiendo con la diversidad de usos y posibilidad de cultivo.

A pesar de tratarse de plantas exóticas se ha constatado una alta diversidad de usos para los cítricos en la zona en estudio. El empleo de los frutos de "cidra" y "pomelo", como recipientes para tereré y mate caliente y la elaboración del "dulce de oreja", no habían sido citados en la bibliografía con ese nombre. Sin embargo, en Haití se elaboraban conservas con el mesocarpo de la "naranja amarga" aunque ya ha sido desplazada por el 
"chadeque" (C. maxima) (Paul \& Cox, 1995). El mismo constituye un ejemplo de procesos de detoxificación o de eliminación de compuestos impalatables -en este caso los flavonoides amargos- mediante el lavado en agua, algo similar a lo descripto por Lancaster et al. (1982) para los compuestos cianhídricos de la "yuca brava" ( $M$. esculenta). Las etnovariedades comunes de "naranja" y "limón" constituyen recursos empleados para diversos fines al igual que lo planteado para la "mandarina común" por Riat \& Stampella (2013) y Riat et al. (2014). Así, las etnovariedades comunes se corresponden con la estrategia de uso múltiple ya que son empleadas con diversos fines, como frutal, medicina, forraje para el ganado, sombra, como también siendo destinado para la venta directa y elaboración de conservas.

Para la cuenca del Río Segura (España) se ha relevado una mayor variabilidad de etnoespecies y de etnovariedades de cítricos -todos cultivados- que en nuestra área de estudio, aunque la diversidad de usos es menor (Rivera Núñez et al., 1998); en aquella región son empleados principalmente para confituras (en desuso), portainjertos, condimentos y postres. Asimismo, aparecen las "bergamotas" y "melarrosas" ( $C$. $\times$ aurantium), también etnovariedades referidas en la bibliografía histórica como la "naranja de mollar" y naranja cajel", las primeras seleccionadas por su corteza comestible y las otras para confitar, respectivamente. Asimismo, para la Península de California se ha relevado una menor diversidad actual (De Grenade et al., 2014), debido quizá a la ausencia de espacios selváticos o boscosos que actúen de reservorios de la diversidad espontánea. También las variedades mencionadas son ampliamente usadas localmente con varios fines incluyendo preparados tradicionales como "panocha de gajo" - similar a una rapadura de cítricos y miel de caña- consumidos durante Semana Santa. 


\subsection{VARIABILIDAD DE CÍTRICOS (CITRUS, RUTACEAE) LOCALMENTE RECONOCIDA EN EL SUR DE MISIONES (ARGENTINA): MICROAMBIENTES Y PRÁCTICAS DE MANEJO}

\subsubsection{INTRODUCCIÓN}

Los frutales cítricos fueron introducidos a América a partir del siglo XVI desde diversos enclaves y por diferentes rutas de ingreso e inmediatamente se han vuelto elementos conspicuos del ambiente siendo empleados con diversos fines, incluso en la planificación de los paisajes por comunidades locales (Stampella et al., 2013c). Como ya se dijo en el capítulo anterior, en el sur de Misiones, se han relevado 30 etnovariedades correspondientes a 9 etnoespecies de cítricos, varias de ellas presentes en las selvas con baja a media intervención antrópica (Stampella et al., 2013b) si tenemos en cuenta la propuesta de la Ecología Histórica que aporta la visión temporal al análisis de la interacción entre las comunidades locales y los ecosistemas en la conformación de los paisajes (Balée, 1998).

Los enclaves tradicionales se basan en la Estrategia de Uso Múltiple (EUM) de los bienes comunes apropiándose, desde la UD, de una gran diversidad de especies, unidades ecogeográficas y paisajes, con fines de subsistencia y de intercambio económico (Toledo et al., 2007). Estos enclaves están caracterizados asimismo por el bajo empleo -o incluso, nulo- de insumos externos (agrotóxicos, fertilizantes, entre otros) y criterios de apropiación cuyos intercambios ecológicos son tan importantes como los económicos, constituyendo reservorios dinámicos de CET (Toledo \& Barreras-Bassols, 2008), constantemente puestos en juego mediante diversas prácticas dirigidas a las plantas y el paisaje, que resultan fundamentales conocer para el implemento de estrategias de conservación in situ de tales bienes. En relación a los procesos locales de selección cultural, la diversidad de prácticas sobre una misma especie permite la aparición y conservación dinámica -es decir, in situ- de las etnovariedades generadas. Estos procesos han sido abordados desde diferentes ópticas. La riqueza de percepciones de la variabilidad de los cítricos -relacionada a su vez con la diversidad cultural de la zona-, la coexistencia de diferentes sistemas de propagación 
basados en técnicas vegetativas (injertos), o centrados en el uso de semillas (éste último llamado "almajara" en el sur de España, común para la reproducción de cítricos y otros frutales, Rivera Núñez et al., 1998), más las prácticas del pasado, diversifican, a partir de un mismo germoplasma basal, el elenco de frutales cultivados y espontáneos. Así, se abre un espectro de prácticas locales sobre el entorno que pueden ser abordadas desde los diferentes grados de relación ser humano-planta o ser humano-ambiente que abarcan desde la recolección de frutos y consumo in situ de los mismos, el manejo de parches de vegetación, el cultivo de plantas en diferentes situaciones de cuidado, hasta la domesticación completa de las mismas, proceso logrado por manipulación del genotipo vegetal, ejemplificado con las "naranjas de ombligo", carentes de semillas (Casas, 2001; Lema, 2010). Así, las prácticas -junto al tipo de vegetación, relieve, topografía, suelos, agua, entre otros- definen distintos microambientes o zonas ecológicas reconocidas localmente por la presencia de los cítricos.

El proceso de domesticación, bien conocido en las plantas anuales, ha sido en cambio recientemente abordado para el caso de las perennes, con fases juveniles más extensa que en las anuales, polinización cruzada, altas tasas de flujo génico intra e interespecífica y diversos mecanismos de reproducción sexual y asexual (Zohary, 2004; Miller \& Gross, 2011). En África, se ha relevado el cultivo de especies de plantas arbóreas en las que se evidencian algunos cambios morfológicos y organolépticos en determinados órganos vegetales sin que ocurra domesticación. Esto ocurre por ejemplo en el "baobab" (Adansonia spp.), la "acacia de corteza blanca" (Acacia albida Delile), y las palmas Butyrospermum sp. y Elaeis guineensis Jacq. (Harlan, 1992). Es decir, un cultivo que no necesariamente es dirigido hacia la dependencia reproductiva de la planta; estadío de manejo que genera cambios en las especies frecuentemente denominados "domesticación incipiente", como ocurre en algunos frutales y plantas útiles: Leucaena esculenta (Moc. \& Sessé ex DC.) Benth, Blighia sapida K. D. Koenig, Sideroxylon palmeri (Rose) T. D. Penn., Crescentia cujete L. y Spondias tuberosa Arruda (Casas \& Caballero, 1996; González-Soberanis \& Casas, 2004; Marius et al., 2010; Aguirre-Dugua et al., 2012; Lins Neto et al., 2012). Tales prácticas de manejo, que conforman el modelo de "silvicultura" (en el sentido de cultivo de plantas "silvestres", no de bosques) planteado por Casas (2001) en base a Harlan (1992), fueron recientemente actualizadas y descriptas extensamente por Lema (2009, 2010) y responden a criterios diferenciales de selección cultural que determinan aquellas plantas 
espontáneas o aquellos fenotipos que serán preferidos para la recolección, que serán erradicadas, que quedarán en pie (toleradas), que serán favorecidas (fomentadas) y/o protegidas (cultivadas sensu stricto). Por lo tanto la selección cultural no es realizada entre la cosecha y la siembra sino que opera seleccionando (erradicando o tolerando) la variabilidad generada natural/culturalmente por diferentes vías, de manera aleatoria y volitiva (Emperaire et al., 2001; Gandolfo et al., 2010).

El objetivo del presente apartado es inventariar los distintos microambientes definidos en relación a la presencia de cítricos, las prácticas sobre los mismos y las etnovariedades presentes en cada uno, como procesos que contribuyen a entender los mecanismos locales involucrados en la generación de la variabilidad de Citrus en Misiones. Asimismo, se analiza, a través de la percepción local de la variabilidad, la diversidad morfológica y organoléptica de "mandarinas comunes" cultivadas bajo diferentes tipos de manejo. Finalmente se discuten, de acuerdo a la propuesta relacional de Casas (2001) y Lema (2010), las prácticas de manejo sobre los distintos microambientes.

\subsubsection{MATERIALES Y MÉTODOS}

\section{Área de estudio}

Los trabajos de campo fueron llevados en los mismos enclaves descriptos en el apartado 5.1.3: Teyú Cuaré (Municipio de San Ignacio del departamento homónimo, TC) y paraje Cerro Mártires (Municipio de Santa María, departamento de Concepción de la Sierra, CM) (Figura 5, capítulo 5.2.2). Las plantas sobre las que se basó el Análisis de Componentes Principales fueron colectadas sólo en Cerro Mártires.

\section{Metodología}

Los trabajos de campo para la realización de este apartado fueron realizados a lo largo de todo el estudio, con especial énfasis en la campaña invernal de 2013. Se realizaron entrevistas abiertas y semiestructuradas y caminatas con los informantes por los distintos microambientes de la UD, complementada con observación participante (Albuquerque et al., 2014; Etkin \& Ticktin, 2010). Para analizar los aspectos incluidos en este capítulo se trabajó en particular con las mismas UD e informantes mencionados 
en el capítulo 5.1.3. Preferentemente se trabajó con pobladores que mantienen contacto cotidiano a través del manejo de este tipo de bienes, cuya edad fue muy variable (entre 12 y 88 años). Durante las entrevistas y caminatas a los distintos espacios se indagó acerca de la variabilidad cultivada, de los distintos microambientes y de las prácticas sobre los mismos y las plantas.

Los frutos empleados en el análisis morfométrico fueron colectados sólo en el paraje de Cerro Mártires entre el 29 de mayo y el 2 de junio de 2013, en compañía de los informantes. En función de los descriptores relevados (capítulo 5.2.4.4) se realizaron las mediciones en 7 frutos de 5 plantas bajo distinto grado de manejo: "de monte o silvestres", con manejo nulo a bajo; "manejadas in situ", con manejo intermedio (cultivadas sensu lato en los campos, rozados y capueras); y "caseras", cultivadas en los alrededores inmediatos del hogar (jardin y huerta). Los datos obtenidos fueron volcados en una base de datos y analizados mediante ACP utilizando el programa Statistica 7.

El material de herbario y los frutos colectados en este relevamiento fue procesado, identificado y depositado en el Herbario de Plantas Útiles y en la Colección de Frutos y Semillas del Laboratorio de Etnobotánica y Botánica Aplicada (CFS, LEBA) de acuerdo a lo planteado en el apartado 5.1.4.

\subsubsection{RESULTADOS}

\subsubsection{Microambientes}

Se relevaron 7 microambientes definidos en relación a la presencia de cítricos y complementados con las prácticas de manejo distintivas y aspectos relativos a la vegetación, suelo, disponibilidad hídrica y cercanía al hogar: jardín, monte frutal, huerta, campo, rozado, capuera y monte (Tabla 6).

El jardín, el monte frutal y la huerta, son los espacios más cercanos al hogar, sujetos a condiciones más controladas cotidianamente y con prácticas de manejo que inciden directamente sobre los frutales. En cambio, los frutales de los campos y rozados generalmente dispuestos en los bordes de transición con el monte, donde se encuentra inmerso este ambiente productivo, no reciben mayores atenciones aunque sí diversas prácticas de manejo. Finalmente, son comunes poblaciones e individuos espontáneos en 
las capueras y montes con grado variable de intervención antrópica, especialmente en aquellos bajo manejo agroforestal tradicional (con bajo disturbio de la flora local).

Tabla 6. Microambientes relevados indicando las prácticas sobre los mismos, las etnovariedades de Citrus presentes y el grupo de etnovariedades al que pertenecen. Asimismo, se indican el tipo de vegetación, suelo y disponibilidad hídrica de cada uno. Las variedades comunes son aquellas que no participan en el injerto, propagadas mediante semillas; las de injerto son aquellas que intervienen en el injerto como portainjertos, propagadas de la misma manera que las comunes; y las injertadas son aquellas injertadas en sentido estricto sobre un portainjerto.

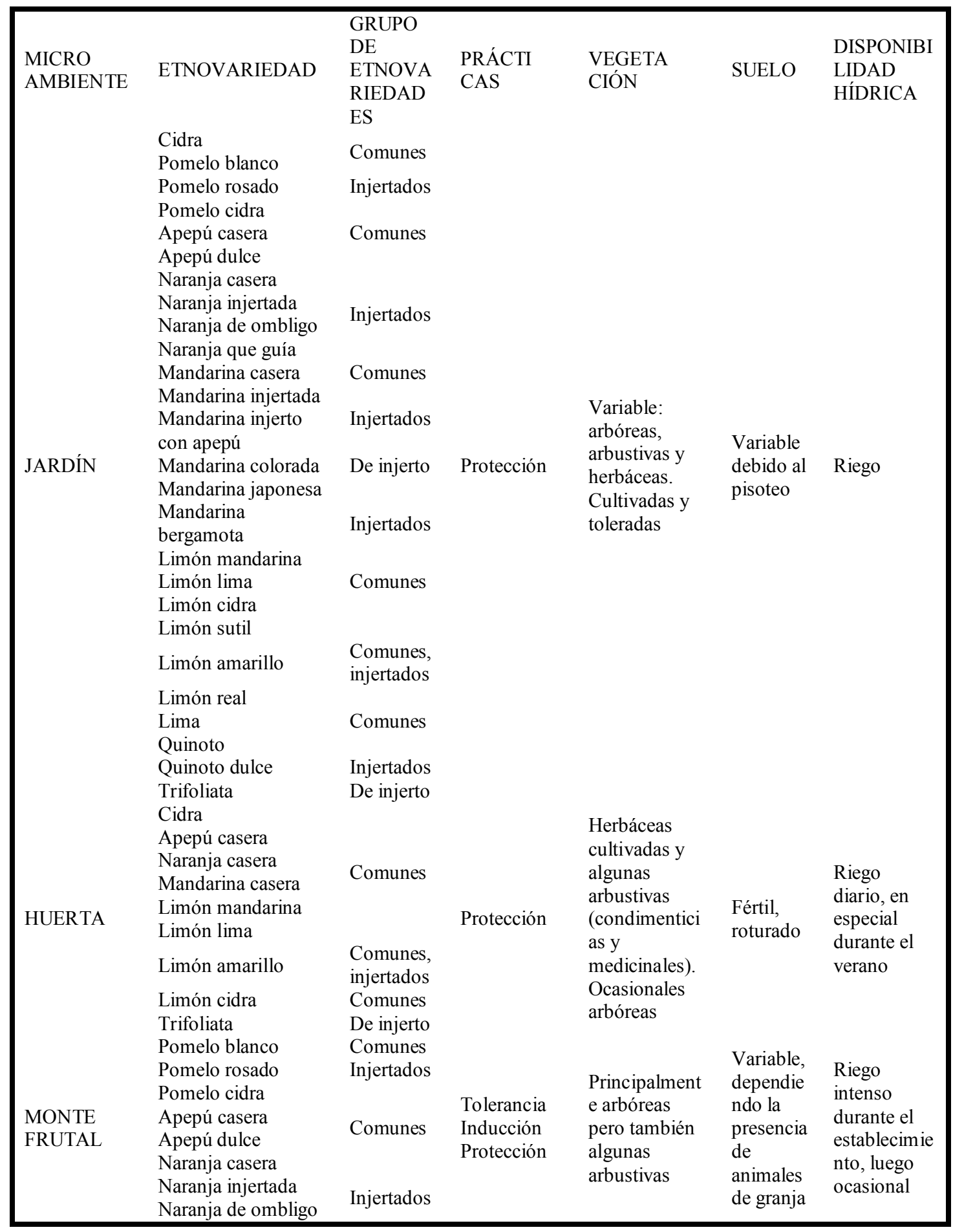




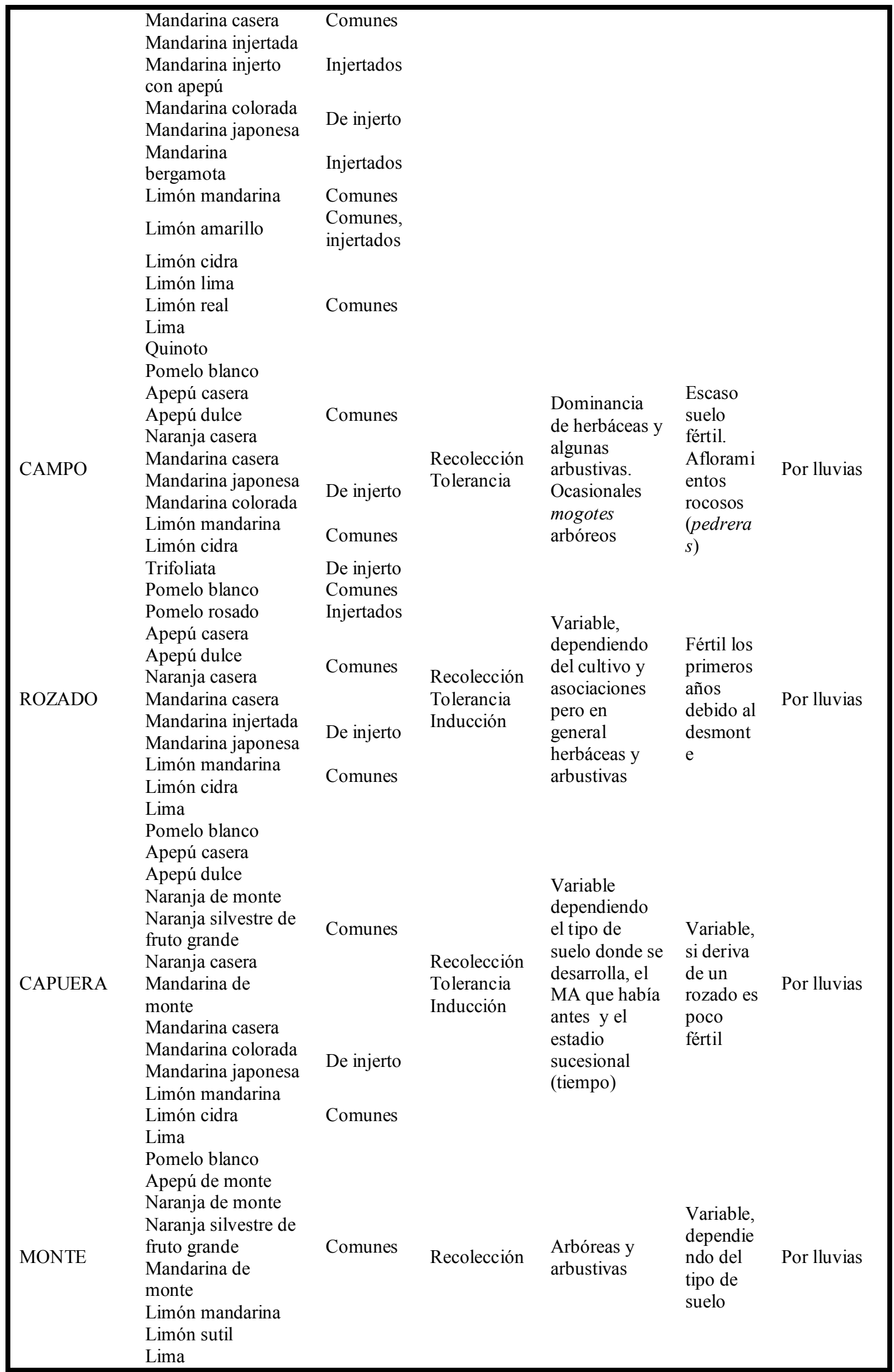


JARDÍN

Está ubicado alrededor del hogar y posee dimensiones variables (Figura 16, capítulo 5.2.3.2). Generalmente está conformado por plantas ornamentales, de sombra, frutales, condimenticias y medicinales, varias de ellas de gran valor emotivo (plantadas $\mathrm{u}$ obsequiadas por familiares fallecidos o lejanos). La mayoría de los ejemplares incluidos aquí, fueron cultivados. Algunas especies provienen de sitios distantes, donde viven familiares; estos traslados fueron citados con frecuencia particularmente para plantas ornamentales y medicinales. Parte de los frutales y de las maderas de valor-es decir, especies forestales como "urunday" (Astronium balansae Engl.), "guayubira" [Cordia americana (L.) Gottschling \& J. S. Mill.], "lapacho" (Handroanthus spp.) y "anchico colorado" [Parapiptadenia rigida (Benth.) Brenan]- son seleccionados (tolerados, fundamentalmente, algo alejados de la construcción) y no se cortan durante las tareas de desmonte practicadas al construir la vivienda y en los alrededores.

Además de los árboles maderables y de los cítricos, varias especies que nacen espontáneamente son toleradas durante la limpieza del predio. Las motivaciones de estas selecciones son variables, pudiendo ser económicos, emotivos, utilitarios y religiosos.

\section{MONTE FRUTAL}

El monte frutal es un espacio conformado por árboles y arbustos frutales que muchas veces se considera como parte del jardin o de la huerta (huerta de frutales fue llamado en algunos casos). La composición del monte frutal es bastante cambiante en cada UD; pudiendo ser desde montes frutales uniespecíficos (naranjales, bananales, de mandarinas, pomelos, limones), hasta de diferentes combinaciones de especies (poliespecíficos). Mientras los primeros se asocian más a productos para la venta en un mercado local, los otros son empleados para consumo de la UD y eventuales trueques. En estos espacios multiespecíficos son comunes los cítricos ("naranja", "mandarina", “pomelo", “limón”, "lima”), “pitanga”, “araticú”, "guayaba”, “mamón”, “mango", "kaqui" (Diospyros kaki L.), "pecán” [Carya illinoinensis (Wangenh.) C. Koch], “castaña" (Castanea sativa Mill.), "vid" (Vitis vinifera L.), "palta”, "durazno", entre otros. 
En estos montes frutales diversos, la disposición espacial puede ser azarosa u ordenada en líneas y surcos de distancia variable; disposición que cambia según las especies presentes, su procedencia y las costumbres familiares. Asimismo, el origen de los frutales incluidos en los mismos, es tan variable como en los jardines antes descriptos. Las plantas pueden haber sido implantadas (Figura 32A, B), toleradas durante el avance de la UD sobre el monte (Figura 32D) o bien espontáneas una vez establecido el microambiente.

Figura 32. Microambientes domésticos. A. Monte frutal recién implantado entre remanentes de uno antiguo. B. Monte frutal de cítricos. C. Huerta familiar. D. Monte frutal por tolerancia, los árboles presentes no fueron plantados.
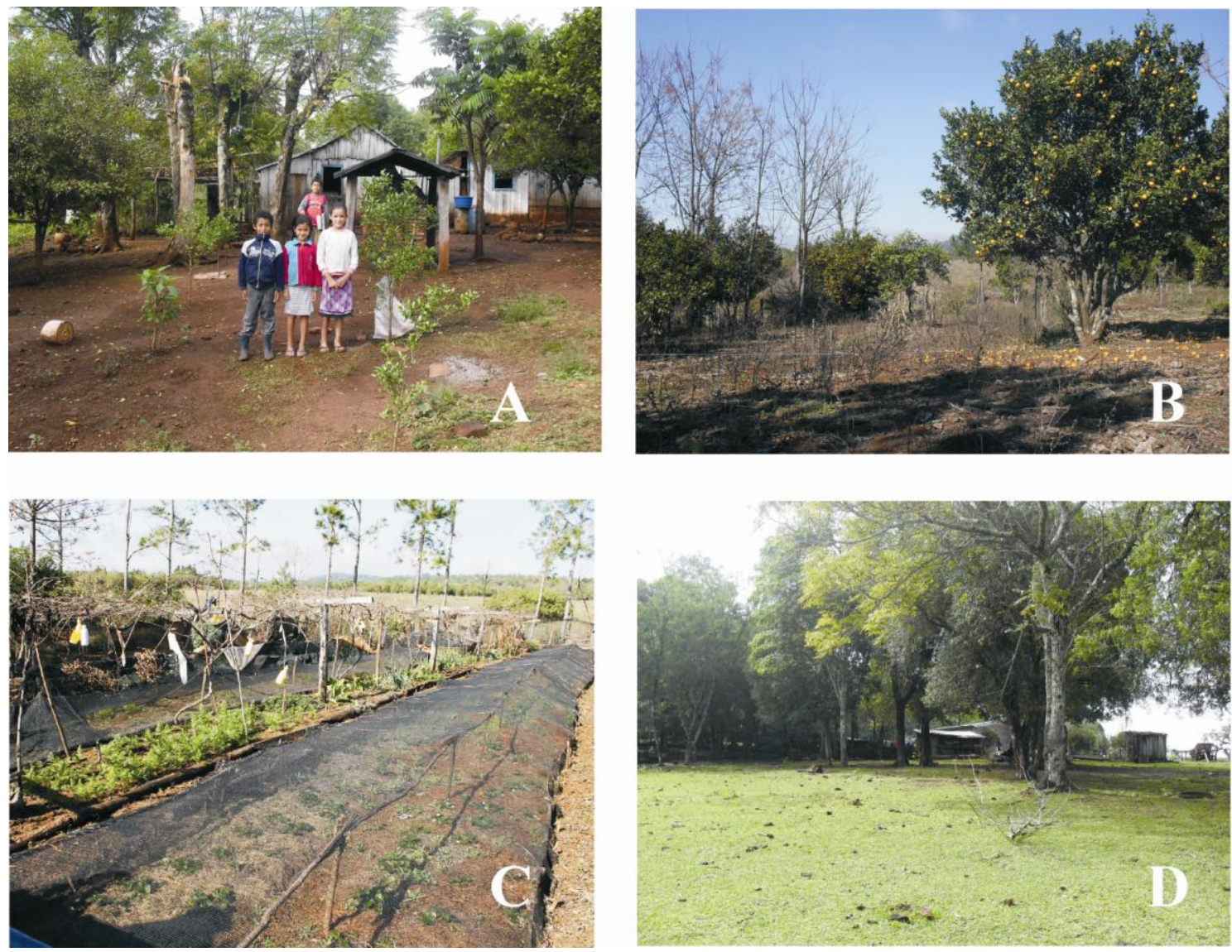

HUERTA

La huerta o quinta es un espacio cercano a la vivienda pero, a diferencia de los dos anteriores, delimitado por un cerco perimetral (Figura 32C). En su interior se cultivan principalmente hortalizas y verduras como "lechuga" (Lactuca sativa L.), "tomate" 
(Solanum lycopersicum L.), "pimiento" (Capsicum annuum L.), "verdeo" (Allium fistulosum L.), “perejil” [Petroselinum crispum (Mill.) Fuss], "zanahoria” (Daucus carota L.), “aipo" (Apium graveolens L.), "repollo" (Brassica oleracea L.), plantas medicinales, condimentos y frutales de porte bajo como "frutilla" [Fragaria $\times$ ananassa (Weston) Duchesne] y "grosella" o "rosella" (Hibiscus sabdariffa L.). Este espacio es empleado frecuentemente, y cuando las dimensiones lo permiten, como vivero para la siembra de semillas de "ciruela" (Prunus domestica L.), "durazno" y de cítricos. Aunque de éstos últimos se prefiere ampliamente la obtención de las muditas en el monte.

\section{ROZADO}

El rozado o labora es una zona desmontada destinada a los cultivos anuales, sin riego controlado. Frecuentemente, cada UD tiene varios rozados en diferentes estadios (series de capueras) como también varios de ellos activos a la vez, por lo cual las asociaciones se hacen muy diversas. Son comunes las asociaciones: maíz-mandioca, maíz-zapallo [principalmente Cucurbita pepo L. y C. moschata (Lam.) Poir.], maíz-poroto, mandioca-zapallo, maíz-batatera (Figura 33A, B). También, un mismo rozado puede tener diferentes parches caracterizados por distintos monocultivos asociados a características microlocales. Usualmente las plantaciones de "caña dulce" siguen los afloramientos rocosos ya que crecen mejor en tales suelos. También se cultiva "soja", “arroz”, “maní” (Arachis hipogaea L.) y "tabaco”. Asimismo se observó en estos espacios algunas especies perennes, como el "ananá" o "abacayí" y plantas arbóreas como cítricos, "níspero" [Eriobotrya japonica (Thunb.) Lindl.], "palta”, "mango", "yerba mate" y frutales del monte, tolerados durante la apertura del rozado.

Asimismo, las variedades empleadas son también diversas. Por ejemplo para las "mandiocas” se emplean las variedades ,pomberita", ,horquetuda“, „,blancae, „,común entre otras-; de las "cañas dulce" se reconocieron 3 variedades: comunes, moradas y forrajeras (éstas últimas para alimentar el ganado).

La superficie del rozado varía de unos pocos metros cuadrados hasta cerca de 5 hectáreas, dependiendo de la cantidad de miembros de la UD. Para su preparación se cortan las leñosas con machete y hacha (o en ocasiones con motosierras portátiles), y 
luego se labra la tierra con arado de tipo Romano tirado por un bueyes (Figura 33C). Hasta hace pocos años, los rozados eran emplazados en zonas de monte talado y quemado para dicho fin, pero ahora acorde a las reglamentaciones de ecología (refiriéndose a la Ley 26.331), es frecuente la reutilización de las capueras, es decir, viejos rozados dejados en descanso varios años y en los que se regeneró parcialmente la vegetación leñosa. En este contexto, los rozados establecidos en sitios con suelos profundos se rotan cada 3 ó 4 años. En algunos enclaves de Teyú Cuaré, sitio con suelos más arenosos y pedregosos que en el resto de la región, luego de la tala no se practica la quema, antes del cultivo. Se argumenta que de este modo se evita la erosión del suelo. En esta región, en consecuencia, la tolerancia de algunas plantas durante la tarea de desmonte consiste simplemente en no dañar al ejemplar. En Cerro Mártires, en cambio, donde la quema al final de la tala es común, los renovales que se pretenden conservar son protegidos por un montículo de tierra para evitar que el fuego los dañe. Asimismo, las plantas adultas son podadas y luego cubiertas de la misma manera antes de la quema.

\section{CAMPO}

El campo es aquél ambiente donde predominan naturalmente las plantas herbáceas; bioma que en la zona se establece en sitios con suelos pobres, ubicados sobre afloramientos rocosos (Figura 33D). Se reserva la palabra potrero para el campo destinado a la cría del ganado. Aunque el potrero puede también estar inmerso en sitios clareados dentro el monte. Este espacio pare el rodeo, pocas veces está delimitado por un alambrado u otro tipo de cercado. Rara vez se encuentran frutales plantados -de semilla o de plántula- en los campos, a excepción de aquellos predios cercanos al hogar donde pueden cuidarse las plántulas durante el crecimiento. Por esto, la mayoría de los frutales del campo tienen su origen en el avance de este ambiente sobre el monte o las capueras, por lo cual, frecuentemente, los cítricos presentes en este microambiente pertenecen a variedades comunes. En cambio, las pocas variedades injertadas que se hallaron corresponden a remanentes de antiguos jardines o montes frutales. Dentro de los frutales que se observaron se pueden mencionar, diversos cítricos, "araticú", "huvenia" (Hovenia dulcis Thunb.), "guaviroba", "soita" (Luehea divaricata Mart.), "arasá" (Psidium sp.), "pindó" [Syagrus romanzoffiana (Cham.) Glassman] y "coco" [Acrocomia aculeata (Jacq.) Lodd. ex Mart.]. Los suelos de los campos son 
relativamente pobres en horizontes cultivables siendo comunes los afloramientos rocosos o pedreras, donde crecen asociados "ananá", "caraguatá" (Bromelia sp.), "pitanga", "cerella" (Eugenia involucrata DC.), "talera" (Celtis sp.) y varias clases de "tunas" (no identificadas), casi siempre en la interface con el monte o cercanos a los cursos de agua.

Figura 33. Microambientes productivos inmersos en el monte. A. Rozado de mandioca, maíz y caña dulce. B. Rozado de maíz y caña (véase como la caña es plantada sobre suelos menos profundos de manera que siguen el afloramiento rocoso. C. Arado de tipo Romano empleado en Cerro Mártires. D. Campo peridoméstico.
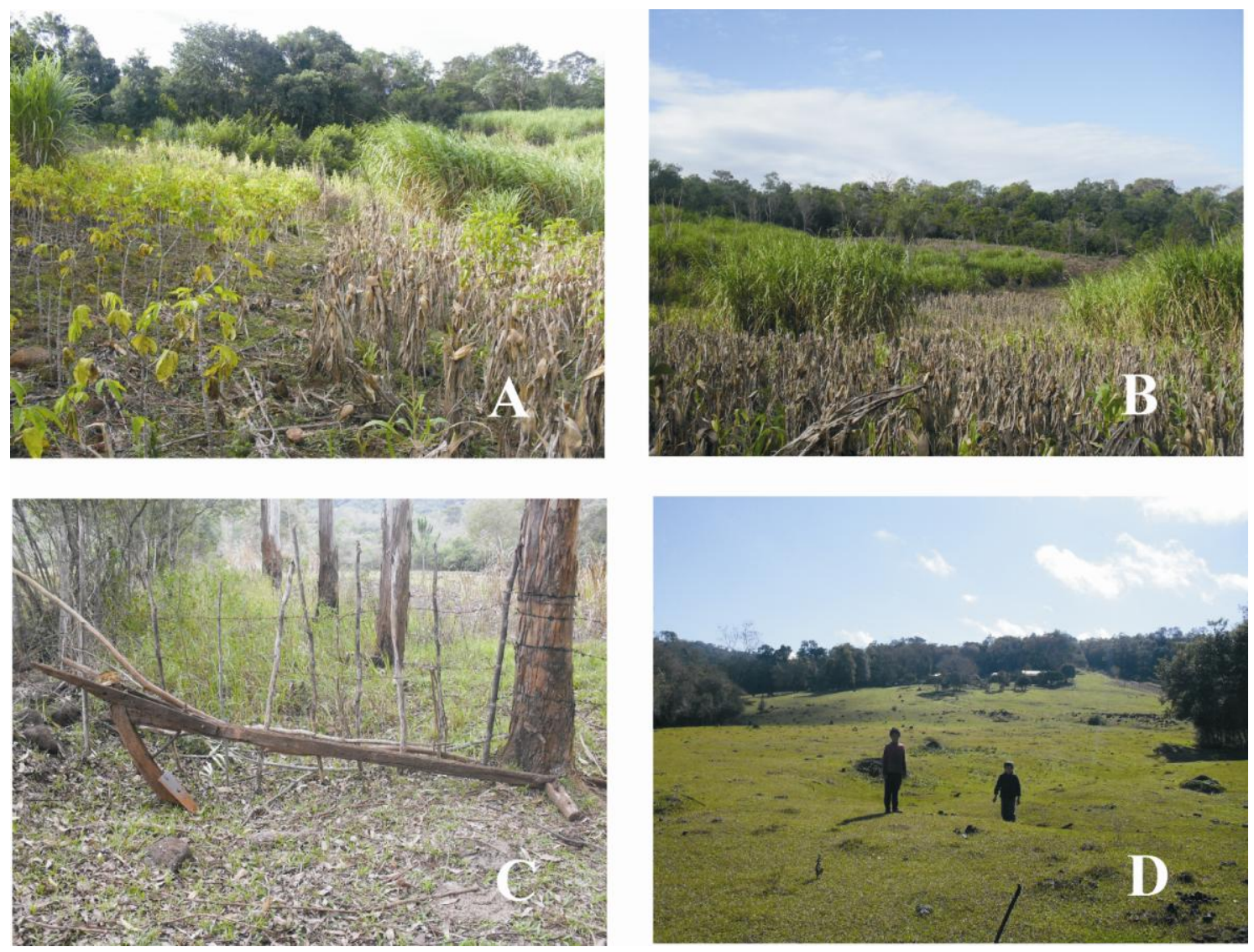

\section{CAPUERAS}

Las capueras son ambientes productivos abandonados -o en descanso-, por ejemplo, un jardín abandonado, un campo sin ganado, un rozado sin cultivos. Por esto el término es polisémico al referirse tanto a ambientes herbáceos, como arbustivos o arbóreos bajos, e incluso sucesiones más avanzadas similares al monte, con elementos arbóreos de mayor 
diámetro y estrato herbáceo-arbustivo menos denso. De acuerdo a las plantas que las componen, el grosor de los tallos y el estadío sucesional, este microambiente es denominado localmente capuerita (herbáceas o subarbustivas), capuera fina (arbustivas o arbóreas bajas) y capuera gruesa (arbóreas) (Figura 34A, B, C). Las capueras también toman el nombre de las especies dominantes: chircal o chilcal, con dominancia de "chilca" Baccharis sp.); guaimirinsal de "guaimirín" [Myrcia selloi (Spreng.) N. Silveira], muy empleado por los niños como frutal), por ejemplo.

Los capuerones son capueras que se parecen al monte pero que difieren de éste en la presencia de plantas arbustivas y subarbustivas en el estrato bajo). Estos últimos son estimados para realizar excursiones de caza y recolección de frutas debido a la abundancia de frutales de varias especies que atraen animales frugívoros. Algunos de estos frutales son "palta”, "naranja común”, "apepú”, y en los más antiguos "aguaí" [Chrysophyllum marginatum (Hook. \& Arn.] Radlk., "jacaratiá" [Jacaratia spinosa (Aubl.) A. DC.], “ombú" (Phytolacca dioica L.) e "higuerón” o "ibapoi” [Ficus luschnathiana (Miq.) Miq.].

Algo similar a lo descripto para los capuerones puede apreciarse en los montes que circundan los arroyos -sometidos a manejo agroforestal- y los peridomésticos donde el ganado vacuno pasa la mayor parte del tiempo durante las horas de sol alimentándose de los frutos, bajos y caídos, de cítricos, Myrtaceae, Arecaceae y Annonaceae, principalmente. En relación a las actividades de recolección de frutas los informantes concuerdan en la mayor abundancia de éstas en el capuerón que en el monte, debido a la mayor luminosidad, a la presencia de individuos remanentes de antiguos montes frutales y jardines, y a la facilidad para el establecimiento y viabilidad de las muditas en este microambiente más luminoso.

\section{MONTE}

Finalmente, el monte (o matto) constituye el espacio dominante en ambos enclaves, considerándose "vírgenes" las selvas del Parque Provincial Teyú Cuaré y del Cerro Mártires (Figura 34D).

Este espacio es visto de diferentes maneras de acuerdo a la afiliación familiar. En general, los colonos y productores yerbateros y forestales lo perciben como fuente de 
maderas de valor para la venta, como reservorio de tierras cultivables y para cría de ganado. Para estas familias, el monte debe, necesariamente, permanecer alejado del ámbito doméstico. No obstante, para los criollos -grupo más numeroso en la zona-, el monte cuenta con un significado mayor, en especial si está ubicado en un sitio peridoméstico. En efecto, el monte es considerado un bien común más de la UD, donde se llevan a cabo numerosas actividades cotidianas, inclusive el juego de los niños.

Se reconocen localmente 2 tipos básicos de monte: bajo y alto. El primero se desarrolla en suelos pobres en humus, sobre o en las cercanías de los afloramientos rocosos; mientras que el segundo está asociado a suelos profundos, ricos en materia orgánica.

Figura 34. Microambientes con bajo manejo local. A. Capuerita. B. Capuera fina. C. Capuera gruesa. D. Monte. Cerro Mártires.
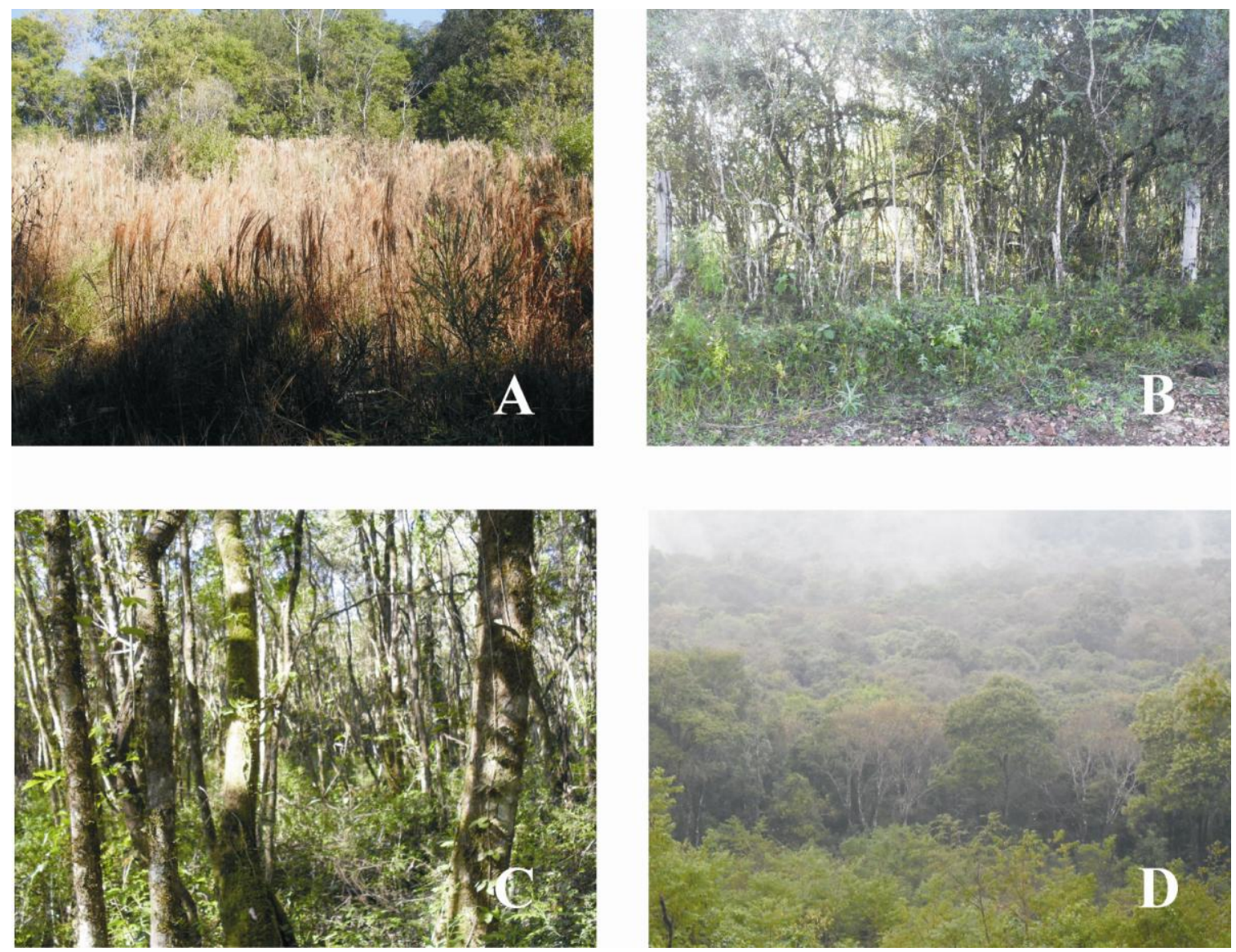

5.3.3.2. $\quad$ Prácticas de manejo 
Las prácticas de manejo observadas se pueden sintetizar en dos niveles, aquellas focalizadas en las plantas propiamente dichas, y aquellas realizadas en cada uno de los microambientes particulares o en grupos de microambientes. Es decir por ejemplo, la poda es realizada y afecta especialmente a un ejemplar; mientras que la apertura de un nuevo rozado tiene una incidencia mayor en el sitio donde se lo realiza y en sitios aledaños, tanto sobre las comunidades de plantas y como de animales.

\section{PRÁCTICAS SOBRE LAS PLANTAS}

$\mathrm{Al}$ iniciarse un monte frutal y un jardín, se emplean muditas espontáneas de las casas de familiares o vecinos, de la anterior casa y/o del rozado, campo, capuera o monte. Cuando se desea cultivar alguna variedad particular, se siembran las semillas en almácigos, o directamente sobre el suelo tanto en el rozado como en el ámbito doméstico. Se utiliza para ello, con frecuencia, tierra extraída del monte. Una vez establecidos los plantines, suelen ser protegidos de las bajas temperaturas y heladas con ramas de "guaimirín". Se elige esta especie, ya que sus ramas luego de cortadas y secas, conservan las hojas por un tiempo prolongado. Otra práctica observada para proteger a las plántulas del frío, fue el cultivo al reparo de alguna capuera herbácea y/o cerca de algún cítrico añejo o muerto en pie.

En general, muy pocas prácticas se realizan sobre las plantas ya establecidas. Debido a la alta disponibilidad de muditas en la zona, las plantas, cuando una planta deja de producir, es reemplazada por otra que ya se ha trasladado al área previendo el reemplazo. En ocasiones, incluso el reemplazo consiste directamente en implantar un nuevo monte frutal cerca del anterior, previendo su declinación productiva.

Las prácticas destinadas directamente a las plantas son podas, removido y abonado del suelo, reposición del suelo erosionado por escorrentía superficial, eliminación de malezas y enredaderas. En efecto, se podan eventualmente las ramas chuponas (aquellas de crecimiento vigoroso, espinosas y poco productivas); se realizan podas de rejuvenecimiento en el caso de plantas añosas; carpidas alrededor del tronco basal para eliminar principalmente la grama (gramíneas) y aflojar la tierra; se abona con ramas trituradas y bosta de vaca (Figura 35A); en suelos con pendientes se nivela con piedras, siguiendo las curvas de nivel, y se rellena con tierra en el caso de haberse erosionado el 
suelo por escorrentía superficial (Figura 35B); finalmente se eliminan las sipó (enredaderas y trepadoras) que cubren las copas.

En el caso del jardín los abonos y el control de malezas son servicios principalmente provistos por los animales de granja, a los que se les permite deambular por casi todos los espacios domésticos. Además unos pocos informantes emplean herbicidas para el control de malezas, actividad reciente en la zona, relacionada a los trabajadores forestales. Algunos informantes se han referido con el término randasear a la aplicación de herbicidas (glifosato) para eliminar las hierbas del jardín y la huerta.

Las técnicas de cosecha de los frutos varían de acuerdo al porte de la planta. Si se trata de plantas injertadas o pequeñas, los frutos son cortados con la mano o mediante un gancho. El gancho es confeccionado inmediatamente con cualquier rama cortada a machete, prefiriéndose aquellas de "talera" debido al profuso patrón de ramificación de las mismas (Figura 35C). En este caso los frutos lejanos son enganchados con el gancho tirándose hacia abajo para desprenderlos. Otra variante del gancho es la horqueta, que no es más que una rama larga con terminación dicótoma que se emplea para agarrar frutos o grupos de frutos mientras se enrosca la horqueta hacia un lado hasta que se corten las ramas fructíferas (Figura 35D). Durante el período de fructificación de las plantas es común encontrar ganchos u horquetas apoyados en las mismas para quien quiera alcanzar los frutos. El uso de este instrumento suele dañar parcialmente las ramas. En particular cuando la horqueta es enroscada sobre varias ramas y en el tironeo las va desgajando. Las heridas generadas en estas prácticas propician el ingreso de patógenos. En ocasiones, se ha relevado el corte del ejemplar, con el objeto de acceder a los frutos más altos.

En efecto, es común recopilar en las historias populares la tala del "naranjo de monte" para alcanzar sus frutos lejanos. En la zona esta práctica fue relevada en Puerto Viejo, en las cercanías de San Ignacio, donde fue adjudicada a los paisanos -pobladores M'bya-; y en las ruinas de Santos Mártires realizada por visitantes.

Otro modo más conservador de cosechar en plantas altas, como suelen ser las de "naranja”, "apepú", “mandarina de monte" y "pomelo", es trepando a la planta. En esta práctica muy común los niños ascienden a la planta y desde allí arrojan las frutas al piso. 


\section{PRÁCTICAS SOBRE LOS MICROAMBIENTES}

Las prácticas de manejo que inciden en la distribución, abundancia y calidad de fruta de los cítricos -como de otros frutales- sin dudas son los factores antrópicos más importantes en el modelado de este recurso local.

Figura 35. Prácticas de manejo sobre las plantas y herramientas de recolección de frutos. A. Erosión del suelo por escorrentía superficial. B. Abonado y reposición del suelo erosionado. C. Gancho para obtener frutos lejanos. D. Horqueta con la misma función que C.
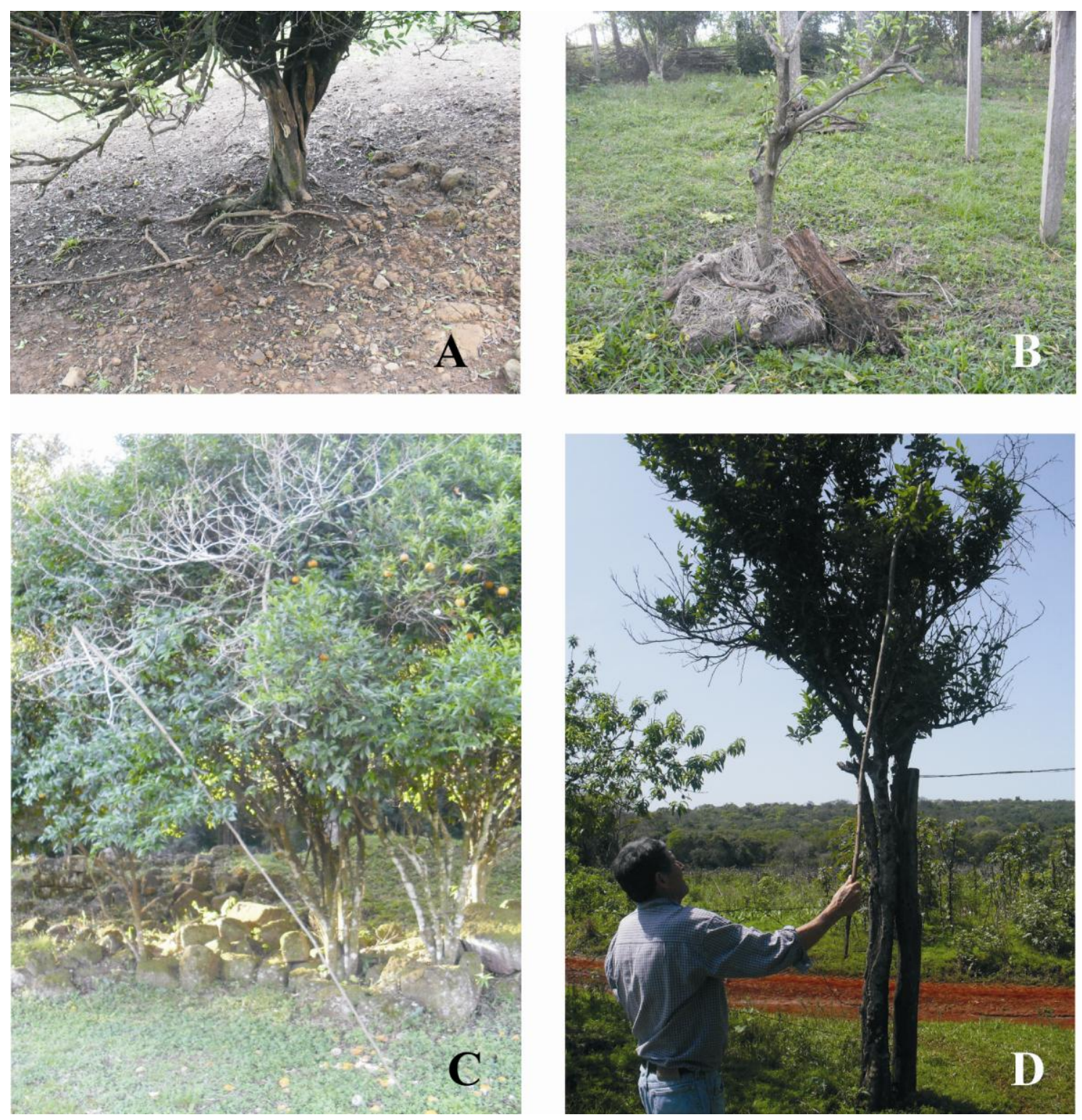
En primer lugar, se observa la recolección y consumo in situ de frutos durante las actividades cotidianas. El desplazamiento por los trillos (senderos, Figura 36) hacia los distintos microambientes casi siempre va acompañado del consumo de frutas, en especial durante los días calurosos. Si los trillos se encuentran en el monte o en la capuera las semillas usualmente germinan, especialmente en aquellos ambientes donde hay un manejo (raleo) de la cobertura arbórea. Esto no suele ocurrir en el campo debido a la presencia de la grama. Del mismo modo el ganado es un agente dispersor asociado a la actividad humana. Dado que los potreros generalmente no poseen delimitaciones, si los montes y capueras que lo circundan cuentan con plantas de estos frutales, se vuelven sitios de forrajeo intenso durante la fructificación. En especial durante el invierno cuando hay más frutas y menos pastos. Como consecuencia, en ambos casos, se observa una mayor concentración de renovales y ejemplares adultos de cítricos en los bordes del monte y en los trillos. El consumo doméstico a la vez promueve la relocalización de las distintas etnoespecies, de ese modo frutos de monte son trasladados como muditas desde el monte al hogar. Algo similar ocurre con las deposiciones de residuos fecales ocurridas en los distintos espacios, mecanismo por el cual se observa el reclutamiento de especies del jardín y del monte frutal en los demás espacios, incluido el monte.

Figura 36. Trillos o senderos en el monte. Cerro Mártires

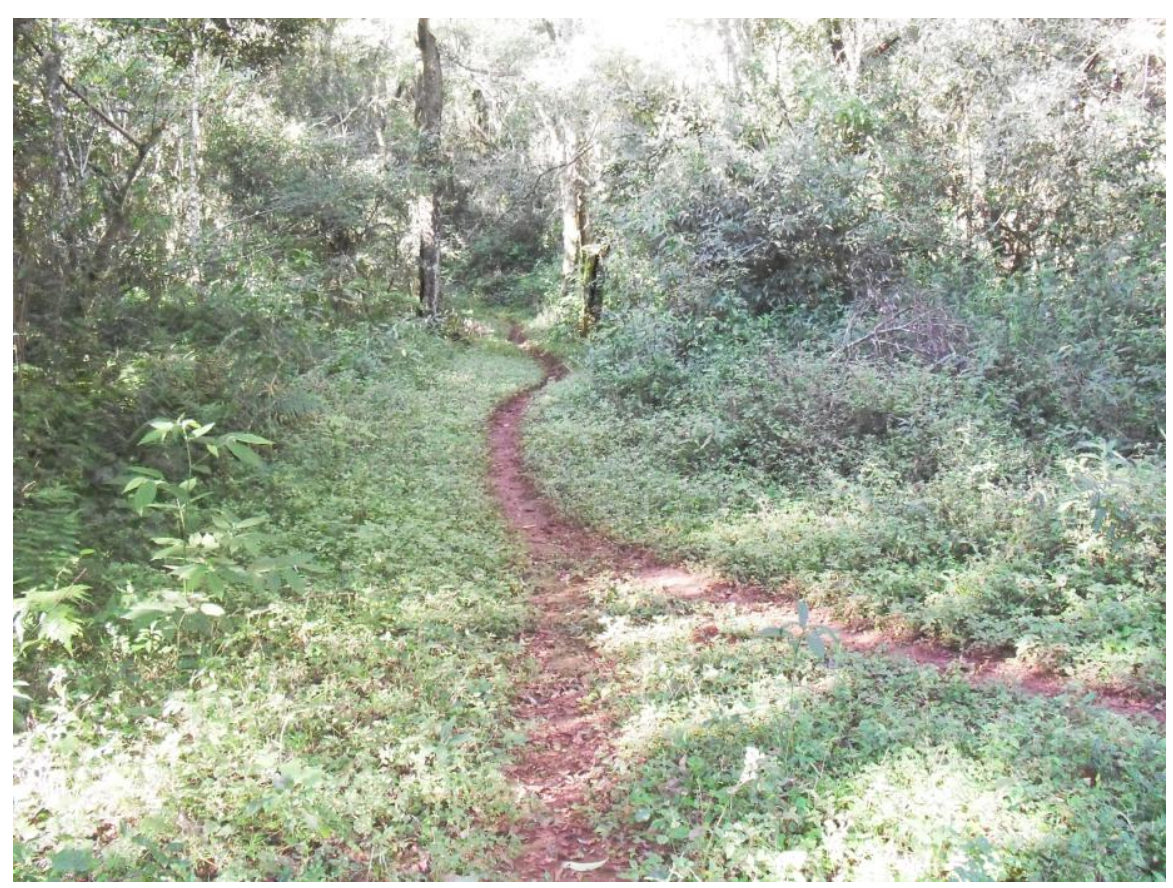


Como ya se ha referido anteriormente en los microambientes (rozado, campo, jardín y monte frutal) los frutales son tolerados durante las tareas de tala del monte o capuera. De ese modo, y de acuerdo a distintos criterios de preferencia, son incorporados al ámbito doméstico, donde pasan a ser denominados frutales caseros (Figura 32D). Como generalidad, estos frutales adquieren características deseables por el mero hecho de pertenecer a los microambientes domésticos con respecto al monte. Entre estas características puede citarse que cargan más (mayor productividad), con fruta más graúda (éste término se refiere a tamaño pero sería más correcto decir que son más pesadas que grandes, ver capítulo 5.3.3.5), jugosas y dulces; así como también disminuye el tiempo de maduración (se tornan más tempranas), y el porte de la planta y la ramificación se torna más densa y achaparrada, facilitando así la recolección de los frutos.

En la concepción local el monte les quita dulzor y jugosidad a las plantas, por lo tanto al alejarse los frutales del monte cambian:

"Hay algunas [naranjas] que son más simples, que tienen menos dulzura porque seguramente los árboles del monte le sacan la dulzura, sí eso les pasa. Y hay alguna que está medio salida del monte, en el costado, que son bien dulce" (S.F., 70 años, Cerro Mártires, julio de 2011).

Una vez incluidas en el nuevo microambiente las plantas toleradas pueden ser fomentadas y protegidas, de acuerdo a las prácticas nombradas para las plantas del jardín y huerta. Las prácticas de fomento incluyen actividades simples y directas como el consumo in situ de los frutos y dispersión de sus semillas, la eliminación de plantas no deseadas que crecen en las cercanías y la ocasional siembra de semillas o plántulas; así como actividades indirectas, tales como la cría de ganado en el monte, especialmente durante el período invernal.

Estas prácticas configuran flujos de germoplasma entre los distintos microambientes (Figura 39, ver más adelante) donde intervienen también los procesos de regeneración natural. El complejo conformado por el jardín, huerta y monte frutal, es receptor de plántulas y semillas al iniciar nuevas plantaciones, por consumo de frutos de monte en los alrededores del hogar y por las deposiciones de las aves. Asimismo, mediante el avance de la UD sobre el monte varios frutales - antes de monte, silvestres- quedan incluidos en estos espacios, mediante tolerancia. El rozado, generalmente alejado 
espacialmente de los demás microambientes e inmerso en el monte, está relacionado con este último. Si bien algunos frutales son llevados del jardín o monte frutal y plantados allí, la mayoría provienen de la tolerancia de los frutales de monte en el avance de este microambiente y por establecimiento de plántulas provenientes de semillas. En el campo, en cambio, debido a la cubierta de gramíneas, características del suelo y actividad del ganado, el establecimiento de plántulas provenientes de semillas es infrecuente, derivando casi exclusivamente los frutales de la tolerancia ante el avance sobre el monte. Finalmente, el monte es receptor de germoplasma por escape de cultivo de las plantas caseras y por regeneración natural (encapuerado) al avanzar el monte sobre los demás microambientes.

\subsubsection{Las prácticas de manejo en la dinámica entre el monte y el campo}

Estos microambientes descriptos no se mantienen estáticos. Según las prácticas locales, diferenciales de acuerdo a la percepción de los distintos actores de las UD, la frecuencia y extensión de éstos varía. En primer lugar, las apreciaciones de los distintos microambientes por los diferentes grupos ("paisanos", "criollos", "colonos" y "productores") no ocurren de la misma manera, en especial del monte, capuera y campo. Para los "paisanos" y en parte para los "criollos" la capuera anuncia la regeneración del monte, microambiente preciado para las actividades de recolección y caza; mientras que para los “colonos" y "productores" indica dejadez y haraganería, ya que está relacionado con un espacio sucio e improductivo, susceptible a ser transformado en un monte frutal, campo o rozado.

Entonces, de acuerdo a los distintos actores sociales, las interfaces de estos microambientes serán dinámicas y las prácticas sobre ellos van a tender a favorecer algunos de ellos a expensas de otros. El monte es el microambiente prototípico de la zona, ya que todos los demás microambientes tienden a monte previo paso por capuera. En algunas zonas el campo ya se encuentra establecido debido a la pobreza del suelo y a las pedreras que afloran, muchas veces atribuidas a "malas" prácticas que erosionan el suelo fértil. Esto suele observarse frecuentemente en los jardines y montes frutales donde el suelo es erosionado por escorrentía superficial durante el período lluvioso.

Sin embargo, los informantes recurren a prácticas de manejo sobre los campos que garantizan la permanencia de este microambiente. Al avanzar este microambiente sobre el monte o capuera mediante la tala de los árboles y arbustos y la quema de los mismos 
se favorecen el establecimiento de comunidades herbáceas, lo que impide el establecimiento de plántulas de especies leñosas. Sin embargo, varias plantas útiles que ya fueron mencionadas anteriormente son toleradas. Al respecto los informantes se refieren de la siguiente manera:

"En el campo uno deja siempre por ahí una planta de mandarina o naranja o de guabiyú o de pitanga. Eso deja uno en el campo o en la orilla de los montes para que uno tenga para uno comer. (...) Casi todos son remedio, muchas cosas que tal vez uno cree que no es remedio y es remedio. Quizá uno no conoce por ese nombre pero quizá sí por otro. La canela de veiado [Helietta apiculata Benth.] es muy buena como remedio para los hígados. La mamica de cadela [Fagara sp.] es buena para los riñones, puro espino en la madera. El ariticum [R. emarginata] para una operación, para ayudar a cerrar una operación es lindo. Porque de Ramón Chicharra, muerto, él dice que tomaba para ayudar a cerrar la operación de él, la tomaba en té”. (S. F., 65 años, Cerro Mártires).

Algunos informantes se refirieron a la siembra de grama, consistente en cualquier Poaceae, empleándose mayormente "pasto elefante" [Cenchrus purpureus (Schumach.) Morrone] y "pasto jesuita" [Axonopus compressus (Sw.) P. Beauv.], práctica que acelera el establecimiento del campo. Asimismo, la permanencia del ganado, que ramonea los renovales de gran parte de especies leñosas que prosperan en este microambiente, es una práctica de mantenimiento del campo como microambiente. El retiro de los animales del campo generalmente es seguido por la invasión de "mata campo" (Vernonia tweediana Baker) que vuelve poco productivo este microambiente al disminuir la abundancia de pasturas aptas para el forrajeo. Al contrario de lo expuesto anteriormente la recíproca es menos costosa. La pregunta acerca de las prácticas que fomentan el avance del monte sobre el campo resultó graciosa a la mayoría de los informantes. Las respuestas variaron en torno a "el monte avanza solito" o "sólo sacando la vaca nomás, pero ¿para qué...?”. Entre las plantas "pioneras” en el avance sobre el campo fueron mencionadas:

"Cualquier planta. Y bueno, de los montes puede ser una planta de bacún [A. edulis], de pitanga [E. uniflora], de aruera [L. molleoides], de cualquier cosa. Y viene viniendo toda esa planta tomando cuenta el campo. Y cuando 
se da de cuenta, si es un campo medio chico, él toma cuenta, sí. Encapuera primero, de maderita fina primero, y de a poco va engrosando y se pone viga o se pone un barrotón grueso" (F. B., 74 años, Cerro Mártires).

\subsubsection{Estrategia de Uso Múltiple (EUM)}

De acuerdo a lo antes expresado, el cultivo de los cítricos no se halla relegado sólo al monte frutal o al jardín, sino también a los diferentes espacios considerados como microambientes. Esta estrategia es observada a nivel de las etnovariedades cultivadas pero también a nivel de las comunidades que conforman el paisaje. La presencia de cítricos en todos los microambientes relevados permite establecer una "marcha de maduración" que se inicia en los microambientes más expuestos a la radiación solar (jardin, campo, huerta), siguiendo por aquellos que presentan cobertura poco densa (monte frutal, capuera), culminando con la recolección de los frutos de las variedades "silvestres" (capuerón, monte). Esta práctica que aumenta la disponibilidad de frutos durante el ciclo anual, a su vez, se diversifica aún más mediante el cultivo de diferentes etnovariedades, e incluso - en el caso de los colonos- empleando diferentes portainjertos. Así, situándonos en las "mandarinas", el ciclo de maduración comienza hacia fines del verano con la "mandarina japonesa” (C. reticulata $\mathrm{cv}$. „Okitsu“, injertado sobre "lima" o "trifoliata"), siguiendo por la "mandarina común", luego la "mandarina colorada japonesa (o colorada chica)", las "mandarinas injertadas" (C. reticulata $\mathrm{cv}$. „Encore", „Ellendale"e y „Murcott"), la "mandarina colorada” (C. reticulata cv. „Cleopatra") y, por último, la "mandarina bergamota”, hacia los últimos meses del año. Exceptuando la "mandarina común", presente en todos los microambientes relevados, las demás etnovariedades son cultivadas en el jardín y monte frutal.

5.3.3.5. Las prácticas de manejo y los cambios morfológicos-organolépticos: el caso de las "mandarinas comunes"

De los 15 descriptores empleados localmente para diferenciar las "mandarinas" silvestres de las cultivadas (capítulo 5.2.3.4), 3 corresponden a atributos de la planta (productividad, altura, rapidez fisiológica), 8 a características de los frutos (tamaño, maduración, delicadeza, accesibilidad, dulzor de la pulpa, acidez de la pulpa, cantidad 
de jugo, grosor de la cáscara) y 4 de las hojas (forma, textura, dureza, intensidad del verdor). De todos estos descriptores, fueron seleccionados 6 de acuerdo a la posibilidad de cuantificación y representatividad (número de menciones). Así, las variables seleccionadas comprenden casi el 60\% del total de las menciones (tabla 7).

Los dos primeros componentes (I y II) totalizan el 55\% de la varianza total de las muestras. En general pueden apreciarse tres ejes de resultados: correlación entre variables, influencia del manejo del paisaje en los descriptores seleccionados, y variabilidad intra-grupos. La altura de la planta se correlaciona inversamente con el dulzor y con el volumen de jugo de los frutos, por lo cual las plantas más altas presentan frutos con menor cantidad de azúcares solubles (menos dulces) y menor cantidad de jugo en la pulpa (más secos). El volumen de los frutos (tamaño) y el grosor de las cáscaras están correlacionados positivamente entre sí, a lo que a mayor tamaño de frutos las cáscaras son más gruesas, pero no lo están con los descriptores anteriormente mencionados (Figura 37). La acidez de la pulpa no presenta casi variabilidad.

Tabla 7. Descriptores locales empleados en la diferenciación de las mandarinas comunes para el PCA, bajo distintos tipos de manejo local.

\begin{tabular}{|c|c|c|c|c|}
\hline 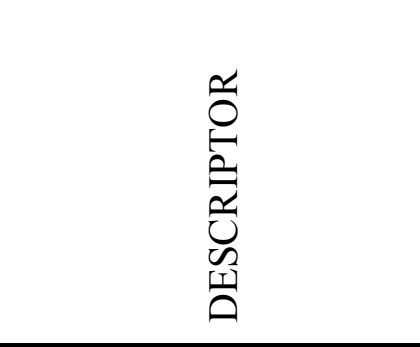 & 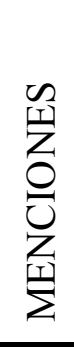 & 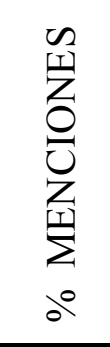 & 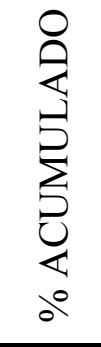 & $\begin{array}{l}\text { 留 } \\
\text { 究 } \\
\text { 帘 }\end{array}$ \\
\hline 1- Dulzor de la pulpa & 16 & 16.3 & 16.3 & grados Brix \\
\hline 2- Tamaño de la fruta & 14 & 14.3 & 30.6 & $\mathrm{ml}$ \\
\hline 3- Altura de la planta & 14 & 14.3 & 44.9 & M \\
\hline 4- Acidez de la pulpa & 7 & 7.1 & 52.0 & $\mathrm{pH}$ \\
\hline 5- Cantidad de jugo & 4 & 4.1 & 56.1 & $\mathrm{ml}$ \\
\hline 6- Grosor de la cáscaras & 3 & 3.1 & 58.2 & $\mathrm{~mm}$ \\
\hline
\end{tabular}

De acuerdo a la disposición espacial de la nube de puntos (que representan a cada fruto medido) las prácticas de manejo sobre los microambientes influyen en la morfología y 
caracteres organolépticos de las "mandarinas" (Figura 38). Esto puede evidenciarse porque las "mandarinas de monte" (silvestres) se agrupan hacia donde se halla el vector "altura de la planta" (primer cuadrante), mientras que las "mandarinas caseras" (cultivadas) se agrupan hacia los vectores "volumen de jugo" y "dulzor de la pulpa" (tercer cuadrante). Las "mandarinas toleradas" (manejo in situ) se hallan intermedias entre las caseras y las de monte. El tamaño del fruto y el grosor de la cáscara son independientes del manejo aunque se encuentran ligeramente correlacionados positivamente con el volumen del jugo. El tipo de manejo no influye en tamaño del fruto y en el grosor de las cáscaras aunque se observa que el grupo de las mandarinas domésticas es menos variable en estos dos descriptores.

Figura 37. Variables empleadas en el PCA. Correlaciones de las variables de acuerdo a los dos primeros componentes principales. Referencias. ${ }^{\circ}$ Brix: cantidad de azúcares solubles en el endocarpo; Vj: Volumen de jugo del endocarpo; altura: altura de la planta; grosor casc: grosor de las cáscaras; y Vf: Volumen del fruto.

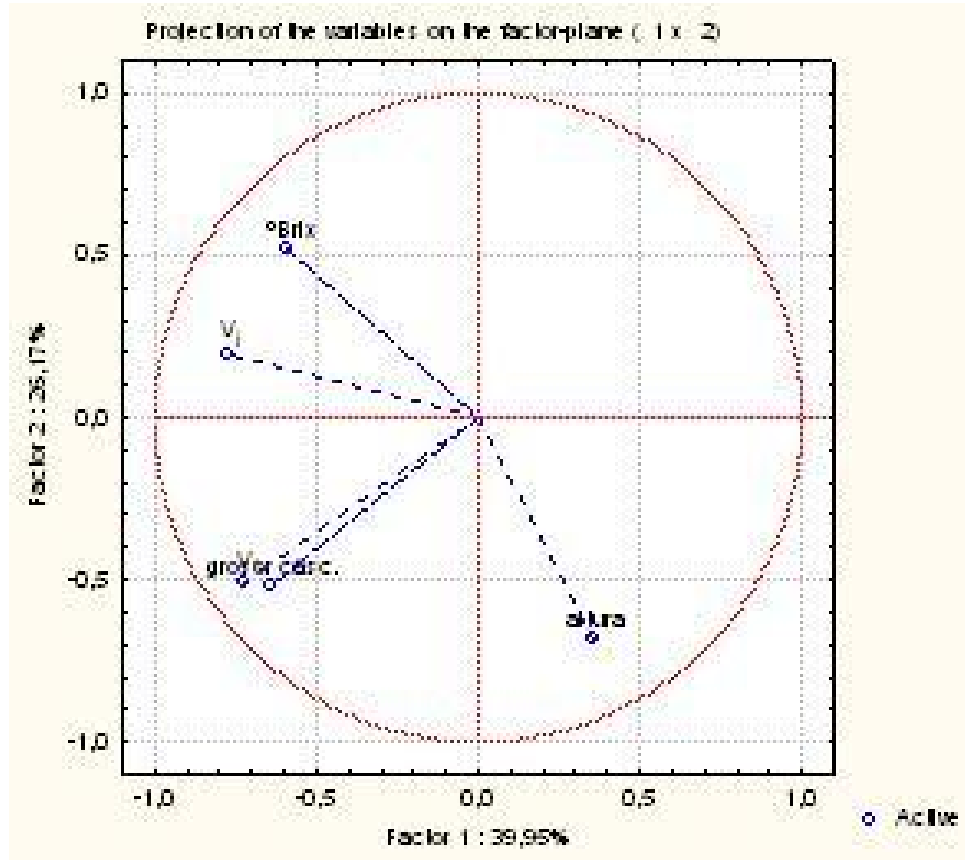

Figura 38. Ordenamiento de las diferentes plantas de "mandarina común" relevadas en Cerro Mártires según tipo de manejo del paisaje. C. Cultivadas en jardín y monte frutal (negro); T: toleradas en campo, rozado y capuera (rojo); S: mandarinas de monte, con bajo manejo (verde). 


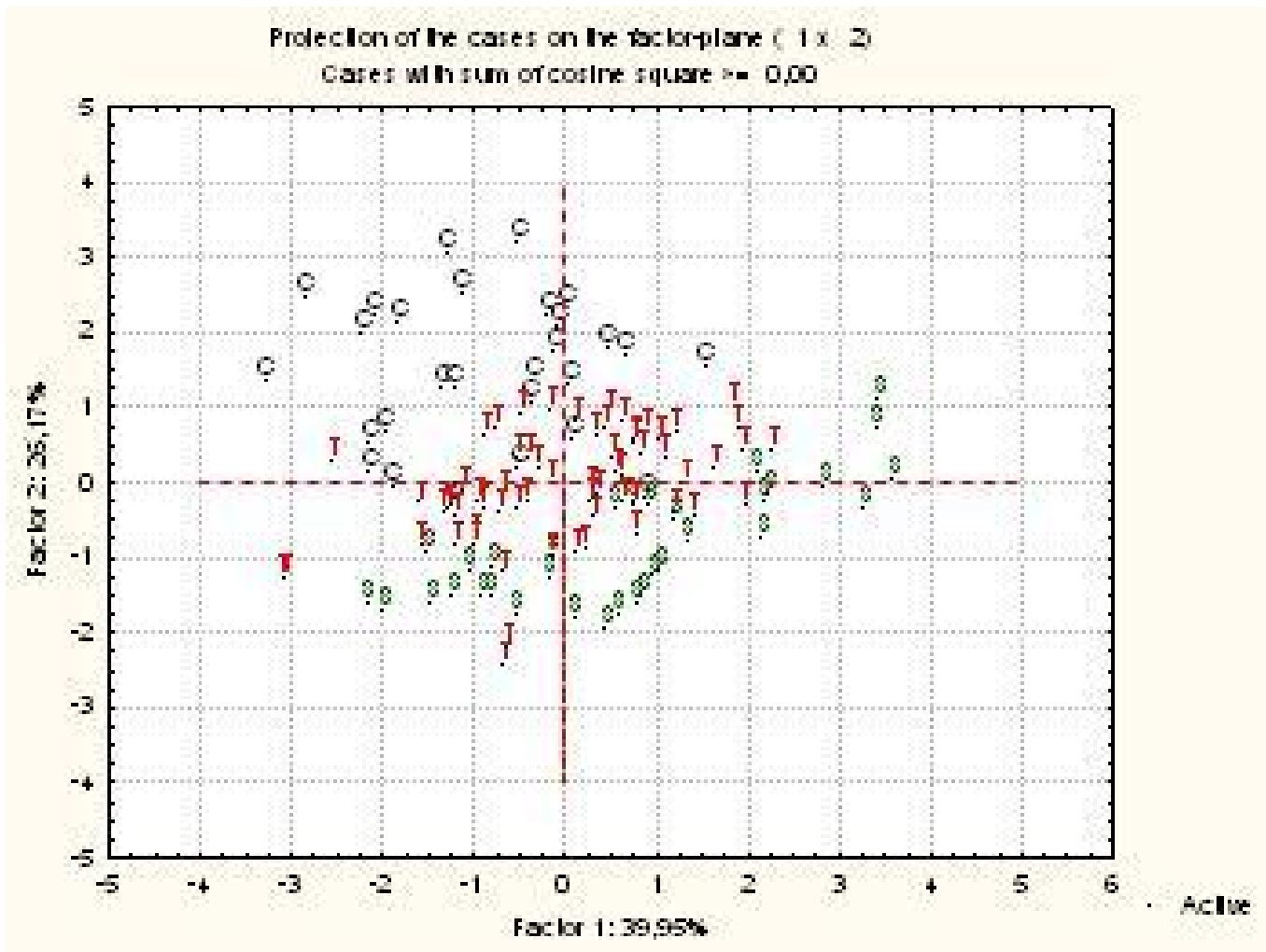

\subsubsection{DISCUSIÓN}

En los cítricos puede apreciarse, dentro un mismo paisaje, un continuum de poblaciones vegetales representantes del proceso de domesticación y que varían desde poblaciones espontáneas o microambientes con baja intervención antrópica (etnovariedades de monte), pasando por aquellas incipientemente domesticadas (caseras), hacia las completamente domesticadas (muchas de las variedades injertadas). Este abanico de posibilidades coincide con el complejo cultivo-maleza-domesticado propuesto por Beebe et al. (1997) para Phaseolus vulgaris. En el mismo, proponen la persistencia de este complejo manteniéndolos en estrecho contacto al cultivarlos, como también la persistencia de prácticas de manejo que resulten en un paisaje incipientemente domesticado y en la tolerancia de variedades arvenses. Con éstas últimas, para el caso de los cítricos se quiere referir a aquellas que ingresan al jardín, monte frutal, huerta y rozado y permanecen como espontáneas. Varios cultivos, especialmente anuales, han sido analizados desde esta perspectiva, resaltando la importancia de las nuevas combinaciones generadas por hibridación de los mismos con las variedades "silvestres" y la importancia para los productores (Jarvis \& Hodgkin, 1999). 
El ingreso de los frutales de monte a la UD, y su consiguiente cambio de nominación, incrementan la diversidad de etnovariedades presentadas en el capítulo 5.1.4.3. Sin embargo, los informantes los perciben como etnovariedades diferentes basándose en los cambios morfológicos-organolépticos representados por el síndrome de domesticación.

Las etnovariedades de monte y caseras representan la misma variedad, sólo que una crece en el monte y la otra en la casa. Este movimiento, descripto claramente para la "papa" (Solanum tuberosum L.) y otros cultivos andinos por Lema $(2013,2014)$ está acompañado por cambios morfológicos y organolépticos. Entre los cítricos, las "mandarinas" cultivadas en los jardines presentan diferencias en altura de la planta, productividad de frutos, dulzor del gomo (cantidad de azúcares solubles presentes en el endocarpo) y cantidad de jugo, con respecto a las que crecen en el monte; mientras que aquellas que crecen en las capueras o campos se ubican transicionalmente entre éstas (Stampella et al., 2013a).

Este mismo flujo ocurre en sentido inverso ("naturalización" o escape de cultivo) y representa el origen de los cítricos de monte ("naranja" y "apepú") a partir de los caseros durante el período jesuítico o colonial. Esto ha sido reportado en la zona para varios frutales, entre ellos "apepú”, “níspero", “limón mandarina”, “pecán”, “té”, "tung", una especie de Butia y Senna macranthera (DC. ex Collad.) H.S. Irwin \& Barneby (Gade, 1976; Krapovickas \& Dematteis, 2008; Delucchi \& Keller, 2010; Hurrell et al., 2011; Keller et al., 2011, 2012, 2013; Stampella et al., 2013b).

La práctica de recolección de plántulas de monte para ser plantadas en los alrededores del hogar o en sistemas productivos fue descrita para Misiones hacia fines del siglo XIX por Ambrosetti (2008a) para la "yerba mate" y para Dioscorea dumetorum (Kunth) Pax en África ecuatorial por Harlan (1992), siendo denominada "protocultura" (Chevalier, 1936 en Harlan, 1992) o "agricultura incipiente". Estos términos fueron criticados por Harris (1989) dado el carácter determinista que representan. Asimismo, representa el origen de muchas variedades, razas locales y cultivares debido a demandas humanas (Vodouhè \& Dansi, 2012).

Sin embargo, la preferencia de plantas semilleras (pies productores de semillas) de familiares y vecinos (plantas caseras) antes que de monte contribuye a la conservación de etnovariedades seleccionadas a lo largo del tiempo (Parra et al., 2010; AguirreDugua et al., 2012). Esta práctica de sembrar variedades de monte y caseras implica 
hibridación y generación de variabilidad, antes que selección y conservación ex situ, contribuyendo, como ya se dijo, a la conservación dinámica del complejo cultivomaleza-domesticado. Las prácticas de manejo se complejizan más aún al tener en cuenta la versatilidad reproductiva de este género que involucra procesos de hibridación inter e intraespecífica, apomixis y poliploidía conocidos como "enjambre híbrido" (Grant, 1989). Por lo tanto, la fijación de características morfofisiológicas de etnovariedades particulares podría realizarse mediante injertos, aislamiento reproductivo (genético, geográfico) o por autopolinización.

Las prácticas empleadas para la implantación de los montes frutales difieren a las descriptas por Sartori (1964), principalmente en la existencia de prácticas de manejo de tolerancia y fomento de otros frutales preexistentes así como de plantas útiles. Así, en este espacio convergen frutales de monte (preexistentes) y cultivados conformando -al igual que el monte peridoméstico- sistemas agroforestales diversos. En las inmediaciones de estos montes frutales suelen instalarse cajones de abejas para aprovechar la intensa floración en la producción de miel. La sombra y los frutos caídos son también aprovechados por los animales menores que rondan el ámbito doméstico y alrededores durante el día (gallinas, patos, gansos, pavos, chanchos, ovejas, perros).

Estos resultados muestran una estrategia de diversificación a diferentes escalas, relacionada tanto a aspectos biológicos como socioculturales. En primer lugar, la diversidad de ambientes donde los cítricos se hallan presentes está relacionada con la EUM a escala de microambientes de las comunidades locales y con la diversidad de grados de relación ser humano-planta (Figura 39) con este género de frutales. En estos ambientes las plantas presentan ligeras diferencias relacionadas al tiempo de maduración, cantidad de jugo, acidez/dulzura del gomo y altura de la planta de acuerdo al microambiente al cual están relacionadas. De esta manera, poblaciones de "mandarina común" pertenecientes a diferentes microambientes presentan características morfofisiológicas particulares de modo que se puede seguir una marcha de maduración desde los ambientes más cercanos al hogar (más expuestos a la radiación solar) hacia aquellos más inmersos en las selvas (capueras, capuerones y montes), ampliando así la disponibilidad temporal de frutas a lo largo del ciclo anual. Estas características morfofisiológicas seleccionadas inconscientemente, y relacionadas a los diferentes microambientes antropogénicos, son denominadas en su conjunto "síndrome de domesticación" (Gepts, 2004; Zohary, 2004). Esto ha sido estudiado en otros frutales 
arbóreos como Chrysophyllum cainito L. donde se ha hallado diferencias significativas en el tamaño de los frutos, concentración de azúcares, cantidad de pulpa (endocarpo), cantidad de compuestos fenólicos (defensa) y grosor del exocarpo, comparando poblaciones cultivadas y silvestres, siendo los dos primeros los más importantes en la diferenciación de las poblaciones (Parker et al., 2010). Lins Neto et al. (2012) encuentran diferencias morfofisiológicas entre diferentes poblaciones de Spondias tuberosa Arruda pertenecientes a diferentes unidades de paisaje (montaña, base de la montaña, pasturas, cultivados, y jardines) pero no significativas como para asegurar tales diferencias. Sin embargo, los frutales pertenecientes a los ambientes antropogénicos (cultivados y jardines) presentan características más estimadas.

Por otra parte, prácticas lesivas como la tala ya son referidas para San Ignacio de fines del siglo XIX (Ambrosetti, 2008a: 87) y constituyen, para el imaginario local, una de las causas de desaparición de los naranjales del monte y de aquellos asociados a las ruinas jesuíticas. Sin embargo, es más posible que la desaparición de los naranjales haya estado relacionada a cambios en las prácticas de manejo y avance del ámbito urbano antes que a prácticas de erradicación localizadas.

Figura 39: Prácticas de manejo sobre los cítricos en los distintos microambiente, indicando las variaciones en las características de algunos descriptores morfofisiológicos. En base a Stampella et al. (2013a).

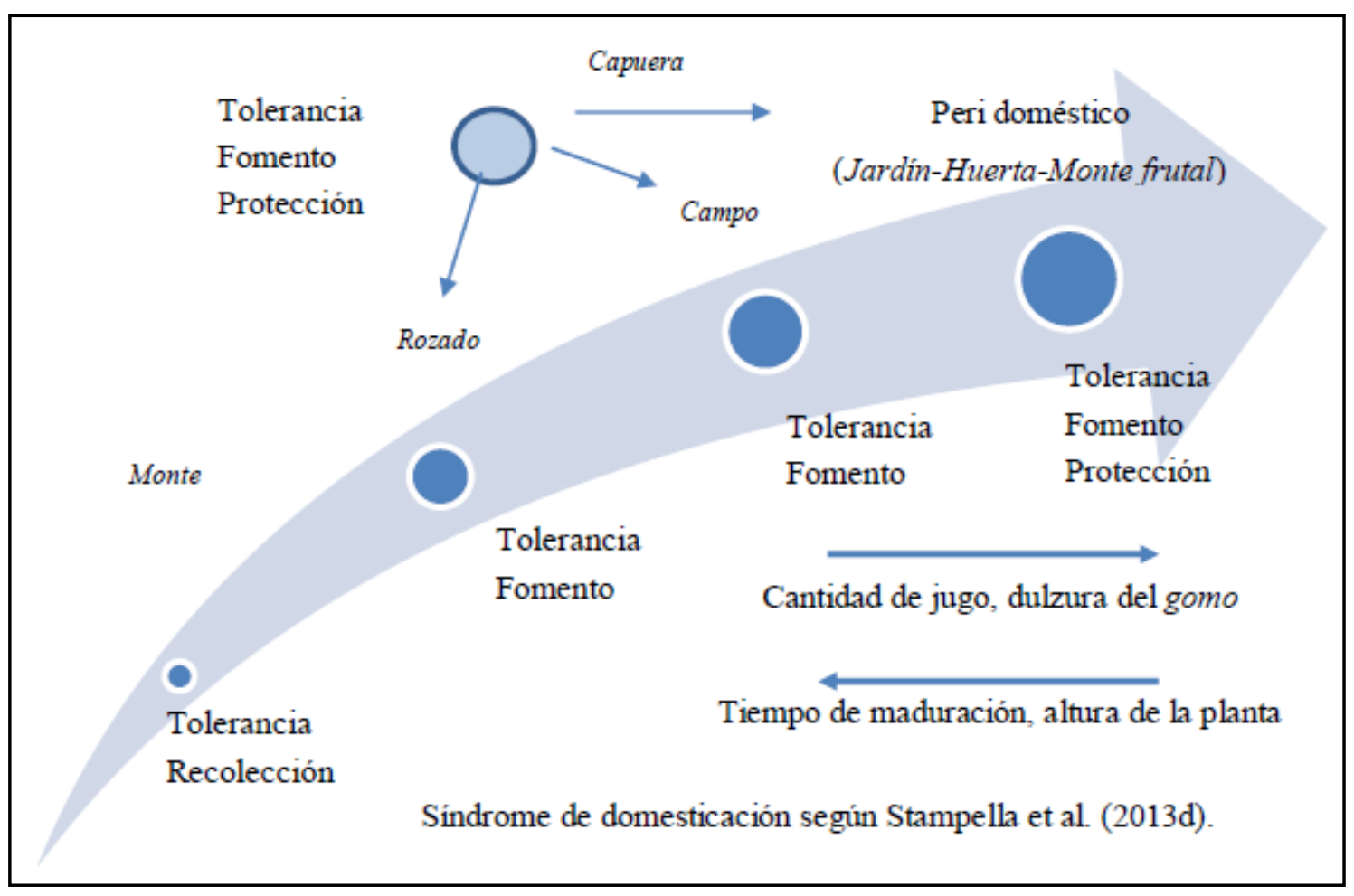


Las incursiones de caza y recolección a los capuerones antes que al monte están relacionadas a intervenciones antrópicas del ambiente de acuerdo a prácticas sustentables enmarcadas en la estrategia de uso múltiple de los recursos (Toledo \& Barreras-Bassols, 2008). De esta manera, la diversidad de plantas útiles se incrementa en microambientes relacionados a este tipo de prácticas como lo demuestra Balée (1993) para el Amazonas brasileño, donde algunos parches de selva, derivados de antiguos rozados, presentan valores de números de individuos, especies y familias, similares a los relevados en los parches de selva densa ("prístina"), pero conformadas principalmente por especies útiles y que prosperan en ambientes disturbados por manejo silvícola. Los estudios enmarcados en la Ecología Histórica enfatizan, entre otras cosas, la naturaleza antropogénica de los ecosistemas considerados "prístinos" al considerar la profundidad temporal de la relación entre las comunidades humanas y el entorno en la conformación de paisajes, entendidos como proyección de la cultura en la naturaleza a través del tiempo (Balée, 1998). 


\subsection{PROPIEDADES MEDICINALES DE LOS CÍTRICOS EN EL SUR DE LA PROVINCIA DE MISIONES (ARGENTINA)}

\subsubsection{INTRODUCCIÓN}

El género Citrus L. (Rutaceae; Aurantioideae) es nativo de las zonas cálidas del S y SE de Asia hasta las zonas templadas de China, Australia e islas del Pacífico sudoccidental, desde donde los musulmanes los dispersaron hacia Medio Oriente, $\mathrm{N}$ de África y Europa a partir del siglo X a XI, con excepción de C. medica L. ya citado por Teofrasto (siglo III a.C.) y Dioscorides (siglo I d.C.) (Ramón-Laca, 2003). A partir del siglo XV son introducidos en América durante el segundo viaje de Colón, fecha desde la cual no cesan las introducciones de nuevos taxa y variedades locales desde diferentes partes del mundo (Stampella et al., 2013c). Este recorrido de los cítricos por distintos lugares geográficos y culturas posiblemente haya enriquecido el elenco de dolencias tratadas con los mismos.

Como ya se planteó en capítulos anteriores, en Argentina son cultivadas distintas variedades comerciales de limones, naranjas, mandarinas, limas y pomelos, principalmente en el NO y NE del país. Esta diversidad no se remite solamente a la cultivada sino también a las poblaciones espontáneas presentes en diferentes paisajes; en especial aquellos con manejo agrosilvícola relacionado a pueblos con actividades de subsistencia. Sin embargo, en estos enclaves tradicionales, no fue relevada la dicotomía nativo/exótico de la flora local, siendo caracterizadas más bien en base a su utilidad o cotidianeidad, por lo cual los cítricos son considerados como "frutales del monte" al igual que muchas Myrtaceae, Annonaceae y Arecaceae nativas abundantes en la zona (Capítulo 6.1). De este modo ocurre una apropiación y resignificación de estos frutales introducidos históricamente que son tomados como elementos identitarios dinámicos (Stampella et al., 2013c). De la misma manera, la "ruda" (Ruta chalepensis L.) forma parte de diferentes culturas del NOA, presente en la medicina natural y sobrenatural (Arenas \& Galafassi, 1994).

A pesar de tratarse de plantas introducidas durante la colonización, la diversidad de variedades empleadas y cultivadas es alta, como también sus usos medicinales en 
numerosos enclaves de América como Bolivia, México, Perú y Argentina (Zamudio et al., 2010; Alonso-Castro et al., 2012; Kujawska et al., 2012; Quiroga et al., 2012; Cadena-González et al., 2013; Monigatti et al., 2013; Odonne et al., 2013).

Los usos medicinales están íntimamente asociados a los conceptos de salud y enfermedad de los pueblos (Hilgert \& Gil, 2006, 2007, 2008). Dado que el trabajo se realiza en una zona pluricultural, con tradiciones diversas, de modo de respetar sus propias valoraciones, se empleará el término "dolencia" o "malestar" para designar lo que la enfermedad (disfunción orgánica) representa para la persona, UD o grupo social, por lo cual debe ser entendida en contextos específicos de normas, significados simbólicos e interacción social (Kleinman, 1980). De esta manera, el enfoque etnoecológico se hace relevante para el abordaje emic o, según Taussig (1995), del punto de vista del paciente sobre su propia enfermedad, que difiere de aquél del médico o curador.

Para Argentina, Paraguay y Brasil son importantes las obras de plantas medicinales de uso popular que aportan información acerca de las plantas empleadas por criollos, M'bya y colonos a partir de fines del siglo XIX. Hieronymus (1882) incluye a los cítricos más conocidos en su Plantae diaphoricae para varias enfermedades relacionadas principalmente al sistema digestivo, además de su uso como antiescorbútico y contra parásitos y venenos. Entre los guaraníes de Paraguay, Bertoni (1927) cita a la "lima sutí" [Citrus $\times$ aurantiifolia (Christm.) Swingle] para el tratamiento de enfermedades epidémicas como malaria y paludismo, comunes en la zona debido a la abundancia de vectores. A partir de mediados del siglo aparecen en Paraguay obras de plantas medicinales de uso popular: Cadogan (1957), Burgstaller (1985) y Rodríguez Barboza (1985) que combinan la nomenclatura guaraní con la hispana, abundando las menciones de los cítricos, especialmente "naranja amarga", "naranja", "limón”, "lima” y "pomelo".

Más específicamente en Misiones se pueden destacar diversos trabajos sobre plantas medicinales algunos de los cuales comparan distintos grupos. Amat \& Yajía (1991) presentan un inventario de las plantas vendidas en el mercado de Posadas, citando entre los cítricos al "apepú" contra la hipertensión y enfermedades respiratorias. Más recientemente, Crivos et al. (2007) mencionan el uso de las cáscaras de "mandarina" en comunidades M'bya para la "rotación del estómago", dolencia relacionada al sistema 
digestivo. Pero es con los trabajos recientes de Keller \& Romero (2006) entre los "criollos" de cercanías de la reserva Yabotí, donde los cítricos presentan valores de uso comparables a las plantas nativas. Esta importancia puede verse, asimismo, en los trabajos de Zamudio et al. (2010) y Zamudio \& Hilgert (2011), en los cuales se explora el empleo de preparaciones compuestas a base de mieles de Apidae en el norte de la provincia; en Kujawska et al. (2012) se indaga comparativamente sobre los remedios empleados por los "criollos" y "polacos"; y en Kujawska \& Hilgert (2014) donde se compara la fitoterapia de los "polacos" del norte misionero con la herbolaria de los polacos en Polonia.

Hilgert \& Gil (2006) han comparado la riqueza de plantas medicinales y los patrones de uso entre diferentes asentamientos del NO de Argentina con distintos grados de aislamiento encontrando mayores valores de riqueza en los enclaves menos aislados. Asimismo, diferentes trabajos analizan la relación directa entre la disponibilidad de los recursos y la importancia cultural de los mismos, argumentando que se usa o se aprende lo que está más cerca de la UD (Phillips \& Gentry, 1993; Ladio \& Lozada, 2000; Albuquerque \& Lucena, 2005; Ladio et al., 2007; Molares \& Ladio, 2012). Sin embargo, también son importantes los procesos de intercambio cultural, más aún en tiempos de globalización, donde los medios de comunicación cumplen un rol primordial (Martínez \& Pochettino, 2004; Pochettino et al., 2008; Ladio \& Molares, 2010).

El caso de los cítricos en la zona en estudio es particular. Se trata de recursos muy comunes en la zona ya que se hallan en varios microambientes de los ámbitos rurales y periurbanos (incluso en el monte) y se encuentran asimismo presentes en los jardines urbanos, lotes baldíos, parques públicos y bordes de las rutas y caminos. Asimismo, las etnoespecies más comunes pueden adquirirse en cualquier comercio, feria o vecino. Sin embargo, si se compara el ámbito urbano con el rural se puede apreciar una disminución del área destinada a espacios verdes (jardines y espacios de vegetación espontánea), mayor lejanía al monte (Domínguez \& Domínguez, 1998; Campillo, 2005; MendozaGarcía et al., 2011), mayor disponibilidad de centros de salud, y menor exposición corporal ante los trabajos que requiere el monte (relacionados a la intemperie y los trabajos pesados) (Crivos et al., 2009). En general la bibliografía es escasa acerca de trabajos que analicen los conocimientos medicinales de acuerdo a un gradiente de urbanización/ruralidad, hallándose sólo el de Mendoza-García et al. (2011) que analizan la riqueza en el uso de las especies medicinales pero no de las dolencias tratadas con las 
mismas. Ahora bien ¿este gradiente de urbanización/ruralidad incide en el repertorio de etnoespecies empleadas y en los conocimientos medicinales? Al respecto, se propone la siguiente hipótesis: la riqueza y diversidad de cítricos aumenta en cercanía a zonas con actividades productivas rurales, en particular la agrosilvícola, ya que conllevan modificaciones en el ambiente que favorecen su establecimiento y dispersión. Asimismo, habrá un gradiente de disminución de riqueza y diversidad entre dichas zonas rurales, el ámbito periurbano y urbano. Por lo tanto, esta diversidad de cítricos asilvestrados o reproducidos por semillas en la provincia de Misiones estará asociada a diferentes actividades productivas (en particular aquellas que involucran producción ganadera extensiva), por lo tanto esperamos hallar menor diversidad de estos recursos en sitios poco modificados. En contextos urbanos, con poblaciones de raíces culturales comparables, habrá mayor diversidad y uso de cítricos espontáneos en los barrios con espacios verdes de mayores dimensiones.

El objetivo del presente apartado es explorar las etnoespecies de cítricos empleadas con fines medicinales, así como las dolencias tratadas con las mismas en dos departamentos del sur de la provincia de Misiones, limítrofes con Paraguay y Brasil, respectivamente; y analizar la dinámica de estos conocimientos en un gradiente de urbanización/ruralidad y de acuerdo al manejo agrosilvícola de las comunidades locales.

\subsection{2.ÁREA DE ESTUDIO Y POBLACIÓN}

Para el desarrollo de este capítulo se trabajó con la totalidad de los enclaves descritos en el capítulo 3, es decir en los departamentos de San Ignacio y Concepción de la Sierra (Misiones, Argentina) ubicados en las cuencas de los ríos Paraná (CP) y Uruguay $(\mathrm{CU})$, respectivamente. En cada uno de ellos se discriminaron 3 sitios de muestreos: urbano, periurbano y rural, detallados en la Tabla 2 (capítulo 3.3). Del mismo modo, en la parte introductoria de esta tesis se explican en detalle los elementos socioculturales y ambientales de los sitios estudiados.

En los enclaves urbanos la mayoría de los entrevistados residen en casas de material, en terrenos que no superan $\operatorname{los} 600 \mathrm{~m}^{2}$; se desempeñan en diversas profesiones, son jubilados o amas de casa. En esta situación de urbanismo los espacios verdes familiares 
se destinan al implante de jardines y pequeñas huertas; los que se disponen alrededor del hogar.

Hacia los enclaves periurbanos, las actividades laborales más frecuentes en estos asentamientos -además de los mencionados para el ámbito urbano-son como jornaleros (o "changueros"), chacreros, empleados en empresas de yerba mate (LC), en la extracción de lajas y en olerías (PV). Las viviendas están confeccionados con madera y mampostería, sobre terrenos un poco mayores que en las ciudades y con espacios de vegetación espontánea. La superficie cultivable se incrementa en la mayoría de los casos con huertas que asemejan a rozados de mandioca, maíz, batata, porotos y algunos frutales, comunes e injertados.

En cambio, en los ámbitos rurales la mayoría de los informantes son chacreros o amas de casa chacreras (de profesión, aunque realizan distintos trabajos temporales en empresas forestales, yerbateras y tealeras). Las viviendas son de madera -recientemente con techos de chapa de zinc- con la adición -en algunos casos- de casas recientes de mampostería (Figura 16, capítulo 5.2). En prácticamente todos los casos la superficie destinada al cultivo es mayor a 25 hectáreas. En ambas cuencas, los enclaves rurales están conformados por caseríos dispersos agrupados relativamente próximos a las escuelas primarias. Cuando los rozados en uso se encuentran alejados de las viviendas se construyen casas temporales de madera, ramas y adobe; las que, luego de abandonadas, devienen en taperas. Dependiendo del acceso a la tierra los campesinos se apropian del paisaje mediante la estrategia de uso múltiple, con una economía por lo general de subsistencia en la que se combinan prácticas de roza y quema, horticultura y sistemas agroforestales a pequeña escala, ganadería, caza y recolección en algunos sectores.

Se observaron unas pocas UD que venden su cosecha y productos elaborados (conservas, dulces, mermeladas, derivados lácteos) en las ferias francas de San Ignacio y Concepción. En la mayoría de los casos correspondieron a familias descendientes de colonos ucranianos, polacos y alemanes. Para el caso de Cerro Mártires las características de las fincas y de los pobladores coinciden con las descriptas por Granitto \& Sarandón (2002) para el paraje de San Juan de la Sierra, situado a 10 kilómetros al ONO, donde predominan las prácticas agrosilvícolas de subsistencia. Así, dentro de las familias con superficies intermedias se caracterizan por la articulación de su producción 
con los mercados locales y regionales, como también menores superficies destinadas a la producción y eventual relación de dependencia de algunos de los residentes de la misma.

Los enclaves estudiados son muy diversos culturalmente, conformados por convivencia -a veces incluso en una misma UD- de "criollos" o "campesinos" (descendientes de los primeros colonizadores y guaraníes, "paisanos" (M'bya), "colonos" o "polacos" (descendientes de los inmigrantes de principios de siglo XX) y "gringos" (habitantes de las ciudades que se establecen -o establecen sus sistemas productivos- en los ámbitos rurales). Sin embargo de acuerdo a la cercanía con las fronteras de los países vecinos, el grupo mayoritario de los "criollos" se relaciona a ambos países, hablando guaraní o portugués (o mezclas con español, denominados localmente guarañol y portuñol, respectivamente). Hay que destacar la importancia de la presencia de inmigrantes de los vecinos países de Paraguay y Brasil (sur) establecidos a lo largo de estos siglos.

\subsubsection{MATERIALES Y MÉTODOS}

Los trabajos de campo fueron realizados de acuerdo a lo descripto en la metodología general. Para indagar acerca de los usos medicinales de los cítricos se relevaron un total de 36 UD, 17 correspondientes a la cuenca del Paraná y las restantes a la cuenca del Uruguay. Todas las familias fueron visitadas al menos en dos oportunidades, cuyos informantes variaron en edad desde 12 a 88 años. Durante las entrevistas, caminatas a los distintos espacios y encuestas, se indagó acerca de las dolencias tratadas con los cítricos, etnoespecies y etnovariedades empleadas, partes empleadas, formas de preparación, administración y otras plantas y compuestos empleados en la elaboración de los preparados, obteniendo apreciaciones locales de la diversidad y las prácticas a partir del discurso.

Para el análisis de los datos obtenidos se empleó el programa Excel. Se realizaron cálculos de Importancia Relativa (IR) para cada una de las etnoespecies en las diferentes situaciones a contrastar (Albuquerque et al., 2014). El índice de IR indica aquellas plantas más importantes de acuerdo a su versatilidad, o sea, que presentan mayor número de dolencias tratadas y sistemas corporales. Asimismo, este índice se halla relativizado con la especie más versátil relevada, por lo cual los valores de IR varían 
entre 0 y 2. Para evaluar la similitud en el elenco de dolencias para las distintas cuencas y gradiente de urbanización/ruralidad se calculó el índice de Simpson (Sánchez \& López, 1988). Este índice porcentual puede ser interpretado como la proporción de dolencias compartidas - de acuerdo a las dos situaciones a comparar- con respecto a aquella situación con menores dolencias tratadas con el recurso herbolario en estudio.

Para analizar si existe una relación entre el manejo del ambiente y el gradiente de urbanización/ruralidad, en cuanto al uso medicinal de las distintas especies, dado que en todos los casos con manejo agrosilvícola alto el uso reportado fue siempre exclusivamente en el ámbito rural, estos datos fueron excluidos del análisis del chi cuadrado. El resto de las situaciones se analizaron con la corrección de Yates (por poseer ceros en las tablas de contingencia) entre gradiente de urbanización/ruralidad (urbano, periurbano, rural) e intensidad de las prácticas agrosilvícolas (intermedio, sin manejo) usando la cantidad de familias que mencionaron usos medicinales de cada especie. Quedó fuera de este análisis la "cidra" por no tener suficientes datos (sólo uno distinto de cero).

\subsubsection{RESULTADOS}

\subsubsection{La filiación de los informantes y sus padres en los 2 departamentos estudiados}

La mayoría de los informantes son nacidos en el mismo departamento donde hoy se encuentran. Así, para San Ignacio y alrededores (cuenca del Paraná) se halló que el 70\% son nacidos en el departamento, 18\% nacidos en otros departamentos (Gral. Belgrano, Oberá, Libertador Gral. San Martín) y una persona nacida en Paraguay y una en Brasil. Para Concepción y alrededores (cuenca del Uruguay) ocurre algo similar, el 75\% es nacido en el departamento, 20\% en otros (Apóstoles, L. N. Além, Eldorado) y una persona en Brasil (Figura 40A).

La situación cambia al considerar los padres de los informantes. Para San Ignacio, el $31 \%$ son nacidos en Paraguay, 29\% son nacidos en el departamento, $11 \%$ en otros departamentos de la provincia (Santa Ana, Oberá, Gral. Belgrano, Eldorado), 11\% en Corrientes, 6\% en Brasil, 6\% en Europa (Turquía, Italia) y 3\% con ascendencia directa M'bya. Así, los padres de informantes nacidos en Paraguay ascienden al tercio del total. En Concepción, el 53\% son nacidos en el departamento, 20\% en Brasil (especialmente 
Estado de Rio Grande do Sul), 12,5\% en otros departamentos (Apóstoles, San Javier, Posadas), 7,5\% en Europa (Ucrania, Polonia), 5\% en otra provincia (Corrientes, Buenos Aires) y $2,5 \%$ de ascendencia M'bya (Figura 40B).

Figura 40. A. Número de informantes por lugar de nacimiento. B. Número de padres de informantes por lugar de nacimiento. Referencias: SI, S. IGN: San Ignacio; G. Belgr.: General Belgrano; LIB. SM: Libertador Gral. San Martín; C: Concepción; S.JAV: San Javier; S. ANA: Santa Ana; OBERA: Oberá; AP, APOST: Apóstoles; AL: L. N. Além; ELD: Eldorado; CAP (Posad.): Posadas; BS.AS.: Buenos Aires; CORR: Corrientes; BR: Brasil; y PAR: Paraguay; EUR: Europa; MBYÁ: descendiente de M'bya-guaraní.
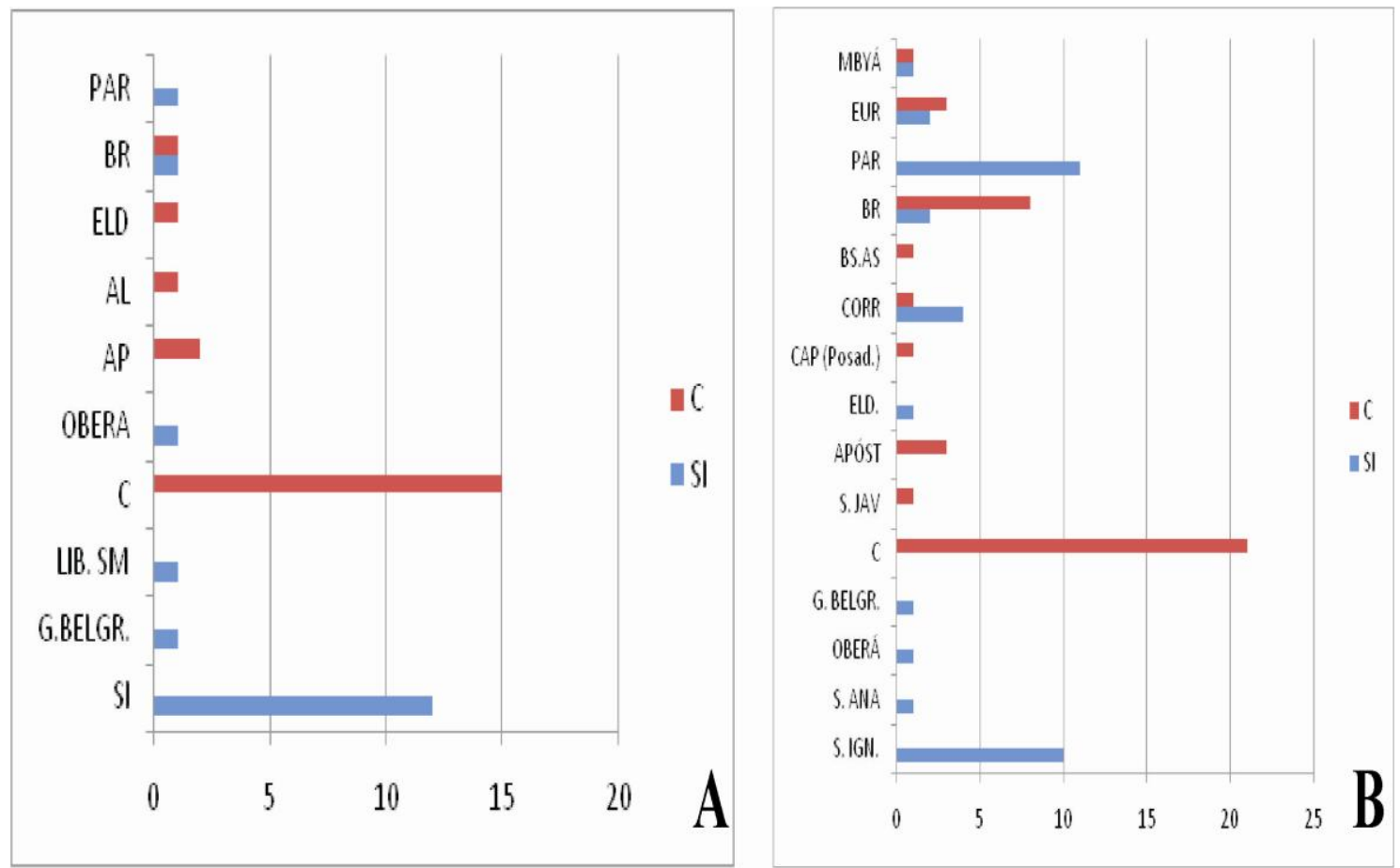

\subsubsection{La importancia de los cítricos en la medicina herbolaria local}

Se obtuvieron 209 referencias acerca de preparaciones medicinales que involucran 7 etnoespecies de cítricos de las 9 que se han relevado en la zona (Tabla 8). Las etnoespecies mencionadas -con el porcentaje de menciones entre paréntesis- son “limón” (23,9\%), “naranja” (19,1\%), “apepú” (17,7\%), “pomelo” $(15,3)$, “lima” $(14,8)$, "mandarina" $(8,6 \%)$ y "cidra" $(0,5 \%)$. Estas menciones se refieren principalmente a variedades comunes, es decir aquellas propagadas mediante semillas (no injertadas), que pueden ser caseras o de monte, aún cuando se prefieren las últimas, asegurando que "tienen más remedio". No obstante, los informantes incluyeron distintos microambientes de la UD como sitios de colecta. Asimismo, las menciones 
correspondientes al "limón real" y al "limón sutil" son escasas con respecto al "limón mandarina" (este último es considerado localmente como el "limón común").

En ambas cuencas se emplean las mismas etnoespecies, con excepción de la "cidra" con sólo una mención en la cuenca del Uruguay. Sin embargo, el porcentaje de menciones para cada etnoespecies varía según la cuenca. La "naranja" y el "apepú" se asocian a la cuenca del Uruguay y del Paraná, respectivamente (Figura 41).

Tabla 8. Etnoespecies de Citrus y microambientes donde son recolectadas. Se ha separado la afiliación sistemática propuesta por D. Mabberley y The Plant List (2013) para apreciar las diferencias.

\begin{tabular}{|c|c|c|c|c|c|}
\hline Etnoespecie & $\begin{array}{c}\% \text { de } \\
\text { menciones }\end{array}$ & C. N. (Mabberley) & $\begin{array}{l}\text { C. N. (The } \\
\text { Plant List) }\end{array}$ & $\begin{array}{l}\text { Sitio de } \\
\text { colecta }\end{array}$ & Voucher \\
\hline Cidra & 0,5 & Citrus maxima & C. maxima & $\begin{array}{l}\text { Jardin } \mathrm{y} \\
\text { monte } \\
\text { frutal }\end{array}$ & Stampella 34, 62 \\
\hline Lima & 14,8 & $\begin{array}{l}\text { Citrus } \times \text { limon ,lima } \\
\text { de Persia }\end{array}$ & C. limettioides & \multirow{6}{*}{$\begin{array}{l}\text { Jardin, } \\
\text { monte } \\
\text { frutal, } \\
\text { campo, } \\
\text { rozado, } \\
\text { capuera } \\
\text { y monte }\end{array}$} & Stampella 35, 79 \\
\hline $\begin{array}{l}\text { Pomelo } \\
\text { blanco y } \\
\text { rosado }\end{array}$ & 15,3 & Citrus $\times$ aurantium & C. paradisi & & $\begin{array}{l}\text { Stampella \& Hilgert } 19 ; \\
\text { Stampella } 39,78,110\end{array}$ \\
\hline $\begin{array}{l}\text { Mandarina } \\
\text { común }\end{array}$ & 8,6 & $\begin{array}{l}\text { Citrus reticulata } \\
\text { „Común de } \\
\text { Concordia }^{\text {Ce }}\end{array}$ & C. reticulata & & $\begin{array}{l}\text { Stampella } 36,43,44,99 \text {, } \\
100\end{array}$ \\
\hline $\begin{array}{l}\text { Apepú } \\
\text { común }\end{array}$ & 17,7 & $\begin{array}{l}\text { Citrus } \times \text { aurantium } \\
\text { „Naranja amarga }\end{array}$ & C. aurantium & & $\begin{array}{l}\text { Stampella \& Hilgert } 10, \\
11 ; \text { Stampella } 30,47,53, \\
82,89,108\end{array}$ \\
\hline $\begin{array}{l}\text { Naranja } \\
\text { común }\end{array}$ & 19,1 & $\begin{array}{l}\text { Citrus } \times \text { aurantium } \\
\text { „Valencia }\end{array}$ & C. sinensis & & $\begin{array}{l}\text { Stampella } 37,107,113, \\
117,128\end{array}$ \\
\hline \multirow{2}{*}{$\begin{array}{l}\text { Limón } \\
\text { mandarina, } \\
\text { limón real y } \\
\text { limón sutil }\end{array}$} & \multirow{2}{*}{23,9} & $\begin{array}{l}\text { Citrus } \times \text { taitensis } \\
\text {,Rangpur }\end{array}$ & C. reticulata & & $\begin{array}{l}\text { Stampella \& Hilgert } 7,8 ; \\
\text { Stampella } 46,80,115, \\
130\end{array}$ \\
\hline & & Citrus $\times$ aurantiifolia & $\begin{array}{l}\text { C. latifolia y } C \text {. } \\
\text { aurantiifolia }\end{array}$ & $\begin{array}{l}\text { Jardin y } \\
\text { monte } \\
\text { frutal }\end{array}$ & Stampella 95 \\
\hline
\end{tabular}

\subsubsection{Dolencias}

Se relevaron 34 dolencias (emic) tratadas con los cítricos que fueron estructuradas en 8 sistemas corporales (etic) (Tabla 9). Del total, el 35\% de las menciones pertenecen a gripes y fiebres, $17 \%$ a padecimientos respiratorios, $13 \%$ digestivos, $12 \%$ relacionados al sistema sanguíneo, 9\% de medicina tradicional, $8 \%$ a dolencias nerviosas, 3\% dérmico y $2 \%$ a padecimientos ósteo-articulares (Figura 42A). Las dolencias más mencionadas fueron, en orden decreciente: para gripe (22\%), para bajar la presión 
(11\%), para la tos $(9 \%)$, sedante $(8 \%)$, para la fiebre $(7 \%)$, refrescante $(7 \%)$, digestivo (7\%) y como preventivo y vitamínico (6\%). Las demás 26 dolencias mencionadas se corresponden con un 22\% del total (Figura 42B).

Figura 41. Porcentaje total de menciones para las etnoespecies (TOTAL, azul) y según cuenca: Cuenca del Paraná (CP, morado) y Cuenca del Uruguay (CU, verde).

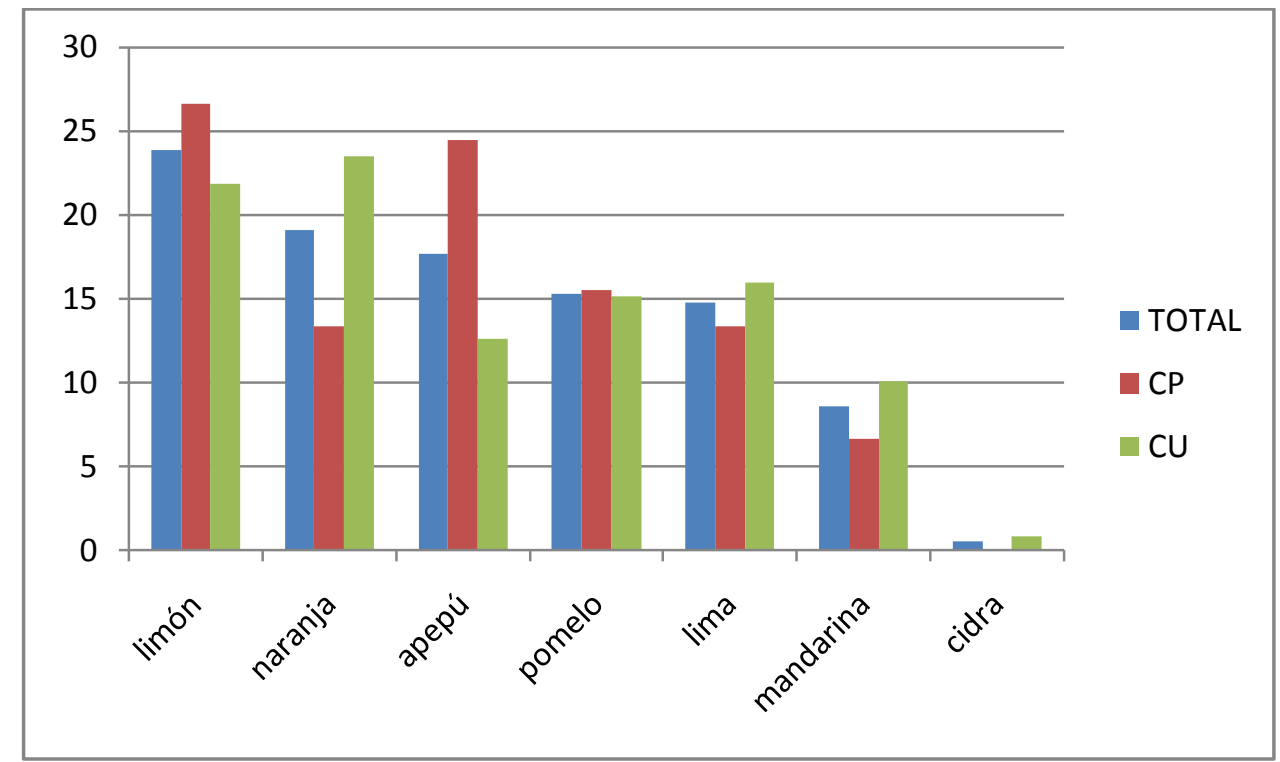

Tabla 9. Dolencias agrupadas de acuerdo al sistema corporal asignado e indicando el número de menciones según cuenca y gradiente de urbanización/ruralidad.

\begin{tabular}{|c|c|c|c|c|c|c|}
\hline \multirow{3}{*}{ SISTEMA } & \multirow[b]{3}{*}{ DOLENCIA } & \multicolumn{5}{|c|}{ NÚMERO DE MENCIONES } \\
\hline & & \multicolumn{2}{|c|}{ CUENCA } & \multicolumn{3}{|c|}{ ENCLAVE } \\
\hline & & $\mathbf{C P}$ & $\mathbf{C U}$ & URB & PERI & RUR \\
\hline \multicolumn{2}{|c|}{ Gripes y fiebres } & 26 & 49 & 25 & 20 & 30 \\
\hline & Gripe & 13 & 36 & 16 & 8 & 25 \\
\hline & Fiebre & 7 & 7 & 4 & 8 & 2 \\
\hline & Preventivo/vitamínico & 6 & 6 & 5 & 4 & 3 \\
\hline \multicolumn{2}{|l|}{ Respiratorio } & 16 & 20 & 9 & 11 & 16 \\
\hline & Asma/broncoespasmos & 2 & 0 & 1 & 0 & 1 \\
\hline & Bronquitis & 1 & 0 & 0 & 0 & 1 \\
\hline & Catarrera/expectorante & 1 & 1 & 1 & 0 & 1 \\
\hline & $\begin{array}{l}\text { Angina/dolor de } \\
\text { garganta }\end{array}$ & 2 & 3 & 1 & 3 & 1 \\
\hline & $\begin{array}{l}\text { Enfermedades } \\
\text { respiratorias }\end{array}$ & 2 & 0 & 2 & 0 & 0 \\
\hline & Resfrío & 1 & 4 & 0 & 3 & 2 \\
\hline & Para la tos & 7 & 12 & 4 & 5 & 10 \\
\hline \multicolumn{2}{|l|}{ Digestivo } & 20 & 8 & 13 & 3 & 12 \\
\hline & Acidez & 1 & 0 & 0 & 0 & 1 \\
\hline & Para adelgazar & 0 & 1 & 1 & 0 & 0 \\
\hline & Colitis & 1 & 0 & 1 & 0 & 0 \\
\hline & Para no vomitar & 1 & 0 & 1 & 0 & 0 \\
\hline & Diabetes & 2 & 0 & 1 & 0 & 1 \\
\hline & Digestivo & 9 & 5 & 7 & 1 & 6 \\
\hline & Dolor de panza & 2 & 0 & 1 & 1 & 0 \\
\hline & Hemorroides & 1 & 0 & 0 & 0 & 1 \\
\hline
\end{tabular}




\begin{tabular}{|c|c|c|c|c|c|c|}
\hline & Males del hígado & 1 & 1 & 0 & 0 & 2 \\
\hline & $\begin{array}{l}\text { Para ir de cuerpo } \\
\text { (laxante) }\end{array}$ & 1 & 0 & 0 & 1 & 0 \\
\hline & Para vomitar & 1 & 0 & 0 & 0 & 1 \\
\hline & Para la vesícula & 0 & 1 & 1 & 0 & 0 \\
\hline \multicolumn{2}{|l|}{ Sanguíneo } & 8 & 17 & 5 & 10 & 10 \\
\hline & Bajar la presión & 8 & 16 & 5 & 10 & 9 \\
\hline & Afinar la sangre & 0 & 1 & 0 & 0 & 1 \\
\hline \multicolumn{2}{|c|}{ Medicina tradicional } & 9 & 9 & 2 & 8 & 8 \\
\hline & Refrescante & 7 & 7 & 2 & 6 & 6 \\
\hline & Pasmo & 2 & 2 & 0 & 2 & 2 \\
\hline \multicolumn{2}{|l|}{ Nervioso } & 9 & 8 & 8 & 3 & 6 \\
\hline & Sedante/tranquilizante & 9 & 7 & 8 & 2 & 6 \\
\hline & Para el corazón & 0 & 1 & 0 & 1 & 0 \\
\hline \multicolumn{2}{|l|}{ Dérmico } & 1 & 5 & 1 & 1 & 4 \\
\hline \multirow{5}{*}{ Dermico } & Aftas en la boca & 0 & 1 & 1 & 0 & 0 \\
\hline & $\begin{array}{l}\text { Antiinflamatorio para } \\
\text { picaduras }\end{array}$ & 0 & 1 & 0 & 0 & 1 \\
\hline & Antiséptico & 0 & 2 & 0 & 0 & 2 \\
\hline & Dolor de dientes & 0 & 1 & 0 & 0 & 1 \\
\hline & Para matar piojos & 1 & 0 & 0 & 1 & 0 \\
\hline \multicolumn{2}{|c|}{ Ósteo-articular } & 2 & 2 & 0 & 1 & 3 \\
\hline & $\begin{array}{l}\text { Dolor de huesos y } \\
\text { columna }\end{array}$ & 2 & 2 & 0 & 1 & 3 \\
\hline \multicolumn{2}{|l|}{ TOTAL } & 91 & 118 & 63 & 57 & 89 \\
\hline
\end{tabular}

De acuerdo a las dolencias tratadas las etnoespecies adquieren distinta importancia según la cuenca considerada (Tabla 10).

Mientras en la cuenca del Uruguay son más importantes "naranja" (2), "limón" (1,94) y "mandarina" (1,52); en la cuenca del Paraguay prevalecen el "apepú" (2), "pomelo" $(1,36)$ y "limón" $(1,36)$. La "lima” y el "pomelo" tienen similares IR en ambas cuencas, en cambio a la naranja (1 er y 4to lugar) y a la mandarina (3er y 6to lugar) se les asignan importancias diferentes (Fig. 43A).

$\mathrm{Al}$ analizar si hay diferencias en la frecuencia de los usos medicinales en familias que residen en sitios con distinto grado de acceso a mercados y servicios de salud, por una parte, con diferentes superficies donde implantar los cítricos, por otra, y con diferente proximidad a áreas boscosas donde proveerse de estos frutales adventicios (es decir según el gradiente entre urbano, periurbano y rural), se han hallado diferencias de acuerdo a las etnoespecies más importantes en cada caso y en la equitatividad de las mismas. En las ciudades, el "pomelo", "limón”, “apepú” y "naranja” poseen valores similares $(2 ; 1,89 ; 1,86$ y 1,86 , respectivamente), mientras que "lima" $(1,18)$ y "mandarina" $(0,93)$ son -claramente- menos importantes. 
Figura 42. Número de menciones para A. los sistemas corporales tratados, y B. las dolencias tratadas con los cítricos.
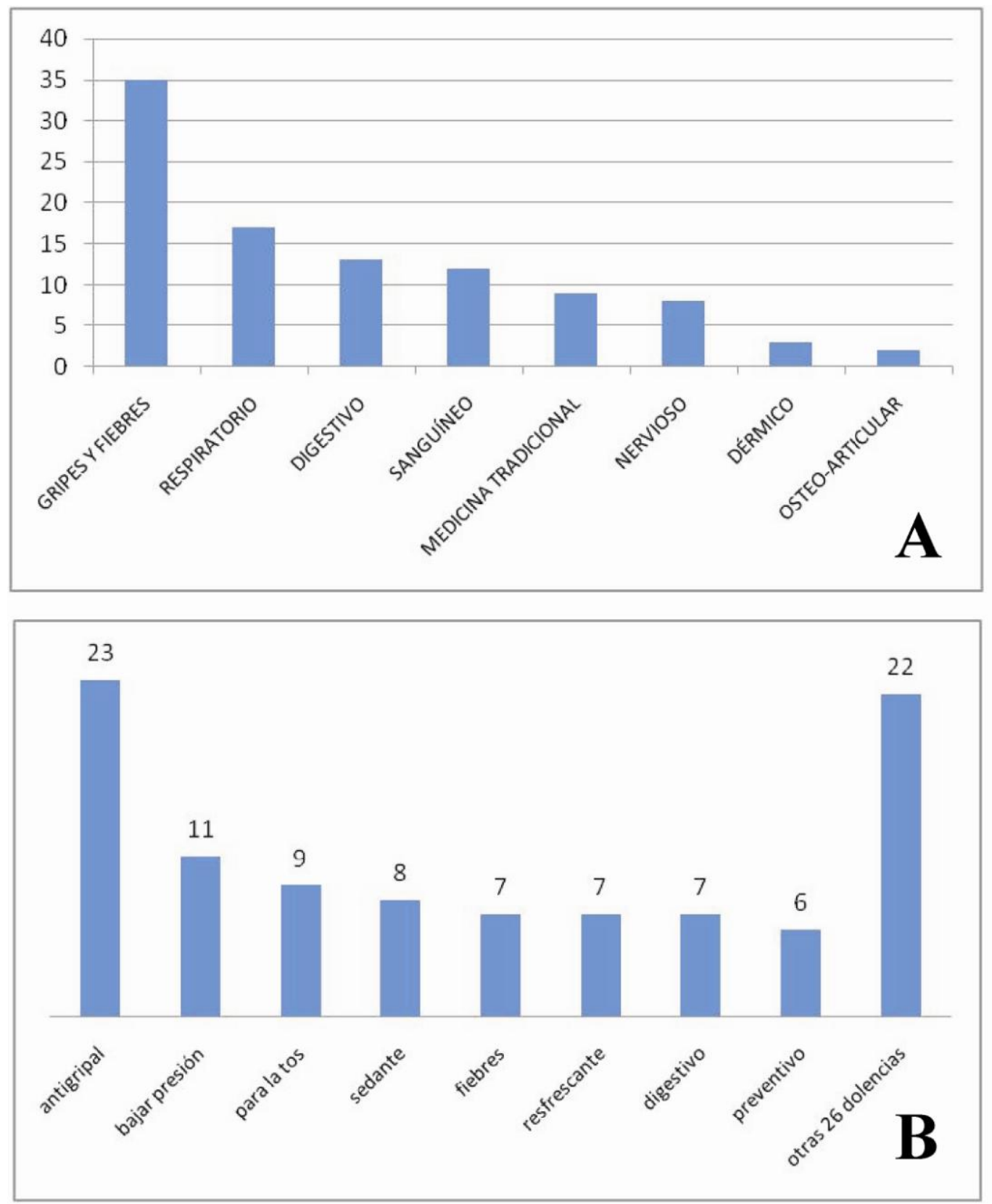

Al considerar el ámbito rural puede verse que todos los valores de IR son mayores a 1,41 marcando una importancia de todas las etnoespecies en el tratamiento de las dolencias. Asimismo, la importancia decrece con la siguiente serie: "naranja”, "limón”, "apepú", "mandarina", "lima” y "pomelo" $(2 ; 1,86 ; 1,61 ; 1,56 ; 1,51$ y 1,41, respectivamente). En los ámbitos periurbanos, está acentuada la importancia del “apepú" (2), bastante menos la "naranja” $(1,38)$ y luego todas las demás etnoespecies con RI menor a 0,86 (Figura 43B). 
Tabla 10. Cálculo de IR para cada etnoespecie según Cuenca y gradiente de urbanización/ruralidad. Referencias: CP: Cuenca del Paraná; CU: Cuenca del Uruguay; URB: urbano; PERI: periurbano; RUR: rural.

\begin{tabular}{|l|c|c|c|c|c|c|c|c|}
\hline \multirow{2}{*}{ ETNOESPECIE } & \multicolumn{9}{|c|}{ IR } \\
\cline { 2 - 9 } & \multicolumn{2}{|c|}{ CUENCA } & \multicolumn{2}{c|}{$\begin{array}{c}\text { GRADIENTE DE } \\
\text { URBANIZACIÓN/ } \\
\text { RURALIDAD }\end{array}$} & \multicolumn{3}{c|}{$\begin{array}{c}\text { MANEJO } \\
\text { AGROSILVÍCOLA }\end{array}$} \\
\cline { 2 - 9 } & CP & CU & URB & PERI & RUR & NO & MEDIO & SI \\
\hline CIDRA & 0 & 0,23 & 0 & 0,26 & 0 & 0,24 & 0 & 0 \\
\hline LIMA & 0,86 & 0,85 & $\mathbf{1 , 1 8}$ & $\mathbf{0 , 5 2}$ & 1,51 & 0,71 & 1,25 & 1,29 \\
\hline POMELO & 1,36 & 1,30 & $\mathbf{2}$ & $\mathbf{0 , 8 6}$ & 1,41 & 1,48 & 1,25 & 1,13 \\
\hline APEPÚ & $\mathbf{2}$ & $\mathbf{1 , 0 7}$ & 1,86 & 2 & 1,61 & 1,79 & 1,88 & $\mathbf{1 , 1 3}$ \\
\hline NARANJA & $\mathbf{1}$ & $\mathbf{2}$ & 1,86 & $\mathbf{1 , 3 8}$ & $\mathbf{2}$ & 1,71 & 1,75 & 1,62 \\
\hline MANDARINA & $\mathbf{0 , 6 4}$ & $\mathbf{1 , 5 2}$ & $\mathbf{0 , 9 3}$ & $\mathbf{0 , 6 1}$ & $\mathbf{1 , 5 6}$ & 1,10 & 1,25 & 1,05 \\
\hline LIMÓN & $\mathbf{1 , 3 6}$ & $\mathbf{1 , 9 4}$ & 1,89 & $\mathbf{0 , 7 9}$ & 1,86 & 2 & 2 & 2 \\
\hline
\end{tabular}

Figura 43. Cálculo de IR para cada etnoespecie según A. Cuencas, y B. Gradiente de urbanización/ruralidad.
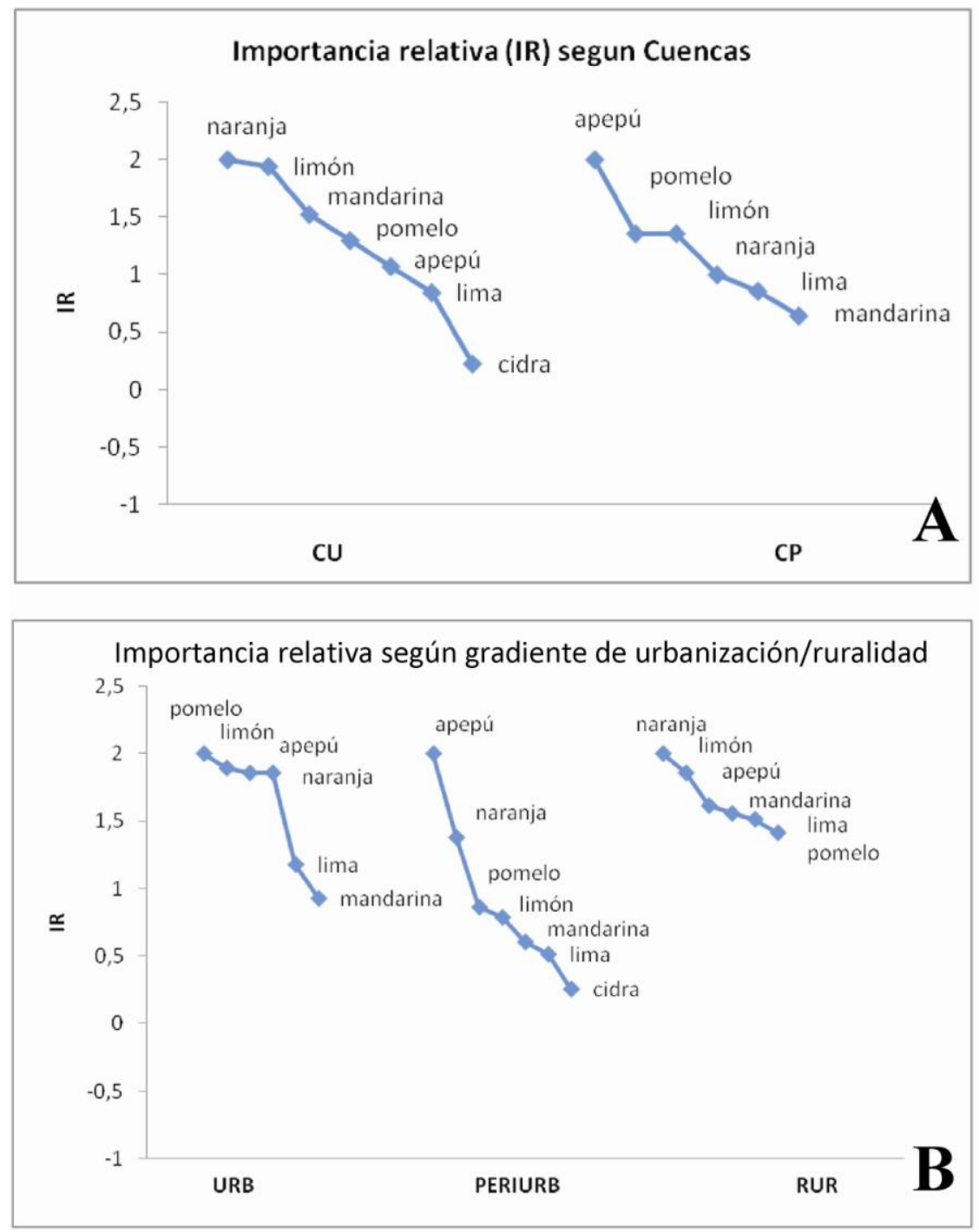
En la tabla 11 se presenta el elenco de etnoespecies, partes empleadas, dolencias tratadas y la preparación en caso de haberse relevado. Se puede observar que entre los criollos y guaraníes las gripes, las dolencias relacionadas al sistema sanguíneo y al dérmico fueron citadas con menor frecuencia; en cambio las dolencias digestivas tienen mayor importancia en este grupo cultural. Al comparar la frecuencia de citas de tratamientos de las distintas dolencias en los tres ambientes del gradiente urbanidad/ruralidad las mayores diferencias se observan en los tratamientos del sistema ósteo-arto-muscular y dérmico, para los enclaves rurales.

\subsubsection{Modos de preparación y administración de los remedios caseros}

Al analizar las partes de la planta empleadas también se observó variabilidad. Se halló que se emplea en orden decreciente jugo del gomo (del endocarpo, 44\%), las hojas (39\%), la fruta (frutos enteros, 8,5\%) y la piel (epicarpo, 4\%). También fueron mencionados las flores (1\%), la pelusa (mesocarpo, 0,5\%) y los brotos (brotes, $0,5 \%$ ) (Figura 44).

Figura 44. Partes de la planta empleadas en la preparación de las recetas medicinales.

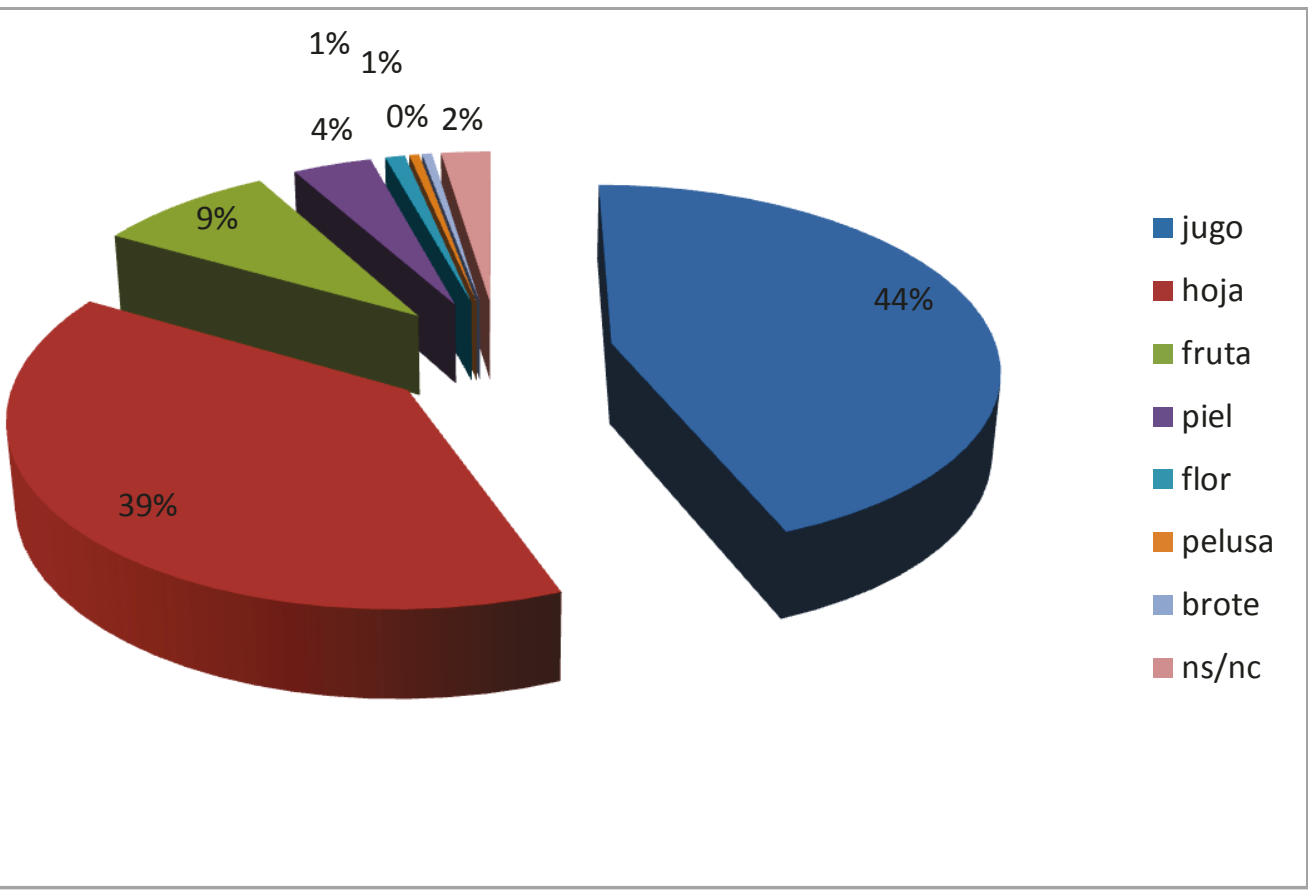


Lo mismo ocurre con la forma de preparación de las medicinas. El empleo directo del jugo del gomo (34\%), puro o diluido en agua, constituye la forma más usual junto a la infusión $(34 \%)$ y el cocimiento $(23 \%)$. El porcentaje restante $(8 \%)$ está conformado por otras preparaciones menos importantes como: calentamiento de los frutos al rescoldo y asado, la elaboración de jarabe o melitus (es decir, un preparado en base a azúcar o miel, respectivamente), mate, tereré, preparación en dulces y freído en aceite vegetal (Figura $45)$.

Figura 45. Porcentajes de menciones acerca de las preparaciones de las recetas medicinales.

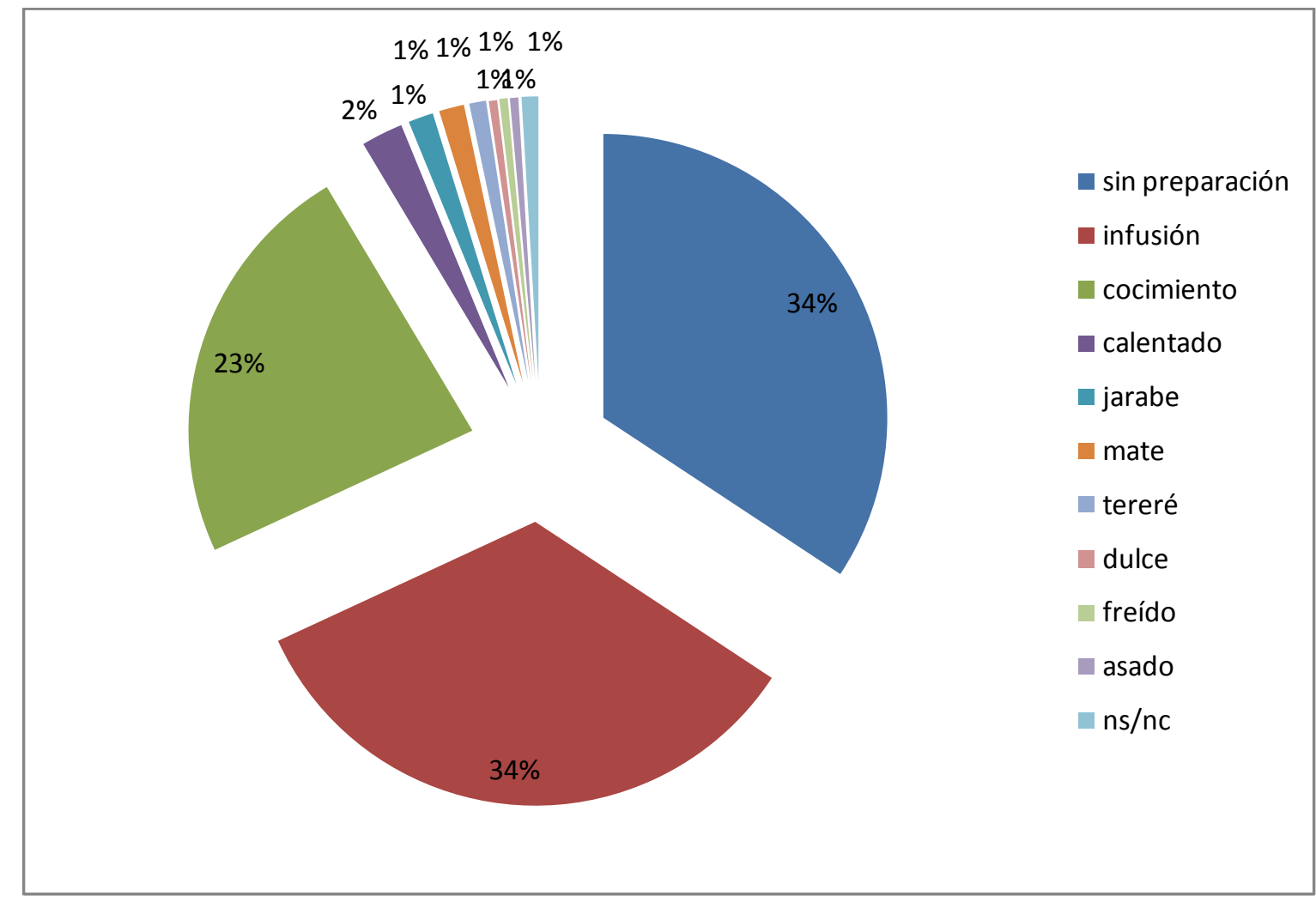

Las combinaciones con otras plantas son también frecuentes (15\% de las menciones). De esta manera las preparaciones involucran hojas de "durazno" ( $P$. persica, llamado en Cerro Mártires también “pesco", por deformación de "pessego”), brotes de "níspero" (E. japonica), hojas y frutos de "eucalipto" (Eucalyptus spp.), ramas de "catai” (Polygonum punctatum), brotes y hojas de "ambay" (Cecropia pachystachya Trécul), brotes de "talera" (Celtis sp.), hojas de "salvia" (Lantana sp.), hojas de "prontoalivio" o "salvia" (Lippia alba), hojas de "sota caballos" o "soita" (L. divaricata), ramas de "malva" (Malvaceae indet.), y ramas de "poleo", "cedrón del campo" o "niño rupá" ( $A$. gratissima y $A$. virgata). A varias de estas plantas se les atribuyen propiedades analgésicas y diaforéticas. 
Al comparar la similitud de dolencias tratadas entre ambas cuencas hallamos un $68 \%$ de concordancia, con 15 dolencias compartidas, 7 exclusivas para la cuenca del Uruguay y 12 para la cuenca del Paraná. Al analizar los usos medicinales en conjunto según el gradiente de urbanización/ruralidad observamos mayor similitud entre el ambiente rural y periurbano (81\%), seguido del urbano y rural $(63 \%)$ y finalmente, donde menor similitud se halló fue entre las familias urbanas y periurbanas (Tabla 12).

En la prueba de una relación entre el manejo del ambiente y el grado de ruralidad, en cuanto al uso medicinal de las distintas especies, además del evidente mayor uso de todas las especies en un ambiente muy manejado en la zona rural, se observó que sí existe una fuerte relación (Chi2 $>9,21 ; \mathrm{GL}=2 ; \alpha=0.01$ ) en todas las especies, el gradiente de urbanización/ruralidad y la intensidad de manejo agrosilvícola. Con base en las frecuencias se trasluce un mayor uso en ambientes sin manejo agrosilvícola que en aquellos con manejo medio, en zonas urbanas y periurbanas. En cambio, en ámbitos rurales hay un mayor uso en ambientes con manejo intermedio que en aquellos sin manejo.

Tabla 11. Etnoespecies de cítricos medicinales, partes empleadas, dolencias tratadas o acción, modo de administración y preparación en caso de haberse relevado.

\begin{tabular}{|c|c|c|c|c|}
\hline CIDRA & jugo & preventivo & jugo & \\
\hline \multirow[t]{13}{*}{ LIMA } & \multirow[t]{7}{*}{ jugo } & Gripe & \multirow[t]{7}{*}{ Jugo } & $\begin{array}{l}\text { En el agua de la pava } \\
\text { para cebar mate }\end{array}$ \\
\hline & & $\begin{array}{l}\text { Para bajar la } \\
\text { presión }\end{array}$ & & Bebido, frío o caliente \\
\hline & & Para el hígado & & Bebido \\
\hline & & Diabetes & & \\
\hline & & Digestivo & & \\
\hline & & Resfrío & & \\
\hline & & tranquilizante & & \\
\hline & Fruto & $\begin{array}{l}\text { Para bajar la } \\
\text { presión }\end{array}$ & Cocimiento & Bebido, frío o caliente \\
\hline & Flores & Para el corazón & $\begin{array}{l}\text { Infusión o } \\
\text { mate }\end{array}$ & \\
\hline & \multirow[t]{4}{*}{ hojas } & Tranquilizante & \multirow[t]{2}{*}{ infusión } & $\begin{array}{l}\text { Tomar por la mañana } \\
\text { y por la noche }\end{array}$ \\
\hline & & Para el corazón & & 3 hojas por taza \\
\hline & & Diabetes & & \\
\hline & & $\begin{array}{l}\text { Para bajar la } \\
\text { presión }\end{array}$ & infusión & $\begin{array}{l}3 \text { hojas por taza, } \\
\text { tomar por la mañana }\end{array}$ \\
\hline
\end{tabular}




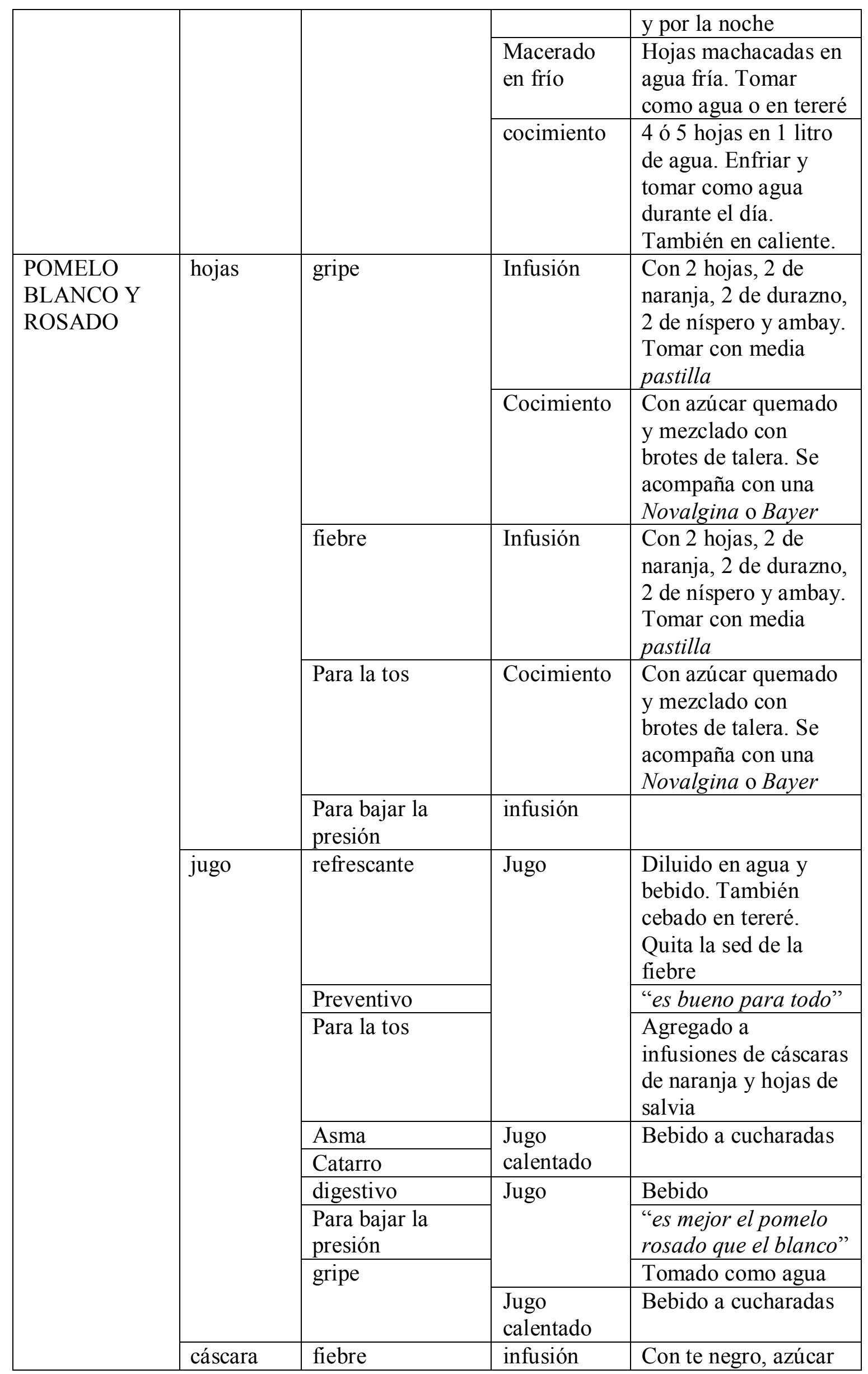




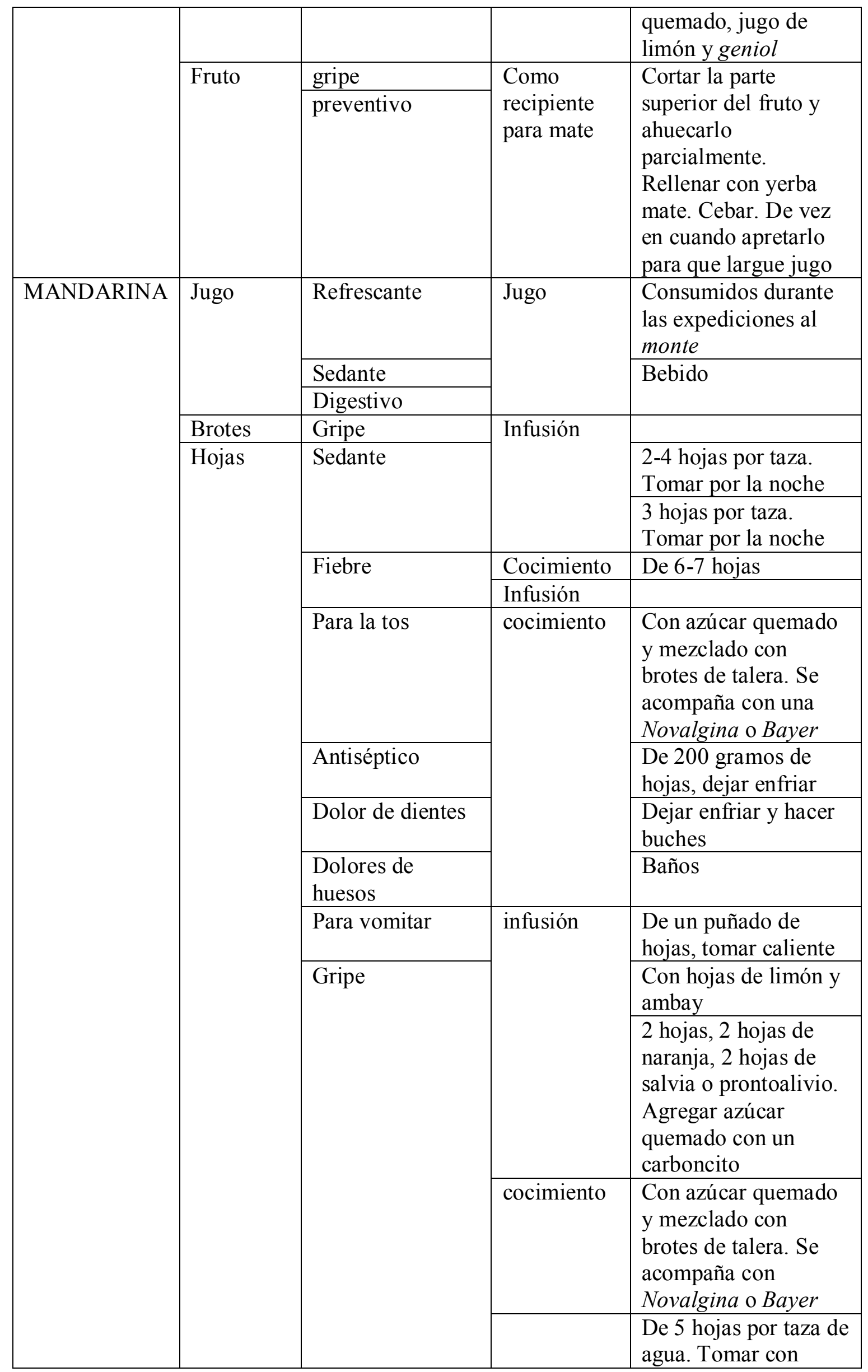




\begin{tabular}{|c|c|c|c|c|}
\hline & & & & $\begin{array}{l}\text { pastillas de } \\
\text { medicamento }\end{array}$ \\
\hline & & & infusión & $\begin{array}{l}\text { De las hojas verdes } \\
\text { trituradas. Endulzar } \\
\text { con miel }\end{array}$ \\
\hline APEPÚ & jugo & Refrescante & Jugo & $\begin{array}{l}\text { Diluido en agua y } \\
\text { bebido. También } \\
\text { cebado en tereré }\end{array}$ \\
\hline & & Preventivo & & Bebido \\
\hline & & Gripe & & $\begin{array}{l}\text { Agregado a la } \\
\text { infusión de té negro } \\
\text { con aspirina }\end{array}$ \\
\hline & & & Cocimiento & $\begin{array}{l}\text { Del jugo de } 3 \text { frutos } \\
\text { en } 1 \text { taza de agua, con } \\
\text { miel de abejas y hojas } \\
\text { de eucalipto }\end{array}$ \\
\hline & & $\begin{array}{l}\text { Enfermedades } \\
\text { respiratorias }\end{array}$ & jarabe & $\begin{array}{l}\text { Se mezcla el jugo con } \\
\text { azúcar o miel y se } \\
\text { entibia. Se bebe a } \\
\text { cucharaditas }\end{array}$ \\
\hline & & broncoespasmos & & $\begin{array}{l}\text { Hervir } 3 \text { litros del } \\
\text { jugo con } 1 \text { litro de } \\
\text { miel hasta reducir a } \\
1,25 \text { o } 1,5 \text { litros. } \\
\text { Agregar canela y } \\
\text { estacionar }\end{array}$ \\
\hline & & Para la tos & & $\begin{array}{l}\text { Mezclado con miel. } \\
\text { Tomar por la mañana } \\
\text { en ayunas y por la } \\
\text { noche }\end{array}$ \\
\hline & & & & $\begin{array}{l}\text { Mezclado con azúcar. } \\
\text { Beber caliente }\end{array}$ \\
\hline & & Angina & & $\begin{array}{l}\text { Mezclado con } 3 \\
\text { cucharadas de miel de } \\
\text { abejas de monte }\end{array}$ \\
\hline & & Pasmo & Cocimiento & Con agregado de sal \\
\hline & hoja & $\begin{array}{l}\text { Para bajar la } \\
\text { presión }\end{array}$ & infusión & 4-4 hojas por taza \\
\hline & & Digestivo & & \\
\hline & & Dolor de huesos & Cocimiento & $\begin{array}{l}\text { Baños en las zonas } \\
\text { afectadas }\end{array}$ \\
\hline & & Gripe & Infusión & $\begin{array}{l}\text { Agregado en } \\
\text { infusiones con te } \\
\text { negro, cafiaspirina y } \\
\text { azúcar quemada con } \\
\text { un carboncito }\end{array}$ \\
\hline & & & & $\begin{array}{l}\text { En caña o cayaza. } \\
\text { Enfriar y estacionar }\end{array}$ \\
\hline & & Angina & Cocimiento & $\begin{array}{l}\text { Dejar enfriar y hacer } \\
\text { gárgaras }\end{array}$ \\
\hline
\end{tabular}




\begin{tabular}{|c|c|c|c|}
\hline & Para la tos & Infusión & $\begin{array}{l}\text { Junto a hojas de sota } \\
\text { caballos }\end{array}$ \\
\hline & \multirow[t]{2}{*}{ Pasmo } & \multirow[t]{3}{*}{ Cocimiento } & $\begin{array}{l}\text { Aplicar en la zona } \\
\text { afectada }\end{array}$ \\
\hline & & & $\begin{array}{l}\text { Junto a hojas de } \\
\text { malva y durazno. } \\
\text { Realizar baños en la } \\
\text { zona afectada }\end{array}$ \\
\hline & $\begin{array}{l}\text { Pasmo de } \\
\text { columna }\end{array}$ & & $\begin{array}{l}\text { Junto a hojas de } \\
\text { eucalipto y poleo. } \\
\text { Realizar baños todos } \\
\text { los días durante } 1 \\
\text { semana }\end{array}$ \\
\hline & Dolor de panza & Infusión & \\
\hline & Hemorroides & Cocimiento & $\begin{array}{l}\text { De } 20-30 \text { hojas, con } \\
2-3 \text { raíces de catai y } \\
\text { una planta de malva } \\
\text { blanca. Dejar enfriar } \\
\text { y hacer baños de } \\
\text { asiento }\end{array}$ \\
\hline & Digestivo & \multirow[t]{3}{*}{ infusión } & $\begin{array}{l}3 \text { hojas por taza. } \\
\text { Tomar en ayunas }\end{array}$ \\
\hline \multirow[t]{3}{*}{ cáscara } & Fiebre & & $\begin{array}{l}\text { Con te negro, azúcar } \\
\text { quemado, jugo de } \\
\text { limón y un geniol }\end{array}$ \\
\hline & Digestivo & & \\
\hline & Piojicida & Jabón & $\begin{array}{l}\text { Elaboración de } \\
\text { jabones con aceite de } \\
\text { coco }\end{array}$ \\
\hline mesocarpo & digestivo & $\begin{array}{l}\text { Dulce de } \\
\text { oreja }\end{array}$ & $\begin{array}{l}\text { Los frutos } \\
\text { previamente pelados } \\
\text { (extracción del } \\
\text { epicarpo) se cortan } \\
\text { longitudinalmente en } \\
\text { 4, se les extrae el } \\
\text { gomo (endocarpo) y } \\
\text { se dejan en una } \\
\text { corriente de agua para } \\
\text { que se les vaya el } \\
\text { amargor. Luego se } \\
\text { hierven en miel de } \\
\text { caña durante algunas } \\
\text { horas y se envasan. } \\
\text { Se les puede agregar } \\
\text { clavo de olor o canela }\end{array}$ \\
\hline fruto & $\begin{array}{l}\text { Llagas de la } \\
\text { aftosa }\end{array}$ & $\begin{array}{l}\text { Medio fruto } \\
\text { con sal }\end{array}$ & $\begin{array}{l}\text { Cortados } \\
\text { longitudinalmente se } \\
\text { les agrega un poco de } \\
\text { sal y se raspan en la } \\
\text { lengua de la vaca. }\end{array}$ \\
\hline
\end{tabular}




\begin{tabular}{|c|c|c|c|c|}
\hline & & & & $\begin{array}{l}\text { Luego se tira obliga, } \\
\text { mediante un tironeo } \\
\text { de la lengua, a que lo } \\
\text { trague }\end{array}$ \\
\hline & & Gripe & \multirow{2}{*}{$\begin{array}{l}\text { Asado o } \\
\text { calentado }\end{array}$} & \multirow{2}{*}{$\begin{array}{l}\text { Fruto asado al } \\
\text { rescoldo. Beber su } \\
\text { jugo tibio }\end{array}$} \\
\hline & & fiebre & & \\
\hline \multirow[t]{11}{*}{ NARANJA } & \multirow[t]{11}{*}{ hoja } & Bajar la presión & \multirow[t]{2}{*}{ Infusión } & \\
\hline & & \multirow[t]{3}{*}{ Para la tos } & & $\begin{array}{l}\text { De } 2-5 \text { hojas. Dejar } \\
\text { entibiar y tomar por la } \\
\text { noche }\end{array}$ \\
\hline & & & \multirow[t]{2}{*}{ Cocimiento } & $\begin{array}{l}\text { Con azúcar quemado } \\
\text { y mezclado con } \\
\text { brotes de talera. Se } \\
\text { acompaña con una } \\
\text { Novalgina o Bayer }\end{array}$ \\
\hline & & & & $\begin{array}{l}\text { Con hojas de salvia } \\
\text { y/o de ambay. } \\
\text { Agregar azúcar y } \\
\text { tomar con una } \\
\text { Aspirina }\end{array}$ \\
\hline & & \multirow[t]{3}{*}{ fiebre } & \multirow[t]{2}{*}{ Infusión } & $\begin{array}{l}\text { De } 4-5 \text { hojas. Dejar } \\
\text { entibiar y tomar por la } \\
\text { noche }\end{array}$ \\
\hline & & & & $\begin{array}{l}\text { De } 2 \text { hojas, } 2 \text { de } \\
\text { pomelo, } 2 \text { de durazno, } \\
2 \text { de níspero y ambay. } \\
\text { Tomar con una } \\
\text { pastilla }\end{array}$ \\
\hline & & & Cocimiento & $\begin{array}{l}\text { De } 3-4 \text { hojas por taza } \\
\text { de agua }\end{array}$ \\
\hline & & \multirow[t]{4}{*}{ Gripe } & \multirow[t]{3}{*}{ Infusión } & $\begin{array}{l}\text { De } 2-5 \text { hojas. Dejar } \\
\text { entibiar y tomar por la } \\
\text { noche }\end{array}$ \\
\hline & & & & $\begin{array}{l}\text { De } 2 \text { hojas, } 2 \text { de } \\
\text { pomelo, } 2 \text { de durazno, } \\
2 \text { de níspero y ambay. } \\
\text { Tomar con una } \\
\text { pastilla }\end{array}$ \\
\hline & & & & $\begin{array}{l}\text { De } 2 \text { hojas, } 2 \text { de } \\
\text { mandarina y } 2 \text { hojas } \\
\text { de salvia o de } \\
\text { prontoalivio. Agregar } \\
\text { azúcar quemado con } \\
\text { un carboncito }\end{array}$ \\
\hline & & & Cocimiento & $\begin{array}{l}\text { Con azúcar quemado } \\
\text { y mezclado con } \\
\text { brotes de talera. Se } \\
\text { acompaña con una } \\
\text { Novalgina o Bayer }\end{array}$ \\
\hline
\end{tabular}




\begin{tabular}{|c|c|c|c|c|}
\hline & & & & $\begin{array}{l}\text { Con hojas de salvia } \\
\text { y/o de ambay. } \\
\text { Agregar azúcar y } \\
\text { tomar con una } \\
\text { aspirina }\end{array}$ \\
\hline & & Angina & & $\begin{array}{l}\text { Dejar enfriar y hacer } \\
\text { gárgaras }\end{array}$ \\
\hline & & Antiséptico & & $\begin{array}{l}\text { De } 200 \text { gramos de } \\
\text { hojas. Dejar enfriar }\end{array}$ \\
\hline & & Sedante & Infusión & $\begin{array}{l}2-4 \text { hojas por taza. } \\
\text { Tomar por la noche }\end{array}$ \\
\hline & & & & $\begin{array}{l}\text { De 6-9 hojas, con } \\
\text { azúcar }\end{array}$ \\
\hline & & Laxante & & En agua o en leche \\
\hline & & $\begin{array}{l}\text { Dolores óseos y } \\
\text { de cintura }\end{array}$ & Cocimiento & Baños \\
\hline & & Digestivo & infusión & $\begin{array}{l}\text { De 2-3 hojas por taza. } \\
\text { Tomar en ayunas }\end{array}$ \\
\hline & & Males del hígado & & \\
\hline & Jugo & $\begin{array}{l}\text { Enfermedades } \\
\text { respiratorias }\end{array}$ & Jarabe & $\begin{array}{l}\text { Jugo disuelto en agua } \\
\text { azucarada o miel. Se } \\
\text { toma a cucharaditas, } \\
\text { entibiado }\end{array}$ \\
\hline & & Refrescante & Jugo & Bebido \\
\hline & & Sedante & & \\
\hline & & Digestivo & & $\begin{array}{l}\text { Agregado en } \\
\text { infusiones }\end{array}$ \\
\hline & Fruto & Gripe & cocimiento & De la fruta cortada en \\
\hline & & fiebre & & $\begin{array}{l}1 \text { taza de agua. } \\
\text { Agregar miel y } \\
\text { bayaspirina }\end{array}$ \\
\hline & cáscara & Gripe & & $\begin{array}{l}\text { Junto con miel. } \\
\text { Tomar todas la } \\
\text { noches }\end{array}$ \\
\hline & & & Infusión & $\begin{array}{l}\text { Quemar (sapecar) la } \\
\text { cáscara en el fuego y } \\
\text { agregarle agua } \\
\text { caliente. Tomar con } \\
\text { bayaspirina o geniol }\end{array}$ \\
\hline & & Resfrío & & $\begin{array}{l}\text { Con agregado de jugo } \\
\text { de limón y endulzado } \\
\text { con azúcar o miel }\end{array}$ \\
\hline & & Para la tos & & $\begin{array}{l}\text { Con hojas de salvia y } \\
\text { jugo de pomelo }\end{array}$ \\
\hline & $\begin{array}{l}\text { Hojas y } \\
\text { epicarpo }\end{array}$ & Fiebre & & \\
\hline LIMÓN & jugo & Fiebre & Jugo & $\begin{array}{l}\text { Agregado a infusión } \\
\text { de té o te negro con } \\
\text { aspirina, tafirol, }\end{array}$ \\
\hline
\end{tabular}




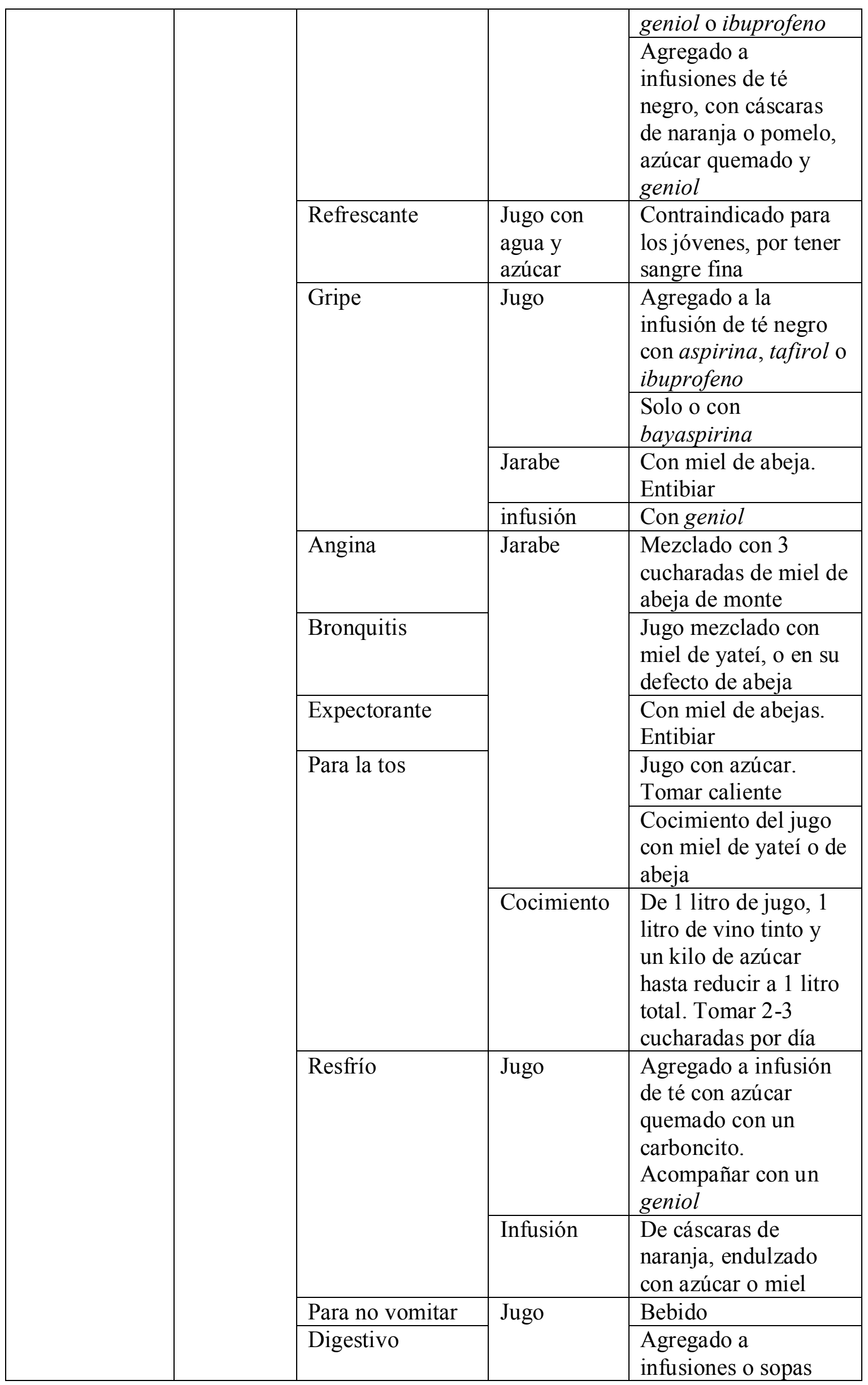




\begin{tabular}{|c|c|c|c|}
\hline & Dolor de panza & & Remedio fresco \\
\hline & Colitis & & \\
\hline & Acidez & & \\
\hline & Afinar la sangre & & bebido \\
\hline & Vesícula & & \\
\hline & Aftas en la boca & Tópico & Aplicar en la zona \\
\hline & $\begin{array}{l}\text { Antiinflamatorio } \\
\text { en picaduras }\end{array}$ & & afectada \\
\hline & Preventivo & Jugo & Con agua \\
\hline & Para adelgazar & Jugo & $\begin{array}{l}\text { Con agua, cebado en } \\
\text { tereré. Su abuso } \\
\text { produce anemia }\end{array}$ \\
\hline fruto & Gripe & Cocimiento & $\begin{array}{l}\text { De medio fruto en } \\
\text { agua. Tomar con } \\
\text { bayaspirina o geniol }\end{array}$ \\
\hline & & & $\begin{array}{l}\text { Del fruto entero } \\
\text { cortado en cuatro. } \\
\text { También puede ser } \\
\text { acompañado con } \\
\text { bayaspirina o } \\
\text { paracetamol }\end{array}$ \\
\hline & & Freido & $\begin{array}{l}\text { Medio fruto con } \\
\text { aceite vegetal, azúcar } \\
\text { y miel }\end{array}$ \\
\hline & & Cocimiento & $\begin{array}{l}\text { Del fruto mezclado } \\
\text { con cedrón del campo } \\
\text { y/o ambay }\end{array}$ \\
\hline & Fiebre & & $\begin{array}{l}\text { Del fruto entero } \\
\text { cortado en cuatro. } \\
\text { Tomar con } \\
\text { bayaspirina o } \\
\text { paracetamol }\end{array}$ \\
\hline & Resfrío & & $\begin{array}{l}\text { Del fruto mezclado } \\
\text { con cedrón del campo } \\
\text { y/o ambay }\end{array}$ \\
\hline & Dolor de garganta & & Del fruto partido \\
\hline flores & Gripe & Infusión & \\
\hline hojas & & Cocimiento & $\begin{array}{l}\text { Con azúcar quemado } \\
\text { y mezclado con } \\
\text { brotes de talera. Se } \\
\text { acompaña con } \\
\text { novalgina o bayer }\end{array}$ \\
\hline & & Infusión & $\begin{array}{l}\text { Con hojas de } \\
\text { mandarina y ambay }\end{array}$ \\
\hline & Para la tos & Cocimiento & $\begin{array}{l}\text { Con azúcar quemado } \\
\text { y mezclado con } \\
\text { brotes de talera. Se } \\
\text { acompaña con } \\
\text { novalgina o bayer }\end{array}$ \\
\hline
\end{tabular}




\begin{tabular}{|l|l|l|l|l|}
\hline & & Bajar la presión & Infusión & \\
\hline LIMÓN REAL & jugo & Refrescante & Jugo & Con agua y azúcar \\
\hline LIMÓN & $?$ & Gripe & & \\
\cline { 3 - 3 } SUTIL & & Para la tos & & \\
\hline
\end{tabular}

Tabla 12. Cálculo del índice de Simpson según cuenca considerada y gradiente de urbanización/ruralidad.

\begin{tabular}{ccccc}
\hline & $\begin{array}{c}\mathbf{N}^{\circ} \\
\text { dolencias }\end{array}$ & $\begin{array}{c}\text { Dolencias } \\
\text { exclusivas }\end{array}$ & $\begin{array}{c}\text { Dolencias } \\
\text { compartidas }\end{array}$ & $\begin{array}{c}\text { Índice de } \\
\text { Simpson }\end{array}$ \\
\hline \hline CU & 22 & 7 & 15 & 68,2 \\
CP & 27 & 12 & & \\
\hline \hline URB & 19 & 9 & 10 & 52,6 \\
PERI & 16 & 6 & & 63,2 \\
URB & 19 & 7 & 12 & 81,3 \\
RUR & 25 & 13 & & \\
\hline PERI & 16 & 3 & & \\
RUR & 25 & 12 & & \\
\hline \hline
\end{tabular}

\subsubsection{DISCUSIÓN}

Se puede observar que entre los criollos y guaraníes las gripes, y las dolencias relacionadas al sistema sanguíneo y dérmico fueron citadas con menor frecuencia; en cambio las dolencias digestivas tienen mayor importancia en este grupo cultural. Al comparar la frecuencia de citas de tratamientos de las distintas dolencias en los tres ambientes del gradiente urbanidad/ruralidad las mayores diferencias se observan en los tratamientos del sistema ósteo-arto-muscular y dérmico, para los enclaves rurales.

En ambas cuencas se emplean las mismas etnoespecies aunque con distinta importancia. El porcentaje de menciones asocian al "apepú" a la CP y a la "naranja" a la CU. Utilizando los índices de IR puede apreciarse que los usos medicinales varían de la misma manera aportando además algunos detalles importantes. Así, se corrobora la mayor importancia del "apepú" en la CP por sobre las demás etnoespecies, mientras que 
se agregan a la "naranja", en orden decreciente de IR, el "limón" y la "mandarina". La diferencia entre ambas cuencas de acuerdo al índice de Simpson fue del 31,8\% (similitud del 68,2\%) representada por dolencias con pocas menciones.

Asimismo, de acuerdo al gradiente de urbanización/ruralidad se han hallado algunas diferencias de acuerdo a las etnoespecies más útiles en cada situación.

Según los relevamientos la mayoría de los informantes son nacidos en la localidad, lo que no indicaría filiación relacionada a los países vecinos. Sin embargo, al tener en cuenta a los padres de los informantes la proporción de residentes en el departamento de San Ignacio nacidos en Paraguay se incrementa de 6 a 30\%, mientras que los residentes en Concepción, nacidos en Brasil, se incrementan de 5 a 20\%. Esto reflejaría asociación de los informantes con los países vecinos según la cuenca considerada.

De las 7 etnoespecies relevadas para el tratamiento de distintas dolencias, la "cidra" resultó muy poco importante presentando sólo una mención en la cuenca del Uruguay. Asimismo, se encuentra ausente en este listado el "cidro" (C. medica), representado en la zona por el "limón cidra" $(C$. $\times$ limon). Esta etnoespecie es citada para el NE de argentina y Paraguay con numerosas propiedades medicinales relacionadas al sistema digestivo, nervioso, en fiebres y como antihelmíntico (Hieronymus, 1882; Rodríguez Barboza, 1985). Sin embargo, queda en duda su afiliación dado que su nombre local es similar al relevado en esta tesis "cidra-limón". Asimismo, es citado para las yungas del NO de Argentina en preparaciones con otros cítricos como tónico (Hilgert, 1997, 1999). Esta autora destaca la retracción de esta variedad en la zona, siendo adquirido su fruto desecado actualmente en los mercados. La "lima ácida" $(C . \times$ aurantiifolia $)$ está localmente asimilada a la etnoespecie "limón”, tal como se dijo en el capítulo 5.2.

Este elenco de etnoespecies relevadas es similar a las presentadas en el norte de la provincia en comunidades de "criollos" y "polacos" (Kujawska et al., 2012; Kujawska \& Hilgert, 2014), incluso en las preparaciones medicinales a base de mieles de distintas abejas (Zamudio et al., 2010). En estos trabajos los cítricos resultaron más importantes en las comunidades de "criollos", presentando altos valores de IR y de \% de menciones, especialmente el "limón mandarina" y la "naranja". En los alrededores de la Reserva de Biósfera Yabotí (C-E de Misiones) Keller \& Romero (2006), en cambio, citan a la "lima ácida", pero no a la "lima [dulce]" y al "pomelo". Así, estas particularidades locales, 
especialmente ricas en la provincia debido al "mosaico cultural" típico de su historia, deben ser tenidas en cuenta en estudios prospectivos.

Pocas dolencias son novedosas en la bibliografía. Su uso como refrescante no es novedoso pero sí es importante en la zona debido a las altas temperaturas que se alcanzan durante el verano, que hacen de estos frutales, ácidos y dulces a la vez, un recurso valioso en esos momentos. Asimismo, el empleo del jugo de "limón" para afinar la sangre fue mencionado por un informante en la ciudad de San Ignacio. El mismo se refirió a esta dolencia como "la sangre se pone gruesa cuando uno come mucho frito, mucha grasa, entonces no corre por el cuerpo y uno se siente pesado...". Esto mismo ha sido citado para España (Alto Aragón) por Palacín et al. (1984).

El pasmo merece mayor atención, debido a la disparidad de sus descripciones. Fue presentado como "una infección que hincha, es bien jodido" (S. F., Cerro Mártires); también como "hinchazón, inflamación que viene por estar trabajando en el calor y pasar al frío o tomar agua fría. A veces pasa en los dientes y pareciera como que se te aflojaran o que se hincharan para infectarse" (E. V., Cerro Mártires). Estas definiciones se acercan más a las de Plath (1996: 251) y Thomas \& Vandebroek (2006), consistentes en inflamaciones con edemas y dolor localizado, aunque también las heridas infectadas (pasmadas), incluyendo la inflamación de las mejillas por infección dental; antes que a las descriptas por Pompa (1993) y Coluccio \& Coluccio (1991). Asimismo, es de destacar la importancia de la Teoría Humoral (frío-calor) relacionada a esta dolencia (Hilgert, 2001; Scarpa, 2012).

El uso de los cítricos en el tratamiento de la hipertensión tampoco es una novedad. Martínez-Crovetto (1981) cita entre los pobladores del NO de la provincia de Corrientes al "pomelo" y al "limón". Amat \& Yajía (1991) citan al "apepú" para el tratamiento de este padecimiento y posteriormente Keller \& Romero (2006) relevan al "apepú" y a la "lima ácida". En Paraguay y sur de Brasil también son escasamente representados (Rodríguez Barboza, 1985; Ritter et al., 2002; Vendruscolo \& Mentz, 2006). El análisis de la bibliografía científica indica que los frutos de "naranja", "limón", "mandarina", “pomelo" y "lima dulce” $(C$. × limon ,Limetta") tienen efecto hipotensor en animales de laboratorio (Germosén-Robineau, 1996; García Mesa et al., 2002; Pérez et al., 2010). Relacionado con lo anterior, el aceite esencial presente en casi toda la planta -más concentrados en las flores, y específicamente el linalool, acetato de linalilo, nerol y 
geraniol- tienen propiedades sedantes, hipnóticas y antiespasmódicas, lo que repercute en la presión arterial.

Con respecto a las dolencias tratadas la mayoría de las menciones se refieren a procesos gripales y febriles, luego respiratorios, digestivos y sanguíneos. La mayor parte de la bibliografía cita estos sistemas como tratados con los cítricos (Hieronymus, 1882; Martínez-Crovetto, 1981; Keller \& Romero, 2006). Los trabajos de Zamudio et al. (2010) y Kujawska et al. (2012) citan a las enfermedades respiratorias como las principales tratadas con los cítricos, quizá debido al acercamiento como plantas acompañantes de remedios a base de mieles, empleadas principalmente para dolencias relacionadas a este sistema.

Así, diferentes autores plantean distintas explicaciones al respecto. La OMS plantea que, ante la falta de centros de salud, los habitantes emplean los recursos más disponibles en el entorno. Sin embargo, no es la falta de centros asistenciales la que determina el uso de plantas medicinales sino la disponibilidad de tales recursos en el paisaje (Ladio \& Lozada, 2000; Albuquerque \& Lucena, 2005; Ladio et al., 2007; Molares \& Ladio, 2012). Esto explicaría dos aspectos de los resultados obtenidos. Por un lado, las mayores similitudes entre los enclaves periurbanos y rurales ya que en cualquier remanente de monte abundan varias de las etnoespecies empleadas en las preparaciones. Por otro, la mayor homogeneidad en los índices de IR para las etnoespecies en los enclaves rurales puede deberse a que la mayoría de las etnoespecies crecen espontáneas o son cultivadas en las parcelas de mayor superficie.

También, la selección volitiva de las comunidades, en base a tradiciones e innovaciones, determinan qué plantas se emplearán por sobre otras (Hilgert \& Gil, 2006, 2007, 2008). La importancia cruzada que presentan las diferentes etnoespecies en ambas cuencas puede estar relacionada a la historia de introducción de estos frutales. Mientras que para la cuenca del Paraná son más importantes "apepú" y luego "limón” y "pomelo", en la cuenca del Uruguay son más empleados con fines medicinales la "naranja", el "limón" y la "mandarina". El “apepú" o "naranja amarga" está relacionada a Paraguay por su nombre en guaraní, inclusive Gade (1976) indica su origen híbrido entre "naranja” y "naranja amarga" en las selvas de Paraguay, ambas introducidas durante la conquista y colonización hispánica. En cambio, la "naranja" fue conocida durante los siglos XVI y XVII como "naranja de la China" (ver Figura 19D, capítulo 5.3.3.1) y "naranja 
Portugal” (Ramón-Laca, 2003), indicando su procedencia geográfica y quienes la dispersaron por Europa y América, respectivamente. En relación con lo anterior, puede explicarse la mayor importancia en el uso medicinal de la "naranja" sobre el "apepú" en las investigaciones de Zamudio et al. (2010) y Kujawska et al. (2012) debido a que en las poblaciones de "criollos" del norte de Misiones hay una mayor proporción de brasileros antes que paraguayos.

La importancia de la "mandarina" en la cuenca del Uruguay, como también su escasa representación en la cuenca del Paraná, puede discutirse de acuerdo a su origen. Si bien C. reticulata es uno de los parentales de la "naranja", hasta fines del siglo XIX la "mandarina" estuvo asimilada a la "naranja", por lo tanto, relacionada a los portugueses antes que a los españoles. Al respecto, Osbeck (1771), el primero que la describió en su viaje a China, la describe como una naranja "de calidad" con piel (epi-mesocarpo) suelta. Más tarde, Saint Hilaire (1825) y Martius (1843) citan dos variedades de "laranjeira tangerina" y "laranga tangerina", respectivamente, en sus obras de Brasil. Para Argentina, Hieronymus (1882) lo llama "naranjo fino" o "mandarino", mientras que Burmeister (1899) lo denomina "naranja mandarina", recomendándolo para su cultivo al igual que el "chirimoyo" (A. cherimola). 
6. DISCUSIÓN GENERAL 
En esta discusión general se pretende hilvanar los diferentes capítulos de esta tesis (en los cuales se presenta la discusión particular del tema abordado en cada uno de ellos). Para lograrlo se ha seguido el esquema conceptual presentado en la Figura 46.

Figura 46. Diagrama propuesto como eje de la discusión de acuerdo a la hipótesis 1.

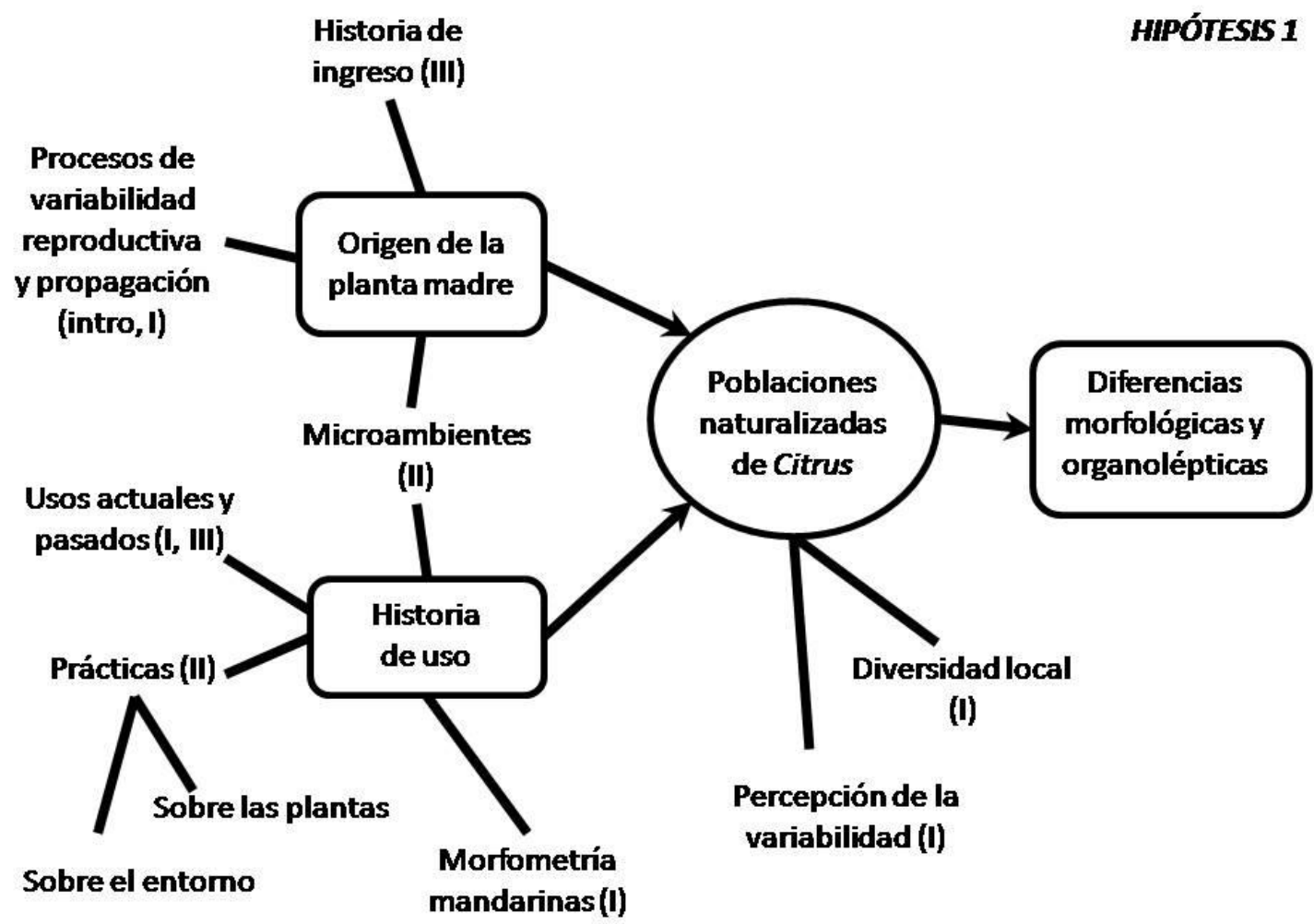

Según la primera hipótesis formulada para esta tesis, las poblaciones adventicias de cítricos presentan diferencias morfológicas y organolépticas de acuerdo al origen de la planta madre y a la historia de uso, lo que refleja procesos diferenciales de selección cultural en los distintos enclaves.

Esta situación es especialmente rica en Misiones debido a las condiciones climáticas apropiadas para el crecimiento de la mayoría de las variedades de cítricos. Para una determinada etnoespecie de Citrus, el origen de la planta madre incluye diferentes aspectos a tener en cuenta, abordados a lo largo de esta tesis y ahora discutidos: la historia de introducción de los cítricos (capítulo 5.1), los microambientes donde se cultivan o se hallan "naturalizados" (capítulo 5.3), la biología reproductiva de los cítricos (capítulo 3.4.1), y los grados de domesticación y formas de propagación (capítulo 5.3). En primer lugar, la historia de introducción de este género de frutales a 
partir del contacto entre el Viejo y el nuevo Mundo, la procedencia de las diásporas y las rutas de ingreso a través del tiempo, fueron de utilidad para caracterizar el material base, exótico, sobre el que actúa la selección cultural y los procesos de hibridación, poliploidía y mecanismos apomícticos de estabilización de dicha variabilidad (capítulos 3.4.1 y 5.2). De esta manera, si bien el "cidro" ( C. medica), uno de los primeros cítricos domesticados, muy resistente y presente en otros enclaves de selva (Hilgert, 1997), no se encuentra presente en la zona como tal, sí se halla formando parte de híbridos como el "limón cidra” $(C . \times$ limon, Rugoso $)$. En relación a la forma de propagación $-\mathrm{y}$ a las prácticas sobre el entorno- la diversidad de microambientes en un mismo paisaje donde son cultivados y/o recolectados estos frutales posibilitó a su vez la recuperación (o ingreso a la UD mediante la fauna local) del germoplasma desde el monte y capueras, a la vez que permitió la inclusión de ciertas plantas mediante prácticas de manejo in situ (como la tolerancia) en el avance de los microambientes productivos (campo, rozado, jardín, monte frutal) sobre el monte (capítulo 5.3).

Las características de las poblaciones nativas y de las corrientes colonizadoras conformaron paisajes culturales con particularidades propias, las cuales se reflejan en las especies vegetales y los usos que presentan. Dentro de las especies frutales introducidas en el Norte de Argentina, los cítricos, de corta historia en común con los europeos (Ramón-Laca, 2003), son altamente valorados no sólo como comestibles sino también como medicinales (Arias \& Ramón-Laca, 2005). Su introducción resultó de la confluencia de las corrientes colonizadoras española (Río de la Plata-Asunción) y portuguesa (Portugal + África + India + SE asiático). Dichos cítricos, a través de la agencia de los jesuitas, se constituyen en un elemento conspicuo en el paisaje local, deviniendo con el tiempo en cultivos característicos de la zona. Asimismo, algunas de estas especies se vuelven espontáneas constituyendo elementos que caracterizan la flora local siendo reconocidos por los pobladores como originarios de la zona (Gade, 1976; Stampella et al., 2013b, capítulo 5.2).

Este estudio de caso permite comprender los procesos de apropiación local de las especies introducidas. La decisión de incorporar elementos exóticos debe entenderse en el marco de las cosmovisiones de estos grupos nativos de distintas zonas de América. Grupos que atravesaron procesos de fuertes transformaciones, pero sin resignar protagonismo en la tomas de decisiones que contribuyen a la reproducción cultural (Lambaré, m. s.; De Grenade et al., 2014). En efecto, participan activamente, ya sea 
rechazando, incorporando, resignificando o abandonando costumbres, objetos y productos dentro de la incesante dinámica social e histórica. Dentro de ese marco cultural, la apropiación de los cítricos convierte a estos frutales, originariamente foráneos, en elementos identitarios que contribuyen a la definición de sus comunidades y escenarios de la vida cotidiana. Esto mismo ha sido relevado para los "duraznos de la Quebrada" (Lambaré \& Pochettino, 2012). Dado que esos ambientes pueden experimentar modificaciones, y suele variar su materialidad a lo largo del tiempo, estas plantas de introducción relativamente reciente, y con registro escrito, permiten al investigador comprender y diseñar la domesticación del paisaje, en cuanto resultado multidimensional del entorno físico, significativo y social (Seeland, 1997; Capparelli et al., 2011).

Para analizar la historia de uso post-introducción se tuvieron en cuenta los siguientes ejes: las prácticas sobre las plantas y sobre el entorno, los microambientes (capítulo 5.3) y usos actuales (Cap. 5.2). Así, las prácticas de manejo sobre las plantas y la selección cultural de determinados caracteres configuran procesos de domesticación en sentido tradicional, entendidos como modificaciones morfofisiológicas y genéticas en las plantas involucradas que las adaptan a determinados microambientes, generalmente de condiciones controladas (León, 1987; Hillman \& Davies, 1990, Harlan, 1992; Casas, 2005). Pero también las prácticas sobre los microambientes, donde se encuentran las plantas, resultan en procesos de domesticación del paisaje -por extensión de la UD sobre el entorno- produciendo cambios morfofisiológicos en las mismas resultantes de la adaptación de las plantas a los ambientes de cultivo, conocidos como síndrome de domesticación (Koinange et al., 1996; Terrell et al., 2003; Gepts, 2004; Zohary, 2004; Casas, 2005). Para los cítricos se han relevado diferencias en la cantidad de azúcares y de jugo del endocarpo, tamaño de las plantas, productividad, entre otros (capítulo 5.3) de acuerdo a los microambientes donde crecen y que se complementan a los propuestos por Koinange et al. (1996) para Phaseolus vulgaris. Las prácticas de manejo sobre los microambientes resultaron más importantes en la zona, especialmente para el caso de los enclaves con UD con producción por subsistencia y estrategias de uso múltiple de los bienes comunes (Toledo, 2002; Toledo et al., 2007; Toledo \& Barreras-Bassols, 2008). El resultado de estos procesos, actuando en conjunto, se plasma en una diversidad de grados de relación ser humano-plantas que representan distintos procesos de domesticación y síndromes adaptativos. 
Las poblaciones humanas locales operan sobre esta diversidad, seleccionando y propagando las etnovariedades de acuerdo a distintos criterios según el grupo -e incluso UD- considerado. La selección de variedades "novedosas" o con características valoradas (mayor dulzor del endocarpo, cáscaras sueltas, carencia de semillas, entre otras) se lleva a cabo mediante la selección de plántulas que crecen bajo la copa de la planta "madre", como también por siembra de las semillas de sus frutos. Esta práctica es comúnmente empleada por los "criollos" con las variedades comunes (sean caseras o de monte) y tiene la desventaja de que las plantas tardan en fructificar. Esto ha sido relevado por Lins Neto et al. (2012) para el "umbuzeiro" (S. tuberosa). En este último trabajo se menciona que los informantes “especialistas" prefieren manejar y recolectar los frutos de las poblaciones pertenecientes a la montaña y a la base de la montaña, antes que los del jardín, pasturas y otras poblaciones cultivadas. Esta práctica de propagar determinadas poblaciones antes que otras denota una selección de determinados caracteres que determina procesos evolutivos ("cuellos de botella") de las poblaciones vegetales. Esto mismo ha sido relevado para las Cactaceae (Casas et al., 1999; Luna-Morales, 2004; Rodríguez Arévalo et al., 2006) en las cuales se evidencia divergencia morfológica y organoléptica entre poblaciones silvestres, manejadas in situ y cultivadas, principalmente relacionadas al tamaño, coloración y cantidad de azúcares de los frutos. Sin embargo, en la zona, debido a la presencia de poblaciones cultivadas, manejadas in situ y naturalizadas, este aislamiento reproductivo no puede llevarse a cabo debido a las altas tasas de hibridación entre las distintas poblaciones. Es por ello que quizá la domesticación del ambiente, antes que de poblaciones o plantas particulares, represente en la zona la posibilidad de obtener variabilidad tal como se presentaron y discutieron en el capítulo 5.3.

Un trabajo de similares características ha sido recientemente publicado por De Grenade et al. (2014) en zonas de influencia de antiguas misiones jesuíticas en Baja California (México). En el mismo se analiza la diversidad actual de cítricos en los oasis relacionando la misma con las introducciones históricas (jesuíticas) y modernas (citricultura e inmigraciones), como también con las prácticas de manejo y selección de la diversidad generada de manera biocultural. Los resultados arribados son semejantes, partiendo de una historia de introducción común, aunque algo más tardía (fines de siglo XVII), con etnovariedades históricas similares e información poco detallada. Sin embargo, en Misiones (Argentina) se ha relevado una riqueza consistente en 30 
etnovariedades, mientras que en Baja California sólo se han encontrado 13, en ambos casos pertenecientes a variedades de "germoplasma antiguo y reciente" (De Grenade et al., 2014: 272). Por otra parte, en Misiones las variedades recientes se encuentran apropiadas localmente y resignificadas con nuevas denominaciones (capítulo 5.2), de la misma manera que, suponemos, ocurrió con la naranja amarga que se convirtió en “apepú" durante los siglos XVII y XVIII. ¿A qué puede deberse esta diferencia de riqueza en ambos enclaves? Las diferencias en el clima y la topografia pueden responder este interrogante: mientras que en Baja California los ambientes son secos (exceptuando los oasis) en Misiones domina un clima subtropical lluvioso donde el monte actúa como un reservorio dinámico de la diversidad introducida. Así, en Misiones tendremos etnovariedades caseras y de monte para "naranja", "mandarina" y “apepú". Algo similar puede apreciarse para el caso de los "duraznos de la Quebrada" (Jujuy, Argentina). En estos enclaves la diversidad de P. persica se remite a los rastrojos y huertos de las UD dado que el ambiente no es propicio para la naturalización de estos frutales, por lo tanto se encuentran sólo las variedades que se decidieron cultivar y mantener (Lambaré \& Pochettino, 2012).

Como vimos anteriormente, las prácticas de manejo in situ son consideradas una forma de cultivo sensu lato (Lema, 2010) y, si consideramos la falsa dicotomía natural/cultural, veremos que las plantas no se "asilvestran" o "naturalizan", sino que son antropizadas. Este concepto de antropización de las especies enfatiza en las prácticas - conscientes e inconscientes- que a largo plazo llevan a una domesticación del paisaje, a través del manejo agrícola ya descripto integrado por prácticas sobre la diversidad genética y prácticas sobre el entorno (Casas, 2005). Este ambiente domesticado propicia asimismo cambios morfológicos y fisiológicos en las plantas (Hilgert et al., 2014). Esto fue propuesto por Harlan (1992: 64) para las etnias australianas que no domestican plantas ni animales sino que "domestican el ambiente donde viven. El paisaje puede ser pensado como llevado a la unidad doméstica", o reformulándolo, creemos que es la UD la que se vuelca en el ambiente conformando el paisaje. Pero son las prácticas dirigidas hacia el entorno, más específicamente hacia los microambientes descriptos, las que influyen mayormente en la distribución, abundancia, disponibilidad de frutales y algunas variaciones morfofisiológicas. Las prácticas descriptas por Casas (2001) y Lema $(2009,2010)$ configuran el paisaje durante las actividades cotidianas como la cría de ganado, el establecimiento de un nuevo rozado, la 
intervención de las capueras, el avance de los campos sobre el monte e incluso el juego de los niños. Casas (2001) basa su modelo de "Silvicultura" en la selección de la vegetación ya establecida (espontánea), por lo cual las plantas exóticas -como los cítricos- se hallan en este repertorio. Esta selección se lleva a cabo sea por erradicación o por cultivo, entendiéndose éste último en su sentido amplio como opuesto a erradicación (Lema, 2010).

Las prácticas de cultivo difieren en el grado de asociación con las plantas. La tolerancia de ciertas plantas preexistente en el ámbito doméstico, es característica en la zona y puede ejemplificarse con las etnovariedades comunes. Durante el avance del ámbito doméstico (campo, rozado, jardín) sobre el monte los cítricos de monte son tolerados durante el rozado de la zona, denominándose automáticamente caseros. Esto mismo puede extenderse a casi todos los frutales y plantas útiles (medicinales, forrajeras, maderables). Algunos ejemplos fueron planteados en el capítulo 2.5.

La inducción o fomento, en cambio, está caracterizada por prácticas que incrementan la densidad poblacional de ciertas plantas, ya sea mediante actividades dirigidas a la población en sí (siembra de semillas o propágulos en el área donde se encuentra la población silvestre) o al ambiente (quemas y talas). Los cítricos también ejemplifican estas técnicas de manipulación. La cría de ganado en el monte, principalmente durante el otoño-invierno, incrementa la densidad poblacional de algunas plantas consumidas por el ganado vacuno, observándose comúnmente las plántulas creciendo en las heces. Esta dispersión y fomento no sólo ocurre con los cítricos sino también con los frutales de las familias Myrtaceae, Annonaceae, Arecaceae y -muy frecuente en la zona- con Hovenia dulcis (Rhamnaceae). Asociado a lo anterior, el manejo de la cobertura arbórea mediante la roza, junto a la tolerancia de plantas de cítricos ya establecidas, posibilita que dichas poblaciones se reproduzcan formando "naranjales" o montes frutales. Esto quizá es lo que haya ocurrido con los "naranjales" asociados a las ruinas jesuíticas, desaparecidos pocas décadas atrás debido al avance de la urbanización. Esto no es todo, si tenemos en cuenta la poca visibilización en los documentos históricos de las prácticas de manejo benéficas (o sinérgicas) es posible pensar que dicho "naranjales" hayan sido manejados hasta hace relativamente poco tiempo por las comunidades locales asociadas a los mismos. De esta manera, los "naranjales" son conformados en ambientes antropizados y luego permanecen por un tiempo variable luego que cesan las actividades y la capuera deviene en monte. Esto mismo fue observado para Elaeis 
guineensis (Arecaceae), donde las poblaciones silvestres crecen en los bordes del monte, no siendo tolerantes a la sombra del interior del monte (Harlan, 1992). Finalmente, la protección ocurre cuando los cuidados sobre las plantas espontáneas incluyen tareas de fertilización, poda, eliminación de competidores y depredadores, protección contra heladas, situación también representada localmente en los jardines domésticos y montes frutales.

Asimismo, en la literatura frecuentemente se distingue entre prácticas conscientes e inconscientes para delimitar las prácticas de cultivo, consensuándose que el cultivo engloba prácticas del primer tipo (Lema, 2010). Sin embargo, dependiendo de quién o quiénes lleven a cabo dichas prácticas la consciencia/inconsciencia varía. Por ejemplo, en el capítulo 5.3 se vio cómo se dispersan las semillas de los cítricos de monte consumidos in situ. Las personas mayores reconocen que dicha práctica incrementa la abundancia de las etnovariedades, como también de otros frutales consumidos de la misma manera. Los niños frecuentemente desconocen dicha práctica de fomento aunque la realizan -y aún en mayor medida que los adultos- cotidianamente por imitación de los adultos o quizá mediante prácticas compartidas (Lozada et al., 2006; Eyssartier et al., 2008). Por lo tanto, mediante el consumo in situ de las frutas de monte ¿los mayores realizan fomento mientras que los niños recolección? ¿Los adultos están cultivando los cítricos mientras que los niños no? ¿Los adultos están cultivando cítricos mediante las actividades de alimentación y juego de los niños?

De cualquier manera, las actividades de aprovisionamiento y producción de alimentos como las descriptas- influyen a través del tiempo en la constitución del paisaje, reflejando distintos aspectos de las creencias y los saberes como también preferencias (Toledo \& Barreras-Bassols, 2008). La EUM, presentada en el capítulo 5.3, es un modo de apropiación de la naturaleza donde los intercambios ecológicos son más importantes que los económicos, siendo característica de algunos productores familiares, grupos originarios y comunidades locales que producen para subsistir. Se caracteriza por la producción generalizada (no especializada) con alta diversidad de recursos y de prácticas productivas, donde intervienen el manejo de diferentes unidades ecogeográficas y distintos componentes bióticos y físicos (Toledo, 1990).

Desde la década de 1980, varios investigadores ya habían dado cuenta del carácter de artefactos culturales de algunos parches amazónicos. Las investigaciones realizadas por 
Posey (1985) entre los Kayapó del Amazonas brasileño dan cuenta de la diversidad de "áreas selváticas especiales" ("special forest areas"): islas de recursos y campos forestales (apêtê), rozados y parcelas agrícolas, jardines de tubérculos, antiguos campos y bordes de caminos; así como de las prácticas relacionadas a la conformación y dinámica de dichos ambientes caracterizados por especies vegetales de domesticación incipiente.

En la constitución de estos paisajes característicos intervienen distintos procesos que pueden ser interpretados a la luz de la teoría etnoecológica y analizados temporalmente mediante la etnobotánica histórica. La heterogeneidad cultural propia de la zona determina una gran heterogeneidad de cosmovisiones acerca del ambiente, siendo los distintos espacios (microambientes) y componentes vegetales, percibidos diferencialmente con distintas valoraciones. Las cosmovisiones particulares (significados y valores simbólicos) y los Conocimientos Ecológicos Locales se materializan en prácticas sobre el entorno, variables espacial y temporalmente. El aprovechamiento de la heterogeneidad ambiental, el manejo sucesional, la domesticación de plantas y de ambientes, la transformación y el manejo múltiple son algunas de las prácticas generadoras de estos paisajes (Davidson-Hunt \& Berkes, 2003; Berkes \& Turner, 2006; Toledo \& Barreras-Bassols, 2008; Capparelli et al., 2011).

Pero es con el término "selva antropogénica" ("anthropogenic forests"), acuñado por Balée (1993), donde se denotan estas áreas selváticas provenientes de antiguas zonas de cultivo (40-100 años de regeneración) en la Pre-Amazonia brasileña, diferenciándolas de la selva no disturbada o floresta densa ("undisturbed forests"). Los valores de frecuencias de determinadas plantas y diversidad de especies y de familias botánicas fueron similares a (incluso levemente mayores que) los medidos para la floresta densa, zona considerada "natural" en el sentido de baja intervención. Estos paisajes son denominados también "florestas antropogénicas" o "selvas cultas" en referencia a la interacción entre comunidades humanas locales y ecosistemas selváticos, analizados desde una perspectiva diacrónica (Descola, 1996; Balée, 1998; Casas, 2001). De esta manera, la noción de paisaje adquiere una dimensión de fenómeno biocultural dialécticamente estructurado e históricamente determinado donde las prácticas del pasado (domesticación de plantas y formas intermedias de manipulación y domesticación) determinan la conformación presente del espacio físico (Toledo \& 
Barreras-Bassols, 2008; Capparelli et al., 2011) muchas veces percibido como "natural".

Desde esta posición pueden problematizarse algunos términos referidos en la literatura y a lo largo de esta tesis. El "asilvestramiento" y la "naturalización" son algunos de los más indicados. Font Quer (1979: 993) se refiere con el término silvestre "que se cría en la selva. (...) Que se da sin cultivo, espontáneamente"; mientras que con naturalización se refiere a "la acomodación de una planta a determinado clima y suelo, de tal manera que aún siendo propia de regiones a veces muy alejadas se comporta como las especies autóctonas. En este caso se dice que la planta se ha naturalizado" (1979: 746). Mientras que en el primer término se opone la selva al cultivo, en el segundo sólo se indica la afinidad de un determinado taxón a un área de condiciones climáticas similares a aquellas de su origen. Estos dos términos no consideran las acciones humanas (pasadas y actuales) sobre el entorno y sobre las plantas, siendo esto cuestionable desde un posicionamiento histórico ecológico. En este sentido se han publicado una serie de trabajos que aúnan diferentes enfoques en el proceso de naturalización en el litoral y área rioplatense en los cuales se describen y analizan no sólo aspectos ecológicos sino también la relación del taxón con las comunidades locales (aspectos utilitarios, ecológicos y cognoscitivos), la historia de introducción y las prácticas de manejo sobre los ambientes muchas veces considerados "naturales" (Delucchi \& Keller, 2010; Keller et al., 2011, 2013; Hurrell et al., 2012; Stampella et al., 2013b; Delucchi et al., 2014).

En la provincia las acciones de conservación sobre los relictos de selva Atlántica cuentan entre los primeros establecidos en el país (Chebez \& Hilgert, 2003) aunque aún no se ha avanzado en la integración de las comunidades locales a tales prácticas. Creemos que dichas comunidades sostienen -y vienen sosteniendo- prácticas diversificadoras de paisajes y de taxa de acuerdo a su mirada holística y estrategias de uso múltiple del entorno, sin embargo hasta hace relativamente poco, para ambientes tropicales y subtropicales, los estudios proponían que el abandono o disminución de la vida rural como una medida para la restauración ambiental (Grau et al., 2003; Klooster, 2003). No acordamos con esto último ya que, como vimos, las selvas y pastizales de la provincia de Misiones distan mucho de ser ambientes "naturales" o "prístinos", como lo demuestran su historia local y su diversidad cultural. Esta oposición naturaleza/cultura en la provincia ha sido analizada desde la Antropología social por Ferrero (2008). Así, como afirma Descola (1996), esta dicotomía que separa naturaleza de cultura, no sólo es 
falsa sino que encuentra en el ambientalismo su propia disolución: la supervivencia de la diversidad de "no humanos", protegidos de daños antrópicos, dependerá de convenciones sociales y acciones humanas (Descola, 1996; Ferrero, 2008).

En cambio se propone la conservación biocultural donde las estrategias estén dirigidas hacia los paisajes sustentables así como también del patrimonio histórico que los pueblos forman parte (Ladio et al., 2007; Rozzi et al., 2010). En este sentido las estrategias dirigidas a la eliminación de los cítricos de las áreas protegidas (Herrera \& Malmierca 1995; Paszko \& Herrera 2006; Rodolfo et al., 2008) no parecen adecuados ya que constituyen a su vez patrimonio jesuítico, reservorio de agrobiodiversidad y recursos alimenticios para la fauna local. Algo similar ocurre con las poblaciones locales y los productores familiares (Riat \& Pochettino, 2014) que dependen indefectiblemente del monte. Como vimos a lo largo de la tesis estas plantas crecen espontáneamente en diversos ambientes domésticos, en otros asociados al ganado, en el monte formando parte del paisaje e incluso definiéndolo. Al igual que muchas otras plantas introducidas los cítricos se encuentran asimilados no sólo a las comunidades locales (M'bya, criollos, colonos) sino también a la fauna nativa. En este sentido, y como alternativa a la falsa asociación exótica-invasora (Gurevitch \& Padilla, 2004), muchos taxa de plantas forman parte de la red trófica local, por lo tanto no presentan efectos negativos sobre la biota local (Simberloff \& von Holle, 1999; D'Antonio \& Meyerson, 2002; Ewel \& Putz, 2004; Rodríguez, 2006; Fridley et al., 2007; Rodewald, 2012). De esta manera, este análisis acrítico y sesgado con desprecio hacia lo exótico debe ser ampliado hacia una visión holística del proceso de naturalización que integre la red trófica, la historia local, la relación de las plantas con las comunidades locales, como también los procesos clásicamente analizados de exclusión competitiva y modificación de hábitat por "transformers" (Zabaleta et al., 2001; DeGasperis \& Motzkin, 2007). ¿Cinco siglos de historia compartida, y de relación con las comunidades locales y fauna local resumidos en exótico?

De la misma manera, posicionándonos en la ecología histórica y en la etnoecología pueden problematizarse algunos conceptos como el de paisaje. Como vimos en el capítulo 3.5, el paisaje puede ser entendido como fenómeno biocultural, diacrónico, construido por la interacción entre las sociedades locales y el entorno, donde el componente simbólico se hace crucial al ser una naturaleza interpretada (Greider \& Garkovick, 1994; Balée, 1998). Si bien la ecología de paisajes (Naveh \& Lieberman, 
2001) reconoce distintos tipos de paisajes naturales y culturales y el correspondiente gradiente, e incluso, estos términos son empleados desde enfoques ecológicos históricos y arqueológicos (Buxó, 2006; Capparelli et al., 2011), desde el punto de vista sostenido en esta tesis, el paisaje es una interpretación del ambiente según determinadas creencias y conocimientos, variables de acuerdo a criterios culturales y temporales. Así "paisaje natural" sería una contradicción en sí, ya que todos los paisajes son interpretaciones humanas de los ambientes, mientras que "paisaje cultural" sería una redundancia ya que todos los paisajes son culturales, terminología que concuerda con lo propuesto por Trinca Fighera (2006). 


\section{CONCLUSIONES}


El abordaje empleado permitió el relevamiento tanto de la diversidad histórica introducida a lo largo de cinco siglos como también de la diversidad actual presente en los enclaves estudiados. Ésta fue clasificada localmente en 30 etnovariedades pertenecientes a 9 etnoespecies que, de acuerdo al tratamiento sistemático considerado se corresponden con 4 especies biológicas y 4 taxa híbridos. Además se han hallado cultivares comerciales resignificados con nuevas denominaciones. En general, son empleadas todas las etnovariedades, con diversos fines, especialmente las "comunes" para 34 dolencias distintas pertenecientes a distintos sistemas corporales.

Asimismo, se relevaron 7 microambientes definidos en función de la presencia de las etnoespecies que presentaron prácticas de manejo con distinto grado de relación con los frutales y el ambiente, de modo que el paisaje en su conjunto abunda de cítricos.

Es de destacar que tales prácticas, en los enclaves rurales, apuntan a la variabilidad y estrategia de uso múltiple a diferentes niveles, antes que a la sujeción de las plantas a un ámbito doméstico y a su estabilización genética.

Un caso como este nos permite asimismo la visualización de la domesticación como proceso antes que como resultado y la incorporación del ambiente en la unidad doméstica en la conformación de los paisajes que incluyen a los seres humanos como parte de la biósfera. La no inclusión de los mismos lleva a falsas dicotomías que oponen a los seres humanos con la biosfera, a la cultura con la naturaleza, a las especies exóticas con las nativas, teniendo en cuenta sólo las acciones destructivas sobre el entorno. En cambio se proponen sistemas productivos sustentables y áreas de conservación in situ de los bienes comunes. 
8. ANEXO 


\subsection{CONSENTIMIENTO PREVIAMENTE INFORMADO}

Lugar y fecha

Estimado/a participante:

Gracias por destinar su tiempo para participar y dar el consentimiento para la realización del presente trabajo de tesis doctoral. El titulo del mismo es "Historia local de naranja amarga (Citrus $\mathrm{x}$ aurantium $\mathrm{L}$ ) del Viejo Mundo asilvestrada en el corredor de las antiguas Misiones Jesuíticas de la provincia de Misiones (Argentina). Caracterización desde una perspectiva interdisciplinaria". El propósito de este trabajo, es identificar los frutales cítricos locales en huertos y jardines familiares del sur de la provincia de Misiones y analizar su relación con los conocimientos asociados a su etnotaxonomía, conservación, usos y prácticas de manejo. Este propósito se realiza en el marco de un trabajo de investigación del Laboratorio de Etnobotánica y Botánica Aplicada, de la Facultad de Ciencias Naturales y Museo de la Universidad Nacional La Plata.

Los resultados podrán ser útiles para visualizar el rol que cumplen las familias en la diversificación de frutales cítricos y en la selección de variedades con características particulares, como también en la conservación de variedades locales y conocimientos vinculados a las mismas. Asimismo permitirá visualizar impedimento para la conservación y limitantes de carácter técnico.

Reconozco que no obtendré un beneficio directo por participar de la presente investigación, pero que mi aporte podrá genera conocimientos para las futuras generaciones.

Si está de acuerdo con la propuesta, por medio de esta carta declaro mi voluntad de permitir la difusión de:

Mi nombre y apellido

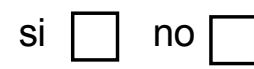

Imágenes fotográficas

si $\square$ no

Grabaciones

si $\square$ no $\square$

Conocimientos

si $\square$ no $\square$

Semillas, frutos y otros materiales

si

no

Acepto participar de la entrevistas realizadas por el Lic. Pablo César Stampella en el marco de su trabajo de investigación, siempre y cuando se me reconozca como fuente de información y se mantenga este conocimiento disponible para el uso.

Una vez más, agradecemos mucho su cooperación

Firma:

Aclaración: 


\subsection{LISTADO DE PUBLICACIONES DERIVADAS DE ESTA TESIS}

Capparelli, A.; Hilgert, N.; Ladio, A.; Lema, V. S.; Llano, S.; Molares, S.; Pochettino, M. L.; y Stampella, P. 2011. Paisajes culturales de Argentina: pasado y presente desde la perspectiva etnobotánica y arqueobotánica. Revista ASADEP on line 2(2): 67-79.

Hurrell, J. A.; G. Delucchi; H. A. Keller; P. C. Stampella y E. L. Guerrero. 2012. Bryophyllum (Crassulaceae): especies ornamentales naturalizadas en la Argentina. Bonplandia 21(2): 73-85.

Stampella, P. C. 2012. Toponimia misionera: de los yerbales jesuíticos al abuso de la caña de azúcar. En: R. Duque-Brasil, G. Taboada Soldati, F. Bezerra Souto, N. Leal Alencar, C. Ming Lin \& F. M. Gontijo Coelho (Eds.), “Quando pensa que não...”: contos, causos e crônicas em etnoecologia, pp. 105-108. Etnooikos, Universidade Federal de Viçosa, Viçosa.

Stampella, P.C.; G. Delucchi y M.L. Pochettino. 2013. Naturalización e identidad del "limón mandarina", Citrus × taitensis (Rutaceae, Aurantioideae) en la Argentina. Boletín de la Sociedad Argentina de Botánica 48(1): 161-169.

Stampella, P. C.; D. A. Lambaré; N. I. Hilgert \& M. L. Pochettino. 2013. What the iberic conquest bequeathed to us: the fruit trees introduced in argentine subtropic, their story and importance in present traditional medicine. Evidence-Based Complementary and Alternative Medicine vol. 2013, Article ID 868394, 17 pages.

Keller, H. A.; P. C. Stampella; G. Delucchi y J. A. Hurrell. 2013. Vernicia fordii y Aleurites moluccanus (Euphorbiaceae) en la Argentina, naturalización y etnobotánica. Boletín de la Sociedad Argentina de Botánica 48(3-4): 553-561.

Delucchi, G.; H. A. Keller; P. A. Cabanillas; P. C. Stampella y J. A. Hurrell. 2014. Pueraria montana var. lobata (Leguminosae) en la Argentina: estado actual de su naturalización. Bonplandia 23(1): 5-14.

Hilgert, N. I.; D. A. Lambaré; N. D. Vignale; P. C. Stampella \& M. L. Pochettino. 2014. ¿Especies naturalizadas o antropizadas? Apropiación local y construcción de saberes sobre los frutales introducidos en época histórica en el norte de Argentina. Revista Biodiversidad Neotropical 4(2): 69-87. 
Stampella, P. C.; G. Delucchi; H. A. Keller \& J. A. Hurrell. 2014. Etnobotánica de Citrus reticulata (Rutaceae; Aurantioideae) naturalizada en la Argentina. Bonplandia 23(2): 151-162. 
8.3. IMÁGENES DE LOS AMIGOS Y AMIGAS EN MISIONES

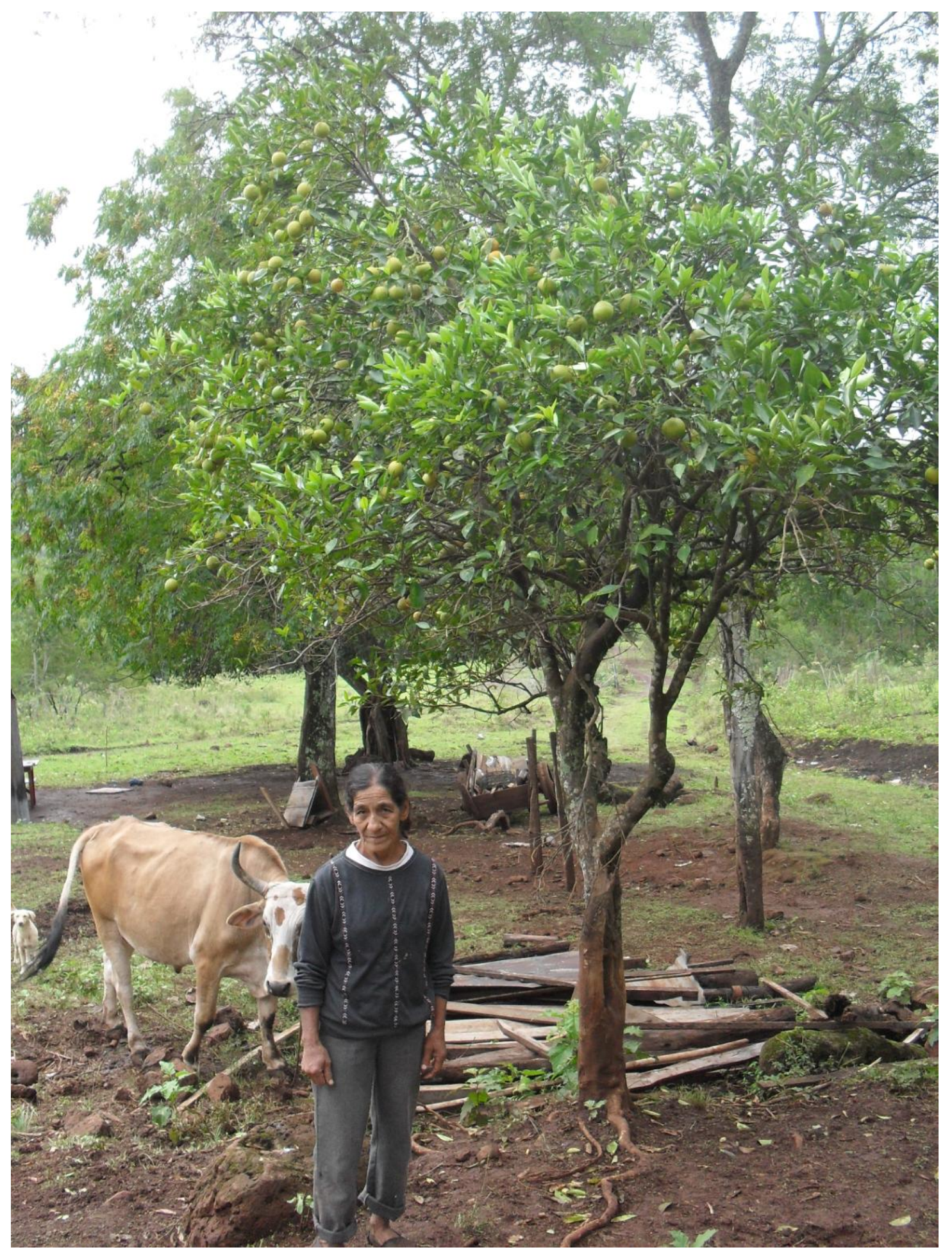



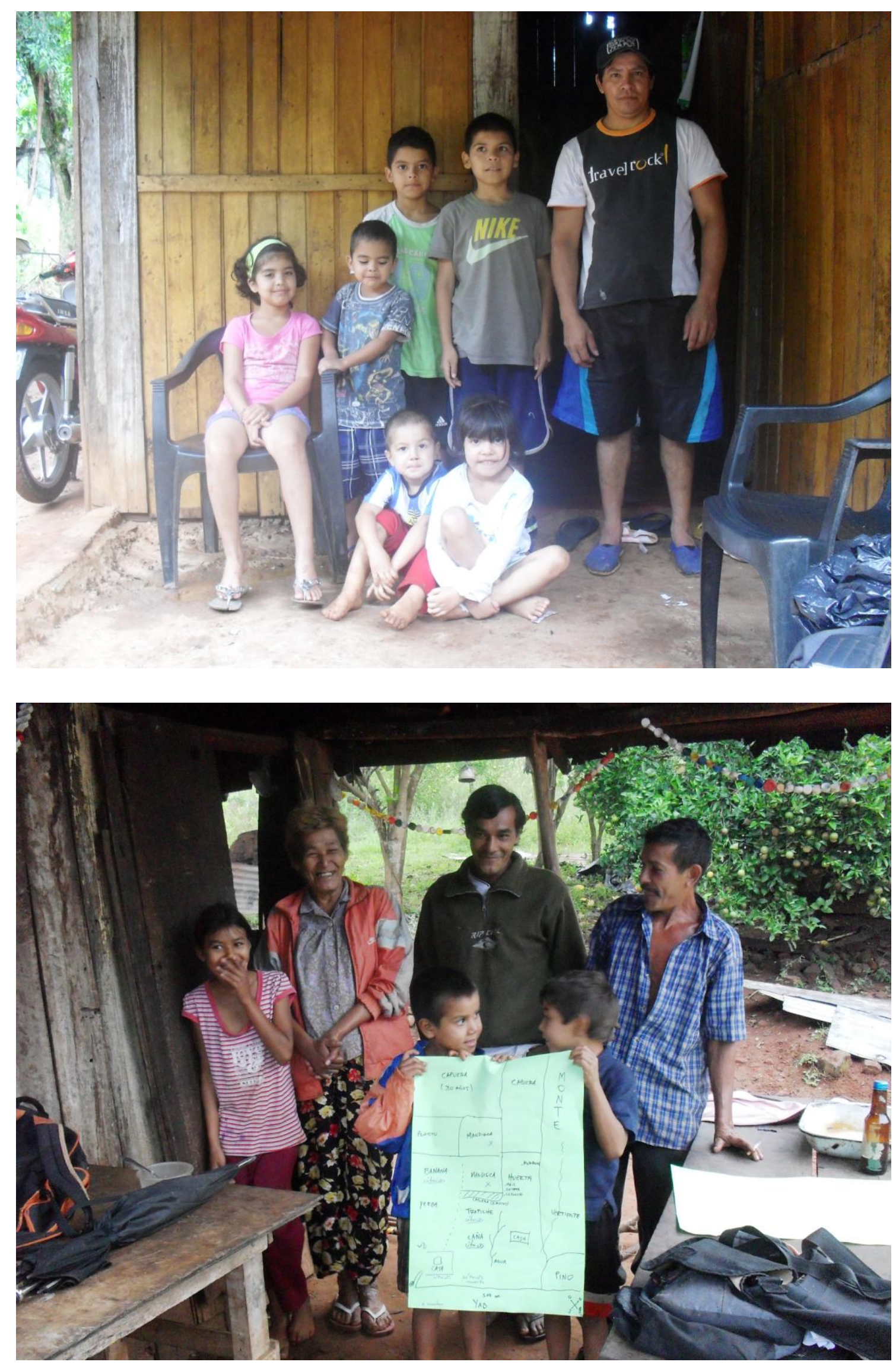

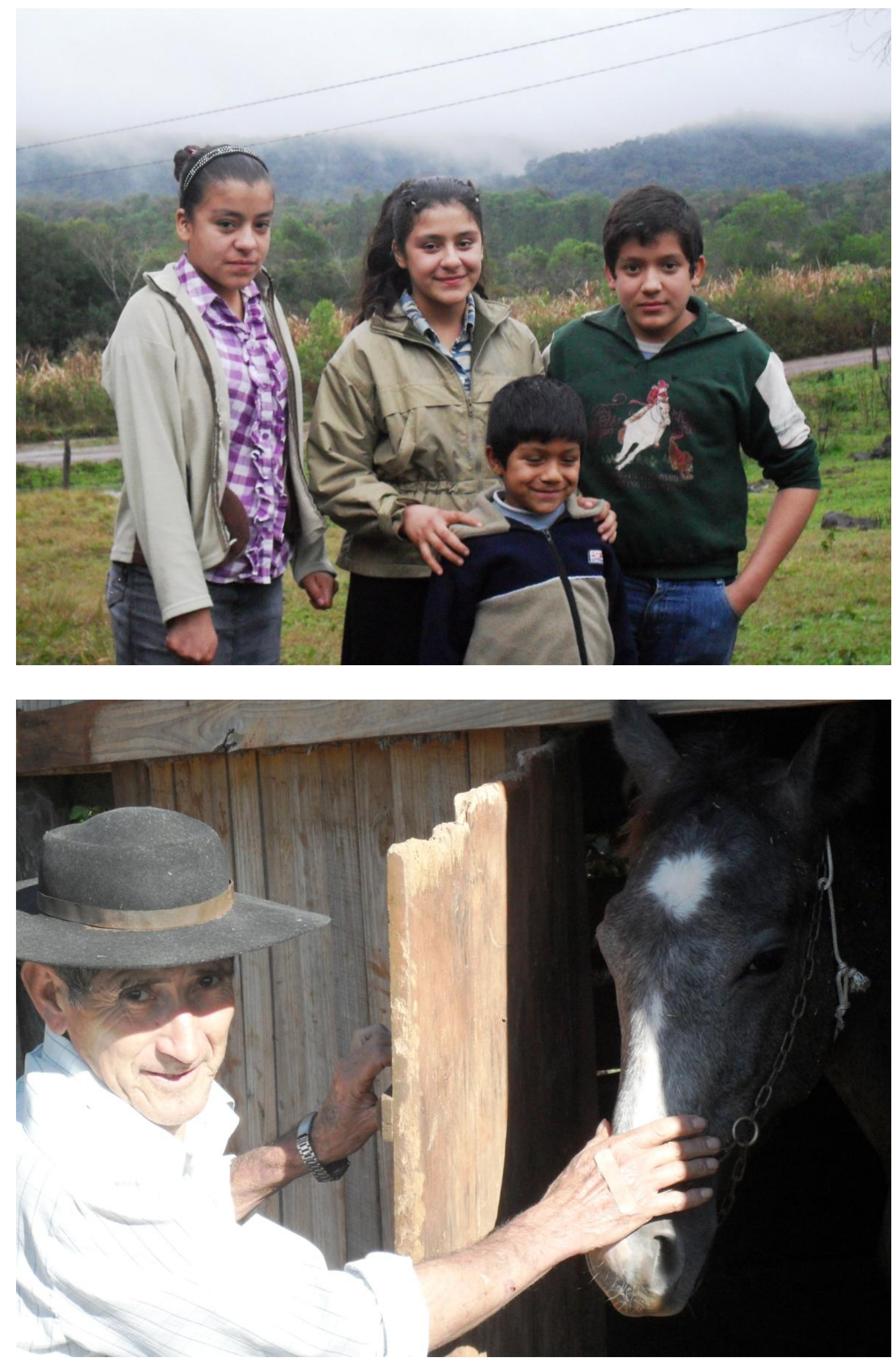

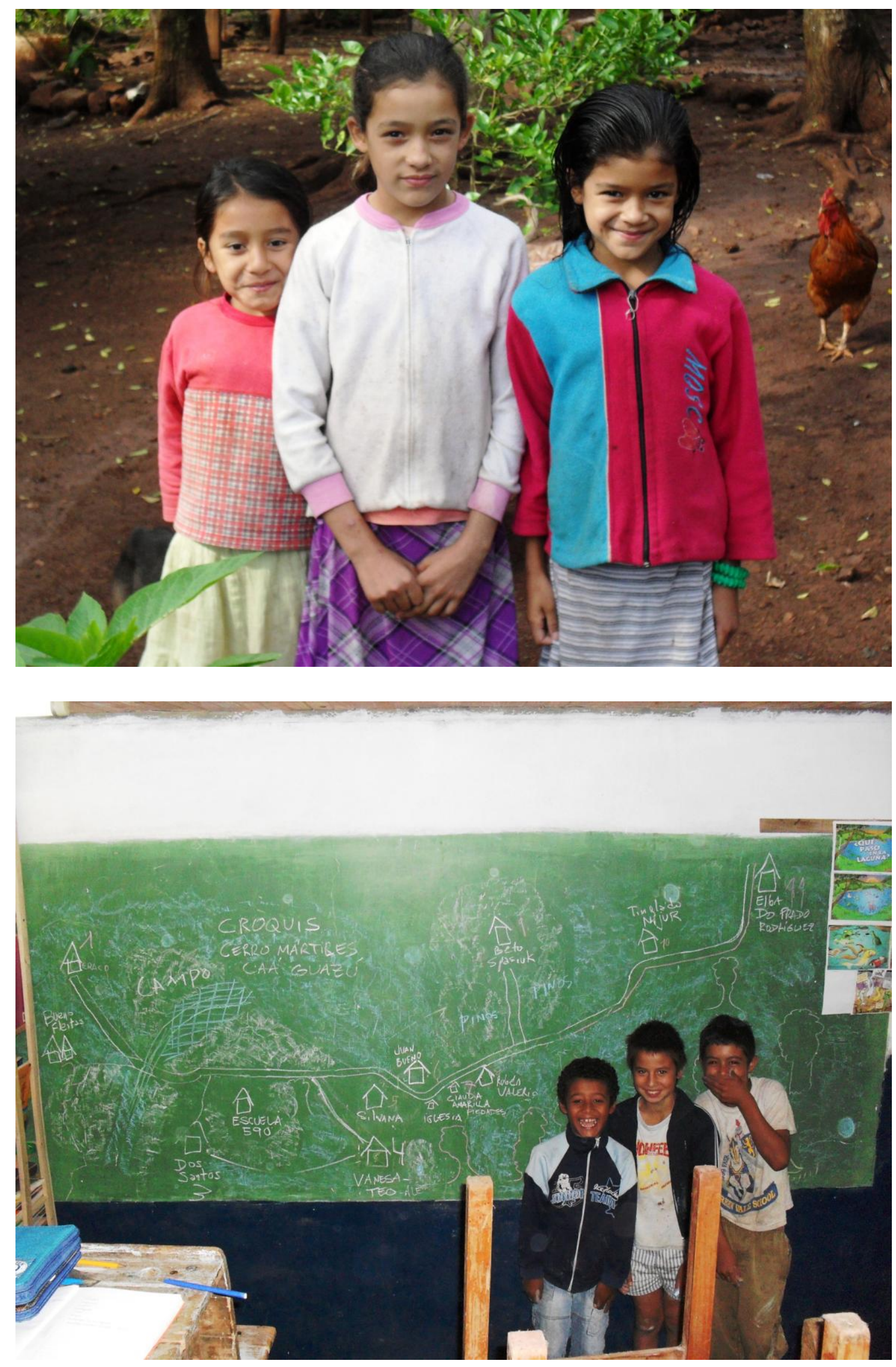

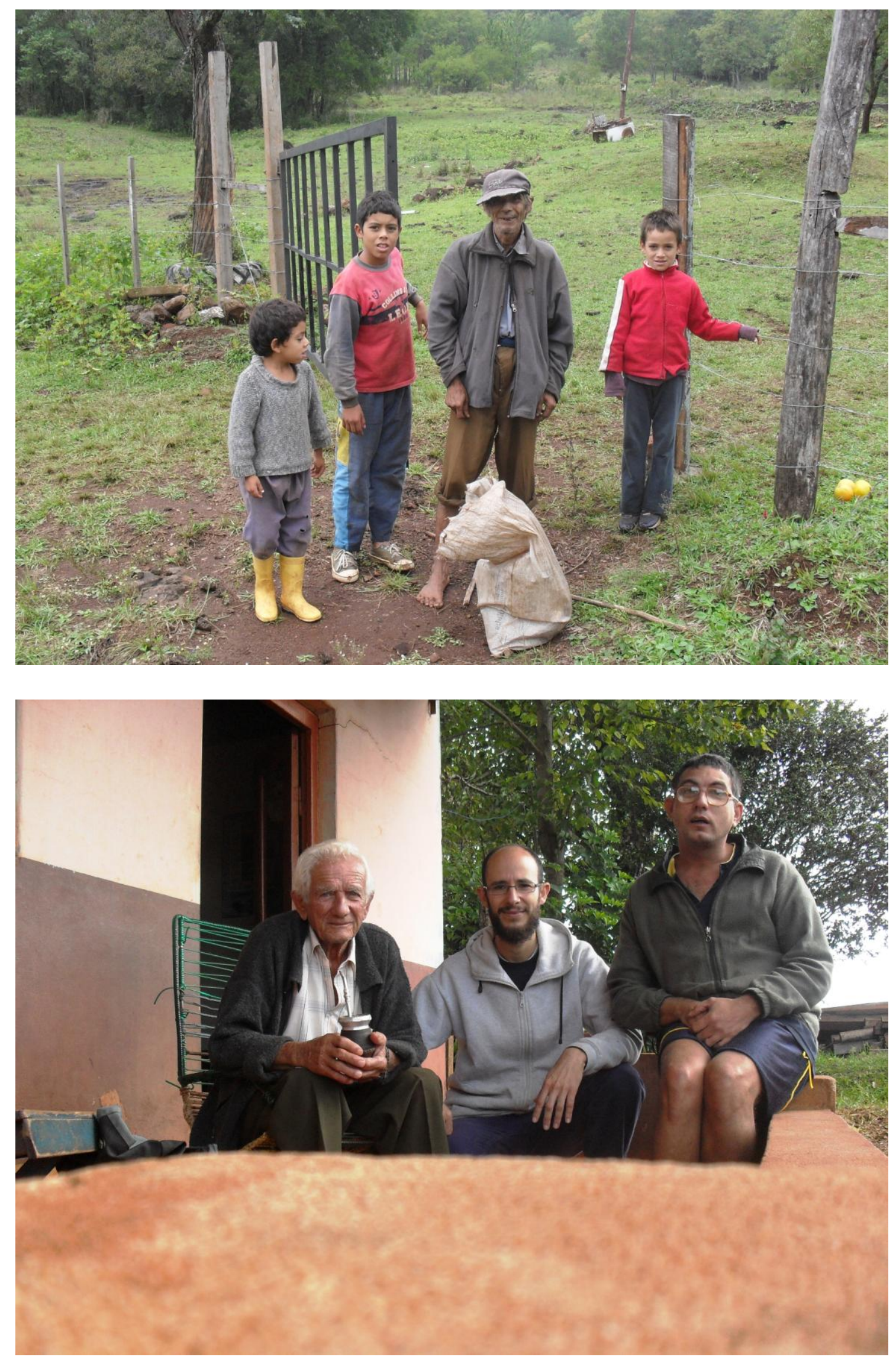

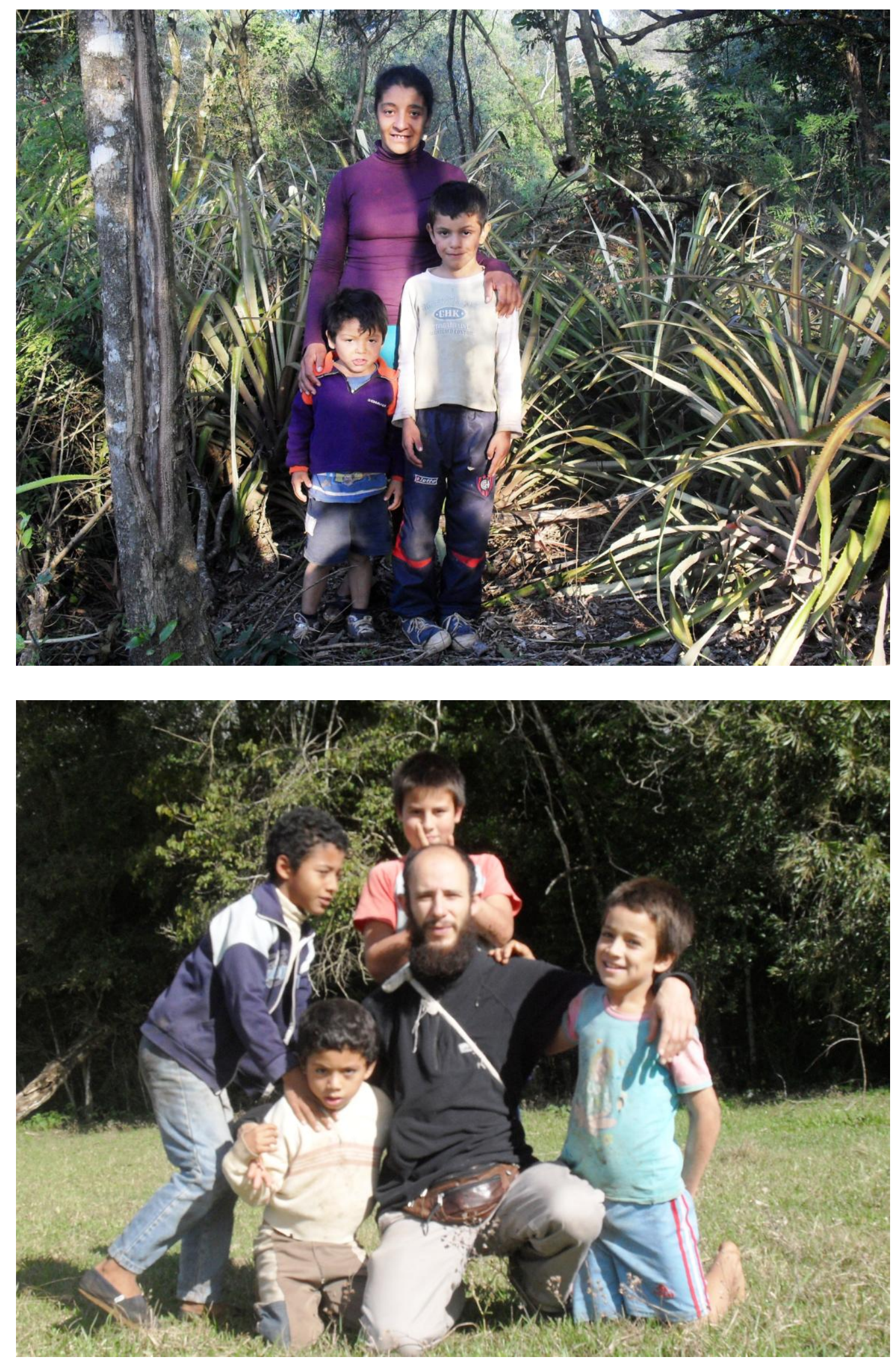


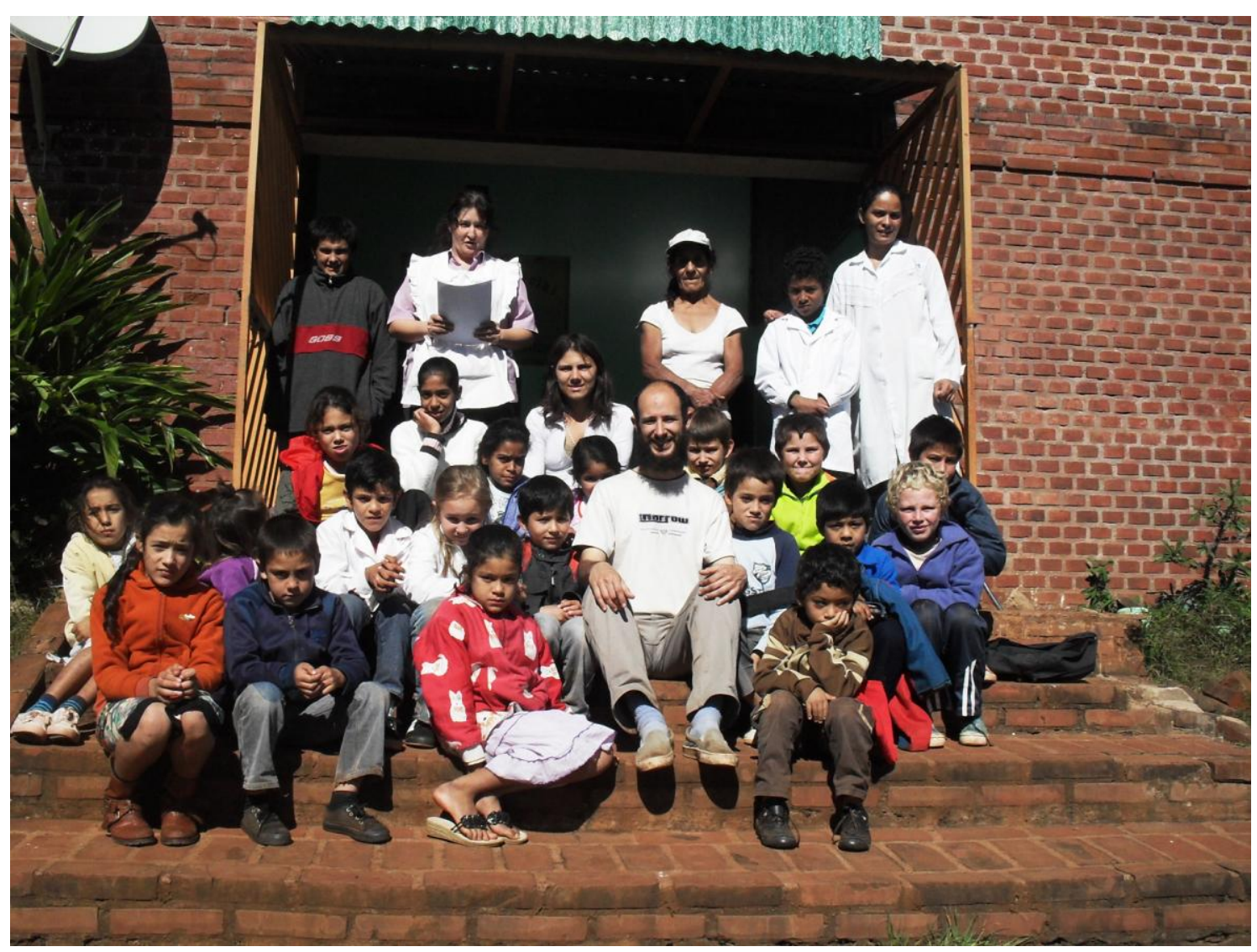


9. BIBLIOGRAFÍA 
Abadie, J. P. 1998. Publicaciones de la Comisión Administradora del Río Uruguay. "El Río Uruguay, empleo histórico y posibilidades futuras”. Paysandú.

Abreu, S. de L. \& M. A. Watanabe. 2008. Agro forestry systems and food security among smallholder farmers of the Brazilian Amazon: A strategy for environmental global crisis. 16ht IFOAM Organic World Congress, Modena, Italy. June 16-20. Consultado en: http://www.orgprints.org/12057/1/12057.pdf. Fecha de consulta: junio de 2012.

Acosta, J. de. 1590. Historia natural y moral de las Indias. Sevilla: Impreso en Casa de Juan León.

Aguirre-Dugua, X.; L. E. Eguiarte; A. González-Rodríguez \& A. Casas. 2012. Round and large: morphological and genetic consequences of artificial selection on the gourd tree Crescentia cujete by the Maya of the Yucatan Peninsula, Mexico. Annals of Botany 109: 1297-1306.

Albuquerque, U. P. \& R. F. P. Lucena. 2005. Can apparency affect the use of plants by local people in tropical forests? Interciencia 30(8): 506-511.

Albuquerque, U. P.; L. V. F. Cruz da Cunha; R. F. Paiva de Lucena \& R. R. Nóbrega Alves (Eds.). 2014. Methods and techniques in ethnobiology and ethnoecology. New York, Humana Press.

Albuquerque, U. P. \& J. A. Hurrell, 2010. Ethnobotany: one concept and many interpretations. En: Albuquerque, U. P. \& N. Hanazaki (eds.), Recent developments and case studies in ethnobotany, pp. 87-98. Recife: NUPEEA.

Alexiades, M. N. \& S. A. Laird. 2002. Estableciendo los fundamentos: relaciones equitativas de la investigación sobre biodiversidad. En: Laird, S. A. (ed.), Biodiversidad y conocimiento tradicional. Participación equitativa en práctica, pp. 41-52. Pueblos y Plantas $N^{\circ}$ 6. Montevideo: Nordan Comunidad.

Alexiades, M. N. \& D. A. Peluso. 2002. Consentimiento previamente informado: antropología y políticas de intercambio intercultural. En: Laird, S. A. (ed.), Biodiversidad y conocimiento tradicional. Participación equitativa en práctica, pp. 245-251. Pueblos y Plantas No 6. Montevideo: Nordan Comunidad. 
Alonso, J. 2004. Tratado de fitofármacos y nutracéuticos. $1^{\mathrm{a}}$ edición. Rosario: Corpus Libros.

Alonso-Castro, A. J.; J. J. Maldonado-Miranda; A. Zárate-Martínez; M. R. JacoboSalcedo; C. Fernández-Galicia; L. A. Figueroa-Zuñiga; N. A. Ríos-Reyes; M. A. de León-Rubio; N. A. Medellín-Castillo; A. Reyes-Munguia; R. Méndez-Martínez \& C. Carranza-Alvarez. 2012. Medicinal plants used in the Huasteca Potosina, México. Journal of Ethnopharmacology 143: 292-298.

Álvarez Ruíz, C.; M. Ortíz Torres; L. Simó Yermenos \& D. Mañon. 1999. Estudio de seis plantas medicinales dominicanas. Acta Medica Dominicana 21(3): 86-93.

Amat, A. G. \& M. E. Yajía. 1991. Plantas medicinales y etnofarmacología en la provincia de Misiones (Argentina). Acta Farmacéutica Bonaerense 10(3): 153-159.

Ambrosetti, J. B. 2008a. Primer y segundo viaje a Misiones por Juan Bautista Ambrosetti. Comentado por J. C. Chebez y B. Gasparri. Buenos Aires: Editorial Albatros, Fundación de Historia Natural Félix de Azara

Ambrosetti, J. B. 2008b. Tercer viaje a Misiones por Juan Bautista Ambrosetti. Buenos Aires: Editorial Albatros, Fundación de Historia Natural Félix de Azara.

Anderson, C. 1996. Variedades cultivadas en el área del Río Uruguay. En: Fabiani, A.; R. Mika; L. Larocca \& C. Anderson (eds.), Manual para productores de naranja y mandarina de la región del Río Uruguay, pp. 63-92. Concordia: Diversificación Productiva, Manual Serie A Nro. 2. INTA.

Arellano, E. \& A. Casas. 2003. Morphological variation and domestication of Escontria chiotilla (Cactaceae) under silvicultural management in the Tehuacan Valley, Central Mexico. Genetic Resources and Crop Evolution 50: 439-453.

Arenas, P. \& G. P. Galafassi. 1994. La ruda (Ruta chalepensis L. -Rutaceae-) en la medicina folclórica del norte argentino. Dominguezia 11(1): 7-50.

Arias B. A. \& L. Ramón-Laca. 2005. Pharmacological properties of citrus and their ancient and medieval uses in the Mediterranean region. Journal of Ethnopharmacology 97(1): 89-95. 
Atanazio da Silva, V.; V. Texeira do Nascimento; G. Taboada Soldati; M. F. Trinidade Medeiros \& U. P. Albuquerque. 2014. Techniques for analysis of quantitative ethnobotanical data: use of indices. En: Albuquerque, U. P., L. V. Fernandes Cruz da Cunha, R. F. Paiva de Lucena \& R. R. Nóbrega Álves (eds.), Methods and techniques in ethnobiology and ethnoecology, pp. 379-396. New York: Humana Press.

Aumeeruddy, Y. 1998. Modos rurales de representación y gestión de los sistemas agrosilvícolas en la periferia del Parque Nacional Kerinci Seblat, Sumatra, Indonesia. Documento de Trabajo de Pueblos y Plantas No 3. París: UNESCO.

Azara, F. de. 1847. Descripción e Historia del Paraguay y del Río de La Plata. Tomo 1. Madrid: Imprenta de Sánchez.

Bacigalupo, N. M. 2005. Rutaceae. En: Burkart, A. \& N. M. Bacigalupo (eds.), Flora Ilustrada de Entre Ríos. Colección Científica del Instituto Nacional de Tecnología Agropecuaria 6 (4b): 56-64.

Báez, J. R. 1944. La primera colonia agrohispana en el Río de la Plata. Revista Argentina de Agronomía 11: 278-286.

Báez, J. R. 1949. Breves apuntes sobre la migración de las plantas agrícolas euroindianas en el momento del descubrimiento. Lilloa 18: 33-36.

Balée, W. 1993. Indigenous transformation of Amazonian forests: an example from Maranhão, Brazil. L'Homme 33(126-128): 231-254.

Balée, W. (ed.). 1998. Advances in Historical Ecology. New York: Columbia University Press.

Banfi, A. 1954. Difusión de buenas variedades cítricas. IDIA 90-92: 102.

Banfi, A. \& H. Beñatena. 1954. Nuevas variedades en la colección de citrus. IDIA 9092: 101-102.

Barreyro, J. G. 1979. Breve historia de Misiones. Buenos Aires: Ed. Plus Ultra.

Bartolomé, L. J. \& G. Schiavoni, 2008. Desarrollo y estudios rurales en Misiones. Buenos Aires: Ediciones CICCUS. 
Bartolomé, M. A. 1978. La situación de los Guaraní (Mby'a) de Misiones (Argentina). En: Roa Bastos, A. (comp.), Las culturas condenadas, pp. 86-111. México D. F.: Ed. Siglo XXI.

Bartolomé, M. A. 2007. Los colonos de Apóstoles. Estrategias adaptativas y etnicidad en una colonia eslava en Misiones. Posadas: Editorial Universitaria, UNaM.

Bartolomé, M. A. 2009. Parientes de la selva. Los Guaranies Mbya de la Argentina. Asunción: Centro de Estudios Antropológicos de la Universidad Católica (CEADUC), Biblioteca Paraguaya de Antropología, vol. 72.

Bayer, R.; D. J. Mabberley; C. Morton; C. Miller; I. K. Sharma; B. E. Pfeil; S. Rich; R. Hitchcock \& S. Sykes. 2009. A molecular phylogeny of the orange subfamily (Rutaceae: Aurantioideae) using nine cpDNA sequences. American Journal of Botany 96(3): 668-685.

Beebe, S.; O. Toro Ch.; A. V. González; M. I. Chacón \& D. G. Debrouck. 1997. Wildweed-crop complexes of common bean (Phaseolus vulgaris L., Fabaceae) in the Andes of Peru and Colombia, and their implications for conservation and breeding. Genetic Resources and Crop Evolution 44: 73-91.

Begossi, A. 1996. Use of ecological methods in ethnobotany: diversity indices. Economic Botany 50(3): 280-289.

Belastegui, H. M. 2006. Los colonos de Misiones. Posadas: Editorial Universitaria, UNaM.

Benavente-García, O.; J. Castillo; F. R. Marín; A. Ortuño \& J. A. del Río. 1997. Uses and properties of Citrus flavonoids. Journal of Agriculture and Food Chemistry 45(12): $4505-4515$.

Berkes, F.; J. Colding \& C. Folke. 2000. Rediscovery of traditional ecological knowledge as adaptative management. Ecological Applications 10(5): 1251-1262.

Berkes, F. \& N. Turner. 2006. Knowledge, learning and the resilience of socialecological systems. Human Ecology 34: 479-494.

Berlin, B. 1992. Ethnobiological Classification. Principles of categorization of plants and animals in traditional societies. New Jersey: Princeton University Press. 
Bernard, R. H. 2000. Social Research Methods. Qualitative and Quantitative Approaches. California: Sage, Thousand Oaks.

Bertolini, M. P. 2005. Documento base para la discusión del plan de manejo del Parque Provincial Teyú Cuaré. Posadas: Instituto Universitario Gastón Dachary.

Bertoni, M. 1918. Descripción fisica y económica del Paraguay. Condiciones generales para la vida orgánica y división territorial. Puerto Bertoni: Ed. Ex Sylvis.

Bertoni, M. 1927. La civilización guaraní. Parte III. Etnografía. Conocimiento. Puerto Bertoni: Imprenta y Edición "Ex Sylvis".

Biganzoli, F. \& M. E. Múlgura de Romero. 2004. Inventario florístico del Parque Provincial Teyú Cuaré y alrededores (Misiones, Argentina). Darwiniana 42(1-4): 1-24.

Bisset, N. G. (ed.). 1994. Herbal drugs and phytopharmaceuticals. A handbook for practice on a scientific basis. Boca Raton: CRC Press.

Blancas, J.; A. Casas; S. Rangel-Landa; A. Moreno-Calles; I. Torres; E. Pérez-Negrón; L. Solís; A. Delgado-Lemus; F. Parra; Y. Arellanes; J. Caballero; L. Cortés; R. Lira \& P. Dávila. 2010. Plant management in the Tehuacán-Cuicatlán Valley, Mexico. Economic Botany 64(4): 287-302.

Bocco, A.; M. Cuvelier; H. Richard and C. Berset. 1998. Antioxidant activity and phenolic composition of citrus peel and seed extracts. Journal of Agricultural and Food Chemistry 46: 2123-2129.

Bowman, K. D. \& F. G. Smitter Jr. 1990. Forbidden fruit (Citrus sp., Rutaceae) Rediscovered in Saint Lucia. Economic Botany 44(2): 165-173.

Brabo, F. J. 1872. Colección de documentos relativos á la expulsión de los jesuitas de la República Argentina y del Paraguay. Madrid: Establecimiento Tipográfico de J. M. Pérez.

Burgstaller, C. 1985. La vuelta a los vegetales. 600 hierbas medicinales y sus propiedades curativas. 700 fórmulas útiles y su preparación en el hogar. Buenos Aires: Ed. Hachette S.A. 
Burkart, A. 1974. Flora ilustrada de Entre Ríos (Argentina). Tomo VI, parte V. Buenos Aires: Colección Científica del INTA.

Burkart, A. 1979. Flora ilustrada de Entre Ríos (Argentina). Tomo VI, parte VI. Buenos Aires: Colección Científica del INTA.

Burmeister, C. 1899. Memoria sobre el territorio de Misiones. Ministerio de Agricultura de la República Argentina. Buenos Aires: Impr., Litogr. y Encuad. de J. Peuser.

Buxó, R. 2006. Paisajes culturales y reconstrucción histórica de la vegetación. Ecosistemas 15(1): 1-6.

Cabeza de Vaca, A. N. 1947 [1490-1558]. Naufragios y comentarios. Buenos Aires: Espasa-Calpe S.A.

Cabrera, A. L. 1976. Regiones Fitogeográficas Argentinas. Enciclopedia de Agricultura y Jardinería. Tomo II. Buenos Aires: ACME.

Cadena-González, A. L.; M. Sørensen \& I. Theilade. 2013. Use and valuation of native and introduced medicinal plant species in Campo Hermoso and Zetaquira, Boyacá, Colombia. Journal of Ethnobiology and Ethnomedicine 9(23). doi:10.1186/1746-42699-23.

Cadogan, L. 1957. Apuntes de medicina popular guaireña. Publicación del Centro de Estudios Antropológicos del Paraguay. Asunción: Imprenta Nacional.

Cadogan, L. 1969. Cadogan, según Cadogan. Entrevista Diario La Tribuna, 9 de febrero de 1969. Consultado en: www.portalguarani.com/obras autores detalles.php?id obras $=17830$.

Cadogan, L. 1992. Diccionarios Mbya-Guaraní-castellano. Biblioteca Paraguaya de Antropología vol. XVII. Asunción: CEADUC-CEPAG.

Calvet-Mir, L.; M. Calvet.Mir \& V. Reyes-García. 2010. Traditional ecological knowledge and landraces in situ conservation in high mountain home gardens of Vall Fosca, Catalan Pyrenees, Iberian Peninsula. En: Pochettino, M. L.; A. H. Ladio \& P. M. Arenas (eds.), Tradiciones \& transformaciones en Etnobotánica, pp. 457-464. San 
Salvador de Jujuy: CYTED - Programa Iberoamericano Ciencia y Tecnología para el Desarrollo.

Cambas, G. 2005. El patrimonio intangible de Santos Mártires del Japón. En: Page, C. A. (ed.), Educación y evangelización. La experiencia de un mundo mejor, pp. 381-384. X Jornadas Internacionales sobre Misiones Jesuíticas, Universidad Católica de Córdoba. Campillo, F. 2005. Plantas autóctonas en jardinería. Revista Agrícola Jardinería y Paisajismo 15: 18-21.

Capparelli, A.; N. I. Hilgert; A. Ladio; V. S. Lema; C. Llano; S. Molares; M. L. Pochettino \& P. Stampella. 2011. Paisajes culturales de Argentina: Pasado y presente desde las perspectivas etnobotánica y paleoetnobotánica. Revista de la Asociación Argentina de Ecología de Paisajes 2(2): 67-79.

Capparelli, A., V. Lema, M. Giovannetti \& R. Raffino. 2005. The introduction of Old World crops (wheat, barley and peach) in Andean Argentina during the $16^{\text {th }}$ century A.D.: archaeobotanical and ethnohistorical evidence. Vegetation History and Archaeobotany 14: 472-484.

Capparelli, A. \& R. A. Raffino. 1997. Arqueoetnobotánica de El Shincal I: tallos finos, frutos y semillas. Tawantinsuyu 3: 40-57.

Carbonell, R. 1992. Estrategias de desarrollo rural en los pueblos guaranies (16091736). Barcelona: Antoni Bosch, Sociedad Estatal Quinto Centenario, Instituto de Estudios Fiscales \& Instituto de Cooperación Iberoamericana.

Cardiel, J. 1994. [1771]. Breve relación de las misiones del Paraguay. Buenos Aires: Secretaría de Cultura de la Nación y Ed. Theoria.

Carvalho, A. M. \& A. Frazão-Moreira. 2011. Importance of local knowledge in plant resources management and conservation in two protected areas from Trás-os-Montes, Portugal. Journal of Ethnobiology and Ethnomedicine 7: 36.

Casas, A. 2001. Silvicultura y domesticación de plantas en Mesoamérica. En: Rendón Aguilar, B.; S. Rebollar Domínguez; J. Caballero Nieto y M. A. Martínez Alfaro (eds.), Plantas, cultura y sociedad. Estudio sobre la relación entre seres humanos y plantas en 
los albores del siglo XXI, pp. 123-157. México D. F.: Universidad Autónoma Metropolitana.

Casas, A. 2005. El manejo tradicional y diversidad biológica, el caso de Xoconochtli. CONABIO. Biodiversitas 60: 1-6.

Casas, A. \& J. Caballero. 1996. Traditional management and morphological variation in Leucaena esculenta (Fabaceae: Mimosoideae) in the Mixtec region of Guerrero, Mexico. Economic Botany 50(2): 167-181.

Casas, A., J. Caballero, A. Valiente-Banuet, J. A. Soriano \& P. Dávila. 1999. Morphological variation and the process of domestication of Stenocereus stellatus (Cactaceae) in Central Mexico. American Journal of Botany 86(4): 522-533.

Casas, A.; J. Cruse-Sanders; E. Morales; A. Otero-Arnaiz \& A. Valiente-Banuet. 2006. Maintenance of phenotipic and genotipic diversity in managed populations of Stenocereus stellatus (Cactaceae) by indigenous peoples in Central Mexico. Biodiversity and Conservation 15: 879-898.

Casas, A.; B. Pickersgill; J. Caballero \& A. Valiente-Banuet. 1997. Ethnobotany and the process of domestication of the xoconochtli Stenocereus stellatus (Cactaceae) in the Tehuacán Valley and La Mixteca Baja, Mexico. Economic Botany 51: 279-292.

Casas, B. de las. 1875. Historia de las Indias, Tomo II. Madrid: Edición del Marqués de la Fuensanta del Valle y D. José Sancho Rayon. Imprenta de Miguel Ginesta.

Chase-Sardi, M. 1989. El tekoha. Su organización social y los efectos negativos de la deforestación entre los Mby'a-guaraní. Suplemento Antropológico 24(2): 33-41.

Chebez, J. C. 2005. Guía de las reservas naturales de la Argentina. Nordeste. Buenos Aires: Ed. Albatros.

Chebez, J. C. \& N. I. Hilgert. 2003. Brief history of conservation in the Paraná Forest. En: Galindo-Leal, C. \& I. de Gusmão Câmara (eds.), The Atlantic Forest of South America, Biodiversity Status, Threats, and Outlook, pp. 141-159. Washington: Island Press.

Chifarelli, D. 2010. Acumulación, éxodo y expansión. Un análisis sobre la agricultura familiar en el norte de Misiones. Buenos Aires: Ediciones INTA. 
CITRUS PAGES. 2014. Consultado en: www. users.kymp.net/citruspages. Fecha de consulta: marzo de 2014.

Cobo, B. 1890-1892. [1580-1657]. Historia del Nuevo Mundo. Publicada por primera vez por D. Marcos Jiménez de la Espada. 3 tomos. Sevilla: Imprenta de E. Rasco Bustos.

Colcombet, L. y C. Noseda. 2000. Sector agrario de la provincia de Misiones”. Informe para Fundación Vida Silvestre Argentina.

Coluccio, F. \& S. B. Coluccio. 1991. Diccionario folklórico argentino. Buenos Aires: Ed. Plus Ultra.

Commelyn, S. 1683. The Belgick, or Netherlandish Hesperides. That is. The management, ordering and use of Limon and Orange trees, fitted to the Nature and Climate of the Netherlands. London: Holford Bookseller.

Compañía Tabacalera de Misiones. 2014. Consultado en: www.cooptabmis.com/citrusespanol.html. Fecha de consulta: febrero de 2014.

Costa-Neto, E. 1998. Folk taxonomy and cultural significance of "abeia" (Insecta, Hymenoptera) to the Pankararé, Northeastern Bahia state, Brazil. Journal of Ethnobiology 18(1): 1-13.

Cotton, C. M. 1998. Ethnobotany: Principles and applications. U. K.: J. Wiley \& Sons.

Crivos, M.; M. R. Martínez \& M. L. Pochettino. 2009. Fitoterapia en los Valles Calchaquíes, Salta, Argentina. En: Vignale, N. D. \& M. L. Pochettino (eds.), Avances sobre plantas medicinales andinas, pp. 47-86. San Salvador de Jujuy: CYTED.

Crivos, M., M. R. Martínez, M. L. Pochettino, C. Remorini, A. Sy \& L. Teves. 2007. Pathways as "signatures in landscape": towards an ethnography of mobility among the Mbya-Guaraní (Northeastern Argentina). Journal of Ethnobiology and Ethnomedicine 3: 2. doi: 10.1186/1746-4269-3-2.

Cruz, M. \& A. Casas. 2002. Morphological variation and reproductive biology of Polaskia chende (Cactaceae) under domestication in Central Mexico. Journal of Arid Environments 51(4): 561-576. 
Cunningham, A. B. 2001. Etnobotánica aplicada. Pueblos, uso de plantas silvestres y conservación. Montevideo: Ed. Nordan-Comunidad.

D’Antonio, C. \& L. A. Meyerson. 2002. Exotic plant species as problems and solutions in ecological restoration: a synthesis. Restoration Ecology 10(4): 703-713.

Davidson-Hunt, I. \& F. Berkes. 2003. Learning as you journey: Anishinaabe perception of social-ecological environments and adaptative learning. Conservation Ecology 8(1): 5.

De Grenade, R.; R. Krueger; G. P. Nabhan \& M. C. Olvera. 2014. Mission and modern Citrus speceis diversity of Baja California Peninsula oases. Economic Botany 68(3): 262-282.

DeGasperis, B. G. \& G. Motzkin. 2007. Windows of opportunity: historical and ecological controls of Berberis thunbergii invasions. Ecology 88(12): 3115-3125.

Del Río Moreno, J. L. \& L. E. López y Sebastián. 1996. El trigo en la ciudad de México. Industria y comercio de un cultivo importado (1521-1564). Revista Complutense de Historia de América 22: 33-51.

Delucchi, G.; E. Farina \& S. S. Torres Robles. 2009. Presencia de Pyrus communis (Rosaceae Maloideae) naturalizada en la República Argentina. Boletín de la Sociedad Argentina de Botánica 44(1-2): 171-174.

Delucchi, G. \& H. A. Keller. 2010. La naturalización del "níspero", Eriobotrya japonica (Rosaceae, Maloideae), en la Argentina. Bonplandia 19(1): 71-77.

Delucchi, G.; H. A. Keller; P. A. Cabanillas; P. C. Stampella \& J. A. Hurrell. 2014. Pueraria montana var. lobata (Leguminosae) en la Argentina: estado actual de su naturalización. Bonplandia 23(1): 5-14.

Descola, P. 1996. La selva culta: simbolismo y praxis en la ecología de los Achuar. $3^{\mathrm{a}}$ edición en español. Colección Pueblos del Ecuador No 3. Quito: Ed. Abya-Yala.

Díaz de Guzmán, R. 2000 [1602]. La Argentina. Crónicas de América. España: DASTIN Historia. 
Dimitri, M. J. 1980. Enciclopedia Argentina de Agricultura y Jardinería. Tomo 1. $2^{\circ}$ volumen. Buenos Aires: Editorial ACME S.A.C.I.

Dimitri, M. J. 1987. Enciclopedia Argentina de Agricultura y Jardinería. Tomo 1. $1^{\circ}$ volumen. Buenos Aires: Editorial ACME S.A.C.I.

Dobrizhoffer, M. 1967 [1784]. Historia de los Abipones. I. Resistencia: Facultad de Humanidades. Universidad Nacional del Nordeste.

Domínguez, G. P. \& G. A. Domínguez. 1998. Jardinería ecológica: necesidades y criterios básicos. Ponencia pública en actas del III Congreso de la Sociedad Española de Agricultores Ecológicos 1: 121-128.

Domínguez, J. 1928. Aimé Bonpland. Su vida en la América del Sur y principalmente en la República Argentina (1817-1858). Ciclo de conferencias. Anales de la Sociedad Científica Argentina 108: 407 y siguientes.

Ekué, M. R. M., B. Sinsin; O. Eyog-Matig \& R. Finkeldey. 2010. Uses, traditional management, perception of variation and preferences in ackee (Blighia sapida K. D. Koenig) fruit traits in Benin: implications for domestication and conservation. Journal of Ethnobiology and Ethnomedicine 6: 12.

Elias, M.; G. S. Mühlen; D. McKey; A. C. Roa \& J. Tohme. 2004. Genetic diversity of traditional South American landraces of cassava (Manihot esculenta Crantz): an analysis using microsatellites. Economic Botany 58(2): 242-256.

Emperaire, L. 2010. La construcción de la diversidad agrícola: conceptos y prácticas. En: Pochettino, M. L.; A. H. Ladio \& P. M. Arenas (eds.), Tradiciones \& transformaciones en Etnobotánica, pp. 175. San Salvador de Jujuy: CYTED Programa Iberoamericano Ciencia y Tecnología para el Desarrollo.

Emperaire, L.; F. Pinton \& G. Second. 2001. Dinámica y manejo de la diversidad de las variedades de yuca del noroccidente amazónico (Brasil). Etnoecológica 5(7): 38-59.

Etkin, N. L. \& T. Ticktin. 2010. Advancing an ethno-ecological perspective that integrates theory and method in ethnobotany. En: Albuquerque, U. P. \& N. Hanazaki (Eds.), Recent developments and case studies in ethnobotany, pp. 33-57. Recife: NUPEEA. 
Ewel, J. J. \& F. E. Putz. 2004. A place for alien species in ecosystem restoration. Frontiers in Ecology and the Environment 2(7): 354-360.

Eyssartier, C. 2011. Conocimiento hortícola y de recolección de recursos silvestres en comunidades rurales y semi-rurales del Noroeste de la Patagonia: Saber-cómo (knowhow) y resiliencia. Tesis Doctoral inédita, Facultad de Ciencias Exactas y Naturales, Universidad Nacional de Buenos Aires.

Eyssartier, C.; A. Ladio \& M. Lozada. 2008. Cultural transmission of traditional knowledge in two populations of north-western Patagonia. Journal of Ethnobiology and Ethnomedicine 4: 25. doi: 10.1186/1746-4269-4-25.

Fernández González, F. \& L. Ramón-Laca. 2002. El tratado sobre los cítricos de Nicolás Monardes. Asclepio 54(2): 149-164.

Fernández Ramos, R. 1929. Apuntes históricos sobre Misiones. Madrid: Ed. Talleres Espasa-Calpe.

Ferrari, J. B. 1646. Hesperides sive de malorum aureorum cultura et usu. Libri Quatuor. Romae: Sumptibus Hermanii Scheus.

Ferrero, B. 2008. Más allá del dualismo naturaleza-sociedad: poblaciones locales y áreas protegidas en Misiones. En: Bartolomé, L. J. \& G. Schiavoni (Comp.), Desarrollo y estudios rurales en Misiones, pp. 177-202. Buenos Aires: Ed. CICCUS.

Font Quer, P. 1979. Plantas medicinales, El Dioscórides renovado. Barcelona: Ed. LABOR.

Fontana, J. 1998. Análisis sistemático-ecológico de la flora del sur de Misiones (Argentina). Candollea 53:211-300.

Fontana, J. L. 2005. Una propuesta para la conservación de los pajonales del Diplothemio-Axonopodetum. San Ignacio, provincia de Misiones (Argentina). Facena 21: 55-67.

Fridley, J. D.; J. J. Stachowicz; S. Naeem; D. F. Sax; E. W. Seabloom; M. D. Smith; T. J. Stohlgren; D. Tilman \& B. von Holle. 2007. The invasion paradox: reconciling pattern and process in species invasions. Ecology 88(1): 3-17. 
Furlong, G. 1962. Misiones y sus pueblos de guaranies. Buenos Aires: Ed. Balmes.

Gade, D. W. 1976. Naturalization of plant aliens: the volunteer orange in Paraguay. Journal of Biogeography 3(3): 269-279.

Gade, D. W. 1979. Petitgrain from Citrus aurantium: essential oil of Paraguay. Economic Botany 33(1): 63-71.

Gallero, M. C. \& E. M. Krautstofl. 2010. Proceso de poblamiento y migraciones en la Provincia de Misiones, Argentina (1881-1970). Avá 16: 245-264.

Gallesio, G. 1811. Traité du citrus. Paris: Chez Louis Fantin, Libraire.

Gálvez, L. 1995. Guaraníes y jesuitas. De la tierra sin mal al paraíso. Buenos Aires: Ed. Sudamericana.

Gambón, V. 1904. A través de las misiones guaraniticas. Buenos Aires: Ángel Estrada y Cía.

Gandolfo, E. S.; T. Marques Ribeiro \& N. Hanazaki. 2010. Can the homegardens persist with the urbanization of the coastline? En: Pochettino, M. L.; A. H. Ladio \& P. M. Arenas (eds.), Tradiciones \& transformaciones en Etnobotánica, pp. 557-561. San Salvador de Jujuy: CYTED - Programa Iberoamericano Ciencia y Tecnología para el Desarrollo.

García Mesa, M.; D. M. Armenteros Herrera; M. M. Vilas; C. Coma Alfonso; J. Hernández Carretero; A. Díaz Batista \& J. Fernández Montequini. 2002. Plantas cítricas en el tratamiento de enfermedades vasculares. Revista Cubana de Angiología y Cirugía Vascular 3(2): 39-46.

García Paris, J. 1991. Intercambio y difusión de plantas de consumo entre el Nuevo y el Viejo mundo. Madrid: Servicio de Extensión Agraria, Ministerio de Agricultura, Pesca y Alimentación.

García-Lor, A.; F. Curk; H. Snoussi-Trifa; R. Morillon; G. Ancillo; F. Luro; L. Navarro \& P. Ollitrault. 2013. A nuclear phylogenetic analysis: SNPs, indels and SSRs deliver new insights into the relationships in the ,true citrus fruits trees ${ }^{\text {ee }}$ group (Citrinae, Rutaceae) and the origin of cultivated species. Annals of Botany 111:1-19. 
Gepts, P. 2004. Crop domestication as a long-term selection experiment. Plant Breeding Reviews 24(2): 1-44.

Germosén-Robineau, L. 1996. Farmacopea vegetal caribeña. Santo Domingo: Tramil.

Giovannetti, M. 2005. La conquista del noroeste argentino y los cultivos europeos. Fronteras de la Historia 10: 253-283.

Giovannetti, M. \& V. Lema. 2005. Cultivos introducidos por los europeos en el Shinkal de Quimivil: La presencia de los Hispanos en la supervivencia ritual. En: Cetti, A.; A. Re; D. Rindel \& P. Valeri (eds.), Entre Pasado Y Presente, pp. 410-429. Buenos Aires: VI Jornadas de jóvenes investigadores en ciencias antropológicas, Instituto Nacional de Antropología y Pensamiento Latinoamericano.

Gmitter, F. G, Jr \& X. Hu. 1990. The possible role of Yunnan, China, in the origin of contemporary citrus species (Rutaceae). Economic Botany 44(2): 267-277.

González-Soberanis, M. C. \& A. Casas. 2004. Traditional management and domestication of tempesquistle, sideroxylon palmeri (Sapotaceae) in the Tahuacán Valley, Central Mexico. Journal of Arid Environments 59: 245-258.

Gran Atlas de Misiones. 2012. Capítulo 7, pp. 370-389, Departamento San Ignacio. Posadas: Instituto Provincial de Estadísticas y Censos.

Granitto, G. M. \& S. J. Sarandón. 2002. Producción de caña de azúcar orgánica: el caso de la cooperativa la Unión de San Juan de la Sierra, Misiones, Argentina En: Sarandón, S. J. (ed.), Agroecología. El camino hacia una agricultura sustentable, pp. 549-557. La Plata: Ediciones Científicas Americanas.

Grant, V. 1989. Especiación Vegetal. 1a Edición. México D. F.: Ed. LIMUSA S.A.

Grau, H. R. \& M. Aide. 2008. Globalization and land-use transitions in Latin America. Ecology and Society 13(2): 16. http://www.ecologyandsociety.org/vol13/iss2/art16/.

Grau, H. R.; T. M. Aide; J. K. Zimmerman; J. R. Thomlinson; E. Helmer \& X. Zou. 2003. The ecological consequences of socioeconomic and land use change in post agricultural Puerto Rico. Bioscience 53: 1159-1168. 
Greider, T. \& L. Garkovich. 1994. Landscapes: The social construction of nature and the environment. Rural Sociology 59(1): 1-24.

Guerra y Sánchez Téllez. 1984. El libro de medicinas caseras de fray Blas de la Madre de Dios, Manila, 1611. España: Editorial Cultura Hispánica.

Gurevitch, J. \& D. K. Padilla. 2004. Are invasive species a major cause of extinctions? TRENDS in Ecology and Evolution 19(9): 470-474.

Harlan, J. R. 1992. Crops \& Man. $2^{\text {nd }}$ edition. Madison: American Society of Agronomy, Inc.

Harris, D. R. 1989. An evolutionary continuum of people-plant interaction. En: Harris, D. R. \& G. C. Hillman (eds.), Foraging and farming. The evolution of plant exploitation, pp. 11-26. London: Unwin Hyman Ltd.

Heckenberger, M. J.; A. Kuikuro; U. T. Kiukuro; C. Russell; M. Schmidt; C. Fausto \& B. Franchetto. 2003. Amazonia 1492: Pristine forest or cultural parkland? Science 301: $1710-1714$.

Hernández Bermejo, J. E. \& A. Lora González. 1996. La documentación histórica y bibliográfica como fuente de información y evidencia etnobotánica. Monogr. Jardín Botánico de Córdoba 39-50.

Hernández, P. 1913. Organización social de las doctrinas guaranies de la Compañía de Jesús. Barcelona: Gustavo Gili Editor.

Hernández, R. 1888. Cartas Misioneras. Reseña histórica y descriptiva de las Misiones Argentinas. Con dos planos de Colonias (reproducción). Buenos Aires: Imprenta "Luz del Alma”.

Herrera, G. Alonso de. 1818 [1513]. Agricultura General. 3 tomos. Madrid: Imprenta Real, Madrid. Disponible en: http://bibdigital.rjb.csic.es/spa/Volumenes.php?Libro=16. Fecha de consulta: diciembre de 2013.

Herrera, J. \& L. Malmierca. 1995. Relevamiento de especies vegetales exóticas en el área Cataratas. Informe Interno. Administración de Parques Nacionales. Centro de Investigaciones Ecológicas Subtropicales (CIES). Delegación Regional Nordeste Argentino. Iguazú. 
Hieronymus, J. 1882. Plantae diaphoricae florae argentinae. Boletín de la Academia Nacional de Ciencias en Córdoba 4(3): 199-598.

Higby, R. H. 1943. Method for manufacturing hesperidin. Patent US 2400693. Disponible en sitio URL: http://www.google.com/patents/US2400693. Fecha de consulta septiembre de 2011.

Hilgert, N. I. 1997. Las plantas vinculadas con el ámbito doméstico y la subsistencia de los campesinos de la cuenca del río Zenta, Dpto. Orán, Prov. Salta. Tesis Doctoral inédita, Facultad de Ciencias Exactas, Físicas y Naturales, Universidad Nacional de Córdoba.

Hilgert, N. I. 1999. Las plantas comestibles en una zona de las Yungas meridionales (Argentina). Anales del Jardín Botánico de Madrid 57(1): 117-138.

Hilgert, N. I. 2001. Plants used in home medicine in the Blanco River basin, in northwestern Argentina subtropical montane forests. Journal of Ethnopharmacology 76: 11-34.

Hilgert, N. 2007. La vinculación del hombre actual con los recursos naturales y el uso de la tierra. En: Brown, A.; M. García Moritán; B. Ventura; N. Hilgert y L. Malizia (eds.), Finca San Andrés. Un espacio de cambios ambientales y sociales en el Alto Bermejo, pp. 159-186. San Miguel de Tucumán: Ediciones del Subtrópico.

Hilgert, N. I. \& G. E. Gil. 2006. Medicinal plants of the Argentine Yungas plants of the Las Yungas biosphere reserve, Northwest of Argentina, used in health care. Biodiversity and Conservation 15: 2565-2594.

Hilgert, N. I. \& G. E. Gil. 2007. Reproductive medicine in northwest Argentina: traditional and institutional systems. Journal of Ethnobiology and Ethnomedicine 3: 19.

Hilgert, N. I. \& G. E. Gil. 2008. Los cambios de uso del ambiente y la medicina herbolaria. Estudio de caso en Yungas Argentina. Boletín Latinoamericano y del Caribe de Plantas Medicinales 7(3): 130-140.

Hilgert, N. I.; D. A. Lambaré; N. D. Vignale; P. C. Stampella \& M. L. Pochettino. 2014. ¿Especies naturalizadas o antropizadas? Apropiación local y la construcción de saberes 
sobre los frutales introducidos en época histórica en el norte de Argentina. Revista Biodiversidad Neotropical 4(2): 69-87.

Hilgert, N. I.; P. C. Stampella; P. A. Cabanillas; M. Núñez; V. Furlán \& M. L. Pochettino. 2013. Usos medicinales de los cítricos (Citrus L.; Rutaceae) en el sur de la provincia de Misiones, Argentina. Presentación oral en las XXXIV Jornadas Argentinas de Botánica, pp. 123. La Plata.

Hillman, G. and M. Davies. 1990. Measured domestication rates in wild wheats and barley under primitive cultivation, and their archaeological implications. Journal of World Prehistory 4(2): 157-222.

Hodgson, R. W. 1965. Taxonomy and nomenclature in the Citrus fruits. En: Krishnamurthi, S. (ed.), Advances in agricultural sciences and their applications, pp. 317-331. Coimbatore: Agricultural College-Research Institute.

Höft, M., S. Barik \& A. Lykke. 1999. Quantitative Ethnobotany. People and Plants Working Papers $\mathrm{N}^{\mathrm{o}}$ 6. París: UNESCO.

Holmberg, E. L. 1887. Viaje a misiones. Boletín de la Academia Nacional de Ciencias en Córdoba 10: 252-288.

Hurrell, J. A.; G. Delucchi \& H. A. Keller. 2011. Carya illinoensis (Juglandaceae) adventicia en la Argentina. Bonplandia 20(1): 47-54.

Hurrell, J. A.; G. Delucchi; H. A. Keller; P. C. Stampella \& E. L. Guerrero. 2012. Bryophyllum (Crassulaceae): especies ornamentales naturalizadas en la Argentina. Bonplandia 21(2): 169-181.

Hurrell, J. A.; E. Ulibarri, G. Delucchi \& M. L. Pochettino. 2010. Frutas frescas, secas y preservadas. En: Hurrell, J. A. (ed.), Biota Rioplatense XV. Buenos Aires: Ed. LOLA.

IBODA. 2014. Instituto de Botánica Darwinion. Base de Datos. Flora del Conosur. Disponible en: www2.darwin.edu.ar/Proyectos/FloraArgentina/FA.asp. Fecha de consulta: 2014.

Iskandar, J. \& R. Ellen. 1999. In situ conservation of rice landraces among the Baduy of west Java. Journal of Ethnobiology 19(1): 97-125. 
Izquierdo, A. E.; C. D. De Angelo \& T. M. Aide. 2008. Thirty years of human demography and land-use change in the Atlantic Forest of Misiones, Argentina: an evaluation of the forest transition model. Ecology and Society 13(2): 3. [online] URL: http://www.ecologyandsociety.org/vol13/iss2/art3/

Izquierdo, A. E.; H. R. Grau \& T. M. Aide. 2010. Implications of rural-urban migration for conservation of the Atlantic Forest and urban growth in Misiones, Argentina (19702030). AMBIO 40(3): 298-309.

Janick, J. 2005. The origin of fruits, fruit growing, and fruit breeding. En: Janick, J. (ed.), Plant Breeding Review 25, pp. 255-320. Hoboken: Wiley.

Jarvis, D. I. \& T. Hodgkin. 1999. Wild relatives and crop cultivars: detecting natural introgression and farmer selection of new genetic combinations in agroecosystems. Molecular Ecology 8: 159-173.

Johns, T. 1989. A chemical-ecological model of root and tuber domestication in the Andes. En: Harris, D. R. \& G. C. Hillman (eds.), Foraging and Farming: the evolution of plant exploitation, pp. 504-519. London: Unwin and Hyman.

Keller, H. A.; G. Delucchi \& H. F. Romero. 2011. Camellia sinensis (Theaceae) en la Argentina: naturalización y usos locales. Boletín de la Sociedad Argentina de Botánica 46(1-2): 145-150.

Keller, H. A.; J. A. Hurrell; R. O. Vanni \& G. Delucchi. 2012. Senna macranthera (Leguminosae), una especie ornamental naturalizada en la Argentina. Bonplandia 21(1): $55-60$.

Keller, H. A. \& H. F. Romero. 2006. Plantas medicinales utilizadas por campesinos del área de influencia de la Reserva de Biósfera Yabotí (Misiones, Argentina). Bonplandia 15(3-4): 125-141.

Keller, H. A.; P. C. Stampella; G. Delucchi \& J. A. Hurrell. 2013. Vernicia fordii y Aleurites moluccanus (Euphorbiaceae) en la Argentina. Naturalización y etnobotánica. Boletín de la Sociedad Argentina de Botánica 48(3-4): 553-561.

Kiple, K. F. \& K. C. Ornelas (eds.). 2000. The Cambridge world history of food. 2 volúmenes. U. K.: Cambridge University Press. 
Kleinman, A. 1980. Patients and healers in the context of culture. An exploration of the borderland between anthropology, medicine, and psychiatry. California: University of California Press.

Klooster, D. 2003. Forest transitions in Mexico: institutions and forests in a globalized countryside. The Professional Geographer 55: 227-237

Koinange, E. M. K.; S. P. Singh \& P. Gepts. 1996. Genetic control of the domestication syndrome in common bean. Crop Science 36: 1037-1045.

Krapovickas, A. \& M. Dematteis. 2008. Butia eriospatha (Drude) Becc., palmera naturalizada en el norte de Misiones (Argentina). Bonplandia 17(1): 91-92.

Kujawska, M. \& N. I. Hilgert. 2014. Phytotherapy of Polish migrants in Misiones, Argentina: Legacy and acquired plant species. Journal of Ethnopharmacology 153: 810830.

Kujawska, M.; F. Zamudio \& N. I. Hilgert. 2012. Honey-based mixtures used in home medicine by nonindigenous population of Misiones, Argentina. Evidence-Based Complementary and Alternative Medicine volume 2012. Article ID 579350, 15 pages. Doi: $10.1155 / 2012 / 579350$.

Kumamoto, J, R. W. Scora, H. W. Lawton \& W. A. Clerx. 1987. Mystery of the forbidden fruit: Historical epilogue on the origin of the grapefruit, Citrus paradisi (Rutaceae). Economic Botany 41(1): 97-107.

Kumar, S.; K. N. Nair \& S. N. Jena. 2013. Molecular differentiation in Indian Citrus L. (Rutaceae) inferred from nrDNA ITS sequence analysis. Genetic Resources and Crop Evolution. doi 10.1007/s10722-012-9814-x.

Kuna, G. de. 2005. La cuestión del patrimonio tangible: caso Santos Mártires del Japón. En: C. A. Page (ed.), Educación y evangelización. La experiencia de un mundo mejor, pp. 385-395. X Jornadas Internacionales sobre Misiones Jesuíticas, Universidad Católica de Córdoba.

Kyndt, T., T. N. Dung, P. Goetghebeur, H. T. Toan \& G. Gheysen. 2010. Analysis of ITS of the rDNA to infer phylogenetic relationships among Vietnamese Citrus accessions. Genetic Resources and Crop Evolution 57: 183-192. 
Laclau, P. 1994. La conservación de los recursos naturales y el hombre en la Selva Paranaense. Boletín Técnico No 2. Buenos Aires: Fundación Vida Silvestre Argentina.

Ladio, A. \& M. Lozada. 2000. Edible wild plant use in a Mapuche community of northwestern Patagonia. Human Ecology 28(1): 53-71.

Ladio, A. \& S. Molares. 2010. Aspectos do estudo da dinámica do uso de produtos etnobiológicos não tradicionais. En: Albuquerque, U. P., R. F. Paiva de Lucena \& L. V. F. Cruz da Cunha (eds.), Métodos e Técnicas na Pesquisa Etnobiológica e Etnoecológica, pp. 365-378. Recife: NUPEEA.

Ladio, A.; S. Molares \& E. H. Rapoport. 2007. Conocimiento etnobotánico de plantas comestibles entre los maestros patagónicos: patrones de variación ambiental este-oeste. Kurtziana 33(1): 141-152.

Laird, S. A. 2002. Introducción: participación equitativa en práctica. En: Laird, S. A. (ed.), Biodiversidad y conocimiento tradicional. Participación equitativa en práctica, pp. 21-34. Pueblos y Plantas $N^{\circ}$ 6. Montevideo: Nordan Comunidad.

Laird, S. A. \& F. Noejovich. 2002. Construyendo relaciones de investigación equitativas con pueblos indígenas y comunidades locales: consentimiento previamente informado y acuerdos de investigación. En: Laird, S. A. (ed.), Biodiversidad y conocimiento tradicional. Participación equitativa en práctica, pp. 205-244. Pueblos y Plantas $\mathrm{N}^{\circ}$ 6. Montevideo: Nordan Comunidad.

Laird, S. A. \& D. A. Posey. 2002. Estándares de sociedades profesionales para la investigación en biodiversidad: códigos de ética y pautas de investigación. En: Laird, S. A. (ed.), Biodiversidad y conocimiento tradicional. Participación equitativa en práctica, pp. 53-73. Pueblos y Plantas No 6. Montevideo: Nordan Comunidad.

Lambaré, D. A. Manu scriptum. Procesos locales de selección cultural en poblaciones de frutales de la familia Rosaceae originarias del Viejo Mundo utilizados por comunidades rurales del noroeste argentino. Tesis Doctoral, Facultad de Ciencias Naturales y Museo, Universidad Nacional de La Plata.

Lambaré, D. A. \& M. L. Pochettino. 2012. Diversidad local y prácticas agrícolas asociadas al cultivo tradicional de duraznos Prunus persica (Rosaceae), en el Noroeste de Argentina. Darwiniana 50 (2): 174-186. 
Lancaster, P. A.; J. S. Ingram; M. Y. Lim \& D. G. Coursey. 1982. Traditional cassavabased foods: survey of processing techniques. Economic Botany 36(1): 12-45.

Lema, V. S. 2009. Domesticación vegetal y grado de dependencia ser humano-planta en el desarrollo cultural Prehispánico del Noroeste argentino. Tesis Doctoral inédita, Facultad de Ciencias Naturales y Museo, Universidad Nacional de La Plata.

Lema, V. S. 2010. Procesos de domesticación vegetal en el pasado prehispánico del noroeste argentino: estudio de las prácticas más allá de los orígenes. Relaciones de la sociedad Argentina de Antropología XXXV: 121-142.

Lema, V. S. 2013. Crianza mutua: una gramática de la sociabilidad andina. Trabajo precirculado en el Grupo de Trabajo No 21, En: Caballero, I. V. \& F. Pazzarelli (coords.), Entre Andes y Amazonía: transformaciones de materias, sustancias y cuerpos. Actas de la X Reunión de Antropología del Mercosur. Córdoba.

Lema, V. S. 2014. Hacia una cartografía de la crianza: domesticidad y domesticación en comunidades andinas. Espaço Amerindio 8(1): 59-82.

León, J. 1987. Botánica de los cultivos tropicales. San José de Costa Rica: Instituto Iberoamericano de Cooperación para la Agricultura.

Leonhardt, C. 1929. Documentos para la historia Argentina. Iglesia. Cartas Anuas de la Provincia del Paraguay, Chile y Tucumán, de la Compañía de Jesús, 1615-1637. Tomo XX. Buenos Aires: Facultad de Filosofia y Letras, UBA.

Lewis, W. H. 2010. Evaluating and protecting indigenous pharmacopeias and traditional knowledge. En: M. L. Pochettino; A. H. Ladio \& P. M. Arenas (eds.), Tradiciones \& transformaciones en Etnobotánica, pp. 313-316. San Salvador de Jujuy: CYTED Programa Iberoamericano Ciencia y Tecnología para el Desarrollo.

Li, C.; A. Zhou \& T. Sang. 2006. Genetic analysis of rice domestication syndrome with the wild annual species, Oryza nivara. New Phytologist 170(1): 185-194.

Lima dos Santos, L., F. J. Vieira, L. Gomes de Sousa Nascimento, A. C. Oliveira da Silva, L. Lima dos Santos \& G. M. de Sousa. 2014. Techniques for collecting and processing plant material and their application in ethnobotany research. En: Albuquerque, U. P., L. V. F. Cruz da Cunha, R. F. Paiva de Lucena \& R. R. Nóbrega 
Alves (eds.), Methods and Techniques in Ethnobiology and Ethnoecology, pp. 161-173. New York: Humana Press.

Lins Neto, E. M.; N. Peroni; C. M. Carneiro Maranhão; M. I. Sucupira Maciel \& U. P. de Albuquerque. 2012. Analysis of umbu (Spondias tuberosa Arruda (Anacardiaceae)) in different landscape management regimes. Environmental Monitoring and Assessment 184: 4489-4499.

Lista, R. 1883. El territorio de las Misiones. Buenos Aires: Imprenta "La Universidad" de J. N. Klingelfuss.

Lizárraga, R. de. 2002 [1607?]. Descripción del Perú, Tucumán, Río de la Plata y Chile. Madrid: Editorial DASTIN Historia.

Lobos, H. 1999. Conquista y fundaciones en las gobernaciones del Tucumán y Río de la Plata. En: Anzoátegui, V. (ed.), Nueva Historia de la Nación Argentina, pp. 411-444. Buenos Aires: Ed. Planeta.

López de Gómara, F. 1941 [1552]. Historia General de las Indias. Tomo 1. Madrid: Espasa-Calpe S.A.

Lozada, M.; A. Ladio \& M. Weigandt. 2006. Cultural transmission of ethnobotanical knowledge in a rural community of northwestern Patagonia, Argentina. Economic Botany 60(4): 374-385.

Luna-Morales, C. del C. 2004. Recolección, cultivo y domesticación de Cactáceas columnares en la Mixteca Baja, México. Revista Chapingo Serie Horticultura 10(2): 95-102.

Luro, F. F. Laigret, J. M. Bové \& P. Ollitrault. 1995. DNA Amplified Fingerprinting, A Useful Tool for Determination of Genetic Origin and Diversity Analysis in Citrus. Horticultural Science 30(5):1063-1067.

Mabberley, D. J. 1997. A classification for edible Citrus. Telopea 7: 167-172.

Mabberley, D. J. 1998. Australian Citreae with notes on other Aurantioideae (Rutaceae). Telopea 7: 333-344.

Mabberley, D. J. 2001. Citrus reunited. Australian Plants 21: 52-54. 
Mabberley, D. J. 2004. Citrus (Rutaceae): A Review of Recent Advances in Etymology, Systematics and Medical Applications. Blumea 49: 481-498.

Mabberley, D. J. 2008. Plant-Book. A Portable Dictionary of Plants, Their Classification and Uses, Cambridge: Cambridge University Press.

Machón, J. F. 1994. La primera invasión portuguesa de 1817. XIV Encuentro de Geohistoria Regional. Resistencia.

Machón, J. F. 2004. El viaje de Amado Bonpland a Misiones en 1821 y otros trabajos. Posadas: Creativa, Diseño-Imprenta.

Marengo, H.; Y. Palma; P. Tchilinguirian; F. Helms; W. Kruck \& D. Roverano. 2005. Geología del área de San Ignacio, provincia de Misiones. Actas del XVI Congreso Geológico Argentino 1: 141-148.

Marius, R. M.; B. Sinsin; O. Eyog-Matig \& R. Finkeldey. 2010. Uses, traditional management, perception of variation and preferences in ackee (Blighia sapida K.D. Koenig) fruit traits in Benin: implications for domestication and conservation. Journal of Ethnobiology and Ethnomedicine 6: 12.

Marlykynti, H.; K. Surendra \& R. Satyawada. 2011. Karyological studies in ten species of Citrus (Rutaceae) of North-East India. Comparative Cytogenetics 5(4): 277-287.

Martin, G. 2001. Etnobotánica. Manuales de conservación serie plantas y gente. WWFUNESCO. Montevideo: Ediciones Nordan-Comunidad.

Martínez-Crovetto, R. 1963. Esquema fitogeográfico de la provincia de Misiones (República Argentina). Bonplandia 1(3): 171-223.

Martínez-Crovetto, R. 1981. Las plantas utilizadas en medicina popular en el noroeste de Corrientes (República Argentina). Miscelanea 69: 1-139.

Martínez, M. R. \& M. L. Pochettino. 2004. Microambientes y recursos vegetales terapéuticos. Conocimiento local en Molinos, Salta, Argentina. Zonas Áridas 8.

Martius, C. F .P. 1843. Systema Materiae Medicae Vegetabilis Brasiliensis: Citrus, pp. 29-30. Lipsiae: Fleischer. 
McKey, D., M. Elias, B. Pujol \& A. Deputié. 2010. The evolutionary ecology of clonally propagated domesticated plants. New Phytologist 186: 318-332.

Meichtry, N. C. 1994. Distribución de la población en el Río de La Plata en el siglo XIX. Las fuentes de información y los procesos generales de ocupación. XIV Encuentro de Geohistoria Regional. Resistencia.

Melià, B. 2005. Escritos guaraníes como fuentes documentales de la historia paraguaya. História Unisinos 9(1): 5-18.

Mendoza-García, R.; A. Pérez-Vázquez; J. C. García-Albarado; E. García-Pérez \& J. López-Collado. 2011. Uso y manejo de plantas ornamentales y medicinales en espacios urbanos, suburbanos y rurales. Revista Mexicana de Ciencias Agrícolas (Pub. Esp.) 3: $525-538$.

Metcalfe, C. R. \& L. Chalk. 1979. Anatomy of the Dicotyledons. $2^{\text {nd }}$ Edition. Volume 1. Systematic anatomy of leaf and stem, with a brief history of the subject. Oxford: Clarendon Press.

Metcalfe, C. R. \& L. Chalk. 1983. Anatomy of the Dicotyledons. $2^{\text {nd }}$ Edition. Volume 2. Wood structure and conclusion of the general introduction. Oxford: Clarendon Press.

Miller, A. J. \& B. L. Gross. 2011. From forest to field: perennial fruit crop domestication. American Journal of Botany 98(9): 1389-1414.

Miller, A. \& B. Schaal. 2005. Domestication of Mesoamerican cultivated fruit tree, Spondias purpurea. Proceedings of the National Academy of Sciences 102 (36): 1280112806.

Miranda, D. E., A. V. Bohren, H. Keller, L. A. Grance \& H. M. Gartland. 2000. Clave de reconocimiento de especies leñosas de Rutaceae presentes en la Selva Paranaense (Argentina), mediante el uso de caracteres dendrológicos. Quebracho 8: 47-55.

Mittermeier, R. A.; P. Robles-Gil; M. Hoffmann; J. D. Pilgrim; T. M. Brooks; C. G. Mittermeier; J. L. Lamoreux \& G. Fonseca. 2004. Hotspots revisited: Earth's biologically richest and most endangered terrestrial ecoregions. Mexico City: CEMEX. Molares, S. 2010. Flora medicinal aromática de la Patagonia: características anatómicas y propiedades organolépticas utilizadas en el reconocimiento por parte de la terapéutica 
popular. Tesis Doctoral inédita, Centro Regional Universitario Bariloche, Universidad Nacional del Comahue.

Molares, S. \& A. Ladio. 2012. The usefulness of edible and medicinal Fabaceae in Argentine and Chilean Patagonia: environmental availability and other sources of supply. Evidence-Based Complementary and Alternative Medicine vol. 2012, 12 pages. doi: 10-1155/2012/901918.

Monigatti, M.; R. W. Bussmann \& C. Weckerle. 2013. Medicinal plant use in two Andean communities located at different altitudes in the Bolívar Province, Peru. Journal of Ethnopharmacology 145: 450-464.

Montenegro, P. de. 1945. Materia Medica Misionera. Edición digital Biblioteca Virtual del Paraguay. Disponible en: http://www.portalguarani.com/2080_pedro_montenegro/15163_materia_medica_mision era_pedro_de_montenegro_.html. Fecha de consulta: mayo de 2011.

Morello, J.; S. D. Matteucci; A. F. Rodríguez \& M. E. Silva. 2012. Ecorregiones y complejos ecosistémicos argentinos. Buenos Aires: Orientación Gráfica Editora.

Mörner, M. 1985. Actividades políticas y económicas de los Jesuitas en el Río de la Plata. Buenos Aires: Hyspamérica.

Morton, J. 1987. Fruits of Warm Climates. Miami: Florida Flair Books.

Myers, N.; R. A. Mittermeier; C. G. Mittermeier; G. A. B. da Fonseca \& J. Kent. 2000. Biodiversity hotspots for conservation priorities. Nature 403: 853-858.

Naveh, Z. \& A. S. Lieberman. 2001. Ecología de paisajes. Buenos Aires: EUDEBA.

Nazarea, V. 1998. Cultural Memory and Biodiversity. Tucson: University of Arizona Press.

Nazarea, V. D. (ed.). 1999. Ethnoecology. Situated knowledge/located lives. Tucson: The University of Arizona Press.

Nicolosi, E. 2007. Origin and taxonomy. En: Khan, I. A. (Ed.), Citrus Genetics, Breeding, and Biotechnology, pp. 19-43. Wallingford: CABI International. 
Nicolosi, E., Z. N. Deng, A. Gentile, S. La Malfa, G. Continella \& E. Tribulato. 2000. Citrus phylogeny and genetic origin of important species as investigated by molecular markers. Theoretical and Applied Genetics 100: 1155-1166.

NSW. 2014. New South Wales Flora on line. Disponible en: www. plantnet.rbgsyd.nsw.gov.au/cgibin/NSWfl.pl?page $=$ nswfl\&lvl $=$ sp\&name $=$ Citrus $\sim$ X + tait ensis. Fecha de consulta: marzo de 2014.

Ochoa, J. J. \& A. H. Ladio. 2011. Pasado y presente del uso de plantas silvestres con órganos de almacenamiento subterráneos comestibles en la Patagonia. Bonplandia 20(2): 265-284.

Odonne, G.; C. Valadeau; J. Alban-Castillo; D. Stien; M. Sauvain \& G. Bourdy. 2013. Medical ethnobotany of the Chayahuita of the Paranapura basin (Peruvian Amazon). Journal of Ethnopharmacology 146: 127-153.

Olson, D.M. and E. Dinerstein. 2002. The Global 200: Priority ecoregions for global conservation. Annals of the Missouri Botanical Garden 89(2): 199-224.

Osbeck, P. 1771. A voyage to China and the East Indies. Vol. 1. London: Benjamin White.

Pagnoux, C., A. Celant, S. Coubray, G. Florentino \& V. Zech-Matterne. 2013. The introduction of Citrus to Italy, with reference to identification problems of seed remains. Vegetation History and Archaeobotany 22: 421-438.

Palacín, J. M.; L. Villar Pérez \& C. Calvo. 1984. Plantas usadas como hipotensoras en el Alto Aragón. Acta Biológica Montana 4: 483-496.

Palacios, J. 1978. Citricultura Moderna. Buenos Aires: Ed. Hemisferio Sur.

Pantiu, A. J., A. Capellari \& V. D. Kurtz. 2010. Sistemas silvopastoriles del centro y norte de la Provincia de Misiones, Argentina. Revista Veterinaria 21(1): 69-75.

Parker, I. M.; I. López; J. J. Petersen; N. Anaya; L. Cubilla-Ríos \& D. Potter. 2010. Domestication síndrome in Caimito (Chrysophyllum cainito L.): fruit and seed characteristics. Economic Botany 64(2): 161-175. 
Parra, F.; A. Casas; J. M. Peñaloza-Ramírez; A. C. Cortés-Palomec; V. Rocha-Ramírez \& A. González-Rodríguez. 2010. Evolution under domestication: ongoing artificial selection and divergence of wild and managed Stenocereus pruinosus (Cactaceae) populations in the Tehuacán Valley, Mexico. Annals of Botany 106: 483-496.

Paszko, L. \& J. Herrera. 2006. Situación actual de las invasiones de plantas exóticas en el Parque Nacional Iguazú. Informe Interno. Administración de Parques Nacionales. Centro de Investigaciones Ecológicas Subtropicales (CIES). Delegación Regional Nordeste Argentino. Iguazú.

Paucke, F. 1942-1944 [1749-1767]. Hacia allá y para acá (Una estada entre los indios mocobies 1749-1767). San Miguel de Tucumán: Universidad Nacional del Tucumán.

Paul, A. \& P. Cox. 1995. An ethnobotanical survey of the uses for Citrus aurantium (Rutaceae) in Haiti. Economic Botany 49(3): 249-256.

Penjor, T., M. Yamamoto, M. Uehara, M. Ide, N Matsumoto, R. Matsumoto \& Y. Nagano. 2013. Phylogenetic relationships of Citrus and its relatives based on matK gene sequences. Plos One 8(4): e62574, doi: 10.1371/journal.pone.0062574.

Pérez, Y.; E. Jimenez-Ferrer; D. Alonso; C.A. Botello-Amaro \& A. Zamilpa. 2010. Citrus limetta leaves extract antagonizes the hypertensive effect of angiotensin II. Journal of Ethnopharmacology 128(3): 611-614.

Peroni, N.; P. Y. Kageyama \& A. Begossi. 2007. Molecular differentiation, diversity, and folk classification of "sweet" and "bitter" cassava (Manihot esculenta) in Caiçara and Caboclo management systems (Brazil). Genetic Resources and Crop Evolution 54: 1333-1349.

Phillips, O. \& A. H. Gentry. 1993. The useful plants of Tambopata, Perú: I. Statistical hypothesis tests with a new quantitative technique. Economic Botany 47(1): 15-32.

Placci G. y M. S. Di Bitetti. 2006. Situación ambiental en la eco región del bosque atlántico del alto Paraná (Selva Paranense). En: Brown, A.; U. Martínez-Ortiz; M. Acerbi \& J. Corcuera (eds.), La situación ambiental Argentina, pp. 197-209. Buenos Aires: Fundación Vida Silvestre.

Plath, O. 1996. Folclor médico chileno. Santiago de Chile: Ed. Grijalbo S.A. 
Pochettino, M. L., P. Arenas, D. Sánchez \& R. Correa. 2008. Conocimiento botánico tradicional, circulación comercial y consumo de plantas medicinales en un área urbana de Argentina. Boletín Latinoamericano y del Caribe de Plantas Medicinales 7(3): 141148.

Pochettino, M. L. \& V. Lema. 2008. La variable tiempo en la caracterización del conocimiento botánico tradicional. Darwiniana 46(2): 227-239.

Pochettino, M. L., M. R. Martínez \& M. Crivos. 2002. Landscape domestication among two mby'a-guaraní communities in Misiones, Argentina. En: Stepp, J.R.; F. S. Wyndham \& R. K. Zarger (eds.), Ethnobiology and Biocultural Diversity, pp. 696-704. U.S.A.: University of Georgia Press.

Poderoso, R. A.; N. Hanazaki \& A. Dunaiski Jr. 2012. How is local knowledge about plants distributed among residents near a protected area? Ethnobiology and Conservation 1: 1-26.

Politis, G. 1996. Moving to produce: Nukak mobility and settlement patterns in Amazonia. World Archaeology 27(3): 492-511.

Pompa, G. 1993. Medicamentos indígenas. Madrid: Ed. América S.A.

Poncet, V.; F. Lamy; J. Enjalbert; H. Joly; A. Sarr \& T. Robert. 1998. Genetic analysis of the domestication syndrome in pearl millet (Pennisetum glaucum L., Poaceae): inheritance of the major characters. Heredity 81: 648-658.

Posey, D. A. 1985. Indigenous management of tropical forest ecosystems: the case of the Kayapó Indians of the Brazilian Amazon. Agroforestry Systems 3: 139-158.

Poujade, R. 1995. Estado de avance del proyecto de recuperación de las Reducciones Jesuíticas de Guaraníes de Santos Mártires del Japón, Santa María la Mayor y Santa Ana. En: Poujade, R., La salvaguarda del Patrimonio Jesuítico, pp. 109-107. Posadas: Ed. Montoya.

Prance, G. \& M. Nesbitt. 2005. The cultural history of plants. New York: Routledge.

Puente y Olea, M. de la. 1900. Los Trabajos Geográficos de la Casa de la Contratación. Sevilla: Escuela Tipográfica y Librería Salesianas. 
Quiroga, H. 1967. Cuentos de amor, de locura y de muerte. Buenos Aires: Ed. Losada S.A.

Quiroga, R.; L. Meneses \& R. W. Bussmann. 2012. Medicinal ethnobotany in Huacareta (Chiquisaca, Bolivia). Journal of Ethnobiology and Ethnomedicine 8: 29. doi: 10.1186/1746-4269-8-29.

Ramón-Laca, L. 2003. The introduction of cultivated citrus to Europe via Northern Africa and the Iberian Peninsula. Economic Botany 57(4): 502-514.

Randall, R. 2012. A Global Compendium of Weeds. 2nd ed. U.S.A.: Dept. Agric. Food, Perth.

Raya-Pérez, J. C.; C. L. Aguirre-Mancilla; K. Gil-Vega \& J. Simpson. 2010. La domesticación de plantas en México: comparación de la forma cultivada y silvestre de Byrsonima crassifolia (Malpighiaceae). Polibotánica 30: 239-256.

Reboratti, C. E. 1983. Políticas Públicas y redistribución de la población en una frontera agraria (Argentina). Revista Geográfica 97: 104-112.

Reis, M.; A. Ladio \& N. Peroni. 2014. Landscapes with Araucaria in South America: evidence for a cultural dimension. Ecology and Society 19(2): 43.

Reyes García, V. \& N. Martí Sanz. 2007. Etnoecología: punto de encuentro entre naturaleza y cultura. Ecosistemas 16(3): 46-55.

Riat, P. \& M. L. Pochettino. 2014. ¿Para usar o para eliminar? El uso local del monte santiagueño (Argentina) y el avance de la agricultura industrial. Zonas Áridas 15: 6891.

Riat, P. \& P. C. Stampella. 2013. Uso multiple de "algarrobos" (Prosopis sp.) y "mandarina" (Citrus reticulata) por los campesinos del norte de Argentina, pp. 129. XXXIV Jornadas Argentinas de Botánica. La Plata.

Riat, P.; P. C. Stampella \& M. L. Pochettino. 2014. Conservación in situ de los bienes comunes: la estrategia de uso múltiple en dos enclaves del NE y $\mathrm{C}$ de Argentina. Comunicación oral ral en el XI Congreso Argentino de Antropología Social. Rosario. 
Ribero, A. B. 2005. Los temas claves de interpretación del patrimonio de Santos Mártires del Japón. Bases para el turismo cultural de la ruta provincial No 30 . En: Page, C. A. (ed.), Educación y evangelización. La experiencia de un mundo mejor, pp. 397401. X Jornadas Internacionales sobre Misiones Jesuíticas, Universidad Católica de Córdoba.

Richardson, D. M., P. Pyšek, M. Rejmánek, M. G. Barbour, F. Dane Panetta \& C. J. West. 2000. Naturalization and invasion of alien plants: concepts and definitions. Diversity Distribution 6: 93-107.

Rindos, D. 1984. The origins of agricultura: an evolutionary perspective. Michigan: Academic Press.

Ríos, G. de los. 1592. Agricultura de Jardines. Disponible en: http://helvia.uco.es/xmlui/handle/10396/2076. Fecha de consulta: abril de 2014.

Ripoll, L. 1985. Hierbas medicinales y remedios caseros. Barcelona: Ed. H.M.B., S.A.

Risso, A. \& A. Poiteau. 1818-1822. Histoire naturelle des orangers. Audot: Libraire, éditeur de 1'herbier de L'Amateur, du Jardin Fruitier, du Bon Jardinier, etc.

Ritter, M. R.; G. R. Sobierajski; E. P. Schenkel \& L. A. Metnz. 2002. Plantas usadas como medicinais no municipio de Ipê, RS, Brasil. Revista Brasileira de Farmacognosia 12(2): 51-62.

Rival, L. 1998. Domestication as a historical and symbolic process: wild gardens and cultivated forests in the Ecuadorian Amazon. En: Balée (ed.), Advances in Historical Ecology, pp. 232-250. New York: Columbia University Press.

Rivera Núñez, D.; C. Obón de Castro; S. Ríos Ruíz; C. S. Ferrández; F. Méndez Colmenero; A. Verde López \& F. Cano Trigueros. 1998. Las variedades tradicionales de frutales de la cuenca del Río Segura. Catálogo etnobotánico. Cítricos, frutos carnosos y vides. Murcia: DM Librero Editor.

Rodewald, A. D. 2012. Spreading messages about invasives. Diversity and Distributions 18: 97-99.

Rodolfo, A. M., J. F. Cândido Jr., L. Godinho Temponi \& M. Zanin Gregorini. 2008. Citrus aurantium L. (laranja-apepu) e Hovenia dulcis Thunb. (uva-do-japão): espécies 
exóticas invasoras da trilha do Poço Preto no Parque Nacional do Iguaçu, Paraná, Brasil. Revista Brasileira de Biociências 6(1): 16-18.

Rodríguez Arévalo, I., A. Casas, R. Lira \& J. Campos. 2006. Uso, manejo y procesos de domesticación de Pachycereus hollianus (F. A. C. Weber) Buxb. (Cactaceae), en el Valle de Tehuacán-Cuicatlán, México. Interciencia 31(9): 677-685.

Rodríguez Barboza, N. 1985. Pojhá Ñaná. Recetario de plantas medicinales usadas en el Paraguay. Ed. La Colmena: Asunción.

Rodríguez, J. A. \& C. N. Ceruti. 1999. Las tierras bajas del nordeste y litoral Mesopotámico. En: En: Anzoátegui, V. (ed.), Nueva Historia de la Nación Argentina, pp. 109-133. Buenos Aires: Ed. Planeta.

Rodríguez, L. F. 2006. Can invasive speceis faciliatet native species? Evidence of how, when, and why these impacts occur. Biological Invasions 8: 927-939.

Roose, M. L., R. K. Soost \& J. W. Cameron. 1995. Citrus (Rutaceae). En: Smartt, J. \& N. W. Simmonds (eds.), Evolution of crop plants. 2nd ed., pp. 443-449. Oxford: WileyBlackwell.

Rosch, E. 1978. Principles of categorization. En: Rosch, E. \& B. Lloyd (eds.), Cognition and Categorization. Hilldale: Laurence Erlbaum Ass.

Rosso, C. N. 2013. La etnobotánica histórica: el caso Mocoví en la reducción de San Javier en el siglo XVIII. Etnobiología 11(3): 54-65.

Rozzi, R.; C. B. Anderson; J. C. Pizarro; F. Massardo; Y. Medina; A. O. Mansilla; J. H. Kennedy; J. Ojeda; T. Contador; V. Morales; K. Moses; A. Paole; J. J. Armesto \& M. T. Kalin. 2010. Filosofía ambiental de campo y conservación biocultural en el Parque Etnobotánico Omora: Aproximaciones metodológicas para ampliar los modos de integrar el componente social ("S") en sitios de estudios socio-ecológicos a largo plazo (SESELP). Revista Chilena de Historia Natural 83(1): 27-68.

Ruíz de Montoya, 1892 [1639]. Conquista espiritual hecha por los religiosos de la Compañia de Jesús en las provincias del Paraguay, Paraná, Uruguay y Tape. Bilbao: Imprenta del Corazón de Jesús.

Saint Hilaire, A. 1825. Flora Brasiliae Meridionalis. I: 338-339. París: A. Belin. 
Sánchez, O. \& G. López. 1988. A theoretical analysis of some índices od similarity as applied to biogeography. Folia Entomológica Mexicana 75: 119-145.

Sánchez Labrador, J. 1910 [1770]. El Paraguay católico. 2 tomos. Buenos Aires: Imprenta de Coni Hnos.

Sartori, E. 1964. Árboles frutales. En: Parodi, L. R. (ed.), Enciclopedia Argentina de Agricultura y Jardinería. Vol. 2. El cultivo de las plantas útiles. Segunda parte, pp. 789927. Buenos Aires: Ed. ACME S.A.

Scarpa, G. F. 2012. Las plantas en la vida de los criollos del oeste formoseño. Medicina, ganadería, alimentación y viviendas tradicionales. Buenos Aires: Asociación Civil Rumbo Sur.

Schaden, E. 1998. Aspectos Fundamentales de la Cultura Guaraní. Asunción: Centro de Estudios Antropológicos (CEADUC), Universidad Católica "N. S. de la Asunción".

Schaller, E. C. 1994. La distribución de la tierra en Misiones durante la administración correntina. 1851-1881. Resistencia: XIV Encuentro de Geohistoria Regional.

Schiavoni, G. 1995. Organización doméstica y apropiación de tierras fiscales en la Provincia de Misiones (Argentina). Desarrollo Económico 34: 595-608.

Schiavoni, G. 1998. Colonos y ocupantes: parentesco, reciprocidad y diferenciación social en la frontera agraria de Misiones. Posadas: Editorial Universitaria, Universidad Nacional de Misiones.

Schmidl, U. 1944 [1552]. Derroteo y viaje a España y las Indias. Colección Austral., Buenos Aires: Espasa-Calpe Argentina S.A.

Schroth, G., M. S. S. da Mota, R. Lopes \& A. F. de Freitas. 2004. Extractive use, management and in situ domestication of a weedy palm, Astrocaryum tucuma, in the central Amazon. Forest Ecology and Management 202: 161-179.

Scora, R. 1975. On the history and origin of Citrus. Bulletin of the Torrey Botanical Club 102: 369-375. 
Seeland, K. (Ed.). 1997. Nature is culture: indigenous knowledge and socio-cultural aspects of trees and forests in non-European cultures. London: Intermediate Technology Publications.

Seo, M. N. \& C. Xifreda. 2008. Rutaceae. En: Anton, A. M. \& F. O. Zuloaga (eds.), Flora Fanerogámica Argentina 106: 1-22.

Sepp, A. 1971 [1696]. Relación de Viaje a las Misiones Jesuíticas, Edición crítica de W. Hoffmann. Tomo I. Buenos Aires: EUDEBA.

Simberloff, D. \& B. von Holle. 1999. Positive interactions of nonindigenous species: invasional meltdown? Biological Invasions 1: 21-32.

Spiegel-Roy, P. \& E. E. Goldschmidt. 1996. Biology of Citrus. Cambridge: Cambridge University Press.

Stampella, P. C. 2012. Toponimia misionera: de los yerbales jesuíticos al abuso de la caña de azúcar. En: Duque-Brasil, R.; G. Taboada Soldati; F. Bezerra Souto; N. Leal Alencar; C. Ming Lin \& F. M. Gontijo Coelho (eds.), “Quando pensa que não...”: contos, causos e crônicas em etnoecologia, pp. 105-108. Viçosa: Etnooikos, Universidade Federal de Viçosa.

Stampella, P. C.; R. Altamirano; R. Dutra; M. L. Pochettino \& N. I. Hilgert. 2013a. Manejo local de "mandarinas comunes" (Citrus reticulata, Rutaceae) en diferentes ambientes por campesinos del sur de Misiones. Póster presentado en las XXXIV Jornadas Argentinas de Botánica, pp. 132. La Plata.

Stampella, P. C.; G. Delucchi y M. L. Pochettino. 2013b. Naturalización e identidad del "limón mandarina", Citrus × taitensis (Rutaceae, Aurantioideae) en la Argentina. Boletín de la Sociedad Argentina de Botánica 48(1): 161-169.

Stampella, P. C.; H. A. Keller; J. A. Hurrell \& G. Delucchi. 2013d. Etnobotánica y naturalización de dos cultivares de Citrus reticulata en la Argentina. Póster presentado en las XXXIV Jornadas Argentinas de Botánica, pp. 131-132. La Plata.

Stampella, P. C.; D. A. Lambaré; N. I. Hilgert \& M. L. Pochettino. 2013c. What the iberic conquest bequeated to us: the fruit trees introduced in argentine subtropic, their 
history and importance in present traditional medicine. Evidence-Based Complementary and Alternative Medicine. Article ID 868394, 17 pages.

Storni, J. S. 1944. Hortus Guaranenesis. Flora. San Miguel de Tucumán: Universidad Nacional de Tucumán, Imprenta y Litografía de Miguel Violetto.

Susnik, B. 1979-1980. Los aborígenes del Paraguay: Tomo II. Etnohistoria de los Guaraníes: época colonial, Museo Etnográfico “A. Barbero”. Asunción: Escuela Técnica Salesiana.

Swingle, W. T. 1943. The botany of citrus and its wild relatives of the orange subfamily. En: Webber, H. J. \& L. D. Batchelor (eds.), The citrus industry I, pp. 129474. Berkeley: University of California Press.

Swingle, W. T. \& P. C. Reece. 1967. The botany of citrus and its wild relatives. En: Reuther, W.; H. J. Webber \& L. D. Batchelor (eds.), The Citrus Industry I, pp. 190-430. Berkeley: University of California Press.

Tanaka, T. 1954. Species problem in citrus (Revisio aurantiacearum IX). Tokyo: Japanese Society for the Promotion of Science.

Tanaka, T. 1966. Hodgson's Citrus classification discussed. Bulletin of the University Osaka Prefecture, Ser. B, 18: 25-29.

Tanaka, T. 1969. Misunderstanding with regard to Citrus classification and nomenclature. Bulletin of the University Osaka Prefecture, Ser. B, 21: 139-141

Tanaka, T. 1977. Fundamental discussion of Citrus classification. Studia Citrologica 14: 1-6.

Taussig, M. 1995. Un gigante en convulsiones. El mundo humano como sistema nervioso en emergencia permanente. España: Gedisa.

Terrell, J. E.; J. P. Hart; S. Barut; N. Cellinese; A. Curet; T. Denham; C. M., Kusimba; K. Latinis; R. Oka; J. Palka; E. D. Pohl; K. O. Pope; P. R. Williams; H. Haines \& J. E. Staller. 2003. Domesticated landscapes: the subsistence ecology of plant and animal domestication. Journal of Archaeological Method and Theory 10(4): 323-368. 
Teruggi, M. 1970. Bosquejo geológico del Paraguay y la provincia de Corrientes. Boletín de la Sociedad Argentina de Botánica 11(supl.): 1-15.

The Plant List. 2013. Disponible en: www.theplantlist.org. Fecha de consulta: octubre de 2013.

Thomas, E. \& I. Vandebroek. 2006. Guía de plantas medicinales de los Yuracarés y Trinitarios del Territorio Indígena Parque Nacional Isiboro-Sécure, Bolivia. Santa Cruz: Imprenta Sirena.

Toledo, V. 1990. The ecological rationality of peasant production. En: Altieri, M. \& S. Hecht (eds.), Agroecology and small-farm developmet, pp. 51-58. Boca Ratón: CRC Press.

Toledo, V. 1992. What is ethnoecology?: origins, scope and implications of a rising discipline. Etnoecologica 1: 5-21.

Toledo, V. 2002. Ethnoecology. A conceptual framework for the study of indigenous knowledge of nature. En: Stepp, J. R., F. S. Wyndham \& R. K. Zarger (eds.), Ethnobiology and Biocultural Diversity, 511-522. U.S.A.: International Society of Ethnobiology.

Toledo, V. \& N. Barreras-Bassols. 2008. La memoria biocultural. La importancia agroecológica de las sabidurías tradicionales. Barcelona: Icaria Editorial.

Toledo, V. M.; N. Barreras-Bassols; E. García-Frapolli \& P. Alarcón-Chaires. 2007. Manejo y uso de la biodiversidad entre los Mayas Yucatecos. Biodiversitas 70: 10-15.

Touwaide, A. 2010. History of botany as ethnobotany. Proposals toward a new approach to the ancient legacy. En: Pochettino, M. L.; A. H. Ladio \& P. M. Arenas (eds.), Tradiciones \& Transformaciones en Etnobotánica, pp. 55-63. San Salvador de Jujuy: CYTED.

Trinca Fighera, D. 2006. Paisaje natural, paisaje humanizado o simplemente paisaje. Revista Geográfica Venezolana 47(1): 113-118.

Trinidade Medeiros, M. F. 2010a. Procedimientos para a análise documental na constituição da informação etnobiológica. En: Albuquerque, U. P., R. F. Paiva de 
Lucena \& L. V. Fernandes Cruz da Cunha (eds.), Métodos e técnicas na pesquisa etnobiológica e etnoecológica, pp. 421-435. Recife: NUPEEA.

Trinidade Medeiros, M. F. 2010b. Historical ethnobotany: an approach through historical documents and their implications nowadays. En: Albuquerque, U. P. \& N. Hanazaki (eds.), Recent developments and case studies in ethnobotany, pp. 127-142. Recife: NUPEEA.

Trinidade Medeiros, M. F., T. C. da Silva, R. da Silva Sousa \& R. R. Vasconcelos Silva. 2014. Oral history in ethnobiology and ethnoecology. En: Albuquerque, U. P.; L. V. Fernandes Cruz da Cunha; R. F. Paiva de Lucena \& R. R. Nóbrega Álves (eds.), Methods and techniques in ethnobiology and ethnoecology, pp. 59-73. New York: Humana Press.

Tuxill, J. \& P. Nabhan. 2001. Plantas, comunidades y áreas protegidas. Una guía para el manejo in situ. Pueblos y Plantas $\mathrm{N}^{\circ} 3$. Montevideo: Nordan Comunidad.

USDA. 2014. United States Department of Agriculture. Disponible: http://plants.usda.gov/java/profile?symbol=CILI3 . Fecha de consulta: enero de 2014.

Uzun, A. \& T. Yesiloglu. 2012. Genetic Diversity in Citrus. En: Çalişkan, M. (ed.), Genetic Diversity in Plants, pp. 213-230. Rijeka: InTech.

Vázquez de Espinosa, A. 1948 [1630]. Compendio y descripción de las indias occidentales. Transcrito del manuscrito original por Charles Upson Clark. Washington: Smithsonian Institution.

Vendruscolo, G. \& L. A. Mentz. 2006. Levantamento etnobotânico das plantas utilizadas como medicinais por moradores do bairro Ponta Grossa, Porto Alegre, Rio Grande do Sul, Brasil. Iheringia, Sér. Bot. 61(1-2): 83-103.

Vera de Flachs, M. C. \& C. Page. 2010. Textos clásicos de medicina en la botica jesuítica del Paraguay. Cuadernos del Instituto Antonio de Nebrija 13: 117-135.

Vodouhè, R. \& A. Dansi. 2012. The "bringing into cultivation" phase of the plant domestication process and its contributions to in situ conservation of genetic resources in Benin. The Scientific World Journal 2012, Article ID 176939, 13 pages. 
Volkamer, J. C. 1708-1714. Hesperidvm Norimbergensivm sive de Malorvm citreorvm, limonvm avrantiorvmqve cvltvra et vsv. Libri 3. Norimbergae.

Webber, H. 1943a. History and development of the Citrus industry. En: Webber, H. \& L. Batchelor (eds.), The Citrus Industry. History, Botany, and Breeding, pp. 1-40. Berkeley: University of California Press.

Webber, H. 1943b. Cultivated varieties of Citrus. En: Webber, H. \& L. Batchelor (eds.), The Citrus Industry. History, Botany, and Breeding, pp. 475-668. Berkeley \& Los Angeles: University of California Press.

Winton, A. L. \& K. B. Winton. 1932. The structure and composition of foods. Vol. I: Cereals, starch, oils seeds, nuts, oils, forage plants. New York: John Wiley \& Sons, Inc.

Winton, A. L. \& K. B. Winton. 1935. The structure and composition of foods. Vol. II: Vegetables, legumes, fruits. New York: John Wiley \& Sons, Inc.

Yen, D. E. 1989. The domestication of environment. En: Harris, D. R. \& G. C. Hillman (eds.), Foraging and Farming. The evolution of plant exploitation, pp. 55-75. London: Unwin Hyman.

Zabaleta, E. S.; R. J. Hobbs \& H. A. Mooney. 2001. Viewing invasive species removal in a whole-ecosystem context. TRENDS in Ecology \& Evolution 16(8): 454-459.

Zamudio, F. 2012. Conocimientos locales y manejo de las abejas sin aguijón (Apidae: Melipinini) entre pobladores rurales del norte de la provincia de Misiones. Tesis Doctoral inédita, Facultad de Ciencias Exactas, Físicas y Naturales, Universidad Nacional de Córdoba.

Zamudio, F. \& N.I. Hilgert. 2011. Mieles y plantas en la medicina criolla del norte de Misiones, Argentina. Bonplandia 20: 165-184.

Zamudio, F. \& N. I. Hilgert. 2012. ¿Cómo los conocimientos locales aportan información sobre la riqueza de especies de abejas sin aguijón (Apidae: Meliponini) del norte de Misiones, Argentina? Interciencia 37(1): 36-43.

Zamudio, F.; M. Kujawska \& N. I. Hilgert. 2010. Honey as medicinal and food resource. Comparison between Polish and multiethnic settlements of the Atlantic Forest, Misiones, Argentina. The Open Complementary Medicine Journal 2: 58-73. 
Zhang, D. \& D. J. Mabberley. 2008. Citrus. En: Wu, Z. Y.; P. H. Raven \& D. Y. Hong (eds.), Fl. of China 11: 90-96. Beijing - St. Louis: Science Press - Missouri Botanical Garden Press.

Zohary, D. 2004. Unconscious selection and the evolution of domesticated plants. Economic Botany 58(1): 5-10.

Zohary, D. \& P. Spiegel-Roy. 1975. Beginnings of fruit growing in the old world. Science 187: 319-327.

Zuloaga, F. O.; O. Morrone \& M. J. Belgrano. 2008. Catálogo de plantas vasculares del cono sur. 3 volúmenes. Saint Louis: Missouri Botanical Garden. 